\title{
Modelo de enriquecimiento para iniciativas OER basado en Meta-análisis de Datos aplicando Análisis de Redes Sociales
}

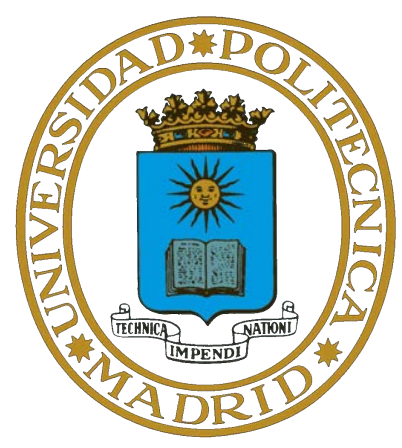

\author{
Autor: Jorge Afranio López Vargas \\ Director: Edmundo Tovar Caro \\ Escuela Técnica Superior de Ingenieros Informáticos \\ Universidad Politécnica de Madrid
}

Una tesis presentada para el grado de PhilosophiceDoctor (PhD) en Software y Sistemas 
Tribunal nombrado por el Sr. Rector Magnífico de la Universidad Politécnica de Madrid, el día de. de 2016

Presidente:

Vocal:

Vocal:

Vocal:

Secretario:

Suplente:

Suplente:

Realizado el acto de defensa y lectura de la Tesis el día..........de.....................de 2016 en la E.T.S.I. /Facultad.

Calificación

El Presidente

Los Vocales

El Secretario 
A mi familia, por que "yo soy lo que nosotros somos".

A mis abuelos, mis tíos, mis primos. En especial, lo dedico a mis padres, mis hermanos y mis sobrinos. A Ma. del Carmen.

Con todo mi amor,

Jorge. 


\section{Agradecimientos}

Quiero expresar mis sinceros agradecimientos a la UTPL, en especial al P. Luis Miguel Romero por siempre confiar en la capacidad de Loja y de todos quienes formamos UTPL.

A la sección departamental de Tecnologías Avanzadas de la Web y SBC, al Laboratorio de Ciencia de Datos (UTPL), gracias por permitirme colaborar con ustedes y por apoyarme siempre, no puedo imaginar haber caminado hasta aquí sin ustedes. En especial a Ma. del Carmen, Audrey, Eduardo, Juan Carlos y René.

A la gente del Vicerrectorado de Investigación de la UTPL, gracias por colaborar y apoyar a todos quienes soñamos con hacer investigación en la UTPL.

A Nelson y Janneth gracias por ser un ejemplo y mi apoyo constante, por todo lo vivido por compartir sueños, ideales y la lucha que busca cambiar no sólo nuestra realidad, sino el futuro de nuestra patria chica.

A mis amigos, los "irreunibles", Rubén, Juan Carlos y Juan Pablo. Gracias por el apoyo constante, las charlas inagotables y los buenos momentos. A Ramiro por los mensajes y el buen humor. A Luis gracias por las charlas en el campus de la UTPL. A mis amigos en Madrid, Bladimir, Paulo y Sandro gracias por su generosidad infinita.

En UPM, a mi director de tesis Edmundo Tovar Caro, gracias por el apoyo y por la oportunidad de ser parte de GICAC. A Alicia Andres mi gratitud por toda la ayuda recibida.

A mi familia, por estar siempre ahí, a mis ángeles en la tierra mi madre y mi hermana por siempre estar pendientes de mi. A mi hermano menor por 
ser mi ejemplo. A mis cuñados. A mis sobrinos: María Vero, Josué, Sophia, Francisco e Isabela son mi alegría.

A María del Carmen, por todo lo que hemos vivido, pero sobretodo por lo que nos falta por vivir.

Una mención especial a mi familia, no a la que se pertenece por vínculos de sangre, sino a aquella que la vida nos otorga. A Lourdes, Cristina, Andrea, José, Cristian y Freddy. Gracias por recibirme en Madrid y dejarme ser uno más de ustedes.

A todos ustedes mi eterna gratitud, por permitirme SER. 


\section{Índice general}

Índice de figuras

Índice de tablas
XIII

1. Introducción 1

1.1. Publicaciones ............................ 2

1.1.1. JCR Papers: (WoK \& SCOPUS Indexed) . . . . . . . . . . . 2

1.1.2. Open Journals . . . . . . . . . . . . . . . . . . . 3

1.1.3. Proceedings (SCOPUS Indexed) . . . . . . . . . . 3

1.1.4. Otros índices . . . . . . . . . . . . . . . . . . 6

1.1.5. Capítulos de libros . . . . . . . . . . . . . . 6

2. Estado del arte 9

2.1. Introducción . . . . . . . . . . . . . . . . . . 9 9

2.2. Recursos Educativos Abiertas (OER) . . . . . . . . . . . . . 9

2.2.1. Impacto de los OERs . . . . . . . . . . . . . . . . . . . 12

2.2.1.1. Prácticas educativas basadas en OERs . . . . . . . . . 16

2.2.1.2. OpenCourseWare $(\mathrm{OCW}) \ldots \ldots \ldots$

2.3. Social computing . . . . . . . . . . . . . . . . . . . 24

2.3.1. Redes sociales . . . . . . . . . . . . . . . . . . . 25

2.3.2. Sistemas de recomendación . . . . . . . . . . . . . 28 28

2.3.2.1. Filtrado colaborativo basado en vecindario . . . . . . . 29

2.3.2.2. Basados en contenidos . . . . . . . . . . . . . 34

2.3.2.3. Sistemas híbridos . . . . . . . . . . . . . . . 36

2.3.2.4. Basados en contexto . . . . . . . . . . . . . 38

2.3.3. Sistemas de confianza/reputación . . . . . . . . . . . . . 42 


\section{ÍNDICE GENERAL}

2.4. Uso de las redes sociales dentro de la educación . . . . . . . . . . . 45

2.4.1. Uso de la Web 2.0 a través de sus herramientas . . . . . . . . . 47

2.4.2. Uso de la Web 2.0 a través de sus conceptos . . . . . . . . . . 48

2.4.3. Otros usos de las herramientas Web 2.0 en educación . . . . . . . 50

2.5. Discusión de los trabajos relacionados . . . . . . . . . . . . . 51

2.5.1. Redes sociales y educación . . . . . . . . . . . . . 5 51

2.5.2. Uso de SNA como herramienta de análisis . . . . . . . . . . 52

2.5.3. SNA para la recomendación . . . . . . . . . . . . . 52

3. El problema

3.1. Introducción . . . . . . . . . . . . . . 55

3.2. Formulación . . . . . . . . . . . . . . . . 555

3.2.1. Representación de las iniciativas . . . . . . . . . . . 57

3.2.2. Aprovechar la información de la Red social . . . . . . . . . . 57

3.2.3. Información insuficiente de los recursos compartidos . . . . . . 58

3.2.4. Usar la estructura de la red . . . . . . . . . . . . . . . . 58

3.2.5. Perfiles de los usuarios . . . . . . . . . . . . . . 58

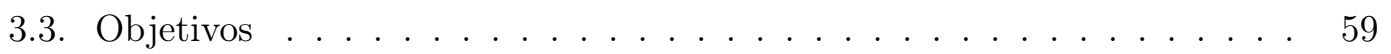

3.4. Contribuciones previstas . . . . . . . . . . . . . 59

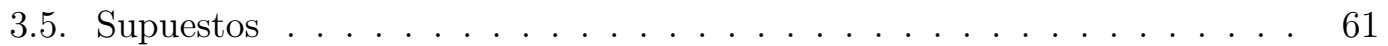

3.6. Hipótesis . . . . . . . . . . . . . . . . . . . . . . . . 61

3.7. Restricciones . . . . . . . . . . . . . . . . . . 62

4. Propuesta del modelo de enriquecimiento para iniciativas basadas en OERs

4.1. Introducción . . . . . . . . . . . . . . . . . 63

4.2. Directrices para el modelo de enriquecimiento . . . . . . . . . . 64 64

4.3. Conceptos preliminares . . . . . . . . . . . . . . . 66 66

4.3.1. Red ........................ 67 67

4.3.2. Etiquetado social . . . . . . . . . . . . . . 67 67

4.3.3. Folksonomía . . . . . . . . . . . . . . . . 67 67

4.3.4. Red de co-ocurrencia de conceptos . . . . . . . . . . . . 68

4.3.5. Red de usuarios . . . . . . . . . . . . . . . . . . . . . . . . 68

4.4. Modelo de enriquecimiento . . . . . . . . . . . . . . . . . . 68 
4.4.1. Captura de datos . . . . . . . . . . . . . . . . . . 70

4.4.1.1. Construcción de Tópicos . . . . . . . . . . . 71

4.4.1.2. Recolección de datos . . . . . . . . . . . . . . 773

4.4.2. Creación de redes . . . . . . . . . . . . . . . 766

4.4.2.1. Identificación de relaciones y construcción de redes . . . 78

4.4.2.2. Instanciar las redes . . . . . . . . . . . . . . 81

4.4.3. Análisis y visualización de redes . . . . . . . . . . . . . 84

4.4.3.1. Analizar a través de métricas de SNA y visualizar . . . 85

4.4.4. Recomendar . . . . . . . . . . . . . . . . . . . 88

4.4.4.1. Social - Usuarios destacados . . . . . . . . . . . 90

4.4.4.2. Producción en el tiempo . . . . . . . . . . . . . 93

4.4.4.3. Enriquecimiento de ítems . . . . . . . . . . . 95

4.4.4.4. Legal . . . . . . . . . . . . . . 96

4.4.4.5. Contenidos compartidos en la red - Contexto . . . . . . 97

4.4.4.6. Valoración . . . . . . . . . . . . . . . . . 98

4.5. Generalización del modelo de enriquecimiento . . . . . . . . . . . . 99 99

4.5.1. Interacción social . . . . . . . . . . . . . . . 101

4.5.2. Influencia de los usuarios . . . . . . . . . . . . . . . . 101

4.5.3. Contexto . . . . . . . . . . . . . . . . 102

4.5.4. Atributos de los nodos . . . . . . . . . . . . . . . . 102

4.5.5. Procedencia de los datos . . . . . . . . . . . . . . . 103

4.5.6. Apertura de los recursos . . . . . . . . . . . . . . 103

5. Validación de las hipótesis propuestas 105

5.1. Introducción . . . . . . . . . . . . . . . . . 105

5.2. Caso 1: Meta-análisis del proyecto TAEE aplicando análisis de redes sociales 109

5.2.1. Componentes y módulos utilizados en el caso . . . . . . . . . . . 110

5.2.2. Validación de hipótesis de investigación . . . . . . . . . . . . 110

5.2.2.1. Construcción de la solución . . . . . . . . . . . . . . 110

5.2 .2 .2 . Validación . . . . . . . . . . . . . 117

5.3. Caso 2: El impacto de los Recursos Educativos Abiertos en la Educación superior en España y Latinoamérica a través del Análisis de Redes Sociales 123 5.3.1. Componentes y módulos utilizados . . . . . . . . . . . . . . . 123 
5.3.2. Validación de hipótesis de investigación . . . . . . . . . . . 127

5.3.2.1. Construcción de la solución . . . . . . . . . . . . 127

5.3 .2 .2 . Validación . . . . . . . . . . . . . . 133

5.4. Caso 3: MOOCKnowledge Study . . . . . . . . . . . . . . . . 139

5.4.1. Componentes y módulos utilizados . . . . . . . . . . . . . 139

5.4.2. Validación de hipótesis de investigación . . . . . . . . . . 139

5.4.2.1. Construcción de la solución . . . . . . . . . . . . . 142

5.4.2.2. Validación . . . . . . . . . . . . . . . . 144

5.5. Caso 4: Recomendación de OERs compartidos en redes sociales utilizando como base el análisis de redes sociales . . . . . . . . . . . . . 147

5.5.1. Componentes y módulos utilizados . . . . . . . . . . . . . . 147

5.5.2. Validación de hipótesis de investigación . . . . . . . . . . . . . 149

5.5.2.1. Construcción de la solución . . . . . . . . . . . . 149

5.5.2.2. Validación . . . . . . . . . . . . . . 152

5.6. Caso 5: Recomendación de OERs para Emprendimiento utilizando un marco de trabajo basado en Análisis de Redes Sociales . . . . . . . . . 163

5.6.1. Componentes y módulos utilizados . . . . . . . . . . . . . 163

5.6.2. Validación de hipótesis de investigación . . . . . . . . . . 165

5.6.2.1. Construcción de la solución . . . . . . . . . . . . . 167

5.6.2.2. Validación . . . . . . . . . . . . . . 169

5.7. Resumen de la validación de las hipótesis propuestas . . . . . . . . . . 173

6. Conclusiones y trabajos futuros 177

6.1. Conclusiones . . . . . . . . . . . . . . . . . 177

6.2. Contribuciones . . . . . . . . . . . . . . . . . . . 179

6.3. Líneas futuras de investigación . . . . . . . . . . . . . . . . . 180

7. Anexos 183

7.1. Anexo A: SERRecomender Documentación de servicios Web . . . . . . 183

7.1.1. Recursos . . . . . . . . . . . . . . . . . . 183

7.1.1.1. Usuarios (cuentas de usuarios) . . . . . . . . . . 185

7.1.1.2. Hashtag relacionadas . . . . . . . . . . . . . 187

7.2. Anexo B - Análisis de los resultados de la aplicación del modelo . . . . . 189

7.2.1. Descripción de la fuente de datos . . . . . . . . . . . . . . . . 189 
7.2.2. Distribución de los grados . . . . . . . . . . . . . . . 191

7.2.3. Usuarios - Social . . . . . . . . . . . . . . . . . . . 194

7.2.4. Hashtags - Contexto . . . . . . . . . . . . . . . . 198

7.2.5. Análisis de resultados . . . . . . . . . . . . . . . 198

Referencias Bibliográficas $\quad[205$ 
ÍNDICE GENERAL 


\section{Índice de figuras}

2.1. Uso de los diferentes tipos de OER . . . . . . . . . . . . . . . . . 16

2.2. Distribución de los grados de una red de usuarios en Twitter . . . . . . . 26

2.3. Representación de la matriz de valoraciones . . . . . . . . . . . . . . . 31

2.4. Grafo de correlación . . . . . . . . . . . . . . . . . . . . . 33

2.5. Publicaciones sobre educación y herramientas de los medios sociales . . . 46

4.1. Componentes del modelo de enriquecimiento . . . . . . . . . . . . . . 69

4.2. Modelo de enriquecimiento . . . . . . . . . . . . . . . . . . . 70 70

4.3. Construcción de tópicos . . . . . . . . . . . . . . . . . 72

4.4. Recolección de datos . . . . . . . . . . . . . . . . . . . 75

4.5. Identificación de relaciones . . . . . . . . . . . . . . . . . . . . 78

4.6. Red bipartita y sus proyecciones . . . . . . . . . . . . . . . 79

4.7. Instanciar las redes . . . . . . . . . . . . . . . . . . . 83

4.8. Análisis de redes . . . . . . . . . . . . . . . . . . . 87 87

4.9. Modelo de Recomendación . . . . . . . . . . . . . . . . . . . . . . . . . . 91

4.10. Modelamiento del tiempo . . . . . . . . . . . . . . . . . . . . 94

4.11. El tiempo visto en algunas medidas de centralidad . . . . . . . . . . 94

5.1. Componentes y módulos del modelo de enriquecimiento que se utilizaron en este caso . . . . . . . . . . . . . . . . . . . . . . . 111

5.2. Red para la pregunta $1 \ldots \ldots \ldots \ldots$. . . . . . . . . . . . . . . .

5.3. Redes para la pregunta $2 \ldots \ldots$. . . . . . . . . . . . . 115

5.4. Temas y palabras claves . . . . . . . . . . . . . . . . . 117

5.5. Participantes a los congresos . . . . . . . . . . . . . . . . . 118

5.6. Visión integral del marco diseño en la propuesta . . . . . . . . . . . . . . 124 


\section{INNDICE DE FIGURAS}

5.7. Componentes y módulos del modelo de enriquecimiento que se utilizaron en este caso . . . . . . . . . . . . . . . . . . . . 125

5.8. Redes de colaboración por etiquetas y continentes . . . . . . . . . . . 129

5.9. Redes de autores de cursos . . . . . . . . . . . . . . . . . 131

5.10. Colaboración entre América del Sur y España . . . . . . . . . . . . . . 132

5.11. Red de colaboración geográfica . . . . . . . . . . . . . . . . . 134

5.12. Componentes y módulos del modelo de enriquecimiento que se utilizaron en este caso . . . . . . . . . . . . . . . . . . . . . . 140

5.13. La red que se construyó en base a las respuesta de 7 preguntas . . . . . 143

5.14. Componentes y módulos del modelo de enriquecimiento que se utilizaron en este caso . . . . . . . . . . . . . . . . . . . . 150

5.15. Una ejemplo de las redes que se construyeron para \#matlab . . . . . . 153

5.16. Componentes y módulos del modelo de enriquecimiento que se utilizaron en este caso . . . . . . . . . . . . . . . . . . . . 166

5.17. Imágenes que muestra las diferentes pantallas del Demo que se construyó para StartUP project . . . . . . . . . . . . . . . . . . 170

7.1. Distribución del grado nodal para la red de menciones y re-tweets entre usuarios . . . . . . . . . . . . . . . . . . . . . . . 192

7.2. Distribución del grado de entrada para la red de menciones y re-tweets entre usuarios . . . . . . . . . . . . . . . . . . . . 193

7.3. Distribución del grado de salida para la red de menciones y re-tweets entre usuarios . . . . . . . . . . . . . . . . . . . . . . 194

7.4. Distribución del grado de la red hashtags . . . . . . . . . . . . . 195

7.5. Relación entre los usuarios según su grado de entrada (eje Y) y el grado de salida $($ eje $\mathrm{X}) \ldots \ldots \ldots \ldots$. . . . . . . . . . . . . . . . . . . .

7.6. La imagen muestra la relación entre los diez primeros usuarios y el rating de los recursos que han publicado) . . . . . . . . . . . . . . . 202 


\section{Índice de tablas}

2.1. Factores que promueven la selección de un OERs . . . . . . . . . . . 17

2.2. Matriz de valoración usuario-ítems usado en el filtrado colaborativo . . . 31

4.1. Relación entre los retos identificados y las características del modelo. . . 66

4.2. Construcción de Tópicos - Condiciones que debe cumplir el entorno para que dadas las entradas se generen las salidas . . . . . . . . . . . . . 74

4.3. Recolección de datos - Condiciones que debe cumplir el entorno para que dadas las entradas se generen las salidas . . . . . . . . . . . . 77

4.4. Identificación de relaciones y construcción de redes - Condiciones que debe cumplir el entorno para que dadas las entradas se generen las salidas 82

4.5. Instanciar redes - Condiciones que debe cumplir el entorno para que dadas las entradas se generen las salidas . . . . . . . . . . . . . . . 84

4.6. Análisis y visualización de redes - Condiciones que debe cumplir el entorno para que dadas las entradas se generen las salidas . . . . . . . . 88

4.7. Método de recomendación - Condiciones que debe cumplir el entorno para que dadas las entradas se generen las salidas . . . . . . . . . . . . . 100

5.1. La relación de las hipótesis y los casos que se emplearon para validar cada uno de ellas. . . . . . . . . . . . . . . . . . . . . . . . . . 106

5.2. Componentes y módulos utilizados. En este caso se aplicó el modelo de enriquecimiento, principalmente como una herramienta de análisis y visualización de datos. Es por ello que con este caso se busca validar la hipótesis H2 . . . . . . . . . . . . . . . . . . . . . . 112 


\section{ÍNDICE DE TABLAS}

5.3. Relación entre las preguntas, las redes construidas y las métricas que se utilizaron para su análisis. La respuesta a cada una de las preguntas permite validar la hipótesis $\mathbf{H 2} \ldots \ldots$. . . . . . . . . . . . . 122

5.4. Componentes y módulos utilizados en el desarrollo de este caso. Este caso ayudó a validar la hipótesis $\mathrm{H} 2 \ldots$. . . . . . . . . . . . . . . 126

5.5. Relación entre los objetivos propuesto por el caso, las redes construidas, las métricas empleadas y el resultado de aplicar cada una de esas medidas. La combinación de estos elementos permite validar la hipótesis H2 . . . 138

5.6. Componentes y módulos utilizados con la ejecución del caso que se describe en este apartado se busca validar la hipótesis H2 . . . . . . . . . 141

5.7. Relación entre los objetivos propuesto por el caso, las redes construidas, las métricas empleadas y el resultado de aplicar cada una de esas medidas. La combinación de esos elementos permite validar la hipótesis H2 . . . . 146

5.8. Componentes y módulos utilizados en el desarrollo de este caso . . . . . 147

5.9. Estadísticas de la información recolectada desde Twitter . . . . . . . . . 152

5.10. Diez URLs populares compartidas en Twitter descritas con el hashtag \#html5 . . . . . . . . . . . . . . . . . . . . 158

5.11. Diez URLs recomendadas por el modelo de enriquecimiento propuesto. . 159

5.12. El uso de de redes y medidas del SNA para construir un modelo de recomendación que se basa en la interacción social entre usuarios, ayudaron a validar parte de la hipótesis H3 . . . . . . . . . . . . . . . . . . . . 160

5.13. El uso de de redes y medidas del SNA para construir un algoritmo de valoración (Ranking) que se basa en el uso diferenciado de la información que proviene de los contenidos compartidos en una red social y aquellos que, ayudaron a validar parte de la hipótesis H4 . . . . . . . . . . 162

5.14. Componentes y módulos utilizados así como las hipótesis que su busca validar con la ejecución de este caso . . . . . . . . . . . . . 163

5.15. Expresiones de búsqueda por área y por competencias con el número de Tweets con URL . . . . . . . . . . . . . . . . . . . . . . . 168

5.16. Descripción de la validación para las hipótesis $\mathbf{H 1}$ y $\mathbf{H 2}$ a través de cada uno de los casos y el método de validación que se utilizó . . . . . . . . 174

5.17. MDescripción de la validación para las hipótesis $\mathbf{H 3}$ y $\mathbf{H 4}$ a través de cada uno de los casos y el método de validación que se utilizó . . . . . . 175 
7.1. Resumen de los Tweets recolectados clasificados bajo el criterio de poseer una URL (un recurso) . . . . . . . . . . . . . . . . . . 189

7.2. Información de los usuarios, clasificados por su aparición en Tweets con

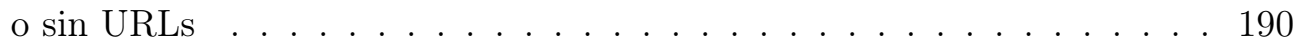

7.3. Cantidad de veces que los usuarios reciben un re-tweets o menciones, si han sido o no publicados en Tweets que contienen URLs . . . . . . . . . 191

7.4. El uso de los hashtags dentro del grupo de datos que se utilizó. . . . . . 191

7.5. Lista de los usuarios destacados que ocupan los 10 primeros lugares según la medida de Intermediación (Betweenness) . . . . . . . . . . . . 197

7.6. Lista de los 10 primeros usuarios según el número de Tweets que han publicado. . . . . . . . . . . . . . . . . 198

7.7. Las diez primeras etiquetas que se obtuvieron tanto por conteo como a través de una medida de centralidad denominada Betweenness (Intermediación) . . . . . . . . . . . . . . . . . . . . . . . . . 199

7.8. Aporte al rating de los diez primeros recursos por parte de la información expuesta socialmente (red de contexto - contenidos) y la información que proviene del título, descripción y keywords del recurso y que se considera no expuesta a un conglomerado. . . . . . . . . . . . . . . . . . . 199

7.9. Los diez primeros recursos ordenados por el rating que se obtiene de la información expuesta dentro de la red social que dentro del modelo se denomina contexto. El rating TDK proviene de información que no ha sido expuesta dentro de la red social (título, descripción y keywords del recurso $\ldots \ldots \ldots \ldots \ldots$

7.10. El número de recursos (URLs) producidas por cada uno de los usuarios y clasificados según el cuartil de los rating de cada recurso . . . . . . . . 202

7.11. Recursos obtenidos según el ranking social del contexto . . . . . . . . . . 203 


\section{Introducción}

En los últimos años, la cantidad de Recursos Educativos Abiertos (OERs) publicados en la Web se ha incrementado sustancialmente, en especial, gracias a iniciativas tales como OpenCourseWare (OCW) y a otras estrategias para la publicación de OERs como los repositorios especializados. El potencial de ésta vasta cantidad de recursos educativos es enorme.

Hoy en día millones de recursos digitales son compartidos en forma URL en diferentes redes sociales en línea, como Facebook (1 millón de links cada 20 minutos) $)_{1}^{1}$ y Twitter (en 2010, de 90 millones de tweets el $25 \%$ contiene links) $)^{2}$

Esos recursos compartidos pueden ser usados para diferentes propósitos que van desde la transmisión de noticias, pasando por anuncios publicitarios, para llegar a propósitos más nobles como el aprendizaje.

Otra contribución de las redes sociales en línea son las relaciones explícitas e implícitas que existen entre los participantes. Explícitas tales como: amigos, seguidores, siguiendo (quienes me siguen), etc., e implícitas que se forman través de las diferentes características de cada red social en línea. Por ejemplo: la co-ocurrencia de hashtags en Twitter. Esas relaciones pueden ser usadas para encontrar información relevante, permitiendo extender el análisis de redes más allá de estadísticas simples.

En su gran mayoría las redes sociales en línea poseen una Interface de Programación de Aplicaciones (técnicamente conocida como API) ${ }^{3}$ que se puede usar para publicar información o para consultar la información almacenada en esas redes. El proceso de

\footnotetext{
${ }^{1}$ http://www.statisticbrain.com/facebook-statistics/

${ }^{2}$ http://techcrunch.com/2010/09/14/twitter-event/

${ }^{3}$ http://www.programmableweb.com/apis/directory $/ 1$ ?apicat=social
} 


\section{INTRODUCCIÓN}

consulta de información está sujeto a ciertas políticas que si bien restringen el acceso al universo de datos, permiten recolectar un subconjunto de datos lo suficientemente grande que los convierte en fuentes de datos interesantes.

En este trabajo se discute el uso de las redes sociales en línea como una fuente de OERs, así como también el uso del Análisis de Redes Sociales (SNA) y sus métricas con el fin de identificar usuarios influyentes por su interacción y el efecto de los mismos dentro de la red, así mismo identificar conceptos que se publican en la red con el fin de conocer el contexto sobre el que se desarrolla un tema. El uso del análisis de redes sociales a nivel de usuarios y contenido es una propuesta que busca superar los problemas de la calidad de los recursos compartidos en redes sociales en línea que como lo resumen Kandylas and Dasdan (2010) los recursos publicados en redes sociales en línea son una mezcla de recursos de alta calidad y spam. Todo esto, en su conjunto, permite crear un modelo de recomendación que usa: a) la información que suministra una estructura de red (por ejemplo una red social). b) los roles de los usuarios (nodos de la red) según su comportamiento en el tiempo, c) la información adicional publicada dentro de la red (contexto / folksonomías) que se genera alrededor de un tema. d) la evaluación del texto (contenidos) de los recursos publicados y e) el uso de licencias (legal) para determinar la apertura de los recursos publicados.

La ventaja de este planteamiento es la capitalización de la inteligencia colectiva que está presente en muchas de las redes sociales en línea.

\subsection{Publicaciones}

Para concluir con la introducción, se presenta un listado de los trabajos realizados y publicados durante el proceso de investigación y que están relacionados con el uso de los conceptos que en esta tesis se promueven.

\subsubsection{JCR Papers: (WoK \& SCOPUS Indexed)}

- Piedra, N. Chicaiza, J. López, J. Tovar, E.: Seeking Open Educational Resources to compose Massive Open Online Courses in Engineering Education. Journal of Universal Computer Science, 2015. 
- López, J., Piedra, N. Chicaiza, J. Tovar, E.: OER Recommendation for Entrepreneurship Using a Framework based on Social Network Analysis. Revista Iberoamericana de Aprendizaje. Volume 10, Issue 4, 1 November 2015, Article number 7293125, Pages 262-268 2015.

- Piedra, N. Chicaiza, J. Quichimbo, P. Saquicela, V. Cadme, E. López, J. Espinoza, M. Tovar, E. (2015) Marco de Trabajo para la Integración de Recursos Digitales Basado en un Enfoque de Web Semántica. Revista Ibérica de Sistemas y Tecnologías de Información (RISTI). doi: 10.17013/risti.e3.55-70.

- Piedra, N. Tovar, E. Colomo-Palacios, R. Lopez-Vargas, J. Chicaiza, J.: Consuming and producing linked open data: the case of OpenCourseWare. Program: electronic library and information systems, Vol. 48 Iss: 1, pp.16 - 40, 2014.

- Tovar, E. Piedra, N. Chicaiza, J. Lopez, J. Martínez, O. Development and promotion of OERs. Outcomes of an international research project under OpenCourseWare model. Journal of Universal Computer Science, 2012.

- Chicaiza, J. Piedra, N. Lopez, J. Martinez, O. \& Tovar, E. Usage of social and semantic web technologies to design a searching architecture for software requirement artefacts. IET Software Journal, 4(6), 407 - 417, 2010.

\subsubsection{Open Journals}

- Piedra, N., Chicaiza, J., López, J. and Tovar, E. An Architecture based on Linked Data technologies for the Integration and reuse of OER in MOOCs Context, Open Praxis, 6 (2), 171-187, 2014.

\subsubsection{Proceedings (SCOPUS Indexed)}

- Piedra, N., Chicaiza, J., Lopez-Vargas, J., Tovar, E.: Guidelines to producing structured interoperable data from Open Access Repositories. Proceedings - Frontiers in Education Conference (FIE). 2016.

- Caro, E.T., Piedra, N., Chicaiza, J., Lopez, J., Artacho, M.R., Castro, M., Martin, S., Ruiz, E.S.C., Diaz, G., Loro, F.G. Open educational resources and standards in the eMadrid network 2016 International Symposium on Computers in Education, SIIE 2016: Learning Analytics Technologies. 2016 


\section{INTRODUCCIÓN}

- Piedra, N. Chicaiza, J. López, J. Tovar, E.: Integrating OER in the design of educational material: Blended learning and linked- open-educational-resourcesdata approach. 2016 IEEE Global Engineering Education Conference (EDUCON). 2016.

- Kloos, C.D., Alario-Hoyos, C., Fernández-Panadero, C., Estévez-Ayres, I., MuñozMerino, P.J., Cobos, R., Moreno, J., Tovar, E., Cabedo, R., Piedra, N., Chicaiza, J., López, J. EMadrid project: MOOCs and learning analytics. 2016 International Symposium on Computers in Education, SIIE 2016: Learning Analytics Technologies. 2016

- Piedra, N. Chicaiza, J. López, J. Tovar, E.: Towards a Learning Analytics Approach for Supporting discovery and reuse of OER. An approach based on Social Networks Analysis and Linked Open Data. 2015 IEEE Global Engineering Education Confer- ence (EDUCON), Tallin, Estonia, 2015.

- Chicaiza, J., Piedra, N. López, J. Tovar, E.: Promotion of self-learning by means of Open Educational Resources and Semantic Technologies. 14th International Con- ference on Information Technology Based Higher Education and Training, Lisboa-Portugal, 2015.

- Piedra, N. Chicaiza, J. López, J. Tovar, E.: "Supporting openness of MOOCs contents through of an OER and OCW framework based on Linked Data technologies", 2014 IEEE Global Engineering Education Conference (EDUCON), IEEE Xplore, pp. 1112 - 1117, 2014.

- Chicaiza, J., Piedra, N., López-Vargas J. y Tovar, E.: Domain Categorization of Open Educational Resources Based on Linked Data Sources. Communications in Computer and Information Science, Springer Verlag, 2014.

- Tovar, E. Piedra, N. López, J. y Chicaiza, J.: "Roadmap towards the Openness of Educational Resources: Outcomes of the participation in the eMadrid network", In Proceedings of the 2014 Frontiers in Education Conference, pp. 383 - 386, 2014.

- Lopez, J. Piedra, N. Chicaiza, J. y Tovar, E.: "Recommendation of OERs shared in social media based-on Social Networks Analysis approach", In Proceedings of the 2014 Frontiers in Education Conference, pp. 2811 - 2827, 2014. 
- Tovar, E. López, J. Piedra, N. Chicaiza: "Impact of open educational resources in higher education institutions in spain and latin americas through social network analysis", In Proceeding of the 120th ASEE Annual Conference and Exposition, Atlanta- GA, United States 2013.

- Piedra, N. Chicaiza, J. López, J. Tovar, E.: Using linked open data to improve the search of open educational resources for engineering students. Source of the Document Proceedings - Frontiers in Education Conference, FIE 2013.

- Piedra, N.; Chicaiza, J.; Lopez, J.; Tovar, E.; Martinez, O. Finding OERs with Social- Semantic search. In Proceeding of IEEE Global Engineering Education Conference (EDUCON), 1195 - 1200, Amman, April 2011.

- Piedra, N. Chicaiza, J. López, J. Martínez, O. Tovar, M. Design study of OERCC ontology. A semantic web approach to describe Open Educational Resources. In Proceeding of The 10th IEEE International Conference on Advanced Learning Technologies (ICALT 2010), July 5-7, 2010, Sousse, Tunisia, IEEE Computer Society, pp. 207-209.

- Piedra, N. Chicaiza, J. Romero, A. Lopez, J. \& Tovar, E. Measuring collaboration and creativity skills through rubrics: Experience from UTPL collaborative social networks course. In Proceeding of The Engineering Education Conference 2010 (IEEE EDUCON), abril de 2010, pp. 1511 - 1516.

- Piedra, N. Chicaiza, J. López, J. Martínez, O. Tovar, M. An approach for description of Open Educational Resources based on semantic technologies. In Proceeding of the Education Engineering Conferences (EDUCON), IEEE, 2010, pp. $1111-1119$.

- López, J. Tovar, E. Piedra, N. Chicaiza, J. Blázquez, M. Castro, M. Arriaga, J. Pescador, F. Romo, J. Casquero, O. Benito, M. \& Landaluce, A. Meta-analysis of the TAEE project applying social network analysis. The Engineering Education Conference 2010 (IEEE EDUCON), abril de 2010, pp. 129 - 136.

- Piedra, N. Chicaiza, J. \& López, J. Martínez, O \& Tovar, E. Open Educational Practices and Resources Based on Social Software: UTPL experience. IEEE Com- 
puter Society. (The 9th IEEE International Conference on Advanced Learning Technologies). Riga, Latvia, july, 2009. (JCR Proceeding).

\subsubsection{Otros índices}

- Piedra, N. Chicaiza, J. Tovar, E. and López, J.: A Framework for improving the effectiveness of the Openness in OER Repositories and Open Educational Datasets. Open Education Global Conference, 2015.

- Chicaiza, J. Piedra, N. and López-Vargas, J.: "Diseño de un vocabulario para conectar e interoperar los syllabus de cursos OCW mediante tecnologías de la Web Semántica", LACCEI Proceedings, 2014.

- Tovar, E. López, J. Piedra, N. and Chicaiza J. A real picture of the current use of Open Educational Resources in Higher Education Institutions in Spain and Latin Americas through the application of emergent technologies. OpenCourseWare Consortium Global Meetings, OCWC Global Conference 2013, Bali-Indonesia, may 2013.

- Piedra, N. Tovar, E. Chicaiza, J. and López J. Serendipity a Faceted Search for OpenCourseWare Content, OpenCourseWare Consortium Global Meetings, OCWC Global Conference 2013, Bali-Indonesia, may 2013.

- Tovar, E. Piedra, N. Lopez J. Chicaiza J. and Martinez O. Semantic Technologies: Linked and OER. Opening and linking the data and content silos, to leverage the knowledge capital represented by our OER repositories. Open Educational Resources Congress, UNESCO, Paris, France, June 2012.

- Tovar E. Piedra N. Lopez J. Chicaiza J. and Martinez O. Linked OpenCourseWare Data: a demonstration of the potential use of OCW Universia linked Data. OpenCourseWare Consortium Global Meetings, Cambridge, U.K., April 2012

\subsubsection{Capítulos de libros}

- Aplicación de tecnologías web emergentes para el estudio del impacto de repositorios OpenCourseWare españoles y latinoamericanos en la Educación Superior. UPM Open Education Office, ISBN: 978-84-695-7225-2, 2013. 
- Piedra, N. López, J. Chicaiza, J. \& García, J. Study of the application of neural networks in internet traffic engineering. International Book Series Ïnformation Science and Computingï.TECH 2008, Varna, Bulgaria, 2008. 


\section{Estado del arte}

\subsection{Introducción}

En este capítulo se presenta un análisis exhaustivo del estado de la técnica de los temas de interés tratados en esta tesis, así como también una discusión sobre las limitaciones de los trabajos de investigación sobre el estado del arte.

Para ello se ha organizado el estado del arte de la siguiente forma: iniciaremos con una introducción a los Recursos Educativos Abiertos, para luego presentar el impacto que los mismos han causado a nivel global, con este fin se analizar algunos trabajos que muestran el resultado de encuestas realizadas a varios participantes y promotores del movimiento de los OERs se mostrará el uso de OERs dentro de prácticas educativas y finalmente se hace una presentación de OpenCourseWare como iniciativa representativa del movimiento abierto dentro de la enseñanza. Se destacará el impacto que éstos han causado durante su trayectoria. Luego se presentará los conceptos fundamentales que se utilizan en este trabajo, analizados bajo la visión integradora de la Computación Social. A continuación se destacan los trabajos más relevantes sobre la aplicación de diferentes técnicas de análisis de redes sociales en procesos de recomendación y enseñanza. Finalmente se presenta una clasificación de los trabajos anteriores para mostrar las tendencias sobre las temáticas que aquí se desarrollan.

\subsection{Recursos Educativos Abiertas (OER)}

Las iniciativas relacionadas con los Recursos Educativos Abiertos promueven el intercambio global con el objetivo de incrementar la capacidad intelectual de los seres 


\section{ESTADO DEL ARTE}

humanos. La idea principal del movimiento hacia los OERs es que el conocimiento es un bien público donde la tecnología en general, y específicamente la Web, brinda una oportunidad extraordinaria para que las personas adquieran las competencias clave en una Sociedad del Conocimiento, mientras comparten, usan y reutilizan contenidos digitales.

Los OERs son recursos y herramientas digitales de enseñanza, aprendizaje e investigación, disponibles en el dominio público o que han sido liberados bajo una licencia de propiedad intelectual, es decir que permiten su uso libre, re-utilización o re-propósito por parte de otras personas interesadas (Piedra et al. 2010a).

La tecnología educativa actual, debe evolucionar de tal forma que el siguiente nivel de infraestructura tecnológica educativa necesitará usar herramientas sociales y tecnologías semánticas aplicadas a la Web. La aplicación de la Web social en proyectos OER ha demostrado que los usuarios regulares pueden aportar contenido, sin el requisito de ser especialistas en un tema. Cualquier persona puede participar activamente como autor en la Sociedad del Conocimiento. Por otro lado las tecnologías semánticas habilitan el poder de la Web semántica para así facilitar el intercambio, re-utilización y el descubrimiento de los recursos educativos.

Las iniciativas de Recursos Educativos Abiertos se basan en el movimiento Acceso Abierto (Open Access - OA). Se han realizado varias declaraciones de apoyo para acelerar los esfuerzos para promover los recursos educativos abiertos, la tecnología y las buenas prácticas de enseñanza en la educación. La declaración de la iniciativa de de Acceso Libre de Budapest (Murray-Rust and Rzepa 2004) fue una de las primeras en promover fuertemente el acceso abierto y gratuito a los contenidos académicos y de investigación.

De la misma manera, la importancia de los OERs ha sido promovida por iniciativas de organizaciones internacionales y nacionales. Algunas de estas iniciativas son: Massachusetts Institute of Technology (MIT) en 2001 con su proyecto OpenCourseWare (OpenCourseWare 2006), proyectos del Centro para Investigación e Innovación Educativa de la OECD (Hylén 2007), iniciativa de la UNESCO a través del Instituto Internacional de Planificación Educativa (UNESCO-IIEP 2008), el proyecto Open Learn ${ }^{1}$ de Open University, el proyecto Connexions de IEEE (Boyd Farmer and Sackett

\footnotetext{
${ }^{1}$ http://openlearn.open.ac.uk
} 
2009) entre otro\$ ${ }^{1}$

Los proyectos OER pueden clasificarse según el modelo (financiamiento, técnica, contenido y personal) utilizado para asegurar su sostenibilidad. Downes (2007a) describe cada uno de esos modelos. El modelo de personal resulta interesante para este trabajo el modelo de personal, es decir, en que grado los participantes podrían realmente ayudar a los recursos. Teniendo en cuenta este punto de vista y según Hylén (2007) existen dos sub-modelos: productor-consumidor y coproducción, una comparación entre ambos modelos se encuentra en WikiEducator 2

En modelos productor-consumir, también conocidos como usuario-productor, una institución o consorcio desarrolla materiales y los libera bajo una licencia abierta, para que puedan ser reusados por otros proveedores. Dentro de este grupo se puede considerar el OpenCourseWare del MIT.

Los modelos de coproducción, en cambio, fomentan la participación abierta y sin restricciones, con el fin de aprovechar los beneficios de la colaboración masiva y los principios de la auto-organización. Este modelo, puede promover la producción colaborativa de recursos comunes.

Las estrategias de co-producción para la generación de OERs pueden ser implementadas usando herramientas de la Web Social. La Web 2.0 o Web social se centra en los contenidos, las relaciones y el conocimiento, pero no específicamente en la tecnología. En (Richardson 2006a) se manifiesta lo siguiente: "La buena noticia para todos nosotros es que hoy en día, cualquiera puede convertirse en un estudiante de toda la vida. Esas tecnologías son fáciles de usar de una manera que era imposible en el pasado".

El uso de las wikis es un buen ejemplo de transición de sitios Web estáticos y restringidos a la participación social y de colaboración (co-autores). O'Reilly (2005) se refiere a la Wikipedia como una experiencia radical de la confianza. Wikipedia, blogs y otras herramientas permiten al usuario publicar y luego la comunidad determina la relevancia y pertinencia del contenido. Los errores se resuelven mediante la corrección social y con el apoyo de la gestión de configuración del contenido (control de versiones).

El eje central de todo software social es su fácil uso, sin embargo un modelo de coproducción de OERs basado en este tipo de servicios tiene algunas debilidades. Schaffert

\footnotetext{
${ }^{1}$ En http://oerwiki.iiep-unesco.org/ se puede encontrar una lista mucho más amplia 2 http://wikieducator.org
} 


\section{ESTADO DEL ARTE}

(2006) identifica los principales riegos, barreras y obstáculos para la implementación de la Web 2.0 en la práctica de la enseñanza aprendizaje.

Además Piedra et al. (2010a) agrega que una de las principales dificultades para adoptar este enfoque es que el uso de herramientas sociales, está generando un crecimiento impresionante en la cantidad de contenidos que están disponibles en Internet. Esta situación está obstaculizando la organización, recuperación e interoperabilidad de los recursos, por lo que se necesita de un procesamiento "inteligente" de esos recursos si lo que se pretende es usarlos en tareas de enseñanza aprendizaje. Por lo tanto es necesario contar con varios mecanismos para la descripción de los recursos, además de contar con herramientas, como sistemas de recomendación, que ayuden a encontrar los elementos relevantes que son generados en las redes sociales aprovechando la inteligencia colectiva que ahí se encuentra.

Dentro de la definición de un OER tienen cabida diferentes tipos de recursos educativos abiertos, en (Farrow et al. 2015) se muestran los siguientes tipos: ebook, audio, juegos, texto abierto, conjuntos de datos, imágenes, herramientas, cursos completos, tutoriales, exámenes, plan de estudios, vídeo, infografías, lecturas, módulos o unidades de un curso. Pero si ampliamos esta definición con la propuesta de (Downes 2007b) un OER es cualquier recurso que apoye a la educación, y como sostiene McGuire (2014) esto podría incluir personas que son guías que ayudan a navegar por repositorios de información o conocedores expertos que permitan llegar a un recurso específico. En la sección 2.4 se muestra una clasificación de los tipos de OER por su granularidad.

\subsubsection{Impacto de los OERs}

Medir el real impacto de iniciativas globales como esta, es una tarea bastante complicada por la diversidad de iniciativas y lo disperso, geográficamente hablando, de su ubicación. Es por ello que el enfoque que aquí se usó tiene tres ejes fundamentales, en el primero de ellos se muestra el impacto de los OERs por su adopción de organismos internacionales. El segundo eje los resultados de encuestas de carácter global que pretenden medir el impacto real que los OERs y su uso han causado dentro de la educación. Finalmente el tercer eje es el análisis de uno de los representantes del movimiento OER y su impacto.

Dentro del primer eje, analizando el interés que los OERs han provocado en organismos internacionales, hasta convertirlos en patrocinadores o en sus activistas. Un 
destacado participante es el caso de La Organización de las Naciones Unidas para la Educación, la Ciencia y la Cultura (UNESCO) que es un organismo especializado de las Naciones Unidas. UNESCO tiene el objetivo de contribuir a la paz y a la seguridad en el mundo mediante la educación, la ciencia, la cultura y las comunicaciones. Es más el término OER fue propuesto por UNESCO en el foro sobre el impacto de los Open Courseware para educación superior en países en vías de desarrollo UNESCO (2002) en el año 2002.

Como se afirma en (UNESCO 2016) desde 2002, UNESCO ha participado activamente en la colaboración internacional sobre OERs mediante conferencias, reuniones de expertos, investigaciones, estudios, guías, talleres de creación, publicaciones y directrice@1 En Junio de 2012 UNESCO organizó el Primer Congreso OER, desarrollado en Paris, que generó la declaración OER de Paris, en donde y en términos generales, se recomienda a los gobiernos de todo el mundo el fomento y uso de los OERs y licencias abiertas. Existen también otras iniciativas tales como: OER Community on the World Summit on the Information Society (WSIS) Knowledge Community (KC) ${ }^{2}$ y el trabajo con sus socios es permanente y en los últimos años han centrado sus actividades en crear conciencia en los docentes y otras instituciones educativas sobre los beneficios de la OERs mediante debates sobre políticas y promoción con la participación de organizaciones clave.

En Butcher and Hoosen (2014) se habla sobre el impacto de la apertura en diferentes ámbitos relacionados a la educación y se menciona por ejemplo una iniciativa de UNESCO denominada "The OER Platform"que cuenta con recursos educativos en 13 idiomas liberados bajo la licencia Creative Commons y se convierte en un ejemplo para que las naciones miembro liberen recursos financiados con fondos públicos bajo licencias abiertas.

Dentro del segundo eje, el estudio de encuestas realizadas, se pueden mencionar el trabajo realizado por (Farrow et al.|2015) en donde se aplicaron 20 encuestas a proyectos, iniciativas y organizaciones de 4 sectores de la educación (K12, universidades, educación superior e informal) en 180 países en un periodo de dos años desde el 2013 al 2015, con

\footnotetext{
${ }^{1}$ http://www . unesco.org/new/en/communication-and-information/access-to-knowledge/ open-educational-resources/documentary-resources/ se puede encontrar un listado de algunas de las publicaciones que UNESCO ha generado en apoyo a la iniciativa OERs.

${ }^{2}$ http://www.wsis-community.org/pg/groups/14358/open-educational-resources-oer/
} 


\section{ESTADO DEL ARTE}

el objetivo de responder a 11 hipótesis propuestos por The Open Educational Resources Research Hub (OERRH).

Los resultados publicados entre otros muestran el impacto positivo de los OERs, a continuación se presenta algunas estadísticas. A nivel de educadores las estadísticas relevantes son:

- El $37.6 \%$ de los educadores afirman que el uso de los OERs mejoran la satisfacción de los estudiantes.

- El $79.5 \%$ de los educadores usan OER para obtener nuevas ideas e inspiración.

- Sólo el $5 \%$ de los educadores dicen que no comparten información sobre OER.

- El $27.5 \%$ de los educadores y el $31.9 \%$ de los estudiantes formales están de acuerdo que el uso de OERs da como resultado mejores calificaciones en los exámenes o pruebas.

- El $36.2 \%$ de los educadores están de acuerdo que el uso de los OERs mejoran otros aspectos que no están relacionados con las calificaciones, tales como el involucramiento de los estudiantes con el contenido de las lecciones y el incremento de la experiencia con nuevas formas de aprendizaje.

- El $35 \%$ de los educadores sostiene que los estudiantes son más independientes y autosuficientes.

- El $35 \%$ están de acuerdo que los estudiantes se interesan más por las clases impartidas cuando en estas se utilizan OERs.

Mientras que las estadísticas a nivel de estudiantes formales que se destacan en el estudio son las siguientes:

- El $55.7 \%$ de los estudiantes formales afirman que el uso de los OERs mejoran su satisfacción.

- $88.4 \%$ de los estudiantes dicen que la oportunidad de estudiar sin costo alguno influyó en su decisión de usar OER.

- El $40.9 \%$ de todos los estudiantes formales consideran que los OERs tienen un impacto positivo en ayudarles a completar su curso de estudio. 
Finalmente dentro del grupo de los estudiantes informales los resultados de las encuestas son las siguientes:

- El $74.9 \%$ de los estudiantes informales usan OER para tener una experiencia de aprendizaje.

- El $31.5 \%$ de los estudiantes informales dicen que su interés en usar REA es una oportunidad de probar el contenido de nivel universitario antes de inscribirse en un curso de pago.

- $31.3 \%$ sostienen que el uso de OERs influenció su decisión para registrarse en sus cursos actuales.

- El $83.2 \%$ de los estudiantes informales dicen que es más probable que tomen otro curso gratuito o estudien un recurso educativo abierto gratuito y el $24.2 \%$ dicen que van a tomar un curso pagado como resultado del uso de OER.

Otra de las preguntas que se platearon dentro del proyecto OERRH, es en qué áreas del conocimiento se utilizan los OERs, según los datos de ese mismo estudio se utilizan en cursos relacionados a: computación y ciencias de la información, psicología y filosofía, religión, ciencias sociales, lenguajes y lingüística, ciencia, matemáticas, artes, literatura, historia y geografía, economía negocios y administración, ciencias aplicadas e ingeniería, medica, salud, atención social, educación, etc. Es decir se cubre todas las áreas del conocimiento haciendo mayor énfasis en alguna de ellas.

Dentro de la misma investigación se puede encontrar el impacto que cada uno de los tipos de OER ha causado dentro de los educadores y como estos últimos han adoptado el uso de OERs de diferente tipo. En la Figura 2.1 muestra el uso de los diferentes tipos de OERs definido $\$^{1}$ en el trabajo de Farrow et al. (2015) que permite encontrar que los principales tipos de OERs que se utilizan son: módulos (secciones de un curso completo), lecturas, infografías y vídeos.

Pero cuales son los principales motivos para utilizar OERs, según el estudio que estamos analizando se resumen en la Tabla 2.1 se listan los factores que según estudio determinan que se seleccione un OER. La primera columna de la tabla muestra la clasificación, realizada por este autor, de los motivos en 4 grandes grupos social, propiedad

${ }_{1}^{1}$ https://goo.gl/KFMsVD apartado 3.2 


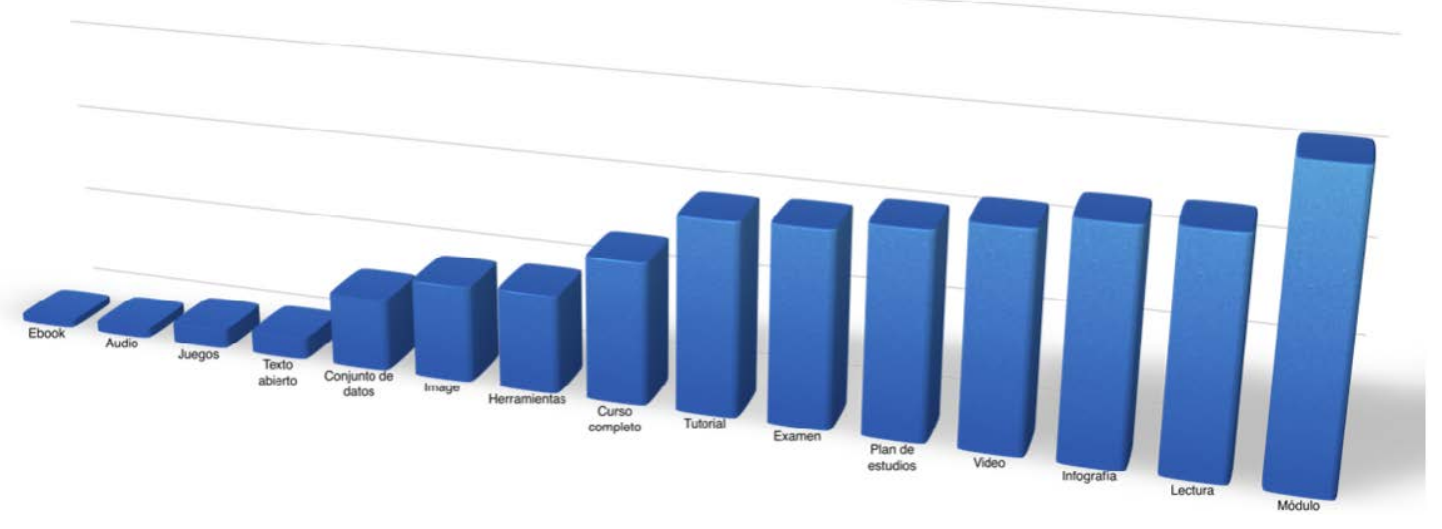

Figura 2.1: Uso de los diferentes tipos de OER - Uso de los diferentes tipos de OER, esto no implica que se use de manera exclusiva un único tipo, sino que pueden existir combinación de varios tipos

del recurso, contenido y personal. Los motivos de tipo social, son fruto de la interacción de varias personas, no así los de tipo personal que responden a necesidades individuales. Mientras que las propiedades del recurso se refieren a las características generales de los recursos y el contenido a características concretas de cada uno de los recursos.

Considerando la abundancia de iniciativas y OERs publicados, el tratar de medir el impacto que han tenido en la educación es una tarea sumamente difícil. Es por ello que en este trabajo se medirá el impacto a través de dos análisis. El primero será el uso de los OERs dentro de prácticas educativas, mientras que para el segundo análisis se toma como representante de los OERs a los OpenCourseWare.

\subsubsection{Prácticas educativas basadas en OERs}

Existe una gran variedad de usos prácticos para los OERs. En (Ehlers 2011) se definen dos actividades amplias para el uso práctico de los OERs, así: compartir/reusar OERs y dentro de prácticas pedagógicas, mientras que (Masterman 2015) agrega una más, el aprendizaje en un mundo abierto.

Utilizando el enfoque propuesto por Ehlers (2011) se muestran algunos trabajos relacionados con la actividades educativas basadas en OERs.

\section{Compartir y reusar OERs}


Tabla 2.1: Factores que promueven la selección de un OERs

\begin{tabular}{|l|l|l|}
\hline \multicolumn{2}{|c}{ Tipo } & \multicolumn{2}{c}{ Motivo } & Porcentaje \\
\hline \multirow{5}{*}{ Social } & $\begin{array}{l}\text { Evidencias de interés en el recurso } \\
\text { (e.g. cantidad de descargas) }\end{array}$ & $45 \%$ \\
\cline { 2 - 3 } & $\begin{array}{l}\text { Creado por persona/institución } \\
\text { respetable/confiable }\end{array}$ & $61 \%$ \\
\cline { 2 - 3 } & Valoración y comentarios del recurso & $47 \%$ \\
\cline { 2 - 3 } & Recomendación & $44 \%$ \\
\hline \multirow{5}{*}{ Propiedad del recurso } & $\begin{array}{l}\text { Actualidad } \\
\text { (reciente creación, actualización o carga) }\end{array}$ & $38 \%$ \\
\cline { 2 - 3 } & Fácil de descargar & $58 \%$ \\
\cline { 2 - 3 } & El recurso cuenta con licencia CC & $24 \%$ \\
\cline { 2 - 3 } & El recurso permite adaptación & $21 \%$ \\
\hline & Provee objetivos y resultados & $66 \%$ \\
\cline { 2 - 3 } & Posee descripción detallada & $51 \%$ \\
\cline { 2 - 3 } & Posee título o imagen atractivos & $15 \%$ \\
\cline { 2 - 3 } & Longitud y complejidad & $43 \%$ \\
\cline { 2 - 3 } & Usa multimedia & $52 \%$ \\
\hline \multirow{5}{*}{ Personal } & Experiencia previa & $33 \%$ \\
\cline { 2 - 3 } & Responde a mis necesidades/intereses & $34 \%$ \\
\cline { 2 - 3 } & Requisito para un proyecto o tarea & \\
\hline
\end{tabular}




\section{ESTADO DEL ARTE}

Uno de los principales usos prácticos que se les da a los OERs es la construcción de bibliotecas de recursos, también denominados como repositorios, que ayudan al acceso a los mismos (D'Antoni 2006), Wiley 2003), Andrade et al. 2011). Esos repositorios educativos pueden ser fruto de diferentes iniciativas, como menciona Santos-Hermosa et al. (2012), los repositorio se pueden clasificar por diferentes criterios tales como: instituciones propulsoras o financiadoras (gobiernos, universidades, instituciones educativas, fundaciones, consorcios), por el formato de sus contenidos (audiovisuales, multimedia), cobertura geo-política (regionales, estatales, internacionales), por el contenido depositado (OCW exclusivamente, OERs por temáticas, buscadores de OERs). El número de los repositorios es indeterminado en una búsqueda hecha por Brody (2017) se encontraron 63 repositorios registrados a 2017, mientras que en (Nottingham|2017) se afirman que existen más de 450 repositorios de acceso abierto registrados dedicados a OERs.

Dentro de un repositorio de OERs también se almacenan metadatos asociados a cada recurso, en (Vargas-Arcila et al. 2016) se puede encontrar algunos esfuerzos dirigidos al manejo de los metadatos en OERs, con el objetivo de identificar cada uno de ellos y permitir el intercambio entre diferentes sistemas de gestión de aprendizaje (Holden 2003), (de la Fuente 2009). Para la correcta gestión de la información de los recursos y sus metadatos en colaboración con otros autores se propuso el uso de tecnología de la Web Semántica y Linked Data y se desarrolló una ontología denominada OER-CC que permite modelar el dominio de conocimiento de los OER buscando facilitar la interoperabilidad y descubrimiento de los OERs (Piedra et al. 2010a) y (Piedra et al. 2010c), (Piedra et al. 2014b).

Un tipo especial de OERs son los buscadores de este de tipo de recursos SantosHermosa et al. (2012). Son varios los buscadores de OERs que existen pero haré énfasis en Serendipity $\bigsqcup^{1}$ que es un proyecto en el cual participé y que siguiendo la misma lógica descrita en el párrafo anterior (uso de la Web Semántica y Linked data) se construyó un buscador de recursos educativos abiertos que fueron compartidos por 280 instituciones miembros de OpenCourseWare Consortium (OCWC) y Universia.net. Serendipity es un buscador basado en facetas que gracias al uso de datos enlazados permite ampliar la categorización de los recursos

1 http://serendipity.utpl.edu.ec 
y ha permitido crear visualizaciones de los datos que posee. Serendipity es una propuesta integradora respetando la diversidad de cada uno de los repositorios, no pretenden convertirse en un estándar más sino mostrar la forma como se puede llegar a interoperar repositorios.

Re-usar los OERs es otra de las actividades y usos prácticos de los mismos, es así que en (Taylor 2007) se presenta el caso de OERy ${ }^{1}$ que es una iniciativa para integrar OERs dentro de cursos evaluables en línea que aseguren que los estudiantes puedan acreditar su formación en las instituciones que participan, Murphy (2012) OERu pretende ofrecer cursos gratuitos para estudiantes, elaborados utilizando únicamente OERs y prácticas abiertas. Otro ejemplo en Tovar et al. (2013a) los autores acuñan el término OCW-S, para nombrar a OCW que utilizan y adaptan recursos educativos abiertos, recomendaciones personalizadas para el aprendizaje y el enriquecimiento con recursos publicados en redes sociales como Twitter. En esta misma línea (Piedra et al. 2014a) presenta un marco de trabajo basado en tecnologías de la Web semántica para promover la inclusión de contenido abierto en MOOCs. Una propuesta similar es desarrollada en (Piedra et al. 2014a $)$ y (Piedra et al. 2015b) con el objetivo de los inscriptos al MOOC pueden descubrir y acceder a los OERs que se extraen de diferentes repositorios.

\section{Modelos pedagógicos}

En los trabajos realizados por Creelman and Ossiannilsson (2011) y Geser (2007) se resumen varias ideas de algunos proponentes del movimiento abierto que sostienen que para alcanzar el verdadero potencial de los OERs, es necesario un cambio radical en la pedagogía. En Masterman (2015) se sostiene que los enfoques educativos abiertos pueden acoplarse a modelos pedagógicos existentes sin comprometer su integridad, sino que pueden mejorar la especifidad del modelo pedagógico.

Un ejemplo de la adopción de recursos abiertos dentro de un modelo de aprendizaje está descrito en (Tovar et al. 2012) en donde se presenta un modelo de aprendizaje recursos abiertos que fue implementado por dos facultades de la

1 https://oeru.org OER university 


\section{ESTADO DEL ARTE}

Universidad Politécnica de Madrid. En ese mismo trabajo se afirma que no es suficiente construir recursos educativos sino que también es necesario establecer un modelo de enseñanza que asegure ayude a cumplir con el objetivo de los OERs. Es decir los OERs necesitan un modelo que los complemente según propiedades y características en (Chicaiza et al. 2015) se sintetizan esas características y propiedades que facilitan su incorporación en proceso de aprendizaje formales.

Otro ejemplo se muestra en el trabajo de Piedra et al. (2016), en donde se integran OERs a clases presenciales (cara a cara) para así crear un modelo de enseñanza "mezclado" (Blended learning) ya que el reuso de los OER, tanto por individuos como por organizaciones, puede tener un importante beneficio a nivel creativo y económico para los entornos de aprendizaje.

En (Tovar et al. 2016) se muestra otro uso de los OERs como parte de un modelo pedagógico, en este caso se desarrolló un enfoque innovador de pedagogía y evaluación basado en los recursos educativos abiertos para apoyar las diversas formas, todas ellas individuales, de aprendizaje y como mejorar la evaluación de todos los tipos de resultados frutos del aprendizaje y también una forma para llegar a determinar las futuras necesidades de aprendizaje, todo lo anterior relacionado con las competencias claves que los emprendedores deben adquirir. Otros ejemplos de casos prácticos del uso de recursos educativos abiertos se pueden encontrar en (Santos et al. 2015) en donde se recopilan prácticas desarrolladas en 12 instituciones de educación superior, 4 de Europa y 8 de América Latina. Este compendio muestra de forma clara, didáctica y realista las experiencias en la oferta de OERs en instituciones de educación superior que tienen algo nuevo y diferente que mostrar.

Así mismo en (Wimpenny et al. 2016) se muestra un compendio de once prácticas educativas basadas en OERs desarrolladas por universidades países que pertenecen a la región sur del Mediterráneo. Las iniciativas son variadas e incluye MOOCs, repositorios de OERs y la implementación de licencias que permitan el acceso abierto a recursos. 


\subsubsection{OpenCourseWare (OCW)}

Son ya 15 años del anuncio que realizó el Massachussets Institute of Technology (MIT) en donde hacían pública su iniciativa, denominada OpenCourseWare, que comprendía en crear sitios Web públicos para casi la totalidad de sus 2000 cursos y la publicación de los materiales asociados a cada uno de ellos (material de lectura, folletos de problemas, programas de estudio, exámenes, simulaciones, vídeos, etc. $)_{1}^{1}$ de forma abierta para fines educativos no comerciales. Los materiales son publicados en formatos estándares para cualquiera con acceso a Internet OpenCourseWare (2006).

Según (OpenCourseWare 2006), los OCW tienen una doble misión: i) facilitar el libre acceso a prácticamente todos los materiales de los cursos del MIT para educadores, estudiantes y aprendices individuales en todo el mundo; ii) ampliar el alcance y el impacto del MIT OCW y el concepto de opencourseware.

Como menciona Vladoiu (2011), la mayoría de los materiales de los cursos que están disponibles en las iniciativas OCW alrededor del mundo han sido publicados bajo la licencia Creative Commons concretamente Attribution-Noncommercial-Share Alike 3.0. Bajo esta licencia se permite descargar, redistribuir, remezclar, modificar o ampliar estos materiales para producir nuevos, siempre y cuando los materiales se utilizen para fines no comerciales y los creadores originales sean reconocidos. Además, se autoriza que el nuevo material sea empleado en idénticas condiciones (Vladoiu 2011).

En la actualidad, OCW es una de las iniciativas de mayor impacto de acceso libre y sin restricciones al conocimiento, que ha impulsado a que otras universidades de prestigio internacional se hayan adherido, generando proyectos propios en coordinación con el OCW-MIT y con el apoyo de lo que hace poco se denominaba OCW consortium (hoy Open Education Consortium - OEC).

El OEC se define como una red global de instituciones, individuos y organizaciones que apoyan un enfoque de educación basado en la apertura que incluya la colaboración, la innovación, el desarrollo colectivo y el uso de materiales educativos abiertos. Es una organización sin fines de lucro de beneficio social registrada en Estados Unidos y que opera en todo el mundo: $2^{2}$

\footnotetext{
1 http://www.nytimes.com/2001/04/04/us/auditing-classes-at-mit-on-the-web-and-free. html

${ }^{2}$ http://www.oeconsortium.org/about-oec/
} 


\section{Incentivos y disuaciones para su uso}

La iniciativa OCW ha generado varios comentarios, muchos a favor y algunos otros en contra. En Arendt and Shelton (2009) se presentan los resultados de un estudio sobre los incentivos y desincentivos para el uso de OCW, que si bien son específicos de una región, se pueden generalizar.

Los incentivos para el uso de los OCW se resumen en:

1. gratuidad en el uso de los materiales.

2. disponibilidad de los recursos en cualquier momento.

3. profundizar en un tema de interés.

4. aprendizaje basado en el conocimiento personal o interés.

5. materiales son bastante fáciles de encontrar y acceder.

Mientras que los principales argumentos disuasivos son:

1. no otorgan ningún certificado o título.

2. no se cubre los temas con la profundidad que se desea.

3. la falta de apoyo profesional (tutores o expertos)

4. la falta de orientación proporcionada por los especialistas de soporte.

5. la sensación de que el material es abrumador.

\section{Impacto de los OCW}

Llegar a determinar con un alto nivel de certeza el impacto que un iniciativa educativa de alcance mundial es una tarea compleja y mucho más si lo que se pretende es medir el impacto del fin último de esas iniciativas. Es por esto que la forma de medir el impacto que aquí se presenta está basada en tres factores: i) en las últimas estadísticas de uso de los OCW del MIT; ii) estadísticas publicadas por el OEC y iii) los perfiles de quienes usan los OCW.

Sobre el uso actual de los OCW, el MIT-OpenCourseWare, a marzo de 2016, cuenta con 2340 cursos publicados de los cuales 1018 cursos han sido traducidos a otros idiomas y se han actualizado 905 cursos. El total de visitas a su sitio Web, en el último año ha sido 205572454 mientras que el total de visitantes 
únicos es de 129379 104. Se han visitado 1176007250 páginas, descargado 24 311597 archivos (.zip) y se han visto 107685507 vídeos publicados en YouTube. Mientras que a nivel de las redes sociales 308381 "Me gusta" en Facebook y 155 551 seguidores en Twitter 1 .

Para el segundo factor de impacto se usaron estadísticas que se obtuvieron de el Open Education Consortium.

El OEC, Es un consorcio que cuenta con la participación de más de 280 organizaciones, distribuidas en 40 países en los que se hablan más de 29 idiomas? El consorcio cuenta con 27799 cursos que son suministrados por 80 instituciones de todos los continentes? Adicionalmente cuenta con varios miembros, a los que se les denomina "sustentandores", entre los que se destaca Universie con más de 1400 universidades Iberoamericanas miembro y con presencia en 23 países.

El último factor que se empleó para medir el impacto está en relación con las personas que visitan los sitios Web relacionados con la iniciativa OCW, además del uso que las personas le dan a los materiales publicados.

Dentro de los perfiles de usuarios de los OCW, el MIT-OCW5 ha clasificado a su audiencia en 3 grandes grupos: educadores (9\%), estudiantes (42\%) y auto aprendices (43\%). Los propósitos son diversos, pero los más representativos para cada grupo son: mejorar el conocimiento personal, incrementar su conocimiento y explorar áreas de conocimiento que están fuera de su campo profesional. Otra información a destacar es el impacto que tiene el sitio Web en sus visitantes: el $80 \%$ consideran que tiene un impacto positivo, mientras que el $91 \%$ esperan un impacto a futuro; finalmente el $96 \%$ de los educadores dicen que el sitio les ha ayudado o les ayudará a mejorar sus cursos.

El OEC lanzó, a través de su sitio Web, una encuestat ${ }^{6}$ con el fin de recoger información de los usuario de los OCW, la encuesta tuvo la participación de 1773 personas de 90 países. Los resultados de la encuesta muestran que la audiencia tiene una clasificación más detallada, los grupos de usuarios son: estudiantes de

\footnotetext{
$\sqrt[1]{\text { http://ocw.mit.edu/about/site-statistics/monthly-reports/MITOCW_DB_2016_03.pdf }}$

2 http://www.oeconsortium.org/members/all/

3 http://data.ocwconsortium.org/dbdump/

${ }^{4}$ http://www.universia.es

5 http://ocw.mit.edu/about/site-statistics/

6 http://www .oeconsortium.org/wp-content/uploads/2013/11/0CW-User-Feedback-Report_ Final_May-2013.pdf
} 


\section{ESTADO DEL ARTE}

secundaria $(12 \%)$, estudiantes universitarios en los primeros grados $23 \%$, estudiantes universitarios en grados avanzados $10 \%$, docentes $8 \%$ auto aprendices $19 \%$, profesionales $22 \%$ y empleadores $2 \%$. El rango de edad más común de los usuarios es 20 a 29 años con un $33 \%$ y los propósitos para usar OCW son: encontrar materiales son útiles para sus intereses propios y los OCW ayudan a actualizar sus habilidades o conocimientos para ejercer su trabajo.

Las estadísticas anteriores muestran el nivel de impacto que han alcanzado los OCW en su primeros 15 años de existencia, que sin lugar a dudas ratifican que se trata de una iniciativa global de gran impacto y que ha fomentado la creación de otras iniciativas que ahora mismo son predominantes en el tema de enseñanza/aprendizaje, aunque, en estas iniciativas predominantes, el tema de acceso abierto empieza a ceder espacio frente a un modelo que genere réditos económicos.

\subsection{Social computing}

Social Computing o Informática Social es un nuevo paradigma de computación que surge por la intersección de la Informática y las Ciencias Sociales, por lo que implica un enfoque multidiciplinario para modelar y analizar los comportamientos sociales en diferentes medios y plataformas con el fin de producir aplicaciones y resultados inteligentes e interactivos. (Tavakolifard and Almeroth 2012). Por su parte Lazer et al. (2009) sostiene que la informática social potencia la capacidad de recolectar y analizar datos con una extensión, profundidad y escala sin precedentes.

Las tres características esenciales del Social Computing son: conectividad (formar relaciones entre personas dentro de un grupo), colaboración (modelar la forma de interactuar de las personas) y comunidad (agrupar a las personas a través de similitudes funcionales y cercanía espacial).

Parte de los servicios que brinda la informática social son: redes sociales, sistemas de recomendación y sistemas de confianza/reputación. Todos los datos de estos servicios son representados como modelos basados en grafos o generalmente conocidos como redes. 


\subsubsection{Redes sociales}

Una red social es un modelo para las conexiones entre individuos, objetos o cualquier otro elemento, también denominado actor o entidad. Las redes están por doquier existen redes en Internet, en World Wide Web, en la economía, en la transmisión de enfermedades, en el terrorismo, etc. Es también un tema que despertado interés de investigadores de diversos campos tales como: matemáticos, físicos, científicos de la computación, sociólogos, biólogos, etc. Newman et al. (2006). Este modelo de red generalmente se representa como un grafo. Un grafo es el principal y más antiguo lenguaje matemático que permite describir las propiedades de cualquier tipo de red. Gracias a su nivel de abstracción un grafo es capaz de describir con claridad la topología y características de una red.

Son muchos los estudios que se han realizado sobre las redes sociales, entre los que se puede destacar los estudios realizados que tratan de buscar un modelo matemático que permita generar redes, uno de los primeros fue el desarrollado por Erdôs and Rényi (1959) en donde se utilizó una distribución binomial para generar una red, el problema con este modelo fue que no refleja a una red real. Es por ello que Barabasi and Albert (1999) desarrolla un modelo que permite generar redes reales considerando que el nodo que tienes más enlaces tiene mayor probabilidad de ser seleccionado por un nodo nuevo que se incorpora a la red. Otros trabajos estudian una de las características que está presente en las redes reales, es así que el trabajo de Milgram (1967) que generó la aparición de la idea de "6 grados de separación", mientras que en el trabajo Watts and Strogatz (1998) determinó que la longitud del camino más largo en una red crece de forma logarítmica respecto al número de nodos.

Desde los años 2000 se han realizado estudios intensos sobre redes, tales como Internet, el World Wide Web, sociales, biológicas, etc. Desde la física y las ciencias de la computación llegando a la biología y la ciencias sociales, los investigadores han encontrado una gran variedad de sistemas que pueden ser representados como redes y sobre todo que existe mucho por aprender a través del estudio de esas redes. Es por ello que un grupo de investigadores han empezado a ha utilizar el término la nueva ciencia de las redes, buscando un punto de inflexión con las investigaciones anteriores en los que generalmente se trabajaba con modelos aleatorios, estáticos y utilizando exclusivamente teoría de grafos. 
En Newman et al. (2006) se distingue tres aspectos importantes que marcan la diferencia con los trabajos antiguos, estos aspectos son: 1) enfocarse en propiedades de las redes del mundo real; 2) redes dinámicas que evolución en el tiempo según reglas dinámicas y 3) entender las redes no solamente desde el punto topológico, sino como un framework sobre el cual se construyen sistemas dinámicos distribuidos.

a)

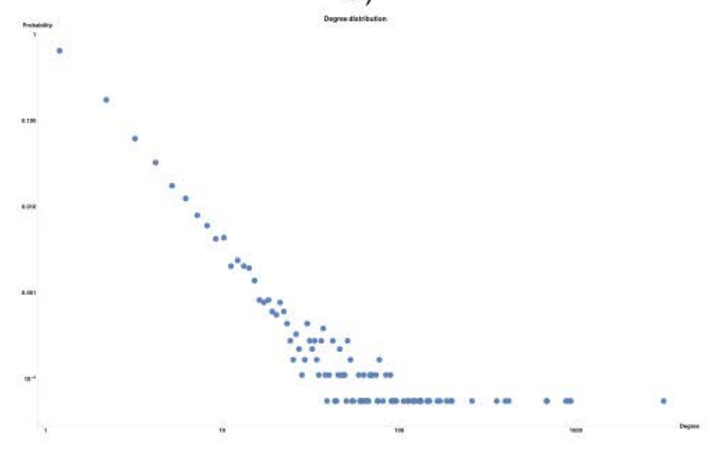

C)

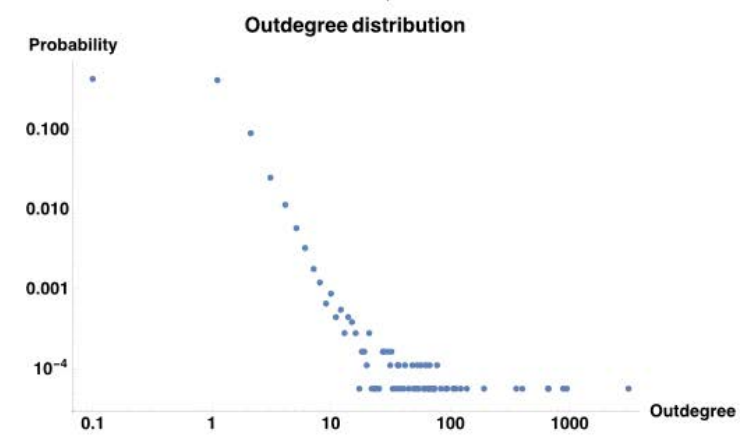

b)

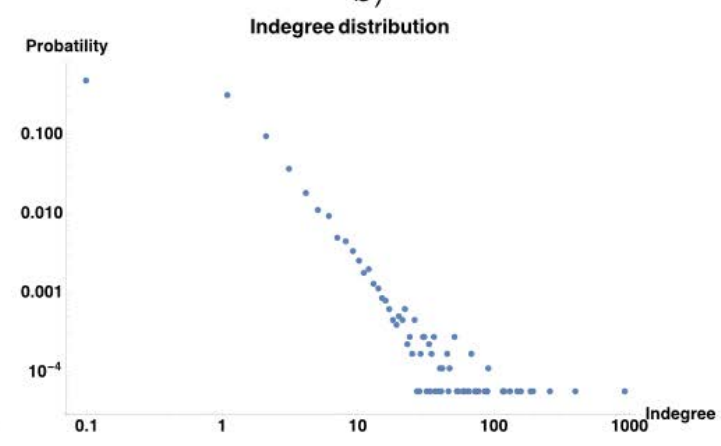

d)

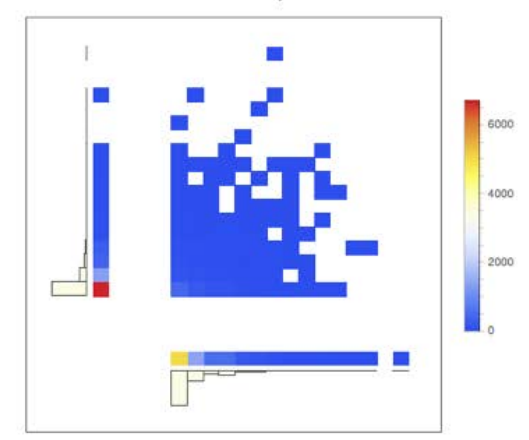

Figura 2.2: Distribución de los grados de una red de usuarios en Twitter - El grado nodal se puede dividir en tres grupos cuando la red es dirigida, así: a) el grado (número total de enlances), b) grado de entrada (el número de enlaces que llegan a un nodo) y c) grado de salida (enlaces que salen de un nodo). Mientras que d) muestra que la red es desasortativa a nivel de grado de entrada y salida, es decir que el grado no es un factor para que los nodos se unan.

Uno de los primeros resultados del trabajo con redes reales ha sido determinar que la distribución del grado nodal que presenta una red real, no se aproxima a una distribución de Poisson, como lo plantean los modelos aleatorios, sino una distribución de Pareto, lo que trae como consecuencia que en redes reales existan los denominados hubs, que son 
pocos nodos con un grado nodal muy alto, por ejemplo en un red formada por usuarios que recibieron re-tweets este tipo de distribución determina que habrían pocos usuarios que han recibido un gran número de retweets. La Figura 2.2 muestra las distribuciones de los grados de una red dirigida de usuarios que usaron el hashtag HTML5 en sus publicaciones y recibieron alguna mención o su publicación fue re-difundida por otro usuario. La información fue extraída desde Twitter.

La distribución del grado nodal junto a otras medidas tales como: el grado medio, el coeficiente de clustering, la distancia media entre nodos y la asortatividad de una red, permiten describir a una red. En (Barabási 2016) se puede encontrar un listado de algunas redes y sus medidas. Este tipo de descripción, basada en métricas, permite tener una visión general de una red, sin la necesidad de visualizar el grafo, ya que dependiendo del volumen de datos (nodos y enlaces) la visualización puede resultar poco productiva, aunque existen técnicas y herramientas de visualización alternativas, tales como: d3-sankey 1 hiveplot 2 , nodetrix 3 , aunque el problema sigue siendo el gran volumen de datos.

En la actualidad mucha de la información disponible, que puede ser representada y analizada como una red, proviene de las redes sociales en línea. Una red social en línea además de modelar las conexiones facilita el intercambio de información entre individuos o grupos utilizando las relaciones entre ellos. Con el nacimiento de la denominada Web 2.0 las redes sociales en línea tuvieron un crecimiento exponencial y hemos sido testigos del surgimiento y desaparición de diferentes redes sociales con diferentes modelos de conexión, interacción, tipos de información intercambiada, en fin, diferentes características y formas. Sin embargo, en la actualidad pocas son las redes sociales en línea que prevalecen, entre las que se puede mencionar a Facebook 4 Twitter $5^{5}$ y Linkedin ${ }^{6}$ como destacadas.

\footnotetext{
1 https://github.com/d3/d3-sankey

2 http://www.hiveplot.com

3 http://www.aviz.fr/Research/Nodetrix

${ }^{4}$ http://www.facebook.com

5 http://www.twitter.com

6 https://www.linkedin.com
} 


\section{ESTADO DEL ARTE}

\subsubsection{Sistemas de recomendación}

En diversos contextos, cuando se trata de encontrar nuevos ítems que respondan a las necesidades o características de un usuario, indudablemente se piensa en sistemas de recomendación, es por ello que las siguientes secciones se presenta información sobre los sistemas de recomendación y el análisis de redes sociales usando el siguiente enfoque: uso redes para potenciar el funcionamiento de los sistemas de recomendación y la aplicación de sistemas de recomendación dentro de las redes sociales, con el objetivo de tener una visión clara de la interacción que se tiene en ambos sentidos.

Una de las formas para enfrentar el exceso de información es el uso de los sistemas de recomendación (RS). Estos sistemas han ganado importancia desde la década de los noventa cuando la Web empezó a ser un medio importante para transacciones comerciales y el comercio electrónico en general (Aggarwal|2016). El objetivo de los sistemas de recomendación es generar sugerencias acerca de nuevos ítems en múltiples contextos y responder a preguntas tales como: ¿qué ítems comprar?, ¿qué música escuchar? o ¿qué noticias leer? y dentro de el dominio de las redes sociales, ¿con qué usuarios conectarse? o ¿a qué usuarios se los puede considerar consejeros de confianza? (Stan et al. 2014).

Un sistema de recomendación está formado por herramientas de software y técnicas que suministran recomendaciones a un usuario acerca de que ítems utilizar o adquirir (Ricci et al. 2011). En su forma más simple las recomendaciones se ofrecen como una lista categorizada de ítems. El concepto de ítem es un término genérico que se emplea para denominar el "objeto" que es recomendado.

Las recomendaciones son generalmente personalizadas. Diferentes usuarios o grupos de usuarios reciben diferentes sugerencias. Sin embargo, existen recomendaciones no personalizadas, que generalmente se presentan como listas "top ten" o los ítems más populares. Si bien este tipo de recomendaciones pueden ser útiles en determinadas circunstancias, típicamente no son tema de investigación por los sistemas de recomendación, ya que como menciona Seroussi et al. (2011) la lista de los ítems más populares puede incluir ítems que ya son conocidos por los usuarios y así la recomendación será poco útil.

El tema de los sistemas de recomendación es bastante diverso ya que es posible utilizar diferentes tipos de datos, todos relacionados con las preferencias y requisitos 
de los usuarios y aplicarlos a diferentes dominios, para construir recomendaciones. Los modelos básicos y más conocidos en los sistemas de recomendación son:

- Filtrado colaborativo.

- Basados en contenidos.

- Híbridos.

- Basados en contexto.

En las siguientes secciones se presenta los conceptos principales de cada uno de los modelos de recomendación mencionados, así como también la relación de éstos con el análisis de redes sociales desde dos dimensiones: 1) uso de la estructura de una red (grafo) y sus métricas y 2) el uso de información que se expresa y almacena como una red.

\subsubsection{Filtrado colaborativo basado en vecindario}

El filtrado colaborativo fue uno de los primeros modelos de recomendación y básicamente trata de imitar el comportamiento habitual de los seres humanos. Basa sus decisiones en las recomendaciones proporcionadas por una comunidad de usuarios similares. Es decir, a un usuario (conocido como usuario activo) se recomienda ítems que a otros usuarios similares (con gustos parecidos) les han gustado en el pasado (Resnick and Varian 1997).

La información base para este método son las interacciones pasadas en las que tanto el usuario activo, como un grupo de usuarios estuvieron de acuerdo respecto a un grupo de ítems, así las recomendaciones que provienen de éstos usuarios similares serían relevantes y de interés para el usuario activo (Ricci et al. 2011). Adicionalmente a la similitud de usuarios, para el proceso de predicción, también se suele usar la similitud entre ítems Sarwar et al. (2001), en donde la idea es que los ítems que son similares a aquellos que el usuario ya ha valorado o consumido son buenos candidatos para recomendar.

El objetivo fundamental de este modelo de recomendación es predecir un valor aproximado(rating) para los ítems que aún no han sido valorados por el usuario activo, a 


\section{ESTADO DEL ARTE}

través de la búsqueda de correlación entre ratings. En la Tabla 2.2 los signos de interrogación deberían ser reemplazados por valores que son estimados usando las valoraciones de usuarios o ítems similares. Generalmente los valores especificados se denominan como datos de entrenamiento mientras que los no especificados son denominados como datos de prueba.

Dentro del modelo de filtrado colaborativo existen dos tipos de métodos de recomendación: métodos basados en memoria y métodos basados en modelos (Breese et al. 1998). El primero también es conocido como basado en vecindarios (Neighborhood-Based), mientras que el segundo método utiliza métodos de minería de datos y aprendizaje automático en el contexto de modelos predictivos.

De los métodos de filtrado colaborativo, el basado en memoria o en vecindarios resulta interesante para este trabajo ya que los vecindarios de usuarios o ítems pueden ser implementados a través del uso de clustering y grafos, es por ello que en los siguientes párrafos se presenta una descripción ampliada del tema.

Son dos los tipos de algoritmos que se encuentran en este método basado de vecindarios:

1. Basados en usuarios, en donde la idea fundamental es encontrar usuarios similares (vecindario) al usuario activo y recomendar ratings para ítems que él aún no a visto. El rating que se calcula como el peso promedio de los ratings de todos los usuarios similares (vecinos).

2. Basados en ítems, en este caso, primero se determina el conjunto de ítems que son similares al ítem a recomendar y que han sido calificados por el usuario activo, para luego calcular el rating del ítem en base a los ratings, que el usuario activo hizo a cada uno de los elementos del conjunto previamente determinado.

Algunas otras diferencias que existen entre estos dos tipos de algoritmos son: mientras el primer tipo de algoritmo usa funciones para calcular la similitud a nivel de filas, el segundo emplea los datos de las columnas (ver Tabla 2.2). Otra diferencia a destacar es que el primero algoritmo usa las valoraciones de los vecinos, mientras que el segundo emplea las propias valoraciones del usuario activo.

La similitud, ya sea entre usuarios o entre ítems, se calcula entre vectores de valoración de dos usuarios a través de varios métodos entre los que se encuentran correlación 
Tabla 2.2: Matriz de valoración usuario-ítems usado en el filtrado colaborativo

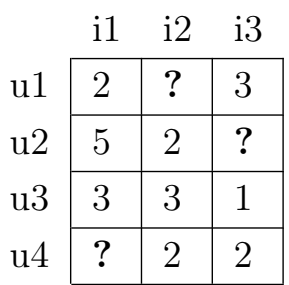

de Pearson, similitud Coseno y algunas variaciones propuestas que buscan mejorar los resultados obtenidos.

Según Sarwar et al. (2000), uno de los principales problemas con el modelo de filtrado colaborativo es que la matriz de valoraciones es incompleta o escasa, lo que complica la tarea de encontrar el vecindario a través de los cálculos de similitud ya sea entre usuarios o entre ítems, además el tiempo necesario para realizar esa actividad es variable según el número de datos que existen y puede llegar a convertirse en un problema de desempeño. Es por ello que se han diseñado nuevos métodos entre los que se encuentran: grafos y clustering para enfrentar el primer y segundo problema respectivamente.

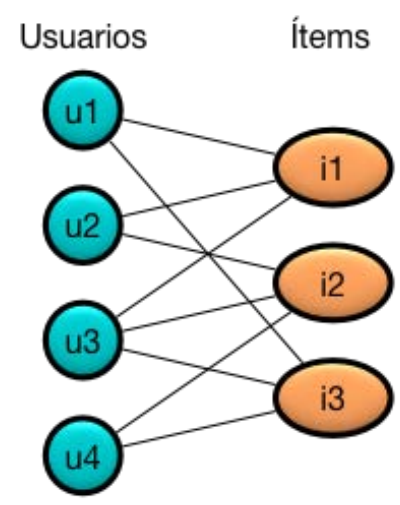

Figura 2.3: Representación de la matriz de valoraciones - Representación de la matriz usuario-ítems de valoraciones de la Tabla 2.2 como un grafo.

El problema de la escasez de valoración de ítems ha sido estudiado desde la perspectiva de la representación de los datos como un modelo de grafos. Los grafos permiten representar las relaciones entre usuarios o entre ítems o entre ambos, además de brindar la posibilidad de usar varios algoritmos, la gran mayoría basados en caminos aleatorios o cortos para encontrar la similitud entre usuarios o ítems. En la Figura 2.3 se puede 


\section{ESTADO DEL ARTE}

ver un grafo que representa la interacción entre usuarios e ítems.

Los grafos usuario-item se pueden usar en lugar de los métodos de similitud que definen vecindarios (de usuario o de ítems), ya que la representación en grafos es más efectiva para matrices con pocos valores, debido a que se puede utilizar la transitividad de enlaces para el proceso de recomendación. El grafo que se forma se caracteriza por ser no dirigido y bipartito, en donde un enlace tiene en un extremo a un usuario y por el otro a un ítem, señalando así que un usuario ha valorado un ítem. Con este tipo de grafos no es necesario que dos usuarios valoren los mismos ítems para ser considerados vecinos, sino que, entre los dos existan caminos cortos.

Los métodos que generalmente se utilizan son caminos aleatorios o la medida denominada Katz. El primero se basa en la noción que el vecindario de un usuario o ítem es definido por el grupo de usuarios o ítems que frecuentemente se encuentran en los caminos aleatorios que tiene como punto de partida a ese usuario. Se pueden emplear algoritmos como PageRank (Page et al. 1999), SimRank (Jeh and Widom 2002) o sus variaciones.

Mientras que Katz (Katz 1953) es una medida de centralidad que calcula la influencia relativa de un nodo dentro de un red midiendo el número total de caminos entre dos nodos. En esta medida existe una penalización que es proporcional a la longitud del camino. El vecindario de un usuario o ítem se forma con los primeros $\mathrm{k}$ nodos que tienen el valor de Katz más alto.

Los grafos usario-usuario, son dirigidos y de un sólo modo. Los enlaces se forman cuando un par de usuarios cumplen con las características denominadas "Horting" y "Predictability" (Aggarwal et al. 1999), un enlace existe desde un usuario $u$ hacia otro usuario $v$, sí $v$ predice a $u$ y $u$ "hort" a $v$. La valoración de un ítem, para el usuario activo, se calcula determinando el valor promedio de las transformaciones lineales, junto con los caminos cortos y la valoración que cada uno de los usuarios asignó al ítem que se necesita predecir.

En los grafos ítem-ítem, son dirigidos, de un sólo modo y a los enlaces se les asigna un peso (una correlación). Un enlace existe si dos ítems fueron valorados por al menos un usuario. El cálculo del peso, en su versión no normalizada, toma en cuenta el número de de usuarios que valoraron los dos ítems, mientras que para normalizarlo se divide el peso sin normalizar dividido para la suma de los pesos de los enlaces de salida. Lo anterior provoca que existan valores asimétricos entre el mismo par de ítems. En la Figura 2.4 
se muestra un ejemplo de un grafo de correlación, con los valores no normalizados y normalizados entre paréntesis.

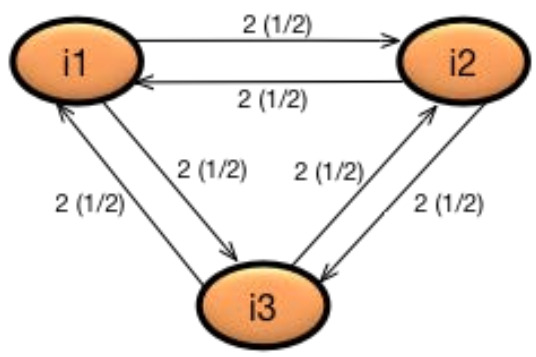

Figura 2.4: Grafo de correlación - Representación de la matriz usuario-ítems de valoraciones de la Tabla 2.2 como un grafo de correlación con valores no normalizados y normalizados.

En (Kang et al. 2016), los autores proponen que para realizar recomendaciones no es suficiente trabajar con una sólo red, sino que en el caso de sistemas de recomendación es necesario trabajar con dos redes (usuarios e ítems). Ellos asumen que los usuarios que tienen gustos similares, la momento de seleccionar ítems, forman comunidades dentro de una red de usuarios; mientras que los ítems que tienen similares encantos, desde el punto de vista de los usuarios, también forman comunidades. En ambos casos se construye un grafo no dirigido con pesos en donde un enlace señala la similitud (medida por el coeficiente de Jaccard) que dos nodos tienen (usuarios o ítems), para finalmente realizar la regularización de los grafos, según una fórmula definida por los autores.

Luego de lo expuesto es posible afirmar que dentro de este modelo de recomendación el principal uso que se le da a una red se reduce al nivel de su estructura (grafo) y la utilización de algunas medidas como PageRank, SimRank y Katz; sin tomar en cuenta la información adicional que proviene de otras características de la red, como por ejemplo influencia o capacidades para re-transmitir información.

El modelo de recomendación basado en filtros colaborativos usa correlación de valoraciones para realizar recomendaciones, sin utilizar otra información tales como los atributos de los ítems, es por ello que otro modelo de recomendación surge cuando se trata de utilizar información adicional a las valoraciones que los usuarios hacen sobre los ítems. Los modelos de recomendación basados en contenidos son descritos en la siguiente sección. 


\section{ESTADO DEL ARTE}

\subsubsection{Basados en contenidos}

El proceso básico para este modelo de recomendación consiste en la definición de perfiles tanto para los usuarios como para los ítems, para luego recomendar aquellos ítems con perfiles que coinciden con el perfil del usuario. El perfil de un usuario se extrae a partir de sus preferencias e intereses generalmente utilizando la información de ítems que anteriormente han sido valorados por el usuario, mientras que el perfil de los ítems se obtiene analizando su contenido.

A diferencia del modelo basado en filtros colaborativos, los sistemas basados en contenidos se enfocan principalmente en las características de los ítems que fueron valorados anteriormente por el usuario activo, es decir no utiliza una comunidad de usuarios similares y sus valoraciones para formular sus recomendaciones. Por lo tanto emplea otro tipo de datos, que se utilizan en este modelo de recomendación según Aggarwal (2016) son:

1. La descripción de varios ítems. En términos de atributos centrados en los contenidos.

2. Perfiles de usuarios, el cual se genera a través de la retroalimentación, implícita o explícita, que un usuario genera para varios ítems.

Este modelo de recomendación generalmente se aplica en escenarios en donde una cantidad significativa de atributos está disponible. Muchos de esos atributos son palabras claves que son extraídas desde las descripciones de los ítems. De hecho, un gran porcentaje de sistemas basados en contenidos extraen atributos de texto de los ítems. Es por ello que este modelo de recomendación se adapta bastante bien a dominios ricos en texto y poco estructurados, como por ejemplo las páginas Web.

Una de las tareas fundamentales para el éxito de este tipo de sistemas de recomendación es la extracción de las características tanto de usuarios como de ítems. Una de las formas que se emplea para la recuperación de las características de los usuarios son las redes sociales. Es así que el trabajo de Alahmadi and Zeng (2015) muestra como la información publicada en las redes sociales en línea puede ayudar a encontrar las preferencias de los usuarios, consideran que muchas de las selecciones que hacen las personas son influenciadas por la confianza en sus amigos. El nivel de confianza se mide por las actividades de comunicación entre dos personas. 
$\mathrm{Al}$ igual que el trabajo anterior, $\mathrm{He}$ and Chu (2010) muestra un sistema de recomendación que utiliza a las redes sociales como una fuente de información que describe a una persona y sus interacciones. El sistema hace recomendaciones considerando las preferencias de las personas, la aceptación general del artículo a recomendar y la influencia de los amigos cercanos y lejanos ya que los autores consideran a la influencia como un actor importante en el marketing de productos. Si bien el trabajo describe el uso de filtros semánticos, únicamente se refieren a la clasificación de los grupos de amigos según el tipo de artículo a recomendar (grupo de amigos para recomendar: música, restaurantes, libros, etc.).

Dentro de la misma línea el trabajo de (Kang et al. 2014 $)$ propone un método que utiliza el vocabulario Friend Of A Friend (FOAF) y análisis de redes sociales (SNA) con el objetivo de obtener de mejor forma las características de los usuarios. FOAF es utilizado para extraer etiquetas y características de los usuarios, con esa información se genera una red, luego se extrae las características comunes entre los ítems y las etiquetas utilizando SNA, a través de un conjunto de medidas entre las que se incluye a el grado de centralidad.

Los trabajos anteriores señalan que la tendencia, dentro de este modelo de recomendación, es el utilizar la información y la estructura de una red para definir de mejor manera el perfil de los usuarios y/o de los ítems. Es por ello que muchos de los trabajos que aquí se encuentran han empezado a utilizar información disponible a través de Linked Open Data, en donde la información principalmente se encuentra almacena en grafos expresados como tripletas RDF (Resource Description Language) y que se navega a través de consultar SPARQL que principalmente describen patrones a encontrar en nodos y enlaces de uno o varios grafos.

El uso de tecnologías de datos enlazados (Linked Data) para mejorar la búsqueda y descubrimiento de OERs se describe en (Piedra et al. 2014b) mientras que el potencial del análisis de redes sociales como una herramienta para analizar actividades educativas se estudió en (Tovar et al. 2013b). Los resultados individuales dan pautas para combinar ambos métodos con el fin de que el proceso de descubrimiento de OERs sea maximizado.

Considerando que dentro de este modelo de recomendación, se utiliza principalmente información para enriquecer la descripción de los ítems a recomendar y tomando en cuenta que en la actualidad mucha de esa información se encuentra expresada a través 


\section{ESTADO DEL ARTE}

de RDF, es posible concluir que este modelo de recomendación utiliza los datos que pueden estar almacenados en una estructura de red (en un grafo).

\subsubsection{Sistemas híbridos}

Hasta aquí los modelos de recomendación revisados trabajan de forma aislada sin ninguna interacción entre ellos. Pero es posible combinar, de diferentes maneras y en diferentes momentos, varios de modelos de recomendación para generar un nuevo modelo. A esos modelos que combinan a los otros se los denomina híbridos.

Los modelos de recomendación presentados hasta el momento utilizan diferentes datos para el mismo propósito. En el filtrado colaborativo se utiliza las valoraciones de una comunidad de usuarios, mientras que en los métodos que se basan en contenidos se utiliza la valoración de un sólo ítem y los atributos de los ítems similares. Cada uno de estos modelos tienen sus fortaleza y debilidades que se ven multiplicadas si trabajan de forma aislada, a pesar de que existen múltiples fuentes de datos que podrían alimentar a cada uno de los modelos de recomendación. Es por ello que nace la necesidad de combinar los diferentes modelos de recomendación con el fin de conseguir mejores recomendaciones.

Uno de los principales retos a los que se enfrentan los sistemas de recomendación se denomina "cold-start" (Schein et al. 2002) que se origina cuando un nuevo usuario o un nuevo item es agregado. Un sistema de recomendación híbrido trata de utilizar las ventajas de un modelo para solucionar los problemas de otro modelo (Ricci et al. 2011), por ejemplo en un modelo de filtrado colaborativo no es posible recomendar un ítems que no hayan sido valorados, sin embargo esto no es un limitante para el modelo basado en contenidos, ya que la predicción para un nuevo ítem se basa en su descripción (atributos), información que generalmente está disponible.

En Burke (2007) se define un sistema de recomendación híbrido como aquel que combina dos o más modelos de recomendación para mejorar la calidad de las recomendaciones, usualmente para tratar de solucionar el problema de "cold-start".

Dentro de este modelo de recomendación existen diferentes criterios para su clasificación una de ellas se puede encontrar en Aggarwal (2016) en donde se distingue los siguientes tres tipos: 1) "Ensemble design", en donde se combina los ratings de varios modelos de recomendación en una única salida. 2) "Monolithic design": en donde existe 
un único algoritmo de recomendación y 3) "Mixed systems" en donde los ítems, obtenidos por diferentes modelos, se presentan juntos. Otro modelo de clasificación ha sido desarrollado por Burke (2007) en donde se distinguen las siguientes siete clases:

- Weighted, aquí la valoración se calcula combinando las valoraciones de los diferentes componentes que forman el sistema de recomendación.

- Switching. El sistema selecciona la valoración entre las valoraciones proporcionadas por los diferentes componentes.

- Mixed. Las recomendaciones de los diferentes algoritmos de recomendación son presentadas juntas.

- Feature combination. Las características derivadas de diferentes fuentes de conocimiento se combinan y se dan a un único algoritmo de recomendación.

- Feature augmentation. Una técnica de recomendación se utiliza para calcular una característica o conjunto de características, que es entonces parte de la entrada a la siguiente técnica.

- Cascade. Se asigna una prioridad a cada algoritmo de recomendación y no existe relación entre los resultados de cada algoritmo.

- Meta-level. Una técnica de recomendación se aplica y produce algún tipo de modelo, que es entonces la entrada utilizada por la siguiente técnica.

Dentro de este modelo de recomendación se ha utilizando las redes de una forma interesante, como se puede encontrar en (Huang et al. 2002) se desarrolló un modelo basado en grafos para integrar los modelos de recomendación de filtros colaborativos y basados en contenidos para implementar un sistema de recomendación de libros. Se construyó una red de dos capas, en donde la primera capa tiene por nodos a usuarios y un enlace señala similitud entre dos usuarios, en cambio la segunda capa emplea nodos que son libros y una relación entre nodos señala la similitud entre libros. Entre nodos de ambas capas existen relaciones que señalan que un usuario compró un libro. Las medidas de similitud, que dentro el grafo se representa como peso en los enlaces, se calculan para los usuarios a través de su información demográfica, mientras que para los libros se aplica conceptos de minería de texto, concretamente frecuencia del término 


\section{ESTADO DEL ARTE}

y la frecuencia inversa de documento (TF/IDF). El proceso de recomendación se inicia buscando caminos de longitud variable entre un usuario y un libro que no ha comprado, para lo cual se utiliza el algoritmo de Hopfield.

Aún no se puede evidenciar claramente el rol que desempeñan las redes dentro de este modelo, pero como lo mostró el trabajo analizado, el rol puede ser de integración de los diferentes modelos de recomendación que participan en el sistema híbrido.

\subsubsection{Basados en contexto}

La recomendación se puede realizar en diferentes dominios, por ejemplo una red social en línea, es por ello que aquí se presentan los sistemas de recomendación que consideran la información del contexto, que muestra los trabajos que han desarrollados sistemas de recomendación para redes.

En diferentes dominios, tales como temporalidad de los datos, ubicación y datos sociales, el contexto de la recomendación juega un rol vital que hace que las estrategias de recomendación sean diferentes con el objetivo de integrar información adicional a las valoraciones y atributos de los ítems.

Los métodos anteriores están enfocados en la recomendación de ítems a usuarios o usuarios a ítems y no consideran información adicional que proviene de el contexto en el que se realiza la recomendación. Los contextos pueden ser variados, tales como: tiempo, lugar, compañía de otras personas, etc. que afectan el proceso de recomendación y como menciona Wang et al. (2013) la recomendación en los medios sociales es diferente de la recomendación tradicional de contenido ya que la recomendación en los medios sociales toma en cuenta información de las relaciones y comportamiento de un usuario. Es por ello que en métodos avanzados de recomendación utilizan información contextual con el fin de mejorar el desempeño global de los sistemas de recomendación (Adomavicius et al. 2005). Esa información contextual se puede categorizar en: i) Tiempo, una recomendación puede evolucionar con el tiempo; ii) Ubicación, una recomendación de sitios siempre dependerá de la ubicación actual del usuario y iii) información social, una recomendación se puede ver afectada por la influencia de amigos, familiares, expertos, etc. Tradicionalmente la información contextual ha sido usada para enriquecer los métodos clásicos de recomendación. La ecuación 2.1 muestra la ecuación de los modelos 
de recomendación tradicionales, mientras que la ecuación 2.2 cuando se considera la información del contexto.

$$
\begin{gathered}
R: \text { Usuarios } \times \text { Items } \rightarrow \text { Ratings } \\
R: \text { Usuarios } \times \text { Items } \times \text { Contexto } \rightarrow \text { Ratings }
\end{gathered}
$$

Es por ello que la noción de sistemas de recomendación contextuales ha sido desarrollada para hacer frente a la información adicional que surge en cada uno de esos dominios Aggarwal 2016) y cuyo uso, sin lugar a dudas ayuda a mejorar el desempeño de los sistemas de recomendación tradicionales y a su vez plantea un nuevo reto, recomendar elementos específicos al dominio.

Uno de esos dominios son las redes sociales, por lo que en las siguientes líneas se discute el tema de los sistemas de recomendación para una red social.

La información disponible dentro de este dominio son las relaciones entre usuarios, por lo que generalmente basa su recomendación en los amigos del usuario activo, ya que existen evidencias que señalan que las personas tienen la tendencia en confiar más en las recomendaciones hechas por sus amigos, antes que en recomendaciones realizadas por usuarios anónimos. Esa tendencia combinada con la popularidad de las redes sociales ha generado un interés creciente en este modelo de recomendación que también se denomina como Sistemas de Recomendación Sociales.

Kurka et al. (2015) ve a estos sistemas como una aplicación de los sistemas de recomendación a los datos generados en las redes sociales en línea con un ámbito que va desde la recomendación de productos, contenido producido por los usuarios de una red, llegando a elementos propios de la red social (amigos, seguidores, tags, etc.). El mismo autor destaca que los datos de las redes sociales en línea, mayormente relaciones entre usuarios, pueden mejorar los sistemas de recomendación tradicionales a través de conceptos como homofilia y contagio, lo que permite reducir la cantidad de datos necesarios para realizar una recomendación.

Una definición formal se encuentra en $($ Guy 2015) en donde se dice que son sistemas de recomendación basados en estructuras de red, actividades y etiquetas sociales o una combinación de esos diferentes aspectos de una red. De forma general, los sistemas que están basados en actividades y etiquetas sociales son ligeramente diferentes de aquellos 


\section{ESTADO DEL ARTE}

que están basados en aspectos puramente estructurales. Los sistemas de recomendación que están basados en aspectos estructurales son generalmente usados para sugerir nodos y enlaces dentro de la red. Mientras que los basados en actividades sociales pueden ser usados para recomendar varios ítems.

Aggarwal (2016) se muestra una clasificación para los sistemas que realizan recomendación dentro de las redes sociales. La clasificación es la siguiente:

- Recomendación estructural (Nodos y Enlaces), que basa su recomendación a través de un ranking de nodos y enlaces.

- Recomendación de Productos y Contenidos a través de influencia social

- Sistemas de recomendación basados en confianza.

- Recomendación a través de retroalimentación (Social Tagging)

Los siguiente trabajos son un ejemplo de los sistemas de recomendación para elementos estructurales de una red. En Armentano et al. (2012) en donde se utiliza una red ego de nivel 2 y el peso de varias características con el fin de encontrar usuarios a quienes seguir dentro de la red social en línea Twitter. Wang et al. (2010) propone un algoritmo de recomendación de usuarios basado en la co-ocurrencia de etiquetas (tags) ya que parten del principio que si dos personas usan la misma tag significa que ellos tienen alguna conexión dentro de la red social. En el trabajo de Lu et al. (2016) se hace una análisis de las medidas grado (degree) y coreness (a qué núcleo pertenece un nodo) e índice $\mathrm{H}$, como una medida para identificar nodos influyentes en procesos dinámicos con el fin de comprender la estructura y función de la red.

La mayoría de estudios que han analizado las recomendaciones en redes sociales en línea, especialmente en Twitter, están relacionadas con la recomendación de formas para adquirir nuevos seguidores (followees); encontrar a quién seguir (followers); qué etiquetas (hashtags) usar; qué Tweets leer y qué tweets deberían re-tuitear (retweet). Esos estudios en su gran mayoría utilizan técnicas de recomendación tradicionales (filtros colaborativos, basados en contenidos e híbridos). Sin embargo algunos otros construyen redes y utilizan la información de la red con el fin de modificar la técnicas tradicionales de recomendación (Sellami et al. 2014), (Weng et al. 2010), (Yan et al. 2012), (Gupta et al. 2013), (Armentano et al. 2012), (Tang et al. 2013). 
Como menciona Yazdanfar and Thomo (2013), existen pocos estudios sobre la recomendación de URLs y aún muchos menos trabajos que utilicen el análisis de redes sociales como un mecanismo de obtención de datos e información. Es por ello que los sistemas de recomendación que utilizando análisis de redes sociales son aún deficientes. Como menciona Park et al. (2012) se espera que ha futuro se desarrollen nuevos enfoques y algunos de ellos que vayan más allá del uso de grafos y empiecen a utilizar medidas del análisis de redes sociales en los algoritmos de recomendación (Yang et al. 2010).

Dentro de ésta área es posible encontrar trabajos como (Abdulwahed et al. 2012) que utiliza una red de seguidores y los seguidores de estos, para encontrar URLs para recomendar.

(Wang et al. 2013) muestra un modelo teórico de recomendación para los medios de comunicación sociales que considera dos tipos recomendaciones, uno orientado al interés y otro orientado a la influencia. El primero se basa en una recomendación conjunta entre lo social y los contenidos que permite recomendar contenidos interesantes a usuarios mediante el uso de sus relaciones sociales, acciones sociales y las similitudes de contenido, para lo cual crea tres redes: i) red social, en donde los nodos representan a usuarios y los enlaces representan conexiones sociales; ii) red usuario-contenido, los nodos representan tanto a los usuarios como al contenido (importado de repositorios especializados o compartido); y iii) red de contenido, en la red que los nodos representan los contenidos y los enlaces con su peso representan la similitud entre contenidos. Mientras que el segundo tipo, basado en la influencia, es un modelo que toma en cuenta tanto la influencia que un usuario puede ejercer sobre otros, como la influencia que un contenido podría tener. En este modelo teórico, se identifican factores predictivos y de eficiencia que junto a un método de factorización de matrices permite identificar los usuarios y contenidos con máxima influencia social.

Uno de las principales ámbitos de aplicación de este modelo de recomendación basado en redes, se encuentra en la recomendación de etiquetas a partir del contenido de objetos generados por un usuario, ámbito que generalmente se denomina como "Tag Recommendation".

Tagging es la acción de asociar una palabra o frase relevante a una entidad (documento, imagen, vídeo, etc.) (Song et al. 2008). Su práctica se hizo popular gracias a las herramientas Web 2.0. 


\section{ESTADO DEL ARTE}

Uno de los trabajos en los que se utiliza un grafo para este modelo de recomendación es el desarrollado por Song et al. (2008) en donde se utiliza un grafo bipartito para representar como nodos a documentos y términos, y como enlaces a la aparición de un término en un documento, además los enlaces tienen su peso (el número de veces que un término aparece en el texto).

\subsubsection{Sistemas de confianza/reputación}

Dentro de una red social uno de los elementos que se considera importante es la influencia de los usuarios que también se suele denominar confianza o reputación. Esa influencia es un factor determinante al momento de tomar una decisión, aceptar una recomendación, ya que es más fácil que se acepte cuando proviene de un usuario conocido. Los sistemas de confianza/reputación representan una tendencia significativa para el apoyo de decisiones para servicios en Internet.

La idea básica de estos sistemas es permitir que las partes que intervienen en un proceso se califiquen unas a otras, generalmente cuando termina el proceso, y usar esa información para obtener una puntuación de confianza o de reputación, el cual pueda ayudar a otros a decidir en el futuro.

En el capítulo 7 del libro (Aggarwal 2011) se dice que la influencia social depende de muchos factores, tales como la fortaleza de las relaciones entre las personas dentro la red, la distancia entre los usuarios, efectos temporales, las características de las redes y de los individuos dentro de la red y presenta a las medidas de centralidad (closeness y betweenness) como métricas relacionadas al concepto de influencia social.

Un trabajo que muestra el uso de la influencia dentro de una red social en línea es el realizado por Bressan et al. (2016) en el cual la influencia es calculada a través de conjunto de heurísticas tales como por ejemplo; el número de seguidores.

Jøsang (2001) distingue entre dos categorías de confianza: la confianza fiabilidad y la confianza de decisión. la confianza fiabilidad se define sobre la base de "la probabilidad subjetiva por el cual un individuo espera que otro individuo realiza una acción determinada de la que depende su bienestar". La confianza de decisión se define como "el grado en que una de las partes está dispuesta a depender de algo o alguien en una situación dada con una sensación de relativa seguridad, a pesar de las consecuencias negativas son posibles". 
Existe una relación de confianza entre dos agentes cuando un agente tiene una opinión sobre la fiabilidad del otro agente y una recomendación es una opinión comunicada acerca de la fiabilidad de un tercero.

En Walter et al. (2008) se hace un estudio de un modelo de un sistema de recomendación basado en confianza en una red social, que se resumen en:

- Aprovechar la rede social de un agente para llegar a la información.

- Hacer uso de las relaciones de confianza para filtrar la información.

Una aplicación de los modelos de confianza se pueden encontrar en los trabajos de Gürsel and Sen (2009), Ozsoy and Polat (2013) y Sun et al. (2015), sostienen que los sistemas de confianza suministran credibilidad de las recomendaciones ya que basan sus recomendaciones en índices de confianza y no únicamente en la similitud de los usuarios. Mientras que Massa and Avesani (2009) discute acerca de las medidas de confianza y muestra una arquitectura para un sistema de recomendación en donde además de la matriz de rating realizada por los usuarios se trabaja con una matriz de confianza entre usuarios.

En Bedi et al. (2007) se muestra el diseño de un sistema de recomendación que emplea el conocimiento almacenado en forma de ontologías y las redes de confianza entre pares de agentes, que representan a los usuarios. En este trabajo las redes de confianza se basan en una primera instancia en la amistad de las personas. En un segundo paso la red de confianza es actualizada por las experiencias entre los agentes (el agente $\mathrm{X}$ recibe una buena recomendación del agente $\mathrm{Y}$ ).

Según el mismo trabajo (Bedi et al. 2007), la reputación se define como una "expectativa sobre el comportamiento de un agente basado en información sobre u observaciones de sus acciones pasadas". Por lo tanto, la reputación puede ser considerada como una medida colectiva de confianza (en el sentido de fiabilidad) basado en las referencias o las calificaciones de los miembros en una comunidad. En (Qian et al. 2016) se muestra un framework de recomendación para redes sociales en línea que utiliza un reputación global y similitud local.

Dentro de las redes sociales en línea el proceso de identificar usuarios influyentes tiene al menos tres aristas, como se describe en el trabajo realizado por Ma et al. (2017), los trabajos existentes han estudiado los atributos de los usuarios, la estructura 


\section{ESTADO DEL ARTE}

de la red y las interacciones de los usuarios buscando encontrar medir la influencia de un usuario dentro de una red.

Los atributos de los usuarios que comúnmente está asociados a su influencia están relacionados con la popularidad el usuario dentro de una red social. En (Kwak et al. 2010) se estudió el número de seguidores que tiene un usuario como una medida de influencia, aunque como se dice en el mismo trabajo, no existe una relación directa entre el número de seguidores y la popularidad de sus publicaciones. En el trabajo desarrollo por Cha et al. (2010) se compararon tres atributos de los usuarios para medir su influencia. Se utilizó el número de seguidores, retweets y menciones, llegando a determinar que no necesariamente el usuario con mayor cantidad de seguidores es el más influyente. Mientras que en (Leavitt et al. 2009) y (Cataldi and Aufaure 2015) se analizan otras propiedades de los usuarios para medir su influencia, sin embargo en esos trabajo la conclusión es la misma utiliza únicamente los atributos de los usuarios no es una medida precisa para determinar la influencia de un usuario.

Otros trabajos miden la influencia tomando en cuenta la estructura de la red y las interacciones entre los usuarios. En (Tunkelang 2009) se propone una variante de PageRank ((Page et al. 1999) que se basa en el número de personas que han leído un tweet y se incluye los retweets recibidos. Dentro de este misma línea se encuentra el trabajo desarrollado por Bakshy et al. (2011) que además agrega a el tiempo como un factor que se debe considerar al momento de calcular la influencia de un usuario o una publicación.

Una de las estrategias más empleadas, dentro del análisis de las redes sociales, es utilizar las denominadas medidas de centralidad para encontrar nodos influyentes $(\overline{\mathrm{Ba}}-$ tool and Niazi 2014). Existen muchas medidas de centralidad en (Jalili et al. 2015a) se muestra un listado de 113 medidas de centralidad 1 Sin embargo muchas de esas medidas están correlacionadas y pueden producir los mismos resultados. La correlación se estudia en los trabajos de: Batool and Niazi (2014), Valente et al. (2008) y Schoch et al. (2017) por mencionar algunos.

${ }^{1}$ http://www. centiserver.org Lista de medidas de centralidad 


\subsection{Uso de las redes sociales dentro de la educación}

En esta sección se tratará de dar respuesta a la pregunta ¿puede la Web 2.0, a través de su filosofía, herramientas y servicios, ser utilizada para mejorar los procesos de aprendizaje? Para dar respuesta a esta pregunta a continuación se presentan algunos trabajos que muestran el uso didáctico de los medios sociales dentro de un proceso de enseñanza aprendizaje.

La Figura 2.5 muestra la distribución de publicaciones que hablan sobre educación y herramientas de los medios sociales. Es obvia la diversidad de las áreas en donde que se han cuestionado acerca del uso de las herramientas y servicios de la Web 2.0 en la educación, existen 1494 documentos indexados por Scopus en el periodo de tiempo comprendido entre 2009 y 2007.

Tim et al. (2005) define siete principios que definen a la Web 2.0, estos principios, muchos de estos principios han sido adoptamos por la comunidad educativa y puestos en práctica con el único objetivo de mejorar el proceso de enseñanza aprendizaje. Posiblemente el principio que mayor aceptación ha tenido es aquel que sostiene que es necesario aprovechar la inteligencia colectiva, que en la Web se manifiesta como: a) la creación de enlaces (no sólo entre páginas Web, sino también entre personas, productos, etc.) y b) trabajo colaborativo (que en la Web tiene muchas manifestaciones a través de wikis, blogs, bookmarking, etc) que en (Tim et al. 2005) se resume como los "efectos de red" producidas por las contribuciones de los usuarios.

Para Take (2009) la Web 2.0 puede fácilmente incrementar el interés de los estudiantes en prácticas creativas, participación y producción y para cumplir con ello destaca tres características de la Web 2.0: interconexiones, creación de contenido y re-mezcla e interactividad, ya que el aprendizaje se produce en cada una de esas prácticas, es decir que ahora las actividades de conectarse, crear, consumir, compartir información producida independiente y desarrollar aplicaciones se hace a escala global.

Geser (2007) sostiene que la Web 2.0 abre una ventana de oportunidades para la innovación educativa ya que provee un conjunto de herramientas y servicios fáciles de usar y sin barreras, además de promover las conexiones, intercambios y colaboración entre personas que comparten intereses comunes. Y sostiene que el uso de herramientas y servicios tales como: blogs, wikis, redes sociales en línea, compartir contenido, podrían tener un fuerte impacto en las prácticas educativas. Con el tiempo esas herramienta y 


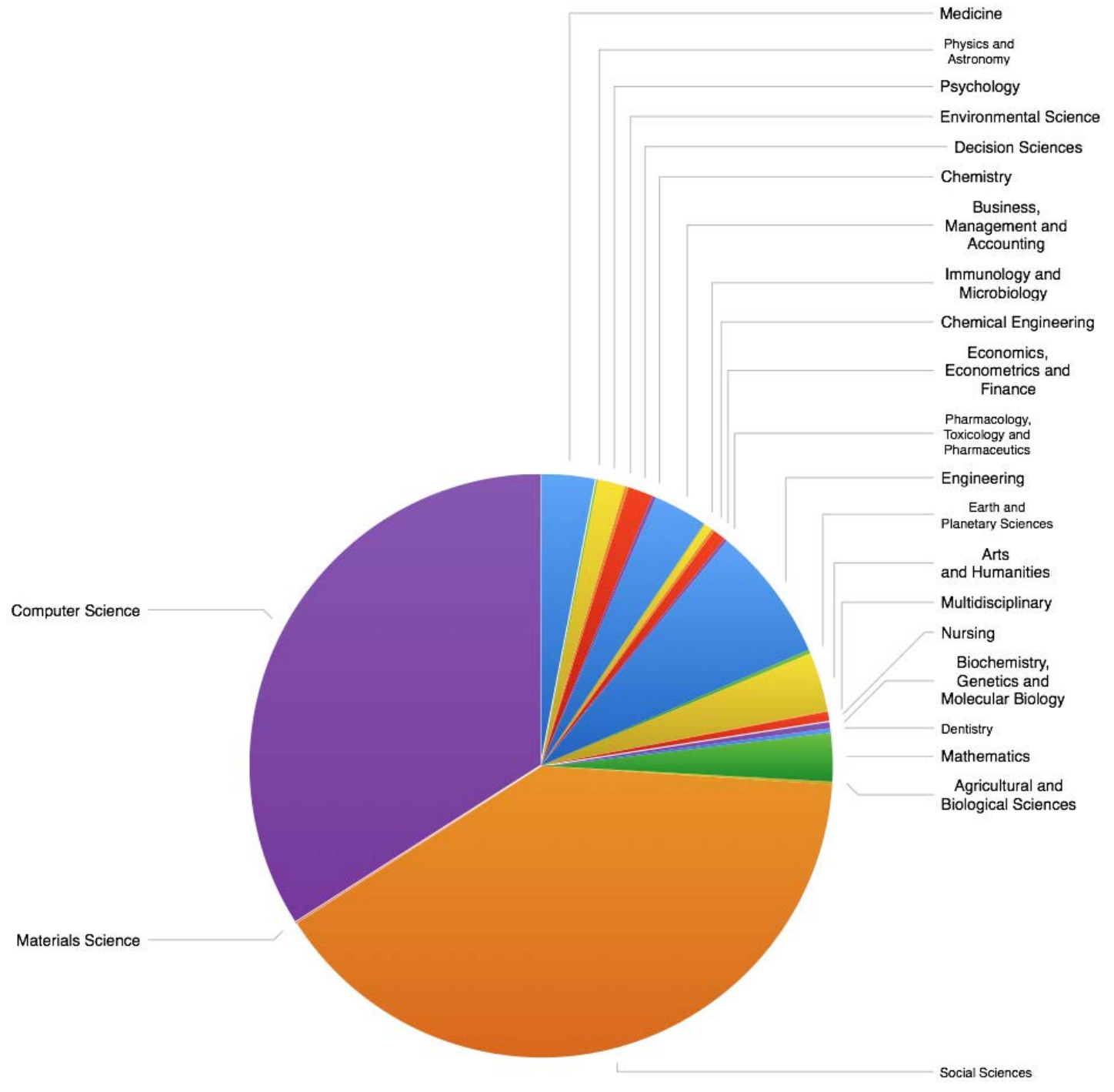

Figura 2.5: Publicaciones sobre educación y herramientas de los medios sociales - Distribución del porcentaje de trabajos publicados e indexados en Scopus. 
otras se convertirán en la primera opción de alumnos y maestros, cuando se busque mejorar la experiencia educativa a través del trabajo colaborativo basado en la Web, el intercambio de ideas y recursos de estudio.

Por su parte UNESCO en (UNESCO 2011) sostiene que el incremento del acceso online hacia los OERs y el uso de social networking ha creado oportunidades para innovación educativa y en UNESCO (2012) se reconoce el valor de las comunidades que comparten contenido educativo y recomiendan que las iniciativas OER faciliten y fomenten compartir OERs a través de herramientas fáciles de usar.

Existen muchos trabajos que hablan del uso de la Web 2.0 en la educación, aquí se hace una clasificación en los siguientes grupos:

- Uso de los principios de la Web 2.0 a través de sus herramientas. Dentro de este grupo tienen cabida todos los trabajos que usan o adaptan las herramientas desarrolladas bajos los principios de la Web 2.0 con el propósito de mejorar los procesos de enseñanza aprendizaje.

- Uso de los principios de la Web 2.0 a través de sus conceptos, aquí se encuentran los trabajos que no usan ni adaptan herramientas, sino que utilizan los conceptos desarrollados en la Web 2.0, es decir, utilizan el "efecto de la red" para potenciar a la educación.

Por cada uno de estos grupos se muestran algunos trabajos representativos que ayudarán a comprender el uso de la Web 2.0 en la educación.

\subsubsection{Uso de la Web 2.0 a través de sus herramientas}

En (Chua and Tay 2012), (Walczowski and Ellis 2008), (Brown 2010), (Zhao et al. 2010), (Pušnik et al. 2010), (Oliveira and Moreira 2010), (Carroll et al. 2008) son trabajos que muestran experiencias en la implementación de herramientas Web 2.0 dentro de entornos virtuales de aprendizaje (VLE por sus siglas en Inglés). En cada uno de los trabajos se describe como la implementación produjo cambios en el comportamiento de los alumnos, aceptando y usando de manera masiva herramientas con filosofía Web 2.0.

Atenas and Havemann (2014) incluye con un indicador de calidad que los repositorios de OERs implementen prácticas propias de los medios sociales para producir un entorno poderoso donde la personas puedan ser parte de una comunidad. En (Butcher 2015) se 


\section{ESTADO DEL ARTE}

dice que uno de los elementos esenciales de repositorios debería ser es la interacción social.

El uso de varias herramientas Web 2.0 se puede encontrar en (Piedra et al. 2010b) que muestra la experiencia de una institución de educación superior en el uso de herramientas sociales (wikis, social bookmarking y blogs) para el desarrollo de de las actividades de un curso completo. Para calificar la participación de los alumnos los autores han desarrollado un conjunto de rúbricas, las mismas que permiten calificar la participación de cada alumno de una forma objetiva.

En (Evans 2014) se utilizó una herramienta de microblogging en un curso y los resultados muestra que existe una correlación positiva entre el uso de las herramienta y el involucramiento de los alumnos en las actividades de aprendizaje organizadas incluyendo el compartir información. En (Lam 2015) se muestra que la construcción del conocimiento, en un curso basado en blended learning utilizando herramientas sociales (WhastApp, Skype y Facebook), se puede dar de forma síncrona a asíncrona a través de actividades que permiten compartir y transferir recursos.

En Minguillón (2010) se muestra el uso de la herramienta Delicious ${ }^{1}$ para crear un repositorio personal de recursos educativos abiertos. El trabajo es complementado con un análisis de la información (tags) que diferentes usuarios han agregado a los enlaces que son parte del repositorio original, en un proceso de retro-alimientación que ayude a comprender de mejor forma qué significado tiene para las personas el concepto "Open educational resource" y que tipos de recursos son etiquetados con el fin de descubrir las necesidades y encontrar diferentes formas para promover el movimiento OER.

En el trabajo realizado por McGuire (2014) se muestra el uso de la red social Twitter, hashtags y Storify $\left.\right|^{2}$ para conectar individuos dentro y fuera de la universidad que tienen interés por el futuro de las bibliotecas. El objetivo era descubrir y compartir recursos educativos que fueran aplicables a proyectos de clase, al involucrarse con expertos a través del uso de la redes sociales en línea, en lugar de buscar los recursos directamente.

\subsubsection{Uso de la Web 2.0 a través de sus conceptos}

En Piedra et al. (2011) y Chicaiza et al. (2010), como co-autor, desarrollamos y pusimos en práctica un modelo que usa tecnologías de la Web Semántica y Social para,

${ }^{1}$ https://del.icio.us

2 https://storify.com 
el primer caso buscar documentación relacionada ingeniería del software, concretamente a requisitos de software. Mientras que en el segundo trabajo se amplio para permitir encontrar OERs relacionados a la enseñanza de ciencias de la computación. En ambos casos se utilizó la anotación social (también conocido como etiquetado social) para mejorar las opciones de búsqueda permitiendo encontrar resultados relacionados, adicionalmente se utilizó para diseñar un sistema de valoración de los resultados basado principalmente en el coincidencia de palabras claves.

En (Siemens 2005) y (Shum and Ferguson 2012) se busca utilizar el efecto de la red como una herramienta para realizar analítica de aprendizaje o como los autores la denominan Analítica de Aprendizaje Social (Social Learning Analytics - SLA) que viene a constituirse en un subconjunto del Learning Analytics y que permite identificar comportamientos y patrones que aporten significativamente al proceso de aprendizaje.

Mientras que Vaquero and Cebrian (2013) trata de usar la evolución de las interacciones de estudiantes universitarios, con el fin de medir la calidad de las mismas, aunque únicamente se limitó a medir la cantidad de interacciones y de conexiones que se establecieron en 4 canales de comunicación tales como comunicación interna, espacios colaborativos, chat e IRC propios de Moodle 1 .

Otro enfoque del uso de los conceptos de la Web 2.0 en educación se puede ver en Hernández-García et al. (2015) en donde se utilizó el efecto de la red para predecir el desempeño académico. Si bien los resultados sugieren que el uso exclusivo de la medición de la estructura de las red que han formado los alumnos, para el propósito de predicción, también abren la posibilidad para usar otras variables y condiciones en donde las métricas del SNA pueden ser vaticinadores válidos. El estudio destaca el uso de SNA para la identificación de actores importantes y roles en el proceso de aprendizaje.

Finalmente García-Saiz et al. (2014) muestra una herramienta desarrollado para ayudar al monitoreo, análisis de actividades colaborativas y los vínculos (enlaces) que los estudiantes han desarrollado con el fin de mejor el comportamiento de los estudiantes en actividades colaborativas, encontrar comunidades de aprendizaje.

\footnotetext{
${ }^{1}$ https://moodle.org Posiblemente el VLE de distribución libre más utilizado por instituciones educativas.
} 


\subsubsection{Otros usos de las herramientas Web 2.0 en educación}

Existen otros usos que se puede dar a los sitios Web desarrollados bajo los principios de la Web 2.0. En este apartado se presentaran algunos ejemplos de estos usos alternativos haciendo énfasis en el uso de estas herramientas como repositorios.

Como lo sostiene (Minguillón 2010) cientos de millones o incluso miles de millones de usuarios de Internet están interactuando todos los días con cientos de millones de potenciales recursos educativos. Desde la Web 2.0, los usuarios son capaces de crear y compartir recursos, por lo que la cantidad de información disponible ha crecido exponencialmente. Según Okada and Leslie (2012), la Web 2.0 también desempeña un rol principal ya que ofrece un entorno, herramientas e información para educadores y estudiantes para encontrar re-usar, re-crear y compartir no solamente tales contenidos, sino también mejorar las experiencias de aprendizaje, prácticas y retroalimentación de recursos existentes.

(Weller 2010) denomina los OERs producidos individualmente (no sólo por educadores) con o sin una finalidad expresa orientada a la educación y que son compartidos a través de sitios o servicios de la Web 2.0 como "little OER", mientras que aquellos generados institucionalmente, presentados en un estilo uniforme, asociados a un portal y que surgen de proyectos con propósitos educativos los denomina "big OER". A decir del autor, las herramientas Web 2.0 se han convertido en repositorio de OERs cuyo utilidad no está en la adaptación, sino en la agregación de diferentes recursos y la creación de una narrativa educativa cohesiva que los agrupe. También se reconoce que una de las principales desventajas es la calidad de los recursos y como llegar a encontrar aquellos recursos que son confiables. Bohrer et al. (2016) afirma que algunos de los medios sociales más conocidos utilizados como herramientas para propagar iniciativas OER son: Twitter, Facebook, Blogs acerca de OER, Flickn! Wikimedia Commons ${ }^{2}$, YouTubł 3 AVA, ELGG Wel[ y video conferencias.

Dentro de este mismo tema Dichev and Dicheva (2012) sostiene que otro aspecto a considerar en la búsqueda de OERs está aquellos que se encuentran fuera de los repositorios, por lo tanto uno de los principales desafíos que las herramientas de descubrimiento

\footnotetext{
1 https://www.flickr.com

2 https://commons.wikimedia.org/wiki/Main_Page

3 https://www.youtube.com

4 https://elgg.org
} 
de OERs enfrentan es encontrar e indexar OERs dispersos a través de repositorios institucionales, sitios sociales y páginas Web personales, además de decidir si se trata o no de un OER. En (Barros et al. 2015) se muestra estadísticas sobre como los usuarios buscan OERs, entre las 5 respuestas 3 pertenecen a iniciativas de la Web 2.0 (sitios de intercambio de vídeos, blogs y páginas web personales y redes sociales en línea). Ese mismo trabajo muestra que la principal preocupación es la calidad de los OERs.

\subsection{Discusión de los trabajos relacionados}

Tomando en cuenta la diversidad de temas se han creado dos categorías en donde se clasificarán los trabajos. El elemento discriminante de cada trabajo será la forma en que emplean el análisis de redes sociales en las actividades relacionadas con la educación.

\subsubsection{Redes sociales y educación}

Como se pudo ver en el estado del arte, las redes sociales han causado gran impacto en diferentes ámbitos de la educación y en los recursos educativos abiertos. En primer lugar los modelos de creación de los OERs, ya que las herramientas Web 2.0 permiten que todos seamos productores y no sólo consumidores de contenido educativo (Richardson 2006b). Este tipo de producción de contenido se denomina co-producción (Etgar 2008).

Mucho del contenido educativo, co-producido y aquel que sigue el modelo productorconsumidor! , se difunde en otras redes sociales en línea (Minguillón 2010), con el objetivo que tanto educadores como estudiantes pueden encontrar recursos educativos Okada and Leslie 2012). Es posible también utilizar el contenido publicado en las redes sociales para la educación, a pesar de que ese contenido no haya sido elaborado expresamente con fines educativos (Weller 2010).

La diversidad de los tipos de OERs hace posible que se utilicen un sinnúmero de herramientas Web 2.0, especializadas para cada tipo de contenido. Sin embargo es necesario desarrollar mecanismos que permitan encontrar recursos confiables que cuente con niveles de calidad lo suficientemente altos para ser utilizados en procesos de enseñanza aprendizaje (Weller 2010).

\footnotetext{
${ }_{1}^{1}$ http://wikieducator.org/Internationalising_online_programs/OER_producer-consumer_ and_co-production_models
} 


\subsubsection{Uso de SNA como herramienta de análisis}

Estos trabajos muestran las tres grandes categorías en los que se pueden agrupar los trabajos que muestran la relación entre educación y el análisis de redes sociales sociales. Las categorías son:

1. Descriptiva: Emplea el SNA y sus medidas para caracterizar el conjunto de datos que representan principalmente información de interacción en herramientas Web 2.0 .

2. Predicción: El SNA se usa para una de las tareas de la analítica del aprendizaje, la predicción del desempeño de los estudiantes tomando en cuenta sus actividades y contexto social.

3. Monitoreo y evaluación: Aquí el SNA se emplea como una herramienta que los docentes pueden emplear para analizar y evaluar el desempeño de sus alumnos en las actividades colaborativas que se hayan propuesto. Algunas de las métricas del SNA se emplean para identificar roles y comunidades.

\subsubsection{SNA para la recomendación}

Son trabajos que usan algún concepto de la teoría de redes para encontrar usuarios influyentes o medir la confianza sobre los usuarios, así como también usan la estructura (topología) de una red para identificar nodos que se pueden usar como referentes en los proceso de recomendación. Sus categorías son:

1. Redes de confianza/Influencia: Usan las redes y sus conceptos - métricas con el fin de calcular el nivel de confianza y/o influencia de un nodo dentro de la red.

2. Basados en la topología de una red: Aquí se clasifican a todos los documentos que usan la estructura de la red para identificar nodos que se pueden considerar como relevantes por su posición dentro de la red.

Muchos de los trabajos, especialmente aquellos que usan el SNA para la recomendación, utilizan información que no está disponible de forma pública, sino que usan información que exige por ejemplo el tener cuenta en la red social en línea o ser parte de el sistema que usan como fuente de datos. Algunos trabajos, especialmente aquellos 
que usan técnicas de recomendación tradicionales ven a la red social como una fuente de información complementaria que se puede emplear como una entrada más en sus algoritmos que llegan a mejorar las recomendaciones realizadas. En su gran mayoría las trabajos presentados consideran que trabajan con todo la información disponible, tanto histórica como actual, lo que en teoría les permite trabajar con la red completa. Muchos de los trabajos consideran a la red como una estructura estática que no cambia en el tiempo, si bien muchas de las características son así, existen otras que son dependientes del tiempo debido a la volatilidad de la información.

Estas características son las que hacen la diferencia entre los trabajos que existen y que fueron descritos en el estado del arte y la propuesta que aquí se desarrolla. 
2. ESTADO DEL ARTE 


\section{3}

\section{El problema}

\subsection{Introducción}

Los Recursos educativos Abiertos son una manifestación del movimiento educativo abierto que tenido una gran acogida por la comunidad educativa a nivel global.

El surgimiento de la Web 2.0 y sus herramientas ha permitido que el movimiento de la educación abierta se potencie con un gran número de herramientas que permiten desde la construcción de recursos, su almacenamiento, difusión e enriquecimiento de entornos de aprendizaje.

La poca disponibilidad de sistemas que apoyen el descubrimiento de contenidos abiertos publicados en las rede sociales en línea se convierte en una limitante para que la comunidad educativa encuentre esos recursos y se beneficie con su uso.

En este capítulo, se hace una formulación de este problema, así como de los objetivos, hipótesis y contribuciones que este trabajo hace en busca de la solución a la problemática actual.

\subsection{Formulación}

Los recursos educativos abiertos son materiales educativos publicados en la Web con licencias abiertas. El Open Education Consortium ${ }^{1}$ es uno de los consorcios más grandes que reúne a instituciones que producen y promueven la creación, difusión, uso y re-uso de los OERs. El número de miembros de la red sobrepasa los 300 y se encuentran

\footnotetext{
${ }^{1}$ http://www.oeconsortium.org/
} 


\section{EL PROBLEMA}

distribuidos por todo el mundo. Para que el movimiento siga creciendo y sea capaz de mejorar las habilidades de las personas, los facilitadores más importantes son instituciones que cuenta con el apoyo y las actitudes positivas de los docentes (Tovar and Piedra 2014).

En los procesos de enseñanza aprendizaje, las experiencias que han incorporado diferentes prácticas educativas abiertas basadas en OERs [Rodriguez et al. (2015), Carbonell and Pons (2015), Abdulwahed et al. (2012), Simhal et al. (2015)] han demostrado un impacto positivo en la comunidad educativa. El acceso a los recursos educativos existentes de una manera que los docentes, estudiantes y autodidactas estén en la capacidad descubrirlos, adquirirlos, discutirlos, adaptarlos a sus propios escenarios de aprendizaje promoverá el desarrollo de valores y actitudes que juegan un papel fundamental en la sociedad del conocimiento Rodriguez et al. (2015).

Con el objetivo de que los docentes o estudiantes integren OERs en sus procesos de aprendizaje (formales o informales), el primer paso es encontrar los recursos que mejor se adapten a sus objetivos o necesidades de aprendizaje. Los OERs pueden ser descubiertos a través de tres formas: 1) usando las palabras correctas en motores de búsqueda generales como Google; 2) accediendo a repositorios de OERs desde cada una de las instituciones proveedoras; 3) utilizando motores de búsqueda especializados que indexan múltiples repositorios de diferentes instituciones.

Otra alternativa, que ha sido escasamente explorada hasta ahora, es encontrar recursos educativos en las redes sociales en línea. Los materiales, cuyos enlaces han sido compartidos por personas a través de una red social, pueden tener importantes características que los convierten en recursos interesantes y recomendables a otros usuarios de la red. Por ejemplo, el uso productivo de Twitter ${ }^{1}$ con propósitos educativos ha sido presentado en varios estudios tales como Sanchez et al. (2013), Morgado et al. (2012), Torres and Guerrero (2013)].

En este trabajo se muestra que es posible encontrar recursos educativos en una red social en línea con el fin de que apoyen a los procesos de enseñanza/aprendizaje de diferentes iniciativas que se fundamenten en el uso de OERs. El enfoque adoptado para proponer una solución a el problema anterior, se puede resumir de la siguiente forma: encontrar un grupo de URLs publicadas en una red social en línea que puedan ser usadas

\footnotetext{
${ }^{1}$ http://www.twitter.com
} 
como OERs y que complementen las necesidades de aprendizaje de una persona en un dominio particular.

Por lo expuesto anteriormente el problema a resolver tiene que cubrir al menos dos frentes. El primero la diversidad de iniciativas que se basan en OERs que van desde iniciativas individuales de los docentes, hasta iniciativas institucionales, pasando por iniciativas con alcance global, sin dejar de lado a los estudiantes o autodidactas que serán los principales beneficiarios una vez que se resuelva el problema. El segundo frente, es la extracción de recursos de las redes sociales, la solución debe aprovechar al máximo la información que está disponible en una red social y sortear las diferentes dificultades presentes en las redes. Es por ello que a continuación se describen los principales retos que cualquier solución propuesta debe resolver.

\subsubsection{Representación de las iniciativas}

Considerando que existen diversas iniciativas y cada uno de ellas puede tener diferentes características, es necesario, trabajar con un mecanismo de descripción de las iniciativas que afronte el problema de la diversidad, además debe ser un mecanismo fácil de producir e inclusive podría generarse de manera semi-automática.

\subsubsection{Aprovechar la información de la Red social}

Los recursos son compartidos por usuarios de una red social, utilizando los mecanismos que esta provee, además de emplear otras características propias de la red social, en donde se interactúa, como por ejemplo el uso de texto, hashtags, menciones a otros usuarios, posición geográfica, re-difusión de la información, etc. Todos esos datos pueden resultar relevantes para diferentes tareas, tal como la recomendación de cualquier elemento.

La diversidad de datos por un lado, contribuye al enriquecimiento de la información, pero por otro lado plantea una serie de retos que se deben superar para obtener un mayor provecho de los mismos. Uno de esos retos es el acceso a la información, mucha de la información que está disponible a través de las Interfaces de Programación de Aplicaciones (API) es limitada por un conjunto de políticas que limitan la cantidad, el tipo y temporalidad de la información a la que se tiene acceso, que de ninguna manera esta relacionada con la privacidad de los usuarios, sino que únicamente responden a un modelo económico. 


\section{EL PROBLEMA}

\subsubsection{Información insuficiente de los recursos compartidos}

Muchas de las veces los recursos que se comparten en una red social en línea, están acompañados de breves descripciones textuales, ya sea por decisión de los usuarios o por reglas de las redes sociales. De ninguna manera se puede considerar a esas descripciones como punto de partida para futuros análisis, es necesario extender esa información, sin llegar a necesitar de técnicas adicionales para su procesamiento, como por ejemplo técnicas de procesamiento de lenguaje natural. Además, cuando se comparte un recurso en una red social, casi nunca se menciona el tipo de licencia que este posee, únicamente y muchos casos, se garantiza el acceso, vía navegadores, a esos recursos.

\subsubsection{Usar la estructura de la red}

Dentro de todas las redes sociales, existe una estructura subyacente que la soporta. De forma generalizada esa estructura se expresa como un grafo y como se estableció en el estado de el arte, es poco utilizada dentro de los diferentes modelos desarrollados para los sistemas de recomendación.

El principal aporte de la estructura en red, es que permite establecer características en base a las relaciones entre los diferentes elementos que intervienen en una red social. $\mathrm{Su}$ utilidad es doble, ya que por un lado cuenta con un nivel de abstracción que permite representar cualquier tipo interacciones a pesar de su complejidad; mientras que por el otro permite transcender las propiedades individuales de los elementos participantes, ya que las características son determinadas por las relaciones y no por propiedades individuales.

\subsubsection{Perfiles de los usuarios}

En muchas de las iniciativas relacionadas con los OERs, los usuarios no han tenido una interacción previa con el sistema, o son sistemas abiertos que no requieren un registro previo y como consecuencia no existen perfiles de los usuarios. Si bien, hoy en día existen otras fuentes de información, como las redes sociales, que pueden emplearse para obtener información de los usuarios y esbozar un perfil, aún se necesita que el usuario ingrese sus cuentas a un sistema para que se realice la explotación de esa información.

Es por ello que cualquier propuesta que pretenda aportar a las diferentes iniciativas relacionadas con OERs, en primera instancia, debería tener como premisa la ausencia 
de perfiles de usuario. En su lugar, esas propuestas deben desarrollar otros mecanismos que permitan describir las necesidades de los usuarios de una forma general que si bien no describan por completo a los usuarios, los ayuden a encontrar OERs según sus necesidades de formación.

\subsection{Objetivos}

El objetivo general de la tesis es enriquecer iniciativas que utilicen OERs a través de un enfoque basado en los conceptos y métricas del análisis de redes sociales que permitan estudiar y analizar explotar la inteligencia de un conglomerado humano. Con este objetivo se pretende apoyar de forma general al movimiento educativo abierto y mejorar el descubrimiento de recursos que tienen una valoración social a través de un meta-análisis de la información que se comparte en una red social.

Para cumplir con el objetivo y proponer soluciones que permitan superar las limitaciones identificadas en el estado del arte, se han planteado los siguientes objetivos específicos:

O1.-Elaborar un modelo de enriquecimiento para iniciativas educativas basadas en OERs, que tenga como fuente de datos a la información difundida en una red social y que a través de un meta-análisis de los datos aplicando análisis de redes sociales maximice el uso de la información.

O2.- Utilizar las manifestaciones de la inteligencia colectiva presentes en actividades colaborativas masivas desarrolladas por seres humanos.

O3.- Desarrollar un modelo de recomendación de recursos educativos que explote la información que una estructura de red y su comportamiento dinámico poseen.

O4.- Implementar el modelo de enriquecimiento propuesto con el fin de validarlo y agregar características al mismo en un ciclo de desarrollo y mejora continuo.

\subsection{Contribuciones previstas}

Las iniciativas basadas en OER son diversas, tanto en su forma como en su fondo y pueden estar orientadas a un grupo de usuarios específicos o pueden tener una grupo objetivo mucho más amplio. Sin embargo todas ellas necesitan de mecanismos que les ayude a ampliar sus recursos, pero no con cualquier tipo de recurso, sino con recursos 


\section{EL PROBLEMA}

que hayan sido valorados y despertado cierto interés dentro de un grupo de interesados sobre una temática concreta.

Las personas se agrupan empleando diferentes mecanismos de afinidad, que dentro del mundo de las redes desde el punto de vista de las ciencias sociales se denomina homofilia, mientras que dentro la ciencia de las redes (visión de las ciencias naturales) a través del denominado apego preferencial. Independientemente de la teoría que trata de explicar la formación de los grupos, el agrupamiento de personas existe y se ha visto masificado por las herramientas de la denominada Web 2.0

El modelo de enriquecimiento a desarrollar se plantea aprovechar la información que esta disponible en una red social en línea para obtener recursos educativos que pueden ser utilizados por diversas iniciativas que empleen este tipo de material, es decir tendrá como característica la generalización. Entre las propiedades más importante del modelo de enriquecimiento están: el visualizar y analizar las redes que se identificadas dentro de los datos, utilizar la información social, contenidos, legal y la producción en el tiempo de la red social para encontrar, ordenar y recomendar recursos, personas, roles y temas relacionados.

Con este trabajo se pretende contribuir a los esfuerzos para mejorar las iniciativas de educación abierta y aprovechar la información que se difunde dentro de una red social en línea. Las principales contribuciones de la tesis, analizadas desde la el punto de vista de la educación formal, informal y de los autodidactas son las siguientes:

- Formación formal: La propuesta de recomendación de recursos extraídos desde las redes sociales, permitiría, a los docentes que se encuentran en la etapa de planificación de un curso, contar con un grupo de recursos socialmente curados y que luego de un proceso de evaluación por parte de ellos puedan ser agregados al curso como material (principal o complementario) del mismo. De esta forma se amplía la cantidad de recursos con el que los docentes pueden contar y los recursos disponibles para los estudiantes.

- Formación informal: En este caso la propuesta, dotaría a un curso la capacidad de recomendar recursos a los estudiantes de forma semi-automática, ya que se necesita como única entrada la descripción del curso a través de palabras claves, ese proceso lo realiza la planta docente. Las recomendaciones se hacen de forma 
automática, convirtiendo al curso en un sistema de recomendación que permite a los alumnos contar con otros recursos que tienen la característica de ser actuales.

- Autodidactas: Una de las características de la propuesta en este punto es que permite a los autodidactas, que muchas veces tienen conocimientos básicos o pobres sobre un tema que no le permiten realizar búsquedas por palabras claves ya que las desconocen en motores de búsqueda tradicional, conocer los temas relacionados a la temática que pretende estudiar, es decir le ayuda a ubicar un tema dentro de su contexto, incrementado así su conocimiento de una temática.

\subsection{Supuestos}

El trabajo descrito en esta tesis está basado en un conjunto de supuestos que se describen a continuación.

S1. La información que proporcionan las redes sociales en línea, a través de los diversos APIs son una fuente de datos lo suficientemente amplia para desarrollar el modelo de recomendación.

S2. Los OERs recomendados han sido publicados bajo una licencia que por lo menos permite su acceso.

S3. Si una publicación dentro de una URL contiene texto u otros elementos, estos son considerados como descriptores de la URL.

S4. La metadata de las páginas Web contiene información complementaria, que permite ampliar la información que se usó para describirlas en la red social.

\subsection{Hipótesis}

Una vez que los supuestos han sido identificados, las hipótesis de nuestro trabajo son descritas. Estas hipótesis dictan las principales características de la solución propuesta debe contemplar.

H1: Un modelo de enriquecimiento que utilice la información publicada en una red social, además de su estructura, con el propósito de encontrar recursos, personas, temas relacionados y roles, apoya a la consecución de los objetivos de las iniciativas educativas que lo implementen. 


\section{EL PROBLEMA}

H2: El Análisis de redes sociales o la ciencia de las redes es una herramienta de análisis que permite describir, desde el punto de vista de las relaciones, a diversas iniciativas educativas permitiendo obtener descripciones diagnósticas, realizar prospectiva y apoyar a la toma de decisiones.

H3: Las relaciones entre usuarios, su comportamiento a través del tiempo complementadas con el contenido que se difunde en una red social analizados a través de un enfoque de análisis de redes sociales permite desarrollar un modelo de recomendación confiable.

H4: Priorizar la información que ha sido expuesta dentro de una red social sobre aquella que no lo fue, permite construir un sistema de ranking para recursos difundidos en una red social.

\subsection{Restricciones}

Finalmente, existe un conjunto de restricciones que limita las contribuciones de este trabajo y establece futuros objetivos de investigación. Estas restricciones son las siguientes:

R1. Únicamente se consideran las URLs cuyo MIME, MEDIA o CONTENT Type sea text/html, sin cubrir el resto de tipos de contenidos que existen en la Web.

R2. El modelo de recomendación propuesto no toma en cuenta las opiniones favorables o desfavorables que una publicación puede generar dentro de una red social. 


\section{Propuesta del modelo de} enriquecimiento para iniciativas basadas en OERs

\subsection{Introducción}

El modelo de enriquecimiento que se propone en esta tesis pretende utilizar la inteligencia colectiva que se manifiesta en las actividades conjuntas desarrolladas por los seres humanos y que muchas veces se difunde a través de lo que hoy conocemos como las redes sociales en línea.

En este capítulo se presenta un modelo de enriquecimiento que puede ser empleado en cualquier iniciativa que este basada en el uso de Recursos Educativos Abiertos (OERs). El modelo se fundamenta en el uso de redes vistas como sistemas dinámicos y que evolucionan en el tiempo. Para el análisis de las redes se propone analizar las relaciones que se dan entre los usuarios de una red social empleando técnicas del análisis de redes sociales y de sus métricas. Esos análisis de usuarios, son complementados con el análisis de contenidos y de licencias con los que han sido publicados los recursos digitales que son parte de la fuente de datos que es analizada.

El modelo tiene como punto de partida a las redes (nodos y enlaces) que se pueden construir a partir de una fuente de datos ya sea por interacciones explícitas o implícitas de no sólo actores humanos. Esas redes son caracterizadas utilizando diferentes métricas propias del análisis de redes sociales, en un proceso de identificación de actores relevantes 


\section{PROPUESTA DEL MODELO DE ENRIQUECIMIENTO PARA INICIATIVAS BASADAS EN OERS}

que además considera el comportamiento de los actores en el tiempo. Dentro de los actores que se proponen dentro de la tesis están: a) personas que desempeñan algún rol dentro de una red y b) conceptos que describen el contexto de la información.

Los actores identificados y los recursos digitales publicados, que fueron sometidos a un proceso de ampliación de información, se convierten en entradas de un método de recomendación que toma en cuenta tres aspectos para realizar el proceso de selección de recursos (enriquecimiento): a) sociales; b) contenidos y c) legal.

\subsection{Directrices para el modelo de enriquecimiento}

El problema que la propuesta debe resolver, tal y como se plantea en la sección 3.2 , es encontrar un grupo de recursos que hayan sido publicados en las redes sociales en línea y que puedan ser utilizados como recursos educativos para complementar los existentes y brindar mayores posibilidades de aprendizaje de un estudiante o autodidacta en un dominio particular.

Para resolver este problema, en este trabajo, se plantea un modelo de enriquecimiento y método de recomendación. A continuación se presenta las características tanto del modelo de enriquecimiento, como del método de recomendación, para finalmente analizar como se resuelve cada uno de los retos que el problema propone que fueron identificados anteriormente.

El modelo de enriquecimiento propuesto busca utilizar como elementos enriquecedores, a los recursos (URLs) que son publicados dentro de una red social en línea, con el fin de que los participantes de la iniciativa enriquecida cuenten con recursos adicionales que le ayudarán en su formación.

Para lograr lo anterior, el modelo emplea a una red social en línea no sólo como una fuente de recursos, sino que también aprovecha otro tipo de información que se puede encontrar en las características propias de la red social y en la interacción entre sus usuarios.

Buscando aprovechar toda la información que se puede encontrar en una red social (recursos, características e interacción), dentro del modelo se ha definido como estrategia utilizar las redes (grafos) como estructura sobre la cual se ejecutarán varios tipos de análisis propios del análisis de redes sociales, sin olvidar que una red es dinámica y cambia con el tiempo. El modelo trabaja con dos redes, la primera una red compuesta 
por la interacción de los usuarios, que permitirá seleccionar a usuarios según su impacto en la red, mientras que el segundo tipo, es una red de conceptos (que también suele denominarse Folksonomía (Smith 2004)) que permitirá identificar el contexto de los recursos.

Según se expresó en el estado del arte, no existe un criterio único para encontrar nodos destacados dentro de una red, es por ello que el modelo no propone criterios o métricas para encontrar esos nodos destacados. En su lugar el modelo se puede adaptar a cualquiera de las medidas.

Dentro de este modelo se considera que si una publicación tiene una URL (potencial recurso), el texto que la acompaña está estrechamente relacionado con ella, aunque también se plantea la necesidad expandir la información de la URL, tomando en cuenta que en muchos casos el texto que acompaña a una URL es insuficiente.

Con las redes (usuarios y folksonomía) y los datos extraídos de las URLs, dentro del modelo se plantea construir un método de recomendación que tome en cuenta los siguientes elementos:

- Relevancia de los usuarios de la red social.

- Folksonomía de los conceptos que están dentro de la red social.

- Licencia de los recursos compartidos dentro de la red social.

- Comportamiento, en el tiempo, de los usuarios.

- Mayor valoración de la información publicada dentro de la red social sobre aquella que no lo es.

A través de la combinación de estos elementos el sistema de recomendación puede generar: a) un modelo de recomendación que permita seleccionar recursos y b) un algoritmo de valoración (ranking) por cada uno de los recursos y que será empleado para la presentación de los resultados. A diferencia de los métodos de recomendación tradicionales (filtros colaborativos, basados en texto e híbridos), el modelo no está en la capacidad de generar un rating (valoración) personalizado para cada uno de los usuarios de la iniciativa educativa, ya que no se cuenta con la información de interacciones (usuario-recurso) pasadas con recursos similares, que tal como se estableció en el estado del arte son la base fundamental para esos métodos. 


\section{PROPUESTA DEL MODELO DE ENRIQUECIMIENTO PARA INICIATIVAS BASADAS EN OERS}

Tabla 4.1: Relación entre los retos identificados y las características del modelo.

\begin{tabular}{|l|l|}
\hline \multicolumn{1}{c}{ Retos } & \multicolumn{1}{c}{ Características del modelo } \\
\hline Representación de las iniciativas. & Representación genérica \\
\hline Aprovechar la información de la red social. & Centrado en el análisis de redes sociales. \\
\hline Usar la estructura de la red. & \\
\hline Información insuficiente de los recursos compartidos. & Expandir información \\
\hline Perfiles de los usuarios. & Centrado en la iniciativa \\
\hline
\end{tabular}

Conjugando todos los elementos descritos anteriormente el modelo de enriquecimiento propuesto reúne las siguientes características:

- Representación genérica: Tanto a nivel de tipos iniciativas como a partes de la iniciativa, es decir puede trabajar con diferentes tipos de iniciativas y también puede trabajar con secciones de una iniciativa.

- Centrado en la iniciativa, el modelo no trabaja con los perfiles de los usuarios de cada una de las iniciativas, en su lugar, utiliza la información de la iniciativa para encontrar recursos.

- Centrado en el análisis de redes, se emplea conceptos propios del análisis de redes sociales y se considerada que cada red es un dinámica.

- Expandir información, el modelo está en la capacidad para obtener más información con el afán de captar más datos que serán utilizados en el método de recomendación.

En el planteamiento del problema, sección 3.2, se detallaron los retos que existen cuando se trata de obtener recursos desde redes sociales. El modelo de enriquecimiento y sus características afrontan de la mejor manera cada uno de los retos propuestos. En la Tabla 4.1 se muestra como las características cubren a los retos identificados.

\subsection{Conceptos preliminares}

En ésta sección de definen los conceptos básicos que serán utilizados a través del resto de la tesis, los conceptos de red, etiquetado social y folksonomía. 


\subsection{1. $\quad$ Red}

Un red es un grafo que representa a una estructura y un comportamiento extraídos de la realidad, formalmente se puede definir así (Lewis 2011):

$$
G(t)=\{N(t), L(t), f(t): J(t)\}
$$

donde:

- $t=$ tiempo, simulado o real

- $N=$ nodos, también conocidos como vértices o actores.

- $L=$ enlaces, también conocidos como lados

- $f: N \times N=$ función de mapeo que conecta dos nodos para obtener la topología.

- $J=$ algoritmo para describir el comportamiento de nodos y enlaces versus el tiempo.

\subsubsection{Etiquetado social}

Basado en la definición propuesta por Mika (2007), es posible definir a al etiquetado social con un conjunto que se forma así:

$$
T \subseteq A \times C \times I
$$

donde:

- $\mathrm{A}=$ conjunto de usuarios

- $\mathrm{C}=$ conjunto de conceptos (etiquetas, palabras claves, etc.).

- $\mathrm{I}=$ conjunto de ítems etiquetados (URLs, fotos, etc.).

\subsubsection{Folksonomía}

Mika (2007) se define a una folksonomía como una red tripartita que nace del etiquetado social

$$
H(T)=\langle N, L\rangle
$$

donde: 


\section{PROPUESTA DEL MODELO DE ENRIQUECIMIENTO PARA INICIATIVAS BASADAS EN OERS}

- $N=A \cup C \cup I$

- $L=\{\{a, c, i\} \mid(a, c, i) \in T\}$

\subsubsection{Red de co-ocurrencia de conceptos}

$$
G=\{N, L, f\}
$$

donde:

- $N=$ conceptos

- $L=$ enlaces

- $f: C \times C=$ función que conecta dos conceptos si se encuentran en la misma publicación.

\subsubsection{Red de usuarios}

$$
G=\{N, L, f\}
$$

donde:

- $N=$ conceptos

- $L=$ enlaces

- $f: A \times A=$ función que conecta dos usuarios si se encuentran en la misma publicación.

\subsection{Modelo de enriquecimiento}

Como se describió en el estado del arte, existen varias aproximaciones para realizar recomendaciones utilizando información que se representa como una red. Algunas de esas aproximaciones utilizan conceptos propios de los sistemas de recomendación que de forma generalizada utilizan a la red como una fuente de datos adicional y en donde se utiliza, de forma ligera, la estructura de la red para obtener datos. Por otro lado las aproximaciones que se basan en la influencia de un actor en la red, necesitan trabajar 
con redes completas, para así medir el verdadero impacto de un actor o publicación, además no consideran la evolución, en el tiempo, que una red sufre.

Considerando lo expuesto anteriormente se ha definido un modelo que tienen los siguientes componentes macros:

- Captura de datos.

- Creación de redes.

- Análisis y visualización de redes

- Recomendación.

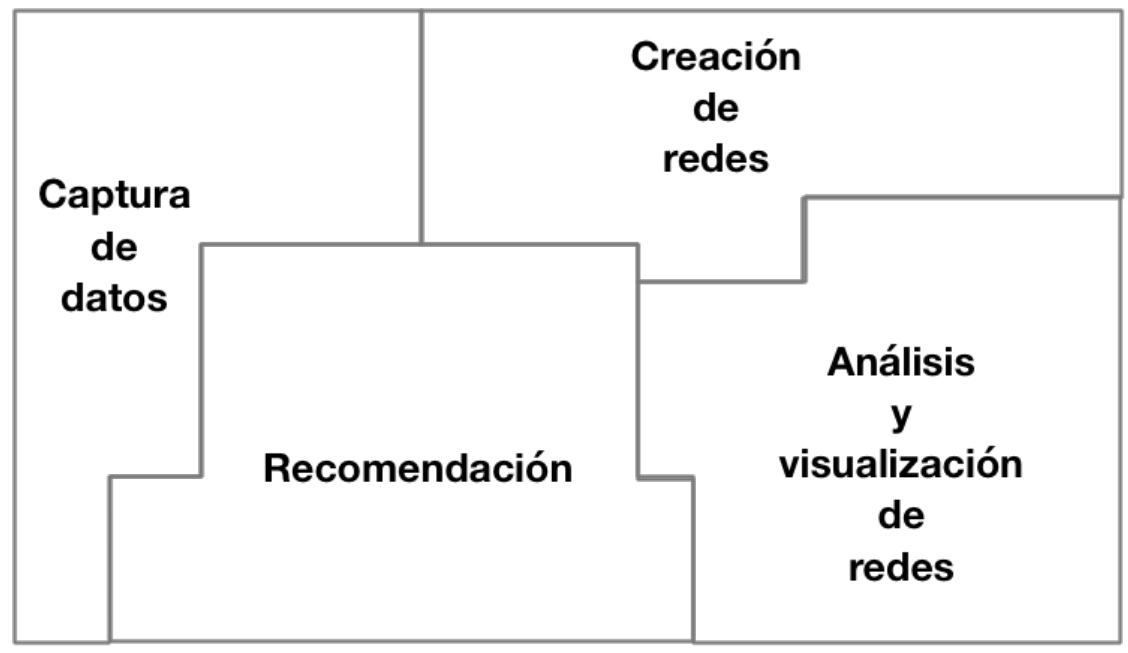

Figura 4.1: Componentes del modelo de enriquecimiento - Representación general de los componentes que el modelo de enriquecimiento utiliza

La Figura 4.1 muestra los componentes, a nivel macro, que el modelo necesita para resolver los problemas que fueron detectadas en el capítulo anterior.

En la (Figura 4.2) se puede ver el modelo de enriquecimiento a un nivel más detallado, en donde destacan los elementos del módulo que realiza las recomendaciones ya utiliza la información que otras aproximaciones anteriores han omitido, es así que se puede ver, tales como: interacción social entre participantes de la red, contenido tanto compartido en la red social como el contenido de los recursos, la información legal de los recursos y el tiempo enfocado sobre la producción de los usuarios de la red. 


\section{PROPUESTA DEL MODELO DE ENRIQUECIMIENTO PARA INICIATIVAS BASADAS EN OERS}

Las principales contribuciones de este trabajo son un modelo de enriquecimiento abstracto para que se aplique a diferentes dominios y un método de recomendación en donde se utilizan diferentes fuentes de datos como entradas y que son aprovechadas para generar varias salidas (elementos a recomendar), todas ellas en formatos procesables por computadores, así que su uso puede ser automatizado. En la Figura 4.2 se muestra el modelo de recomendación con todos los elementos que se consideraron necesarios para cumplir con la propuesta del modelo.

En las siguientes secciones se describen cada uno de los componentes que forman parte de el modelo de enriquecimiento.

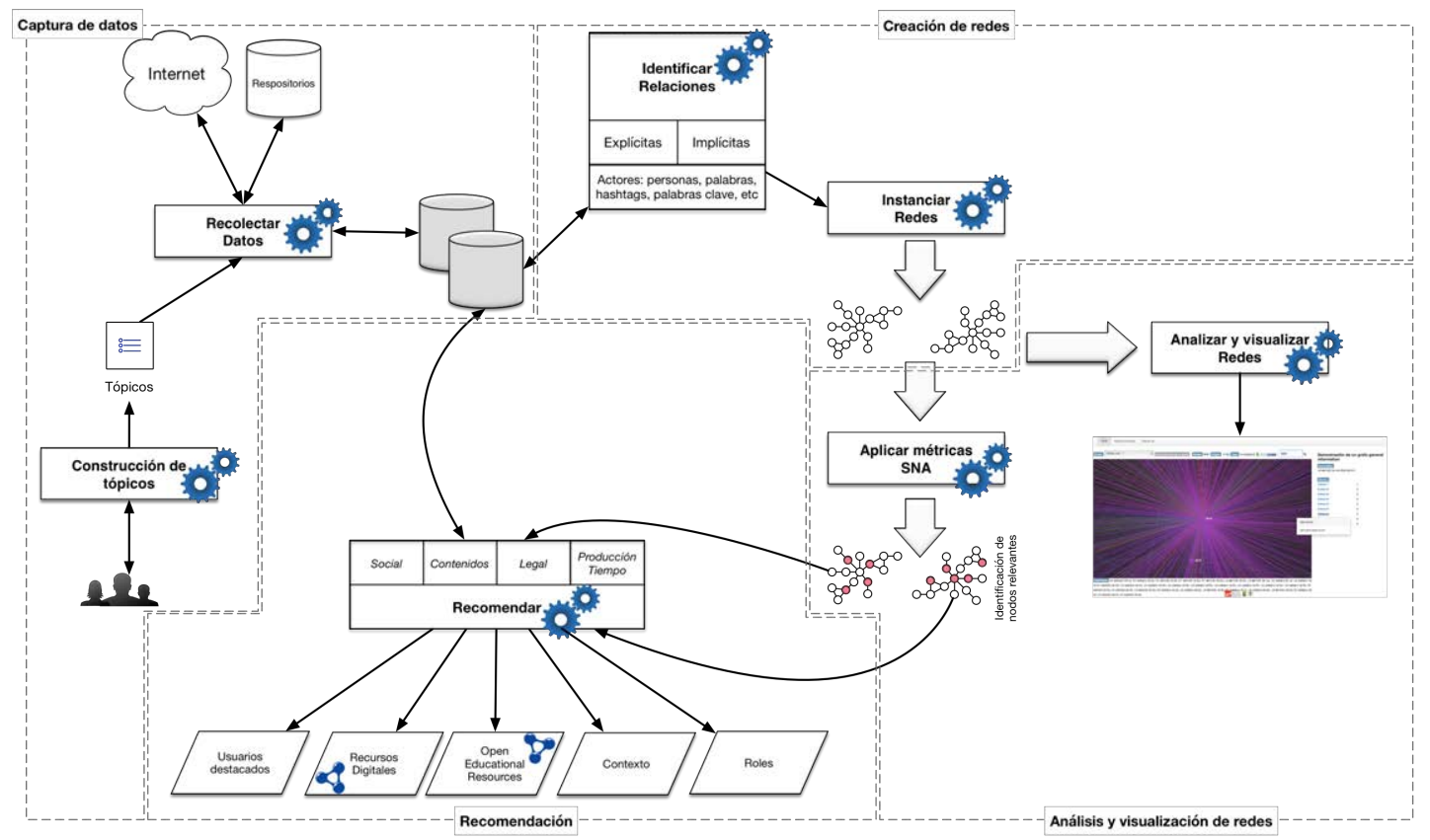

Figura 4.2: Modelo de enriquecimiento - Un esquema del modelo de enriquecimiento.

\subsubsection{Captura de datos}

La captura de datos es el componente que se encarga de de obtener los datos de entrada que serán utilizados por el resto de componentes.

Las fuentes de datos que utiliza este componente son diversas, es así que se podría utilizar una base datos, información disponible a través de Internet que se puede acceder a través de mecanismos de crawlen 1 otra de las fuentes son las redes sociales en línea.

${ }_{1}^{1}$ https://es.wikipedia.org/wiki/Ara na_web Un rastreador Web que inspecciona páginas Web 
Tomando en cuenta la diversidad de las fuentes de datos y sobre todo el uso generalizado de mecanismos como API's Web, este componente considera de suma importancia las políticas y restricciones que también son generales dentro de este tipo de APIs, para así evitar problemas de acceso a los datos.

Este componente cuenta con los siguientes módulos:

- Construcción de tópicos.

- Recolectar de datos.

El detalle de cada uno de estos módulos se presenta en las siguientes secciones.

\subsubsection{Construcción de Tópicos}

En esta fase de manera general se realizan tres contribuciones, la primera es definir un conjunto de palabras claves que describan de forma resumida a la iniciativa que se busca enriquecer; la segunda, definir los criterios de búsqueda que se van a utilizar en las diferentes fuentes de datos y la tercera determinar las fuentes de datos que se utilizarán. Para cumplir con los objetivos es describen procesos y recomendaciones a seguir que garantizan que este proceso, que es clave, genere buenos resultados.

\section{- Detalle del proceso}

La entrada de datos para el modelo de enriquecimiento es una lista de tópicos o palabras claves que sintetizan la descripción, muchas veces textual, de la iniciativa que se pretende enriquecer. El objetivo de esta etapa es construir "expresiones de consulta" que permitan buscar información en cada una de fuentes de datos. Las búsquedas se realizan utilizando los mecanismos propios de cada una de las fuentes de consultas.

En la Figura 4.3 se puede ver los elementos que participan en la construcción de los tópicos.

Esta actividad es manual o podría convertirse en semi-automática y se recomienda que un grupo de expertos en el tema sean quienes realicen la selección final de los tópicos. La estrategia a seguir es re-usar los elementos de la iniciativa que sinteticen o resuman las características de la misma, así por ejemplo se puede usar:

- Las palabras claves o keywords

- Los títulos o subtítulos de las secciones que forman los elementos de la iniciativa. 


\section{PROPUESTA DEL MODELO DE ENRIQUECIMIENTO PARA INICIATIVAS BASADAS EN OERS}

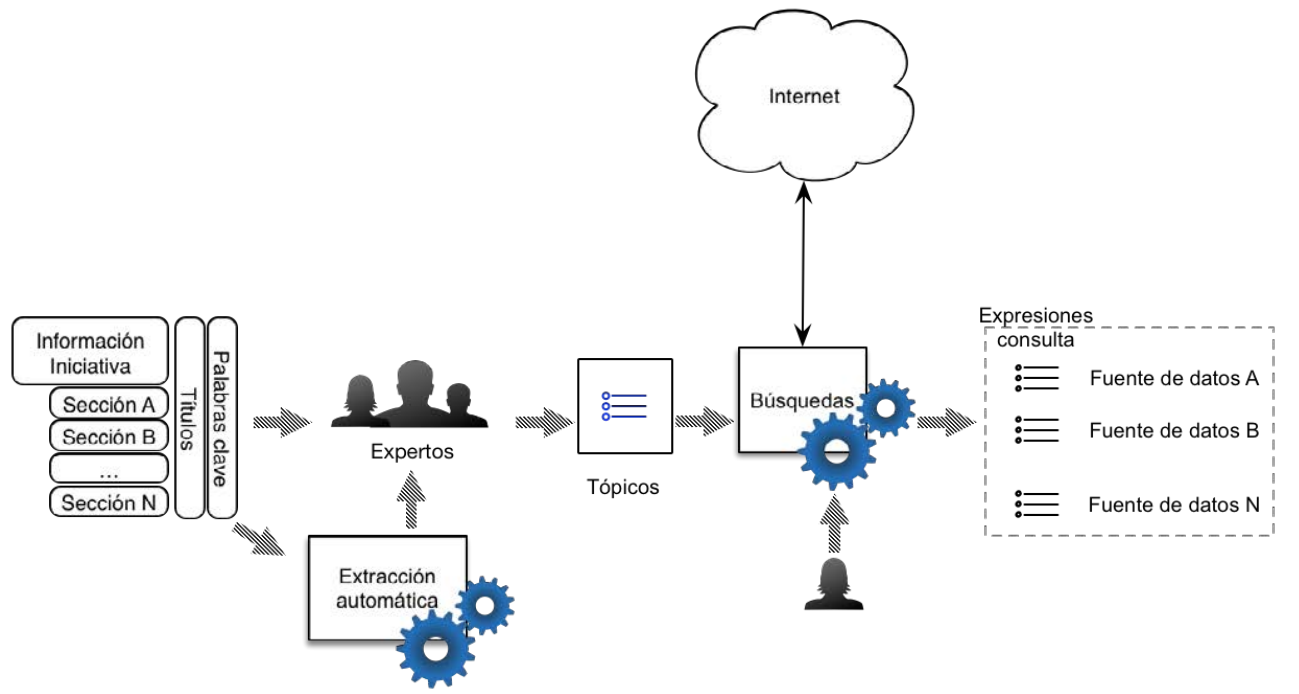

Figura 4.3: Construcción de tópicos - La construcción de tópicos es un proceso manual o podría ser automático, pero que debe ser realizado/revisado por un grupo de expertos en el que se puede utilizar como datos títulos y/o palabras claves

Con la lista de tópicos es necesario construir "expresiones de consulta" que tengan sentido para cada una de las fuentes de datos. Esta tarea es dependiente de los mecanismos de búsqueda que se implementan en cada fuente de datos. Además se debe considerar los diferentes criterios de búsqueda que se pueden utilizar, por ejemplo: búsquedas exactas, facetadas, uso de símbolos y operadores lógicos. Por ejemplo si consideramos a Twitter como una fuente de datos y si se desea buscar los tweets que contienen el hashtag Java y además una URL se debe usar la siguiente expresión!

$$
\text { \#Java filter:links }
$$

Otro ejemplo de expresión de consulta: en Serendipity si se desea buscar información sobre Java en español se debe usar:

$$
q=J a v a \& f f=\text { language:"Spanish" }
$$

Cada expresión de consulta, antes de ser parte del las expresiones de consulta, debe ser puesta a prueba y verificar que devuelve resultados, esto debido principalmente a de forma metódica y automátizada.

${ }^{1} \mathrm{El}$ detalle de los operadores que se pueden usar para buscar en el API de Twitter está en https: //dev.twitter.com/rest/public/search.

http://serendipity.utpl.edu.ec 
que muchas fuentes de datos (repositorios, redes sociales en línea, base de datos, etc.) poseen políticas de acceso y límites sobre el número de consultas que se pueden realizar, un ejemplo de las políticas se muestra en la siguiente sección.

Una recomendación para esta actividad es utilizar las interfaces de búsqueda que las fuentes de datos disponen, generalmente de forma abierta y gratuita, aunque los resultados que de ahí se obtienen pueden variar cuando se usan otros mecanismos como servicios Web de búsqueda, un ejemplo de ello es Twitter, como se señala en la documentación del API de búsqueda de Twitter ${ }^{1}$ el comportamiento de el API de búsqueda es similar pero no exactamente igual a las funciones de búsqueda Web o móvil del cliente oficial de Twitter, ya que el API de búsqueda está enfocado en la relevancia y no en la completitud. En el caso de Twitter se pueden utilizar la página de búsqueda 2 y el constructor de búsquedas avanzada ${ }^{3}$, para realizar las pruebas y verificar la existencia o no de resultados para cada uno de las expresiones de consulta.

Para la selección de las fuentes de datos es necesario considerar que no todos las fuentes de datos tienen un mecanismo para el acceso a sus datos y aquellos que poseen tienen diferentes propósitos. Este es punto importante de considerar ya que de ello dependerá el acceso a la información y el tipo de información que se pueda recolectar. Así por ejemplo en Facebook cuando se realizan búsquedas es posible encontrar: usuarios, páginas, eventos, grupos y lugares que sean públicos sin brindar la posibilidad de realizar búsquedas en el contenido, sino más bien obtener información de un elemento concreto.

Para finalizar la Tabla 4.2 muestra las condiciones que la fase necesita para dada un conjunto de entradas, sea capaz de producir unas salidas.

\subsubsection{Recolección de datos}

Esta fase contribuye a construir una fuente de datos que será utiliza por las fases restantes. La construcción de la fuente de datos se hace utilizando el listado de fuentes, las expresiones de consulta definidas en la fase anterior y las políticas de acceso asociadas a cada uno de las fuentes.

\section{- Detalle del proceso}

\footnotetext{
${ }^{1}$ https://dev.twitter.com/rest/public/search

2 https://twitter.com/search-home

3 https://twitter.com/search-advanced
} 


\section{PROPUESTA DEL MODELO DE ENRIQUECIMIENTO PARA INICIATIVAS BASADAS EN OERS}

Tabla 4.2: Construcción de Tópicos - Condiciones que debe cumplir el entorno para que dadas las entradas se generen las salidas

\begin{tabular}{|c|c|c|}
\hline $\begin{array}{l}\text { Condiciones del en- } \\
\text { torno }\end{array}$ & Entradas & Salidas \\
\hline $\begin{array}{l}\text { - Existe un experto en } \\
\text { la temática de la ini- } \\
\text { ciativa que se pre- } \\
\text { tende enriquecer para } \\
\text { que seleccione los des- } \\
\text { criptores claves. } \\
\text { - Las interfaces de bús- } \\
\text { queda de los reposito- } \\
\text { rios estén funcionan- } \\
\text { do. }\end{array}$ & $\begin{array}{l}\text { - Palabras claves que } \\
\text { describen la iniciativa } \\
\text { educativa. } \\
\text { - Títulos y/o subtítulos } \\
\text { de las diferentes sec- } \\
\text { ciones que describen a } \\
\text { la iniciativa. } \\
\text { - Listado de fuentes de } \\
\text { datos candidatas. }\end{array}$ & $\begin{array}{l}\text { - Una lista de "expre- } \\
\text { siones de consulta" } \\
\text { que devuelven resul- } \\
\text { tados para cada una } \\
\text { de las fuentes de da- } \\
\text { tos. } \\
\text { - Listado de las fuentes } \\
\text { de datos que usarán } \\
\text { para la recolección de } \\
\text { información. }\end{array}$ \\
\hline
\end{tabular}

El objetivo principal de esta fase es construir una fuente de datos que será empleada por los procesos de las fases restantes. Este proceso emplea la lista de fuentes de datos y las expresiones de consulta definidas en la fase anterior. Los datos se obtienen almacenando los resultados de la ejecución de las expresiones de consulta asociadas a cada fuente de datos. Dentro de la recolección de datos, existen dos elementos importantes: i)las políticas de privacidad de usuarios y ii) los límites de acceso a los datos. La Figura 4.4 muestra el detalle del proceso.

Las políticas de privacidad de usuarios buscan restringir el acceso a la información que el usuario considere sensible y que se encuentra fuera del dominio público, generalmente para tener acceso a esa información es necesario contar con la autorización expresa del usuario. Es por ello que en esta etapa se recomienda realizar la recolección de la información pública disponible a través de los mecanismos de consulta y que no demande autorización de terceros.

Un ejemplo de la privacidad de la información de los usuarios: en Twitter no es posible tener acceso de forma pública a la lista de tweets marcados como favoritos por un usuario. 


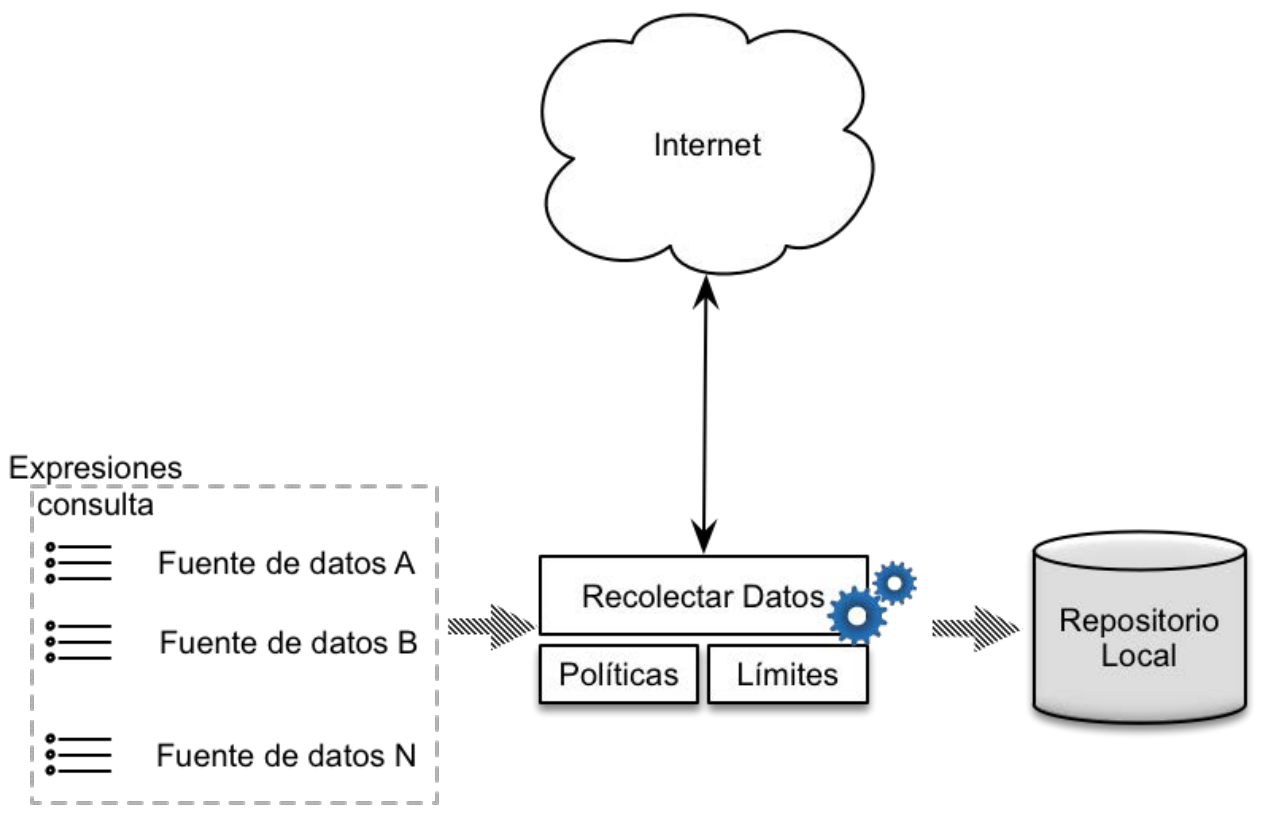

Figura 4.4: Recolección de datos - La recolección de datos es un proceso que se hace en base a las políticas y límites impuestos por las redes sociales en línea.

Muchas fuentes de datos implementan cuotas que limitan el acceso a sus datos, especialmente en sus APIs Web. Esos límites tienen por objetivo normar el acceso a los datos y son necesarios respetarlos ya que si se sobrepasan se podría llegar a negar definitivamente el acceso a los datos.

Un ejemplo de los límites, en Twitter el límite de acceso se ha clasificado según el tipo de usuario, aunque el número máximo de resultados y la ventana de tiempo se mantienen en 100 tweets por consulta y 15 minutos respectivamente, de la siguiente manera:

- Si se trata de una cuenta que pertenece a un usuario se pueden realizar 180 consultas, lo que permite obtener 7200 tweets por hora.

- Mientras que para una cuenta de pago que representa a una aplicación se pueden realizar hasta 450 consultas, permitiendo captar 180000 tweets en una hora.

Como consecuencia de los límites de acceso, el proceso de recolección de datos que se implemente debe contar con ciertas características cuando se trata de invocar a las diferentes mecanismos de consulta, en especial APIs Web, suministradas por las fuentes 


\section{PROPUESTA DEL MODELO DE ENRIQUECIMIENTO PARA INICIATIVAS BASADAS EN OERS}

de datos. Por ejemplo: una de las características que se puede implementar en esta fase podría ser considerar la frecuencia con que nuevos resultados aparecen, así se pueden ejecutar las consultas que devuelven pocos resultados nuevos una menor cantidad de veces, lo que que a su vez permite que las consultas que arrojan resultados nuevos con mayor frecuencia mayor sean ejecutados un número mayor de veces.

Las condiciones del entorno, entradas necesarias y salidas producidas se resumen en la Tabla 4.3

\subsubsection{Creación de redes}

Dentro de este modelo se identificaran relaciones entre los datos que pueden ser representadas como red y que sean significativas para el problema que se está tratando de resolver. Este modelo de enriquecimiento se basa en el estudio de la estructura de una red, es por ello que este componente es de suma importancia para el modelo.

Las relaciones pueden ser variadas, así como las redes que se construyen, la diversidad de redes son valiosas cuando se trata de hacer un análisis basado en SNA y visualización de los datos que los que se está trabajando. Sin embargo el modelo recomienda que por lo menos se trabaje con dos tipos de redes. El primer tipo que sea construido por relaciones explícitas entre los participantes de la red. Mientras que el segundo tipo de red provenga de relaciones implícitas de los conceptos que se intercambian. Así se tendrá una visión global de las interacciones sociales y las información que fluye en la red.

Otra de los aspectos que se consideran en este componente es el almacenamiento de la red, es por ello que se propone utilizar dos esquemas de trabajo, el primero basado en un modelo de datos relacional, mientras que el segundo propone el uso de un modelo NoSQL 1 .

Los módulos que forman este componente son los siguientes:

- Identificación de relaciones y construcción de redes.

- Instanciar redes.

El detalle de cada uno de ellos se presenta en las siguientes secciones.

${ }^{1}$ https://es.wikipedia.org/wiki/NoSQL No sólo SQL es una amplia clase de sistema de gestión de base de datos que difieren del modelo clásico basado en SQL. 
Tabla 4.3: Recolección de datos - Condiciones que debe cumplir el entorno para que dadas las entradas se generen las salidas

\begin{tabular}{|c|c|c|}
\hline $\begin{array}{l}\text { Condiciones del en- } \\
\text { torno }\end{array}$ & Entradas & Salidas \\
\hline $\begin{array}{l}\text { - Las expresiones de } \\
\text { consulta devuelven re- } \\
\text { sultados. } \\
\text { - Es necesario que los } \\
\text { mecanismos de bús- } \\
\text { queda estén funcio- } \\
\text { nando y cumplir con } \\
\text { las políticas y límites } \\
\text { de acceso a los datos } \\
\text { según los repositorios. } \\
\text { - La mayor cantidad de } \\
\text { información es de ac- } \\
\text { ceso público y no exis- } \\
\text { te la necesidad de } \\
\text { contar con autoriza- } \\
\text { ciones individuales de } \\
\text { los usuarios para te- } \\
\text { ner acceso a ella. }\end{array}$ & $\begin{array}{l}\text { - Una lista de "expre- } \\
\text { siones de consulta" } \\
\text { que devuelven resul- } \\
\text { tados para cada una } \\
\text { de las fuentes de da- } \\
\text { tos. } \\
\text { - Listado de las fuentes } \\
\text { de datos que usarán } \\
\text { para la recolección de } \\
\text { información. } \\
\text { - Políticas y límites de } \\
\text { uso de los APIs de } \\
\text { consulta de cada una } \\
\text { de las fuentes de da- } \\
\text { tos. }\end{array}$ & $\begin{array}{l}\text { - Un repositorio con to- } \\
\text { dos los datos que de- } \\
\text { vuelven las expresio- } \\
\text { nes de consulta. }\end{array}$ \\
\hline
\end{tabular}




\section{PROPUESTA DEL MODELO DE ENRIQUECIMIENTO PARA INICIATIVAS BASADAS EN OERS}

\subsubsection{Identificación de relaciones y construcción de redes}

Este proceso se enfoca en el análisis de los datos recogidos con el fin de encontrar características que pueden expresarse como relaciones entre ellos para que posteriormente se pueda construir redes. En este aportado se muestran los procesos que se deben ejecutar, así como también las recomendaciones y mejores prácticas a seguir para garantizar que las redes y posteriores análisis respondan a las necesidades de información.

- Detalle del proceso En las relaciones se encuentra el potencial de una red y su diferencia con las ciencias sociales que realizan el estudio de los atributos de individuos mientras que en el análisis de redes sociales se estudian los atributos de pares de individuos (Borgatti and Everett 1997), es por ello que esta actividad es de suma importancia ya que determina el éxito o fracaso de una red para resolver un problema particular Barabási (2016) y determinan el tipo de respuestas que las redes pueden proporcionar.

Una relación representa la interacción entre dos nodos (Barabási 2016). Las relaciones poseen muchas características y propiedades que a continuación se presentan. La figura 4.5 muestra un resumen del proceso.

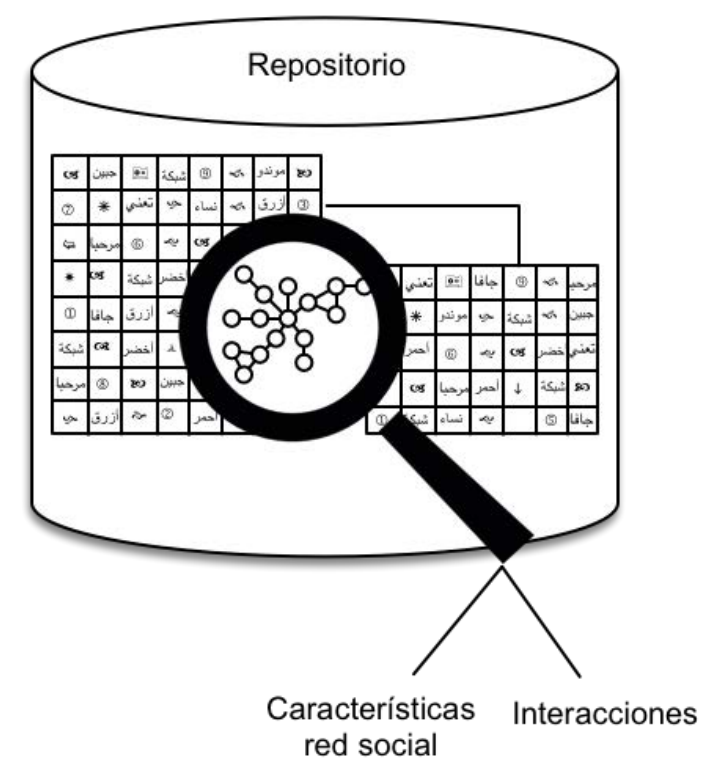

Figura 4.5: Identificación de relaciones - Este proceso analiza los datos recolectados y las características de las redes sociales para construir redes.

- Tipos de relaciones 
Se ha clasificado a las relaciones en dos grupos: explícitas e implícitas. La definición y ejemplificación se muestran a continuación:

- Explícitas: Son relaciones en las que un nodo manifiestan de forma clara y directa su interacción con otro(s) nodo(s). Algunos ejemplos de estas relaciones:

- Lista de amigos en Facebook o lista de seguidores en Twitter.

- Co-autoría de libros o publicaciones científicas.

- Implícitas: Son un tipo de relaciones en la que los nodos comparten algún elemento en común, por ejemplo:

- Dos investigadores se relacionan entre si cuando escriben sobre una misma temática.

- Los ingredientes de las recetas de cocina están relacionados cuando son parte de varias recetas.

Dentro de la teoría de redes al primer tipo de red se la denomina "de un sólo modo" (one-mode), mientras que el segundo se denomina "bipartita", "bigrafo" o de "dos modos" y son redes que están formados por nodos de diferentes tipos.
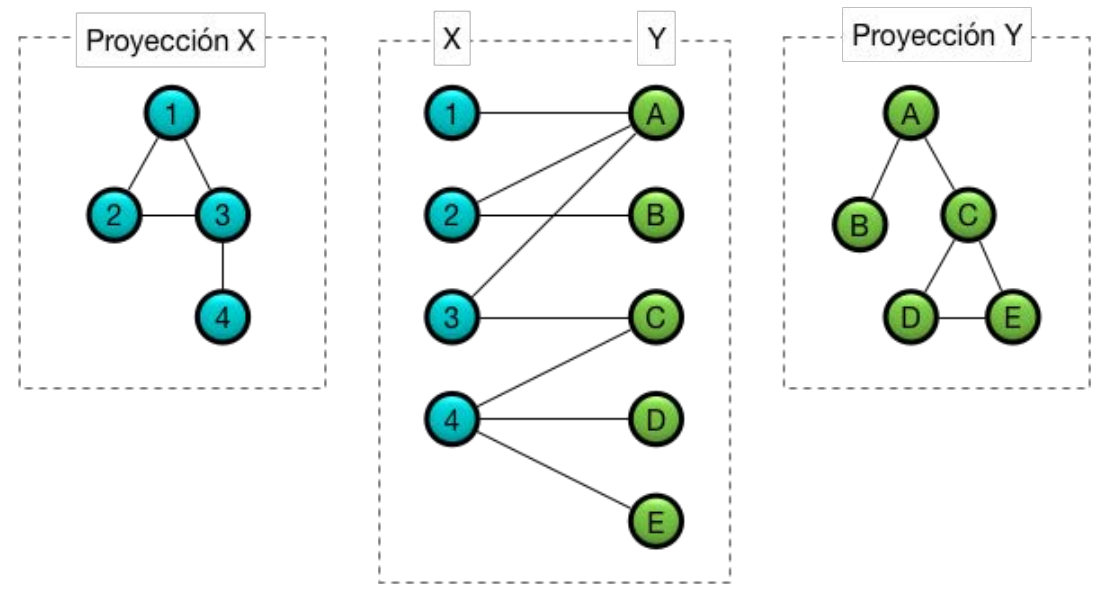

Figura 4.6: Red bipartita y sus proyecciones - Cuando la relaciones son implícitas se generan redes bipartitas es recomendable trabajar con sus proyecciones 


\section{PROPUESTA DEL MODELO DE ENRIQUECIMIENTO PARA INICIATIVAS BASADAS EN OERS}

Latapy et al. (2008) afirma que las redes bipartitas carecen de herramientas y métricas que permitan realizar su análisis, por lo que se recomienda usar el método denominado "Proyección" para generar dos redes de un sólo modo. La Figura 4.6 muestra una red bipartita con nodos de dos tipos X y $\mathrm{Y}$, dicha red se puede transformar en 2 redes de un sólo modo. La primera proyección conecta los nodos del tipo X a través de un link si ellos están conectados al mismo nodo de tipo Y en la representación bipartita. La segunda proyección conecta los nodos de tipo Y si ellos se conectan a un mismo actor de tipo X.

Si bien el término "social" se relaciona estrechamente con los seres humanos y por ello se asocia a una "red social" con una "red de personas", esto ha cambiado desde hace algún tiempo y el análisis de redes sociales, no se aplica exclusivamente a redes de personas sino a redes cuyos actores también denominados nodos pueden ser: palabras (Türker et al. 2016), palabras claves, URLs, genes, compuestos químicos, notas musicales, personajes ficticios (tiras cómicas, series de televisión), neuronas, especies de animales, y un extenso etc. Es por ello el campo de aplicación de este tipo de análisis es bastante amplio o como menciona Scott and Carrington (2011) cualquier unidad que pueda ser conectada con otra puede ser estudiada como un nodo.

\section{- Simetría de las relaciones}

Una vez que se ha identificado las relaciones y clasificado en uno de los tipos descritos en el punto anterior, es necesario analizar la simetría de la relación, para determinar si la relación en unidireccional o en ambos sentidos, a esto también se la denominad como reciprocidad de la relación.

Según la simetría, las relaciones pueden ser de dos tipos:

- Simétricas: Cuando la relación se dan en ambos sentidos o existe reciprocidad entre los nodos que participan de la relación. Ejemplo: relación de amistad en Facebook, ambos nodos son amigos.

- Asimétricas: Son relaciones que fluyen sólo en un sentido, esto permite que los nodos sean clasificados en nodos origen y nodos destino. Ejemplo: En Twitter un usuario A puede seguir a un usuario $\mathrm{B}$, sin que implique que B siga a $\mathrm{A}$.

La simetría de la relación tiene un efecto global y traen como consecuencia que las redes sean clasificada en redes i) dirigidas (asimétricas), ii) no dirigidas (simétricas) o iii) 
mixtas, según el sentido de la relación. Esta característica tiene impacto en las métricas que se utilizan en el análisis de redes sociales, este tema se tratará más adelante.

\section{- Peso de la relación}

La intensidad de una relación entre dos nodos puede ser cuantificada por un peso (weight). Dentro de una red social, el peso de una relación está en función de la duración, intensidad emocional, intimidad e intercambio de servicios (Granovetter 1973). Mientras que para redes no sociales, existen muchas interpretaciones.

La interpretación del peso depende del tipo de red que se está construyendo. Por ejemplo en una red de amistad el peso de un enlace puede señalar cuanto se conocen dos personas (representadas por nodos); si la red trata de medir la influencia de un nodo sobre otro, el peso de la relación determina cuan influyente es un nodo sobre otro. Inclusive el peso puede señalar rechazo entre los nodos.

Medir el peso de la relación es una tarea que no siempre se logra realizar de la forma apropiada (Barabási 2016) y como consecuencia se realizan aproximaciones con redes no ponderadas.

El uso o no del peso en una relación, determinar que la red se denomine como redes ponderadas o no ponderadas. Algunas medidas de SNA usan el peso de las relaciones.

\section{- Otras consideraciones}

Existen otros conceptos que se aplican a las relaciones, pero que no tienen su contraparte en las redes o aún no existen métodos ni herramientas que lo soporte. Uno de ellos son los multigrafos en donde dos nodos pueden tener múltiples enlaces entre sí.

Es posible que algunos datos puedan ser expresados como atributos tanto para los nodos como para las relaciones, esos atributos pueden ser de diferente tipo y generalmente se utilizan como filtros, especialmente cuando se visualiza la red, aunque también podrían ayudar a construir sub-redes. Más adelante se habla del impacto de los atributos en el desempeño que tiene el software que representa a la red.

La Tabla 4.4 presenta un resumen de las condiciones del entorno, entradas y salidas que se reciben y generan dentro de esta fase respectivamente.

\subsubsection{Instanciar las redes}

El aporte principal de esta fase es la creación de varias redes que responden a las relaciones identificadas en la fase anterior. Dentro de las redes construidas se debe tener 


\section{PROPUESTA DEL MODELO DE ENRIQUECIMIENTO PARA INICIATIVAS BASADAS EN OERS}

Tabla 4.4: Identificación de relaciones y construcción de redes - Condiciones que debe cumplir el entorno para que dadas las entradas se generen las salidas

\begin{tabular}{|c|c|c|}
\hline $\begin{array}{l}\text { Condiciones del en- } \\
\text { torno }\end{array}$ & Entradas & Salidas \\
\hline $\begin{array}{l}\text { - Acceso a la fuente de } \\
\text { datos. }\end{array}$ & $\begin{array}{l}\text { - Una fuente de datos. } \\
\text { - Diccionario de datos } \\
\text { que describan a la } \\
\text { fuente. } \\
\text { - Características de la } \\
\text { red social. }\end{array}$ & $\begin{array}{l}\text { - Lista de relaciones } \\
\text { identificadas. } \\
\text { - Características de ca- } \\
\text { da tipo de relación. }\end{array}$ \\
\hline
\end{tabular}

al menos dos redes, una de usuarios y otra de conceptos que son la base para el modelo de enriquecimiento.

\section{- Detalle del proceso}

Una vez definido el modelo de red que se utilizará como modelo de datos es necesario poblarlo con instancias según el modelo. En este paso se debe tomar algunas consideraciones importantes, muchas de ellas relacionadas con el volumen de datos y el desempeño de la red, especialmente cuando se trata de realizar el análisis. La figura 4.7 muestra esquemática este proceso.

Un modelo de red se puede implementar utilizando diferentes mecanismos tales como bases de datos relacionales u orientadas a grafos, aunque el desempeño de las segundas es superior a las primeras siempre y cuando se cumpla con las requerimientos de hardware que demandan.

Con el uso de las base de datos relaciones, es posible poblar el modelo de red a través de consultas SQL, siempre y cuando el volumen de datos no sea excesivo, considerando que es necesario hacer JOIN de varias tablas. Otra alternativa es crear dos tablas adicionales para que representen a los nodos y a los enlaces, esta opción se puede emplear cuando el volumen de datos es grande.

Mientras que dentro del enfoque orientado a grafos es preciso diferenciar que a su vez se puede optar por dos opciones: transaccionales y no transaccionales. Las primeras 


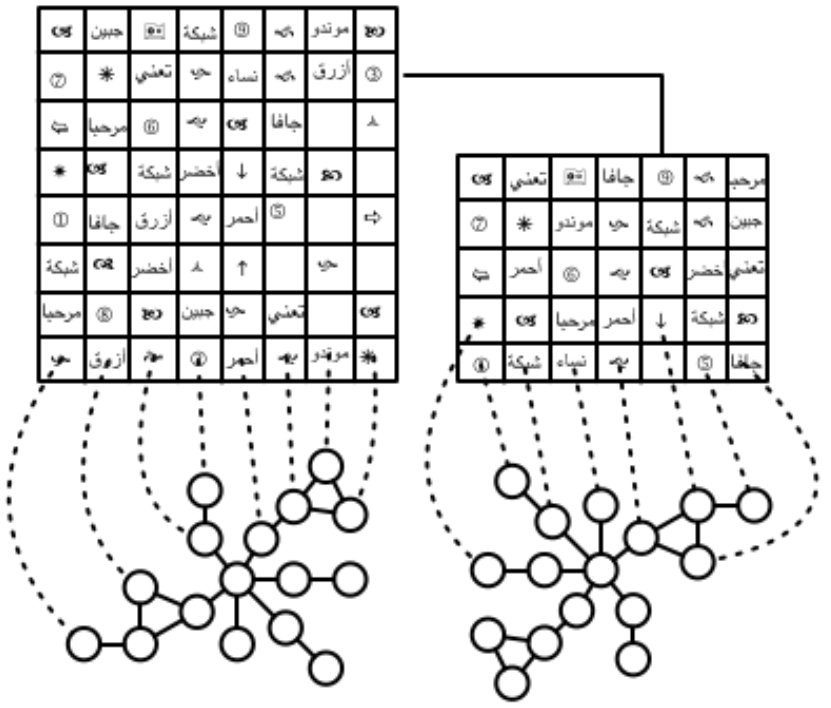

Figura 4.7: Instanciar las redes - Este proceso transforma los datos que generalmente están en forma tabular en una red (grafo).

sin embargo por sus características para el soporte de transacciones demanda de muchos más recursos hardware que las no transaccionales. Dentro de las tecnologías no transaccionales existe una gran cantidad de alternativas cuya principal fuente de entrada son archivos de texto separados por comas.

Independientemente de la tecnología para representar las redes, es necesario considerar que el tamaño de la red (nodos y relaciones) es un factor determinante en el desempeño de la ejecución de muchas de las métricas, sin embargo existen alternativas de BigData para el trabajo de grandes volúmenes de datos.

Como ya se mencionó tanto los nodos como las relaciones pueden tener atributos, que a nivel de estructura de datos de convierten en un campo que según el tipo de dato ocupa una determinada cantidad de bits. Esos atributos se puede utilizar para realizar filtros de los elementos de la red, sin embargo pueden llegar a afectar el desempeño de la red, especialmente considerando que la red se debe cargar en la memoria RAM. Es por ello que se recomienda que para redes con un gran número de nodos y relaciones se minimice el uso de atributos tanto de nodos como de enlaces y se cambie la forma de trabajo a uno en donde el único atributo de un nodo o relación sea un identificador que luego haga posible encontrar fácilmente otros atributos. En caso de usar los atributos 


\section{PROPUESTA DEL MODELO DE ENRIQUECIMIENTO PARA INICIATIVAS BASADAS EN OERS}

Tabla 4.5: Instanciar redes - Condiciones que debe cumplir el entorno para que dadas las entradas se generen las salidas

\begin{tabular}{l|l|l}
$\begin{array}{l}\text { Condiciones del en- } \\
\text { torno }\end{array}$ & Entradas & Salidas \\
\hline - Acceso a los datos. & - Nodos y sus atributos & - Varias redes. \\
- El mecanismo de per- & identificadas. & - Una red que tenga co- \\
sistencia de las redes & - Relaciones y sus atri- & mo nodos a personas \\
debe estar funcionan- & butos identificadas. & $\begin{array}{l}\text { y que muestre alguna } \\
\text { do. }\end{array}$ \\
& & $\begin{array}{l}\text { relación de colabora- } \\
\text { ción. }\end{array}$ \\
& - Una red formada por \\
& los conceptos que es- \\
& tán presentes en los \\
& datos. \\
&
\end{tabular}

para generar una sub-red, es aconsejable que se trabaje con una nueva red que se construya con los datos filtrados y no construir la red para luego filtrar.

El modelo de enriquecimiento que se desarrolla en esta tesis, propone trabajar con dos tipos de redes. La primera una red en donde se muestre interacción entre personas (co-autoría, re-tweet, etc.) con el fin de identificar "influencia" entre personas. La segunda red debe permitir construir una folksonomía de los conceptos que se desarrollan en al red. Estas dos redes son la base para los siguientes pasos del modelo.

Finalmente la Tabla 4.5 resumen las condiciones del entorno, las entradas que recibe la fase y las salidas que se generan.

\subsubsection{Análisis y visualización de redes}

Este componente utiliza las redes que fueron construidas por el componente anterior, con dos objetivos claros, analizar y visualizar las redes.

El análisis que se propone en este componente, está basado en el uso de métricas del SNA y el análisis de las propiedades que adquieren los actores cuando se encuentran 
dentro de una red, con el fin de interpretar la estructura de la red y encontrar patrones en las diversas interacciones entre los actores de las redes propuestas.

La visualización de los análisis realizados es otro módulo que busca utilizar a la red como un elemento fundamental para la presentación de resultados. Dentro de este componente se promueve el uso preferente de visualizaciones interactivas y dinámicas que permita a los usuarios navegar sobre red y obtener información de cada uno de sus elementos.

El módulo que están dentro de este componente es:

- Analizar, a través de métricas de SNA y visualizar.

\subsubsection{Analizar a través de métricas de SNA y visualizar}

En este fase del proceso de enriquecimiento y con los datos que se han generado hasta el momento es posible realizar un análisis de las redes generadas y según el número de elementos de la red es posible también visualizarlos. Los análisis que se realizan en esta fase son únicamente análisis descriptivos, en base a las métricas propias del análisis de redes sociales.

\section{- Detalle del proceso}

Uno de los primeros resultados que se puede obtener con las redes ya construidas provienen de la ejecución de varias métricas propias de la teoría de redes. Esas medidas puedes ser topológicas, espectrales, locales o globales. Las medidas topológicas, son medidas locales que describen a un actor tomando en cuenta su posición dentro de una red. Las medidas espectrales, si bien son medidas locales, se diferencian de las anteriores ya que no sólo toman en cuenta la posición de un actor dentro de la red, sino las conexiones que este tiene. Las medidas globales permiten tener una visión general de toda la red.

Una consecuencia del elevado número de elementos de una red es la dificultad para entenderlos visualmente a través del diagrama de un grafo, sin embargo se pueden utilizar otro tipo de diagramas que permitan entender a la red.

Dentro de esta primera fase de análisis se recomienda realizar los siguientes análisis para las medidas individuales:

- Centralidad (degree, betweenness, closeness, pagerank) 


\section{PROPUESTA DEL MODELO DE ENRIQUECIMIENTO PARA INICIATIVAS BASADAS EN OERS}

- Coeficiente de Clustering

Mientras que las medidas globales que se pueden realizar son:

- Densidad.

- Coeficiente de Clustering global

- Detección de comunidades (modularidad)

Las gráficas que se pueden realizar son las siguientes:

- Grafo (si el número de elementos lo permite)

- Diagramas de densidad o calor

- Distribucción del grado

- Homofilia de la red.

Los datos, según la herramienta, pueden ser fácilmente exportados y construir no sólo documentos estáticos sino dinámicos que muestren los análisis realizados. Una alternativa es utilizar el plugin LoxaWebSite Export ${ }^{1}$ para la herramienta Geph ${ }^{2}$ que permite incluir todos los análisis en un sitio Web dinámico y que puede es fácilmente configurado sin la necesidad de conocimientos técnicos.

La figura 4.8 es un ejemplo de lo que se puede realizar a través del análisis y visualización de redes, el análisis permite destacar: nodos a través de diferentes características como su tamaño y también se pueden destacar enlaces por ejemplo por su peso. La visualización puede ser estática (generalmente imágenes) o dinámica en donde se puede interactuar con los elementos, acercar o alejar la red para tener diferentes perspectivas de la misma.

La Tabla 4.6 muestra las condiciones que la fase necesita con el fin de recibir las entradas y generar las salidas correspondientes.

${ }^{1}$ http://www.j4loxa.com/sna/gephi/plugins/index.html

2 https://gephi.org 
a)

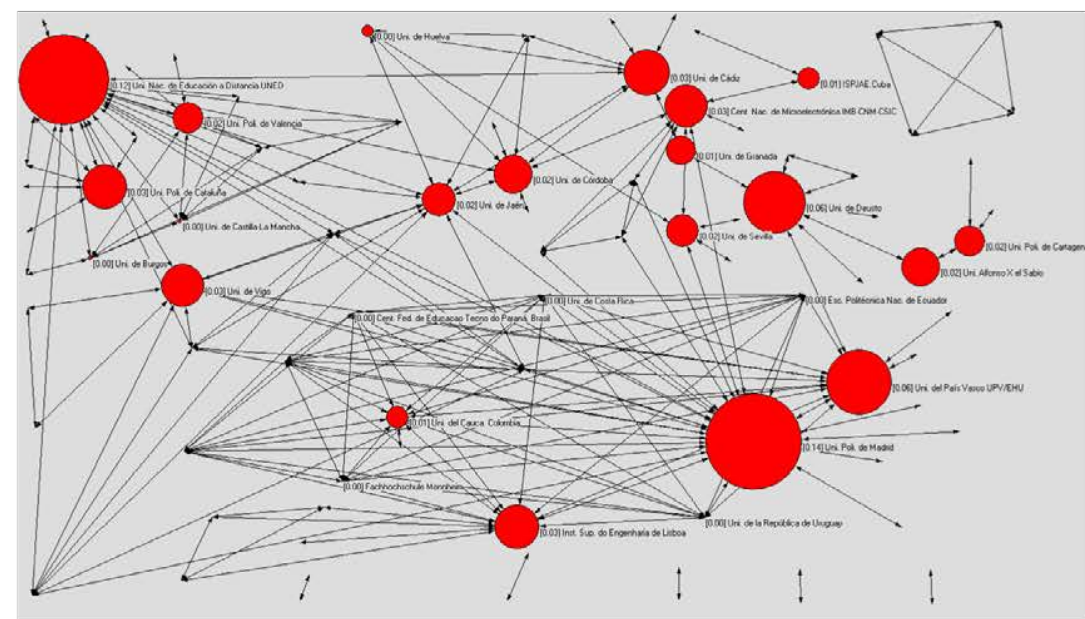

b)
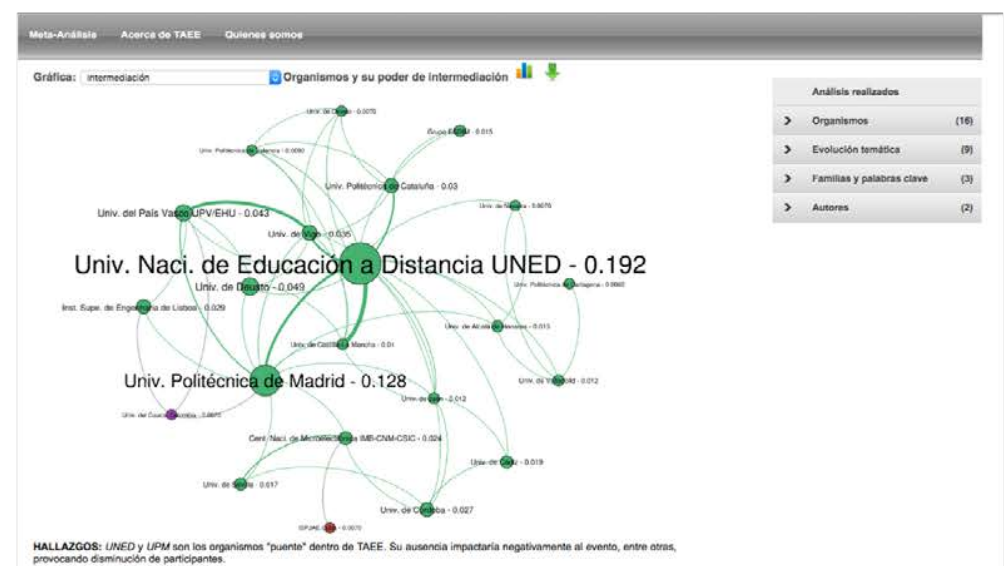

ara

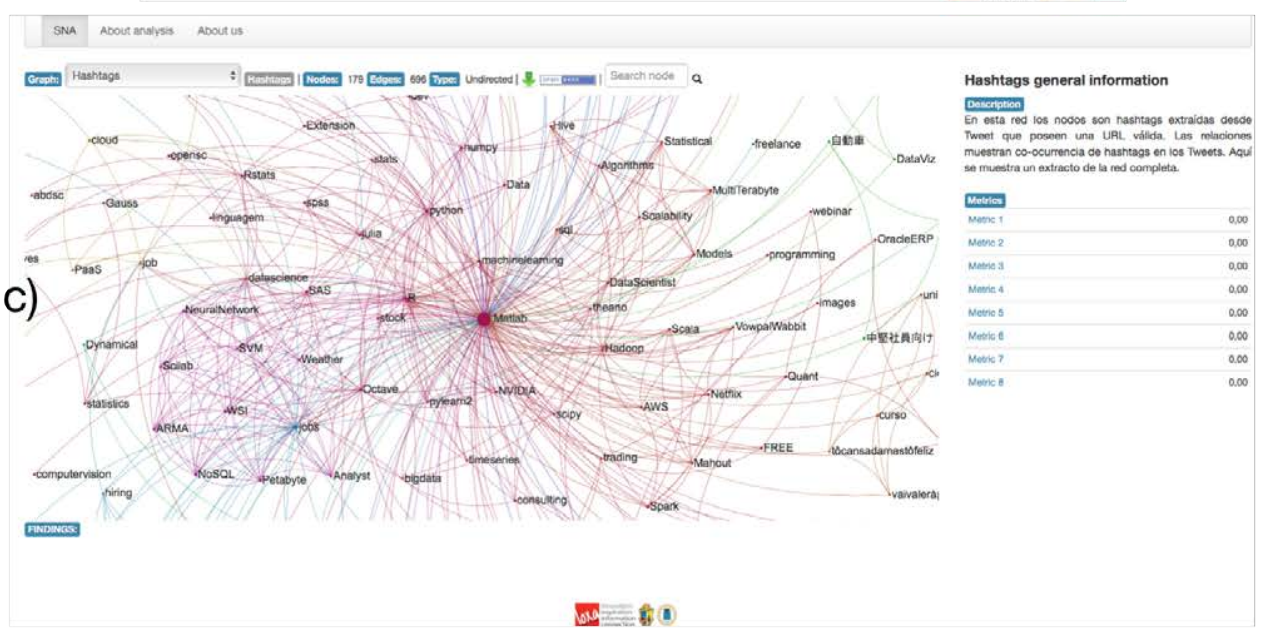

Figura 4.8: Análisis de redes - Las figuras a) y b) son un ejemplo del análisis de redes sociales generadas con la herramienta Gephi y LoxaWebSite export. a) es una visualización estática de una red, mientras que b) y c) son dinámicas y generados con el plugin desarrollado durante esta tesis, b) fue generado con la versión 0.1 mientras que c) a la nueva versión 0.3 


\section{PROPUESTA DEL MODELO DE ENRIQUECIMIENTO PARA INICIATIVAS BASADAS EN OERS}

Tabla 4.6: Análisis y visualización de redes - Condiciones que debe cumplir el entorno para que dadas las entradas se generen las salidas

\begin{tabular}{|c|c|c|}
\hline $\begin{array}{l}\text { Condiciones del en- } \\
\text { torno }\end{array}$ & Entradas & Salidas \\
\hline $\begin{array}{l}\text { - Acceso a los datos re- } \\
\text { presentados como re- } \\
\text { des. } \\
\text { - El tamaño de las re- } \\
\text { des no debe sobre- } \\
\text { pasar las capacidades } \\
\text { del equipo. }\end{array}$ & - Un grupo de redes. & $\begin{array}{l}\text { - Visualización de las } \\
\text { redes, en donde se } \\
\text { destaque nodos y/o } \\
\text { relaciones. } \\
\text { - Análisis de cada una } \\
\text { de las redes tanto glo- } \\
\text { bales (ver lista), como } \\
\text { locales (ver lista). }\end{array}$ \\
\hline
\end{tabular}

\subsubsection{Recomendar}

Una vez que se ha analizado la red, este componente propone utilizar parte de la información producto de ese análisis para realizar recomendaciones de los recursos que han sido compartidos dentro de una red social en línea.

Con ese fin este componente propone utilizar el componente social de una red social en línea, para encontrar usuarios destacados y los recursos que ellos han compartido como ítems a recomendar. Para encontrar esos usuario se propone el uso de métricas de centralidad de SNA para encontrar aquellos usuarios que han causado algún efecto dentro de la red.

Dentro de este componente también se propone el uso de los contenidos, tanto de los contenidos compartidos en la red social en línea, como de los contenidos de los recursos compartidos en la misma red social. Los primeros contenidos (los compartidos en la red social) adquieren una importancia mayor que los otros, debido que al ser expuestos a un grupo de personas (miembros de la red social) han sido de cierta forma juzgados y aceptados o rechazados.

Los contenidos, tanto los compartidos en la red como los que provienen de los recursos son utilizados para valorar cada uno de los recursos identificados. Esta valoración 
con información que proviene de la interacción social, como la información que proviene de los recursos permite ordenar los recursos según su importancia.

Otro de los principios sobre los cuales se basa este componente es considerar a una red como estructura dinámica que cambia con el tiempo y que el tiempo también puede afectar en el desempeño/producción de los actores participantes de la red. Esa producción en el tiempo permitirá evaluar a los usuarios de la red y permitirá seleccionar a aquellos usuarios con mayor desempeño, complementado así la selección de usuarios destacados que se mencionó anteriormente.

Finalmente otro de los elementos que se consideran dentro de este componente es el uso de las licencias con las que se publican los contenidos, principalmente el uso de licencias abiertas que permitan el re-uso de los recursos compartidos. En caso de que no se llegue a determinar la licencia del recurso, por lo menos se garantizará el acceso a los mismos.

Los módulos que forman este componente se listan a continuación y se describen en las siguientes secciones.

- Social - Usuarios destacados

- Producción en el tiempo

- Enriquecimiento de ítems.

- Contenidos - Contexto

- Valoración.

- Legal.

\section{- Detalle del proceso}

La intuición que subyace al modelo de recomendación es la siguiente: para generar recomendaciones de ítems (URLs) y sus respectivas valoraciones (para ranking) se propone trabajar con la información tanto de los usuarios como de los conceptos que se encuentran dentro de los datos y que se pueden representar como redes. Con este fin se analiza la red de usuarios con el objetivo de encontrar aquellos usuarios que han publicado ítems (al menos uno) y que por el efecto que tuvieron en la red pueden ser considerados como destacados. Así mismo se analiza la red de conceptos buscando determinar el contexto que está alrededor tópicos definidos anteriormente y que permitirá 


\section{PROPUESTA DEL MODELO DE ENRIQUECIMIENTO PARA INICIATIVAS BASADAS EN OERS}

encontrar ítems relacionados y no sólo aquellos que tienen una coincidencia exacta con los tópicos.

Sin embargo, es necesario considerar que la información de los ítems que están dentro de una red, especialmente una red social en línea, no es extensa, es por ello que los ítems deben ser enriquecidos con información que ellos mismos poseen y que los describen. Esa información permitirá determinar que tan relacionado está el ítem con el contexto de los tópicos.

Otro elemento a considerar, para el modelo de recomendación es el tiempo, para ello se propone representar el tiempo para clasificar la producción de los usuarios, esto tiene como propósito esbozar el comportamiento de un usuario dentro de una temática. Ese comportamiento se puede emplear con un doble propósito. Primero asignar un rol a cada usuario y segundo el comportamiento ayudará a encontrar a los usuarios destacados.

Finalmente, mucha de la información que circula en las redes sociales no posee una licencia que señale explícitamente lo que es o no permitido hacer con esa información, es por ello que se ha clasificado a la información en recursos digitales, a aquellos que no tienen licencia o tienen una licencia de solo acceso, y en recursos educativos abiertos a aquella información que posee una licencia de uso abierta.

El algoritmo se resumen en: considerar los ítems publicados por usuarios destacados y valorarlos según su proximidad con los conceptos asociados a un tema (descrito por los sus tópicos).

Un elemento sobre el cual se ha construido este modelo de recomendación es la posibilidad de sustituir sus componentes, así por ejemplo: para encontrar los nodos destacados se puede utilizar cualquier medida de centralidad, sin que esto demando de un cambio en el modelo de recomendación. Lo mismo sucede con el contexto, la medida para encontrar conceptos que mejor lo describan puede ser cambiada sin que demande cambios en el modelo de recomendación. La Figura 4.9 muestra el modelo de recomendación.

\subsubsection{Social - Usuarios destacados}

Dentro del modelo de recomendación propuesto es necesario seleccionar aquellos usuarios que por su accionar han generado un efecto dentro de la red, a esos usuarios se los denominará destacados. 


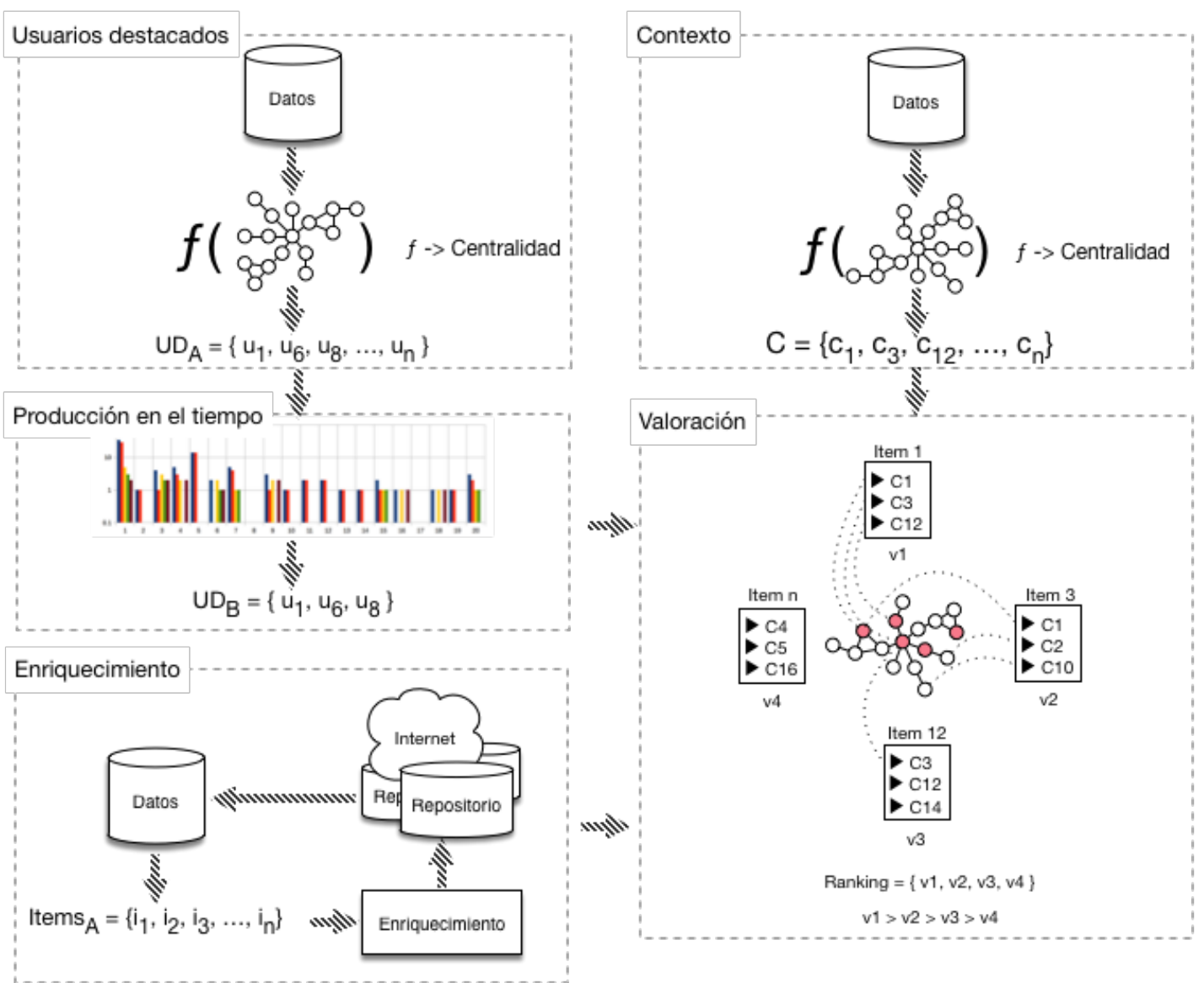

Figura 4.9: Modelo de Recomendación - En este modelo de recomendación que toma en cuenta a los usuarios destacados (UD), Items enriquecidos (Items) y conceptos (C) 


\section{PROPUESTA DEL MODELO DE ENRIQUECIMIENTO PARA INICIATIVAS BASADAS EN OERS}

Con este objetivo se propone utilizar la topología de la red para encontrar a los usuarios destacados ya que la topología de una red permite encontrar nodos, que gracias a sus relaciones (enlaces) ocupan ciertas posiciones que los convierten en nodos destacados y que ejercen un determinado rol dentro de la red.

Existe un gran número de medidas que se basan en la topología de la red que asignan una valoración para cada uno de los nodos con el fin de valorar a cada uno de los nodos según la posición que han alcanzado dentro de una red. En el trabajo realizado por (Jalili et al. 2015b), del cual se deriva un sitio Wel卬, se puede encontrar una lista con más de cien medidas de centralidad.

En esta tesis, no se pretende entrar en una discusión detallada de cada uno de las medidas de centralidad, por lo contrario se propone que se utilice la medida de centralidad que de mejor forma destaque a los nodos según el fin con el que se construyó la red. Es posible entonces contar con libertad para responder a la naturaleza de los datos.

Por ejemplo en una red, es posible que se prefiera alguna medida de centralidad basada en distancias geodésicas (caminos cortos), mientras que en otro red y por la naturaleza es posible que se prefiera medidas espectrales que destaquen a los nodos por la calidad de sus conexiones. Siguiendo el mismo ejemplo, para el primer caso se podría usar la medida intermadiación (Betweenness) mientras que para el segundo PageRank.

Formalmente, este proceso se puede describir, tomando como referencia a la ecuación 4.1 así:

$$
f(G)=U D_{A}=\left\{u_{1}, u_{2}, u_{3}, \ldots u_{m}\right\}
$$

de donde:

- G es una red de usuarios.

- $f(G)$ es una función que se aplica sobre una red con el fin de destacar nodos. Un ejemplo de la función puede ser cualquier medida de centralidad.

- $U D_{A}$ es un conjunto de usuarios destacados en el que se cumple que $U_{D A} \subseteq N$

- $\left|U D_{A}\right|=m \leq|N|$ es el número de usuarios destacados.

1 http://www.centiserver.org 
Este proceso, de destacar usuarios, se puede realizar sobre todas las redes en donde sus nodos sean usuarios. En cada una de esas interacciones $f$ puede ser diferente, según la naturaleza de los datos. El resultado siempre será un grupo de usuarios $U D_{A}$

\subsubsection{Producción en el tiempo}

Como se argumentó en el estado del arte las redes no son estáticas sino todo lo contrario, se encuentran en constante cambio, se agregan nuevos nodos y relaciones. $\mathrm{Y}$ es necesario tratar de modelar ese aspecto por que el tiempo aporta información adicional relevante que puede ayudar a la caracterización principalmente de los nodos de la red.

En esta tesis el tiempo se utiliza para clasificar la producción de ítems de parte de los actores de la red, es decir, una heurística para realizar la selección de usuarios, es revisar su historial productivo. Para ello se realiza una clasificación de la producción en actual y producción pasada que a su vez se clasifica en dos tipos de producción: producción tipo ${ }^{* *}$ y tipo ${ }^{*}$, el primer tipo señala una producción superior que la del segundo tipo.

La Figura 4.10 muestra gráficamente que la mayoría de los datos que se recogen desde las redes sociales en línea pueden incluir datos actuales, es decir datos que se producen en el instante de tiempo de la recolección de los datos. Además el proceso de recolección puede capturar datos que provienen de antes que se inicie el proceso de recolección, pero que tienen una repercusión que les permite estar latentes en el futuro (P. actual recolectada).

Con la clasificación anterior es posible que se pueda realizar selecciones de nodos de varias formas, que se adapten a la naturaleza de los datos y el propósito del análisis que se ejecuta.

El resultado de este proceso es un conjunto de usuarios, que se denomina $U D_{B}$, cuyo tamaño es menor al que genera la ecuación 4.6. Al igual que el proceso anterior, el criterio de selección de los usuarios es abierto, ya que el impacto de la producción en el tiempo se puede ver en muchas de las medidas de centralidad como se puede ver en la Figura 4.11 .

Una descripción formal de la fase sería:

$$
f\left(U D_{A}\right)=U D_{B}=\left\{u_{1}, u 2, u 3, \ldots, u_{m^{\prime}}\right\}
$$




\section{PROPUESTA DEL MODELO DE ENRIQUECIMIENTO PARA INICIATIVAS BASADAS EN OERS}

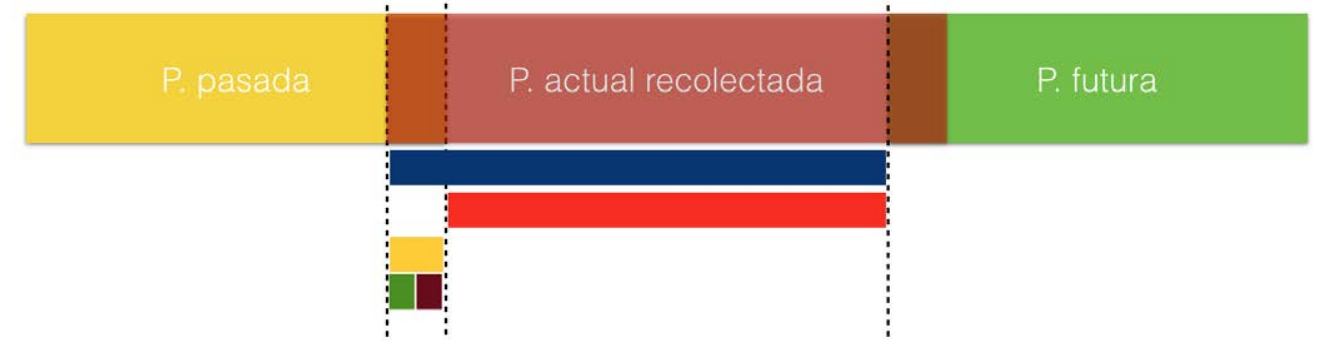

Toda la producción

Sólo producción actual Sólo producción anterior

Figura 4.10: Modelamiento del tiempo - Un modelo de producción que toma en cuenta el tiempo como factor de clasificación.

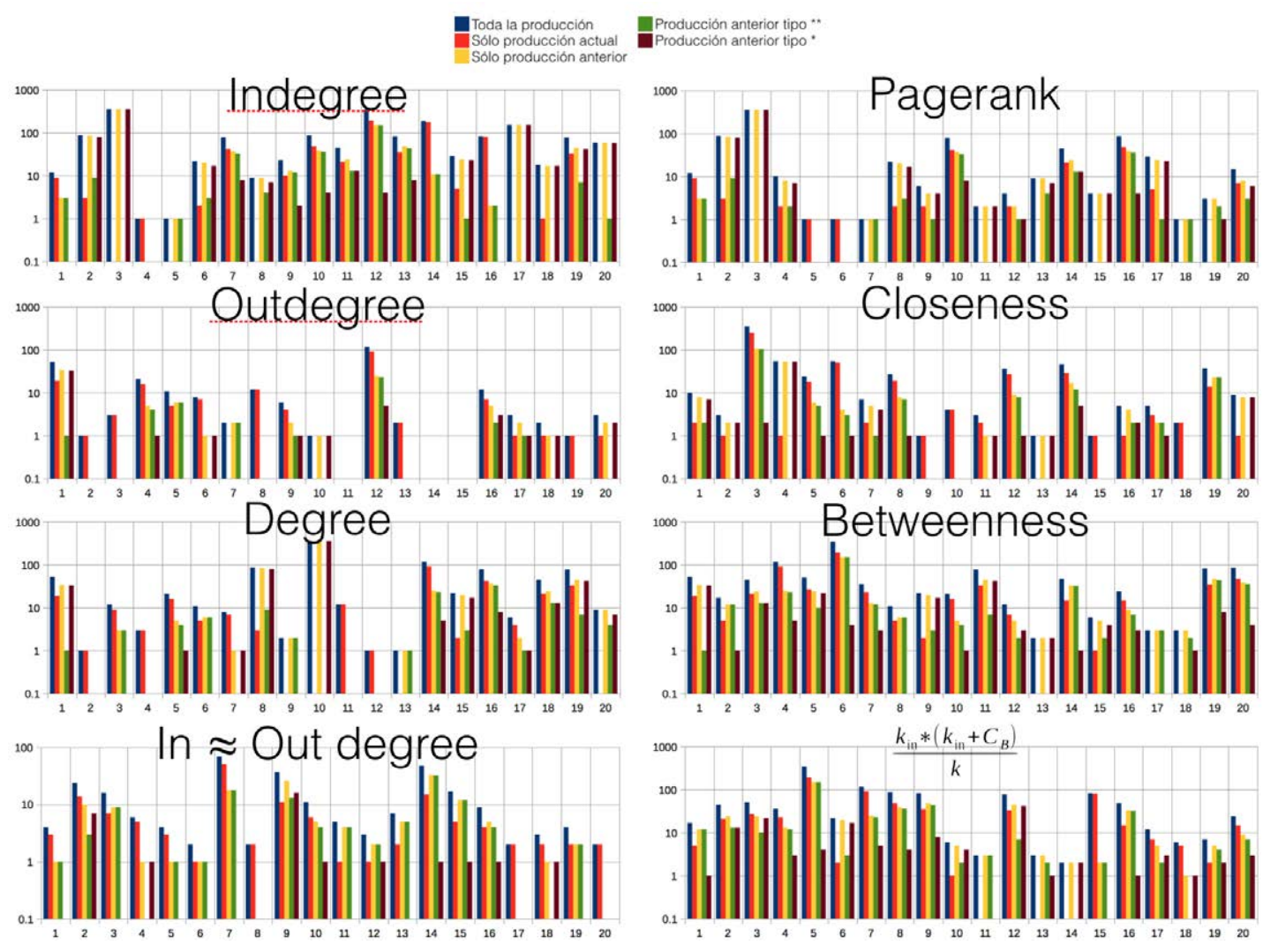

Figura 4.11: El tiempo visto en algunas medidas de centralidad - El efecto de la producción en el tiempo en los nodos ordenadas según una medida de centralidad. Los datos corresponden se obtuvieron de Twitter y hablan sobre HTML5 
de donde:

- $U D_{A}$ fue definido en la Ecuación 4.6 .

- $f$ es una función que selecciona los nodos según su desempeño en el tiempo.

- $U D_{B}$ es un conjunto de nodos, en el que se cumple $U D_{B} \subseteq U D_{A}$.

- $m^{\prime}$ es el número de usuarios y $m^{\prime} \leq m$.

\subsubsection{Enriquecimiento de ítems}

Este proceso se encarga de obtener mayor información de los ítems que se recomendará con el objetivo de complementar la información que se encuentra publicada y disponible dentro de la red.

Las formas de enriquecimiento que se pueden aplicar dependen de la naturaleza de los ítems, para este trabajo se considera que los ítems son enlaces (links) y los mecanismos de enriquecimiento empleados se describen más adelante. Mucha de la información que se utiliza en este proceso, proviene de la estructura de las páginas HTML y sus etiquetas como por ejemplo $<$ title $></$ title $>$ que permite obtener el título de una página Web. El uso de las etiquetas HTML es opcional, lo que ocasionó que no solamente se confié en esa fuente de datos, sino que se busque esa información a través de otros mecanismos tales como las etiquetas de: The Open Graph protocol(prefijo: og: $)_{1}^{1}$ y Twitter Cards(prefijo: twitter: ${ }^{2}$. Debido a que su uso es masivo y muchas veces generado automáticamente por ciertas herramientas (por ejemplo gestores de contenidos) y que buscan que las páginas Web se vean de la mejor forma cuando se publican en redes sociales.

La información que se busca es la siguiente:

- Título: El título de una página Web da una idea general de lo que se encontrará. Se puede encontrar tanto como etiqueta $\operatorname{HTML}($ title) o en open graph y twitter card como meta etiqueta con los nombres: og:title y twitter:title respectivamente.

- Descripción: La descripción es otro elemento que puede ayudar a aportar información relevante del página Web. Se puede extraer a través de las meta etiquetas con nombre: descripción, og:description y twitter:description.

\footnotetext{
1 http://ogp.me

2 https://dev.twitter.com/cards/overview
} 


\section{PROPUESTA DEL MODELO DE ENRIQUECIMIENTO PARA INICIATIVAS BASADAS EN OERS}

- Keywords: Finalmente se obtienen las palabras clave utilizando la meta etiqueta con nombre keywords.

- Licencia: Posiblemente la tarea más compleja ya que no existe estándar (etiqueta) que nos permita encontrar fácilmente la licencia. Sin embargo se utiliza la propiedad rel="license" al estilo de uso de Creative Commons 1

La información que se recolecta se usará para determinar un valor que represente la relación entre la descripción del ítem y los conceptos importantes que se describirán más adelante. Con ese objetivo es necesario que el contenido tanto en el título, la descripción y los keywords sean tokens. La tokenización es un proceso que está fuera del alcance de esta tesis, y que requiere de varios elementos como la detección de idioma y la eliminación de stop words. En las implementaciones siguiendo el modelo, este proceso fue realizado automáticamente utilizando código de acceso libre y en caso de no poder detectar el idioma se utilizó por defecto Inglés.

\subsubsection{Legal}

Una de las características de un OER es el uso de licencias abiertas que permitan el re-uso de los recursos.

Dentro de este tema el modelo propone dos niveles de acceso, considerando si el recurso (metadata y/o contenido) señalan o no el tipo de licencia. Los niveles se describen a continuación:

1. Acceso, cuando no se ha podido determinar que el recurso use una licencia Creative Commons. A pesar de ello se garantiza el acceso al recurso a través de un navegador Web. Este tipo de material se denomina Recurso digital.

2. Apertura, cuando el recurso cuenta con una licencia Creative Commons (@). A este tipo de recursos se los denomina OER.

Técnicamente esta sección realiza la validación que el recurso esté accesible a través de un navegador Web. Mientras que para encontrar la licencia utiliza el Creative Commons Rights Expression Language (ccREL) que es el estándar recomendado por Creative Commons (CC) Abelson et al. (2008).

${ }^{1}$ https://creativecommons.org/choose/ 


\subsubsection{Contenidos compartidos en la red - Contexto}

Parte del modelo de enriquecimiento es utilizar el contenido que ha sido publicado dentro de una red social, ya que el valor que adquiere al ser expuesto ante un conglomerado humano otorga a esa información una relevancia superior a aquella información que no lo es.

La propuesta que aquí se desarrolla, denomina contexto a la información relacionada a un tópico y que se obtiene desde una red (Folksonomía).

Generalmente esa información se encuentra como: texto, palabras clave, etiquetas o hastags(Twitter) con la diferencia que son creados y utilizados por un grupo personas, de forma colaborativa y es ahí en donde radica su importancia, no es producto de una persona sino de un grupo de personas.

Al igual que con la información de los usuarios, el contexto se obtiene a través de la aplicación de medidas del análisis de redes sociales, sobre una red que está construida sobre los conceptos que están dentro de un grupo de datos. Las relaciones son de coocurrencia, es decir cuando un ítem es descrito con varios conceptos y se enriquece cuando varios usuarios describen con diferentes conceptos el mismo ítem.

En la Ecuación 4.3 se define lo que es una folksonomía y se ve claramente que está formado por tres, que a través de proyecciones se puede llegar a construir una red formada únicamente por conceptos. Según el número de datos la información del contexto puede crecer, lo que haría complicado trabajar con todos los conceptos, es por ello que se propone utilizar medidas de centralidad para encontrar conceptos que por su posición dentro de la red se podrían considerar generales.

$$
f(G)=C=\left\{c_{1}, c_{2}, c_{3}, \ldots, c_{n}\right\}
$$

de donde.

- G es una red de conceptos.

- $f$ es una función que a través de una medida del análisis de redes sociales, ayuda a encontrar conceptos.

- $C$ es un conjunto de conceptos, en el que se cumple que $C \subseteq N$.

- $|C|=n \leq|N|$ es el número de conceptos. 


\section{PROPUESTA DEL MODELO DE ENRIQUECIMIENTO PARA INICIATIVAS BASADAS EN OERS}

El conjunto de conceptos que se obtiene a través de la ecuación 4.8 será utilizada para la valoración (ranking) de cada uno de los ítems.

\subsubsection{Valoración}

La lista de usuarios destacadas y filtrada según la producción de los mismos en el tiempo $U D_{B}$ se utiliza para obtener los ítems que han sido producidos por los usuarios destacados. Estos ítems serán los recursos a recomendar, previo a una valoración que se describe a continuación.

La valoración de los ítems que fueron producidos por los usuarios destacados $\left(U D_{B}\right)$, se realiza calculando la proximidad de cada uno de los ítems con los conceptos que son parte de la folksonomía. Para ello se toma los tokens producto del proceso de enriquecimiento y se compara con cada uno de los elementos del conjunto de conceptos $(C)$, en caso de no coincidir con ninguno de los conceptos se busca la distancia del token al concepto utilizando para ello la red de conceptos.

Para realizar la valoración es necesario considerar dos casos:

a) token $\in C$

$$
V_{t}=c_{i}
$$

b) token $\notin C$

$$
V_{t}=\frac{1}{\min \left(\operatorname{dist}\left(t_{i}, C\right)\right)+1}
$$

de donde,

- $V_{t}$ es la valoración para el token $i$ de uno de los ítems.

- $c_{i}$ es el valor que la medida de centralidad asigna al token $i$.

- $t_{i}$ es el token $i$ asociado al ítem.

- $C$ ya se definió en 4.8 .

- dist genera un conjunto de distancias entre el token $i$ y los conceptos del conjunto $C$

- min es una función que devuelve la distancia más corta. 
Finalmente se obtiene la valoración (ranking) así:

$$
V_{\text {Item }}=\sum_{i=1}^{l} V_{i} * \delta
$$

de donde,

- $V_{\text {Item }}$ es la valoración de un ítem.

- $V_{i}$ es el valor que cada token aporta según 4.9 o 4.10 .

- $\delta$ es un factor para valorar de donde provienen los datos.

Es decir, proponemos que para la valoración de los ítems se utilice cada uno de los tokens y su relación con los conceptos, considerando que puede existir tanto una coincidencia exacta, como una relación de proximidad. El factor $\delta$ se utiliza para beneficiar la procedencia de los tokens. Así

- Si el token proviene de la interacción social (hashtags) $\delta=1,2$.

- Caso contrario (proviene del título, descripción o keywords) $\delta=1$

Como se puede ver la función de delta es ayudar a potenciar los contenidos que han sido producidos o difundidos socialmente.

Esta fase de recomendación debe cumplir con ciertas condiciones, con el fin de que las entradas que recibe se puedan transformar en las salidas que genera, esa información se presenta en la Tabla 4.7

\subsection{Generalización del modelo de enriquecimiento}

Son muchas las redes sociales en línea que actualmente existen y es posible que ahora mismo se estén desarrollando nuevas. Lo mismo sucede con las métricas de centralidad que utiliza el análisis de redes sociales para encontrar grupos de usuarios influyentes. $\mathrm{Al}$ igual que los dos temas anteriores las iniciativas educativas basadas en OERs son diversas. Es por ello que este apartado se describen algunos elementos/características que permiten que el modelo adopte una enfoque general y se libere de ataduras buscando que el mismo pueda ser aplicado diferentes iniciativas educativas basadas en OERs y a diferentes redes sociales en línea, inclusive se podría pensar en traspasar la barrera de 


\section{PROPUESTA DEL MODELO DE ENRIQUECIMIENTO PARA INICIATIVAS BASADAS EN OERS}

Tabla 4.7: Método de recomendación - Condiciones que debe cumplir el entorno para que dadas las entradas se generen las salidas

\begin{tabular}{|c|c|c|}
\hline $\begin{array}{l}\text { Condiciones del en- } \\
\text { torno }\end{array}$ & Entradas & Salidas \\
\hline $\begin{array}{l}\text { - Acceso al repositorio } \\
\text { de datos. }\end{array}$ & $\begin{array}{l}\text { - Redes de actores. } \\
\text { - Redes de conceptos. } \\
\text { - Ítems a recomendar. }\end{array}$ & $\begin{array}{l}\text { - Recursos educativos } \\
\text { abiertos ordenados, } \\
\text { aquellos recursos con } \\
\text { licencias abiertas. } \\
\text { - Recursos ordenados } \\
\text { que por su licen- } \\
\text { cia no pueden ser } \\
\text { considerados como } \\
\text { abiertos. } \\
\text { - Un listado de usua- } \\
\text { rios que pueden ser } \\
\text { considerados como } \\
\text { expertos. } \\
\text { - Temas relaciona- } \\
\text { dos que describen } \\
\text { a la iniciativa que } \\
\text { se enriquece y que } \\
\text { permiten tener un } \\
\text { conocimiento amplio } \\
\text { del tema. } \\
\text { - Roles de usuarios y } \\
\text { agrupados por los ro- } \\
\text { les que desempeña ca- } \\
\text { da usuario. }\end{array}$ \\
\hline
\end{tabular}


la red social y utilizar el modelo propuesto en otro tipo de fuente de datos en donde existan manifestaciones de trabajo colaborativo por ejemplo, aunque este tema queda para trabajos futuros.

Los elementos de generalización están relacionados con los usuarios, su influencia, el contexto de la información, los atributos de los participantes, la procedencia de los datos y la apertura de los recursos.

\subsubsection{Interacción social}

Dentro del modelo prima la interacción entre usuarios, independiente de la fuente de datos, con el objetivo de buscar explotar la inteligencia colectiva que surge en la interacción de seres humanos.

El modelo de enriquecimiento propone que uno de los componentes principales para realizar las tareas de análisis/visualización y recomendación es el estudio, a través de SNA, de cualquier tipo de interacción realizada por seres humanos independiente de la fuente de datos.

Esto permite que el modelo traspasar la barrera de las redes sociales en línea, permitiendo que se aplique en diferentes fuentes de datos en donde existan cualquier tipo de interacción entre seres humanos, por ejemplo: bases de datos científicas a través de la relación de co-autoría, base datos de proyectos a través de la co-participación, etc.

\subsubsection{Influencia de los usuarios}

El concepto de influencia dentro de una red es aún un tema de desarrollo y en una opinión personal lo seguirá siendo, es por ello que existen un sinnúmero de métricas de SNA que pretenden encontrar a un grupo de nodos influyentes, bajo diferentes criterios e ideas y algoritmos sencillos o complicados. Es necesario considerar que muchas de métricas propuestas se encuentran estrechamente correlacionadas pudiendo presentar el mismo grupo de nodos como los más influyentes.

Es por ello que el modelo no realiza recomendaciones sobre el uso de exclusivo de una única medida de centralidad. Si bien en los casos en los que se aplicó el modelo (ver sección 5), se usó mayoritariamente intermediación (Betweenness), el criterio siempre ha sido la naturaleza de los datos y el aporte que esta medida puede realizar a los trabajos propuestos. 


\section{PROPUESTA DEL MODELO DE ENRIQUECIMIENTO PARA INICIATIVAS BASADAS EN OERS}

Por lo tanto el modelo de enriquecimiento, ha sido diseñado de forma modular para que permita la apertura a el cambio de la función (métrica, algoritmo, etc.) que permite encontrar usuarios que pasan a denominarse destacados, dejando de lado el término influyentes. Esta generalización permite flexibilidad y también agrega características de personalización a las diferentes iniciativas.

\subsubsection{Contexto}

El término folksonomía, el cual tiene su máxima expresión en las redes sociales en línea, esto segue atando a un tipo de fuente de datos producido por las herramientas Web 2.0.

Para romper esta atadura, el modelo de enriquecimiento utiliza el término contexto para referirse a la información que se produce por seres humanos y que es parte de la fuente de datos que se analiza.

El contexto puede obtenerse desde diferentes fuentes y a través de diferentes mecanismos, la única sugerencia es que este tipo de información cuente con la autoría de un ser humano, ya que al igual que los usuarios destacados, se busca explotar las manifestaciones de las expresiones humanas que se pueden considerar como parte de la inteligencia colectiva.

El análisis del contexto es otro de los pilares fundamentales del modelo de enriquecimiento y que complementa al análisis de la interacción social. Es decir el modelo propone como mínimo dos tipos de análisis basados en SNA: usuarios y contexto con el fin de garantizar un aporte significativo de la propuesta.

\subsubsection{Atributos de los nodos}

Los nodos de los dos tipos de redes (usuarios y contexto) que serán analizados vía el análisis de redes sociales podrían tener muchos atributos de diferente índole, según el grupo de datos sobre el cual se este trabajando.

Muchos de esos atributos son particulares y suscritos al contexto de la fuente de datos y se pueden utilizar dentro del SNA, su función se reduce a filtros de información que permite ver los nodos que cumplen ciertas características.

Considerando esta variabilidad en el número y tipo de atributos que los nodos pueden tener, es necesario encontrar un atributo que sea lo suficientemente común para 
considerarse universal e independiente de la naturaleza de los datos y que aporte al análisis de los datos, no sólo filtre.

Si consideramos que las redes son dinámicas y evolucionan en el tiempo, se propone que el tiempo sea uno de los atributos a considerar que permita clasificar a los usuarios en roles. En concreto dentro del modelo de enriquecimiento se propone que ese atributo sea la producción en el tiempo de los usuarios el atributo que ayude en el análisis y que clasifique a los usuarios.

\subsubsection{Procedencia de los datos}

Desde donde provienen los datos es otro de los factores que podrían aportar información al modelo propuesto, es por ello que se plantea como un requisito que el modelo debe asumir.

Considerando que una de las características principales del modelo es explotar la inteligencia colectiva, se propone que la procedencia de los datos sea otra de sus manifestaciones, para ello se propone que la información que ha sido expuesta ante un colectivo tenga una mayor valoración que aquella que no lo fue.

La información es creada por personas es decir es fruto de un esfuerzo individual o de un grupo reducido de personas, lo que sin lugar a dudas es una fuente valiosa de información a tomarse en cuenta, sin embargo cuando esa información es expuesta a otras personas, su valía se incrementa ya que el colectivo puede generar mayor información, como por ejemplo la adopción de lo expuesto.

\subsubsection{Apertura de los recursos}

Muchos de los recursos disponibles en la Web, hoy por hoy no cuentan con un correcto manejo de una política de licenciamiento siendo un tema aún pendiente de resolverse o si existen políticas implementadas no son correctamente gestionas, por ejemplo la licencia estándar de que Youtube asigna como un valor predeterminado.

Un escenario común es encontrar en la Web con un sitio o algún contenido multimedia cuyo contenido sea valioso y no cuente con una licencia abierta o simplemente no se haga mención alguna a ese tema. Sin embargo el material que no puede considerarse abierto por la falta de licencias, aún puede utilizarse como recurso de aprendizaje.

Es por ello que dentro del modelo de enriquecimiento propuesto, es necesario que existan dos tipos de material. El primero sera el material que cuente con licencias 


\section{PROPUESTA DEL MODELO DE ENRIQUECIMIENTO PARA INICIATIVAS BASADAS EN OERS}

abiertas, es decir un OER, mientras que el segundo, aquellos recursos que no posean licencia y que serán considerados como recursos digitales.

Estas generalizaciones permitirían al modelo aplicarse a diferentes iniciativas educativas, así como también utilizar datos de diferentes redes sociales en línea como fuente para realizar recomendaciones. Inclusive se podría utilizar el modelo con otras fuentes de datos diferentes a las redes sociales en línea. Este tema está fuera del contexto de esta tesis y se plantea como un trabajo futuro. 


\section{5}

\section{Validación de las hipótesis propuestas}

\subsection{Introducción}

El camino recorrido, hasta llegar a la definición del modelo de enriquecimiento descrito en el Capítulo 4, ha tenido varias etapas. Cada una de esas etapas han contribuido con diferentes aportes que se han convertido en características y que se reflejan en los componentes y módulos del modelo de enriquecimiento, quedando pendiente la validación del modelo de enriquecimiento a través de la validación de las hipótesis que se plantean en la sección 3.6. Es por ello que en este capítulo se validarán las hipótesis propuestas. El mecanismo para la validación de las hipótesis se basa en la aplicación del modelo de enriquecimiento en diferentes casos reales.

Es por ello que el objetivo principal de este capítulo es validar cada una de las hipótesis que se propusieron en la sección 3.6. El modelo de enriquecimiento propuesto plantea una solución para enriquecer iniciativas educativas basadas en el uso de OERs, aprovechando la información que está disponible en las redes sociales en línea. Con este fin utiliza los conceptos del análisis de redes sociales y la ciencia de las redes como herramientas principales. La visión de la ciencia de las redes es utilizar las relaciones entre entidades como eje fundamental para su análisis, permitiendo destacar las propiedades que se adquieren, por las relaciones/interacciones, entre participantes, y la ubicación que estos adquieren dentro de la red.

Por lo anteriormente expuesto es posible decir que los casos que se presentan a 


\section{VALIDACIÓN DE LAS HIPÓTESIS PROPUESTAS}

continuación apuntan a tres grandes retos: el primero es utilizar el SNA como una herramienta de análisis de la información producida por diferentes iniciativas educativas, este reto está en relación directa con la hipótesis H2; el segundo reto es extraer y recomendar recursos relevantes (socialmente valorados), el reto se relaciona con las hipótesis H3 y $\mathbf{H} 4$ y como consecuencia del reto anterior, el tercero reto es enriquecer una iniciativa educativa y sus componentes, este reto está en relación directa con la hipótesis H1 . Por tal motivo la estructura que se emplea para describir cada una de los casos es común y ha sido diseñada para dar una visión general del caso, haciendo énfasis en el problema que se presentó y cómo las soluciones implementadas aportaron a la validación de las hipótesis propuestas (ver Sección 3.6).

Los casos a desarrollar, en las próximas secciones, así como su relación con cada una de las tesis se sintetizan en la Tabla 5.1. Esta tabla se complementa en las siguientes líneas en donde se muestra una breve descripción del propósito de cada uno de los casos.

Tabla 5.1: La relación de las hipótesis y los casos que se emplearon para validar cada uno de ellas.

\begin{tabular}{|c|c|}
\hline Hipótesis & Caso \\
\hline $\begin{array}{l}\text { H1: Un modelo de enriquecimiento que utilice la información } \\
\text { publicada en una red social, además de su estructura, con el } \\
\text { propósito de encontrar recursos, personas, temas relacionados } \\
\text { y roles, apoya a la consecución de los objetivos de las } \\
\text { iniciativas educativas que lo implementen. }\end{array}$ & $\begin{array}{l}\text { Caso } 4 \\
\text { Caso } 5\end{array}$ \\
\hline $\begin{array}{l}\text { H2: El Análisis de redes sociales o la ciencia de las redes es } \\
\text { una herramienta de análisis que permite describir, desde el } \\
\text { punto de vista de las relaciones, a diversas iniciativas } \\
\text { educativas permitiendo obtener descripciones diagnósticas, } \\
\text { realizar prospectiva y apoyar a la toma de decisiones. }\end{array}$ & $\begin{array}{l}\text { Caso } 1 \\
\text { Caso } 2 \\
\text { Caso } 3\end{array}$ \\
\hline $\begin{array}{l}\text { H3: Las relaciones entre usuarios, su comportamiento a } \\
\text { través del tiempo complementadas con el contenido que } \\
\text { se difunde en una red social, analizados a través de un } \\
\text { enfoque de análisis de redes sociales permite desarrollar } \\
\text { un modelo de recomendación confiable. }\end{array}$ & $\begin{array}{l}\text { Caso } 4 \\
\text { Caso } 5\end{array}$ \\
\hline
\end{tabular}


Tabla 5.1 - continuación de la página anterior

\begin{tabular}{|l|l|}
\hline \multicolumn{1}{|c|}{ Hipótesis } & Caso \\
\hline H4: Priorizar la información que ha sido expuesta dentro & \\
de una red social sobre aquella que no lo fue, permite & Caso 4 \\
construir un sistema de ranking para recursos difundidos & Caso 5 \\
en una red social. & \\
\hline \hline
\end{tabular}

Complementando la Tabla 5.1 a continuación se muestra una descripción breve de cada uno de los casos.

- Caso 1: Meta-análisis del Proyecto TAEE aplicando análisis de redes sociales (Sección 5.2). El caso muestra cómo a través del SNA se dio respuesta a 4 preguntas formuladas por los organizadores de un congreso. Las preguntas se encuentran relacionadas con los trabajos que ahí se exponen. Este problema se solucionó, en rasgos generales, con la creación de redes, su análisis (a través de diversas métricas) y su visualización. Con el desarrollo de este caso se pretende validar la hipótesis H2 (SNA como una herramienta de análisis). Con ese objetivo se diseñó de un modelo de análisis, basado en redes y las medidas del SNA, que es capaz de responder a las preguntas propuestas por los organizadores del evento.

- Caso 2: El impacto de los Recursos Educativos Abiertos en la Educación superior en España y Latinoamérica a través del Análisis de Redes Sociales (Sección 5.3). El caso se centra en utilizar el SNA para medir el impacto de los OERs en España y Latinoamérica. Es decir una herramienta para realizar analítica del aprendizaje. El problema que se propone en el caso tuvo solución a través de la construcción de redes, el análisis de las mismas y el uso de métricas para encontrar actores destacados (que causan o causaron algún impacto en la red). Al igual que en el caso anterior, con el desarrollo de este caso se busca validar la hipótesis (H2) que propone el uso de SNA como herramienta de análisis y visualización de datos. El mecanismo de validación de la hipótesis consiste en crear un modelo que se base en redes y las métricas propuestas por SNA para describir la situación actual de las iniciativas OCW, medir el impacto de los OCW y determinar el potencial de colaboración que existe. 


\section{VALIDACIÓN DE LAS HIPÓTESIS PROPUESTAS}

- Caso 3: Estudio de MOOCKnowledge (Sección 5.4). El caso se centra en analizar la información que proviene de encuestas aplicadas a estudiantes que cursaron un MOOC. Al igual que en los casos anteriores el problema se resolvió a través del uso de los componentes del modelo de enriquecimiento que permiten crear redes, analizarlas y visualizarlas. La solución busca validar que la hipótesis H2 se cumple. Para ello, se utilizará un mecanismo de validación en el que a través de la construcción de una red sea posible identificar clusters y sus posibles conexiones.

- Caso 4: Recomendación de OERs compartidos en redes sociales utilizando como base el análisis de redes sociales (Sección 5.5). El caso se centra en buscar y recomendar OERs publicados en una red social en línea. Para resolver este problema fue necesario usar los componentes y módulos del modelo de enriquecimiento que permiten contar con un mecanismo para la construcción de tópicos, recolección de datos y realizar recomendaciones. La solución a el problema pretender validar las hipótesis $\mathbf{H 1}$ que se relaciona con el uso de la información de una red social y su estructura para ayudar a cumplir los objetivos de una iniciativa educativa y $\mathbf{H 3}$ que propone que el análisis de varios tipos de redes para crear un modelo de recomendación fiable. La validación, de las hipótesis, se hará recuperando recursos publicados en la red social, a través de un modelo de recomendación y un algoritmo de valoración que se basan en redes y métricas del SNA. Una vez recuperados se compararon con los recursos más populares difundidos en la red y se puede ver la diferencia entre ambas aproximaciones.

- Caso 5: Recomendación de OERs para Emprendimiento utilizando un marco de trabajo basado en Análisis de Redes Sociales (5.6). El caso se centra en buscar OERs publicados en una red social e integrarlos a una plataforma de formación de emprendedores. Para resolver el problema se utilizó todo el modelo de enriquecimiento, algunos componentes en mayor medida, tales como captura de datos y recomendación, dejando otros como complementarios tales como el análisis y visualización de datos. La solución propuesta pretende validar las hipótesis H1 ya que pretende demostrar que el uso de un modelo de enriquecimiento ayuda a una iniciativa concreta a cumplir con los objetivos propuestos, H3 que propone que el análisis de varios tipos de redes para crear un modelo de recomendación fiable y 
H4 que promueve el uso preferencial de la información expuesta en una red social sobre aquella que no. La validación se basará en recuperar recursos publicados en la red social, a través de un modelo de recomendación y un algoritmo de valoración que se basan en redes y métricas del SNA. Una vez recuperados los recursos se utilizaron como parte de una plataforma para que forma emprendedores.

La estructura que se utilizó para describir cada uno de los casos es la siguiente:

- En una primera sección se describe brevemente el caso, mencionando el paper en donde se puede encontrar los detalles.

- La siguiente sección muestra cada uno de los componentes del modelo de enriquecimiento que fueron utilizados en el desarrollo del caso.

- Finalmente se describe cómo a través del caso y los resultados se llegan a validar las hipótesis con las que se relacionan. Aquí se hace una descripción de la construcción de la solución las redes construidas y los análisis realizados.

Cada caso está acompañado de una figura que muestra el uso de los módulos y sus componentes. Por cada uno de los componentes se ha definido una escala de colores que señala el uso aproximado de cada uno de módulos. La escala es la siguiente: si el módulo se utiliza menos de un $50 \%$ el color será rojo. Mientras que si se usa un porcentaje igual o superior al $50 \%$ el color será verde. Esta escala es aproximada y subjetiva, ya que señala la importancia de cada componente para el caso en desarrollo.

\subsection{Caso 1: Meta-análisis del proyecto TAEE aplicando análisis de redes sociales}

Uno de los componentes del proyecto de Tecnologías Aplicadas a la Enseñanza de la Electrónica (TAEE) ${ }^{1}$ son unas conferencias bianuales que iniciaron en 1994 y que por varios años han generado datos que hasta ese entonces (2010) no habían sido analizados. Dentro de TAEE participan principalmente instituciones educativas y empresas de Europa, Norte, Centro y Sur América

Los organizadores hicieron énfasis en su interés sobre el análisis de las relaciones que han surgido entre diferentes elementos, tales como: organizaciones, temáticas tratadas y

${ }^{1}$ http://taee.euitt.upm.es 


\section{VALIDACIÓN DE LAS HIPÓTESIS PROPUESTAS}

su evolución en el tiempo, así como también el crecimiento de las ontologías de clasificación para trabajos que habían sido creada en las primeras ediciones y que cambiaba con el transcurso de cada edición. El objetivo final era contar con información que ayude a la toma de decisiones y que sirva de modelo para otras iniciativas similares. El detalle del trabajo lo pueden encontrar en López Vargas et al. (2010)

\subsubsection{Componentes y módulos utilizados en el caso}

Las características del problema determinan los componentes del modelo de enriquecimiento que fueron utilizados. En este caso la característica más relevante del problema fue utilizar la información que provienen de las relaciones que surgen en actividades colaborativas como la creación de papers, la descripción de los mismos, a través de palabras clave y la clasificación de trabajos a través de unas categorías ontológicas. Es por ello que los componentes y módulos que se utilizaron se pueden ver en la Figura 5.1. Mientras que en la Tabla 5.2 se puede ver un resumen de los componentes y módulos utilizados.

La solución del problema que se describe en este caso, demostró que el análisis de redes sociales se puede utilizar como una herramienta de análisis de iniciativas educativas ya que permite realizar descripciones diagnósticas, prospectiva y apoyar a la toma de decisiones, por lo tanto los resultados del problema ayudan a validar la hipótesis H2, los detalles se encuentra descritos en la sección 5.2.2.

\subsubsection{Validación de hipótesis de investigación}

En esta sección se muestra los acciones ejecutadas buscando dar una solución al problema propuesto por el caso. Así como también se llega a validar las hipótesis con las que se relaciona el caso.

\subsubsection{Construcción de la solución}

El propósito del trabajo fue dar respuesta a un grupo de preguntas formuladas por los organizadores de TAEE. Las preguntas fueran las siguientes:

- Pregunta 1: ¿Cuáles son las relaciones y el nivel de cohesión de los diferentes organismos (a nivel de España y entre continentes) que participan en TAEE? 


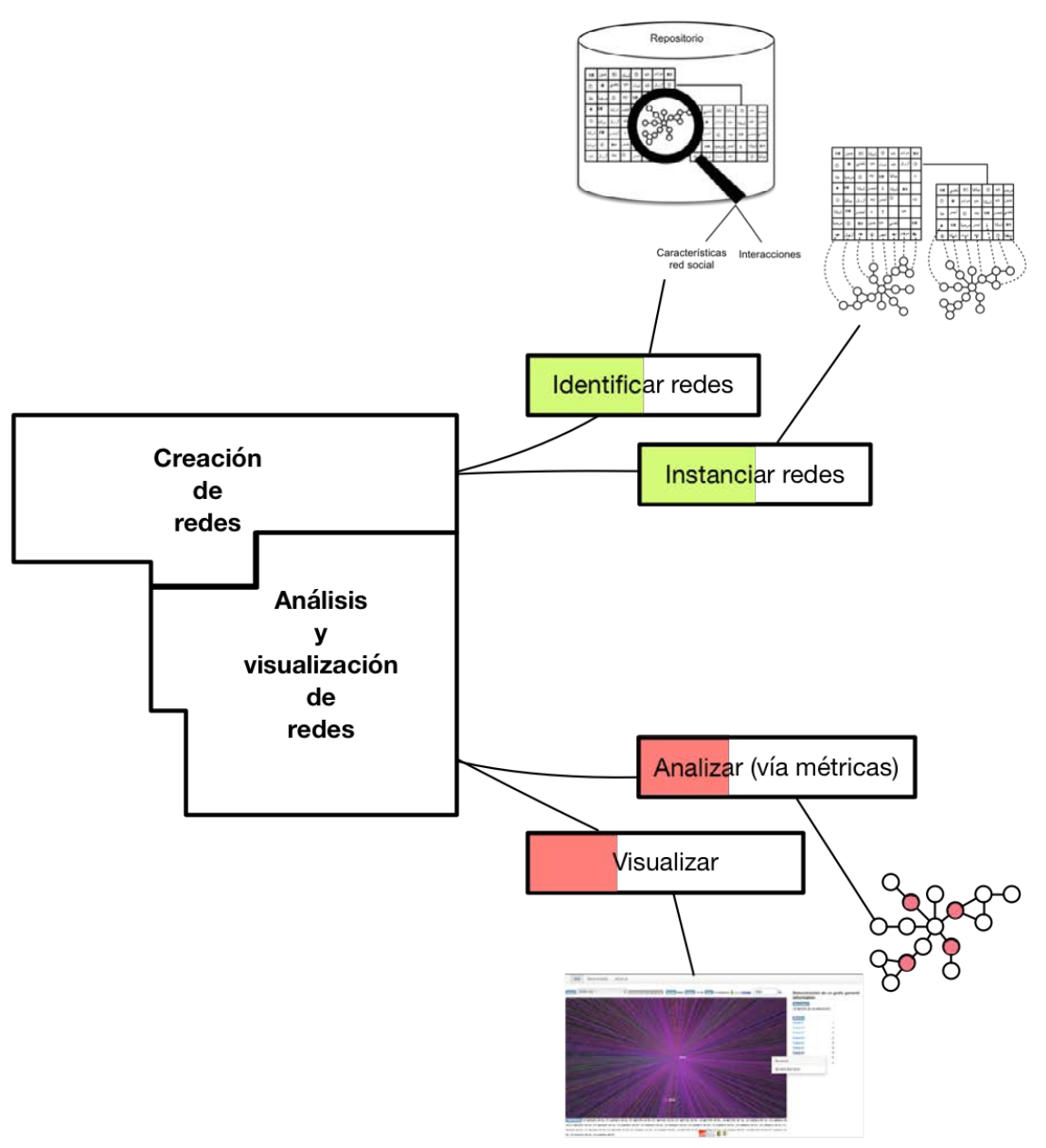

Figura 5.1: Componentes y módulos del modelo de enriquecimiento que se utilizaron en este caso - El caso empleó dos componentes del modelo y por cada componente dos módulos. El color en cada módulo señala el porcentaje que se empleó en el caso con respecto a lo que propone el modelo de enriquecimiento. El rojo señala que este componente no tan importante como lo son los componentes marcados en verde. 


\section{VALIDACIÓN DE LAS HIPÓTESIS PROPUESTAS}

Tabla 5.2: Componentes y módulos utilizados. En este caso se aplicó el modelo de enriquecimiento, principalmente como una herramienta de análisis y visualización de datos. Es por ello que con este caso se busca validar la hipótesis H2.

\begin{tabular}{|c|c|}
\hline Usado & Componentes del modelo de enriquecimiento \\
\hline \multicolumn{2}{|r|}{ Creación de redes } \\
\hline \multicolumn{2}{|c|}{ Identificar redes } \\
\hline$\checkmark$ & $\begin{array}{l}\text { Redes explícitas. Se construyeron las siguientes redes: } \\
\text { - Co-autoría de trabajos. }\end{array}$ \\
\hline$\checkmark$ & $\begin{array}{l}\text { Redes implícitas. Se construyeron las siguientes redes: } \\
\text { - Organismos. } \\
\text { - Temas y subtemas. } \\
\text { - Temas y palabras claves. }\end{array}$ \\
\hline \multicolumn{2}{|c|}{ Instanciar redes } \\
\hline$\checkmark$ & $\begin{array}{l}\text { Se utilizó: } \\
\text { - Base de datos relacional para almacenar los datos. } \\
\left.\text { - Programación para construir archivos (.ne }{ }^{1}\right) \\
\left.\text { - Software SNA (Pajek }{ }^{2}\right)\end{array}$ \\
\hline \multicolumn{2}{|r|}{ Análisis y visualización de redes } \\
\hline \multicolumn{2}{|c|}{ Analizar redes } \\
\hline$\checkmark$ & $\begin{array}{l}\text { Analizar a través de métricas de SNA. Métricas utilizadas: } \\
\text { - Densidad (Density). } \\
\text { - Grado (Degree). } \\
\text { - Cercanía (Closeness). } \\
\text { - Intermediación (Betweenness). } \\
\text { - Peso de los enlaces (Weight). }\end{array}$ \\
\hline \multicolumn{2}{|c|}{ Visualizar } \\
\hline$\checkmark$ & - Imágenes en documentos estáticos sin opciones de interacción. \\
\hline \multicolumn{2}{|c|}{$\begin{array}{l}\text { Hipótesis a validar } \\
\text { (Con la ejecución de los componentes y módulos anteriores se pretende } \\
\text { validar la siguiente hipótesis) }\end{array}$} \\
\hline H2 & $\begin{array}{l}\text { El Análisis de redes sociales o la ciencia de las redes es } \\
\text { una herramienta de análisis que permite describir, desde el } \\
\text { punto de vista de las relaciones, a diversas iniciativas } \\
\text { educativas permitiendo obtener descripciones diagnósticas, } \\
\text { realizar prospectiva y apoyar a la toma de decisiones. }\end{array}$ \\
\hline
\end{tabular}


- Pregunta 2:¿Cómo ha evolucionado la temática tratada en el congreso?

- Pregunta 3: ¿Cuáles son las nuevas incorporaciones ontológicas en materia de tecnología a lo largo de estos años?

- Pregunta 4: ¿Cómo ha evolucionado la temática en las investigaciones y estudios relacionado con la docencia de la electrónica?

Para responder a las preguntas planteadas se contó con una base de datos que reúne la información de los congresos de TAEE. La fuente de datos que se utilizó tiene las siguientes características:

- 8 congresos fueron analizados desde 1994, hasta el 2008.

- 150 sesiones

- 963 documentos

- 1348 palabras clave

- 1092 organismos participantes.

- 1674 autores

- 9 familias temáticas

- 4425 objetos de aprendizaje

- 5000 referencias.

- Redes construidas Todas las redes que se construyeron, fueron elaborados con el objetivo de responder a las 4 preguntas formuladas por los organizadores de las conferencias. A continuación se describe cada una de las redes utilizadas por cada una de las preguntas.

Con el objetivo de describir las redes construidas, se presentará: una imagen de la red, la descripción de lo que representan tanto los nodos como los enlaces, una descripción textual de la red que ayudará a entender los detalles que la imagen es incapaz de mostrar y las medidas de SNA que se emplearon con el objeto de encontrar ciertos elementos.

\section{- Pregunta 1}




\section{VALIDACIÓN DE LAS HIPÓTESIS PROPUESTAS}

¿Cuáles son las relaciones y el nivel de cohesión de los diferentes organismos (a nivel de España y entre continentes) que participan en TAEE?

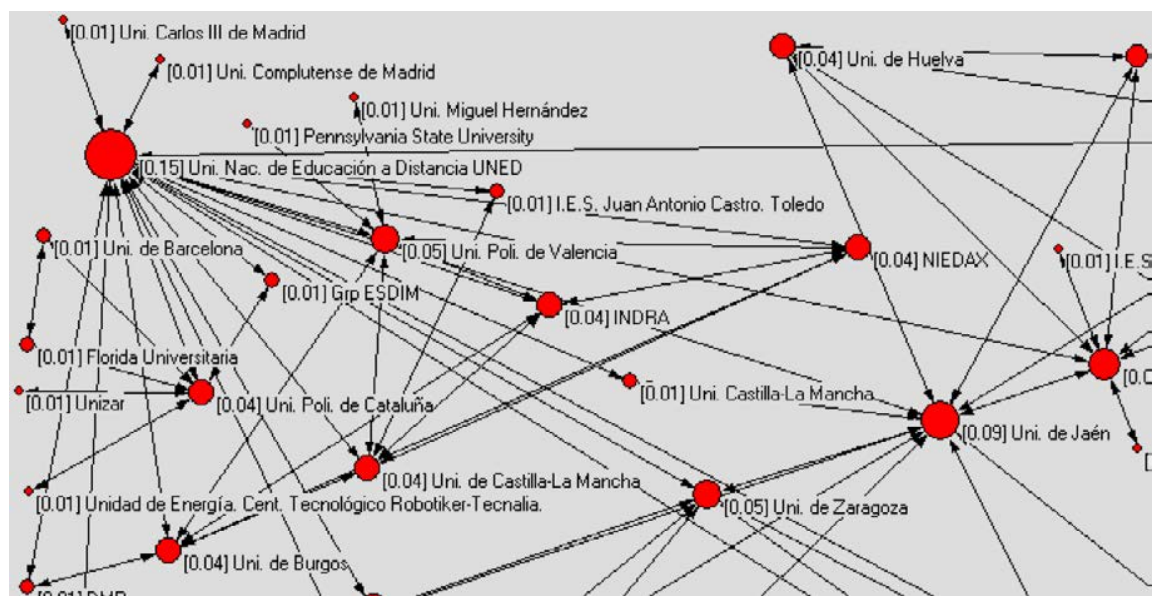

Figura 5.2: Red para la pregunta 1 - Un fragmento de la red que se utilizó para responder a la pregunta propuesta.

Para responder a esta pregunta se construyó una red que tiene por nodos a los organismos participantes en las diferentes ediciones del congreso, los enlaces señalan cooperación entre instituciones. Es necesario señalar que no existe una cooperación directa entre instituciones, ya que las instituciones por sí solas no escriben trabajos, sino que la red resulta de una proyección de la co-autoría de trabajos entre personas que pertenecen a diferentes organizaciones.

Con la red construida se aplicaron 4 medidas propias del SNA, la densidad que permitió medir el nivel de cohesión de todos los organismos y las medidas de centralidad grado, cercanía e intermediación que ayudaron a encontrar organizaciones destacadas que son vitales para el desarrollo del evento.

En la pregunta se pide que se analice la situación de España y otros organismos que pertenecen a diferentes continentes, por lo que los nodos contaban con una propiedad que indica el continente al que pertenece y que se utilizó como filtro para crear varias redes, una por continente.

\section{- Pregunta 2}

¿Cómo ha evolucionado la temática tratada en el congreso? 


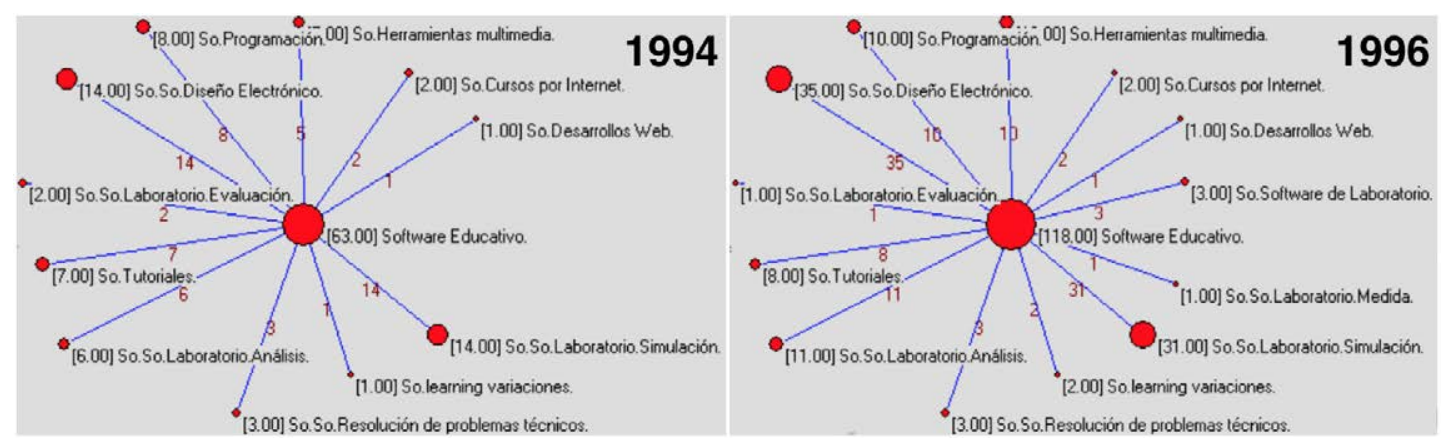

Figura 5.3: Redes para la pregunta 2 - Muestran una temática del congreso en 2 años diferentes

Dentro de TAEE, cada documento presentado en el congreso es clasificado y asignado a una o más temáticas, empleando un esquema temático por los organizadores del congreso, dicho esquema temático cuenta con 9 temas que agrupan a 79 subtemas.

Las redes que se construyeron tenían por nodos a los temas y subtemas, mientras que los enlaces señalan que un subtema pertenece a un tema, el peso de cada enlace señala el número de documentos clasificados en un tema y subtema. Un ejemplo se puede encontrar en la Figura 5.3. Si bien la figura muestra únicamente un tema y su evolución en dos ediciones, una versión completa de la red se puede encontrar en el vídeo: Evolución de la Ontología del Congreso TAEE (1994 - 2008)

Dentro de las redes construidas se emplearon dos medidas de SNA, el grado nodal y el peso de los enlaces. La primera medida ayudó a encontrar el nivel de especialización alcanzado por cada uno de los temas, es decir cuántos subtemas le pertenecen. Mientras que el peso de los enlaces representaron el número de documentos clasificados en un tema y subtema.

En esta pregunta la red jugó un papel de visualización de los datos, ya que los valores de las métricas se pueden obtener a través de conteos simples, sin llegar a construir una estructura como una red. Sin embargo el efecto que la visualización causa justifica ampliamente el haber utilizado la red.

\section{- Pregunta 3}

¿Cuáles son las nuevas incorporaciones ontológicas en materia de tecnología a lo largo de estos años?

\footnotetext{
1 https://www youtube. com/watch?v=55IWngBBXzw
} 


\section{VALIDACIÓN DE LAS HIPÓTESIS PROPUESTAS}

Para responder a esta pregunta se utilizó una red con la misma estructura que la empleada en la Pregunta 2, es decir con temas y subtemas como nodos y enlaces representando la relación jerárquica entre ambos. Las medidas de SNA empleadas fueron las mismas, la diferencia fue que el análisis se centró en 5 temas (Automática, Dispositivos y componentes, Software Educativo, Sistemas y Robótica) por considerarlos estrechamente relacionados con la tecnología.

Adicionalmente, se utilizó medidas estadísticas, tales como la moda y la mediana para analizar la evolución e incorporaciones de conceptos a los temas anteriormente mencionados.

\section{- Pregunta 4}

¿Cómo ha evolucionado la temática en las investigaciones y estudios relacionado con la docencia de la electrónica?

El trabajo realizado para responder a la pregunta planteada fue similar al que se describió en 5.2.2.1. con la diferencia que el análisis se centró en el tema Docencia, ayudando a determinar que el nivel de especialización de la temática es escaso.

\section{- Otros análisis}

Con la información del evento disponible y organizada, fue relativamente sencillo ampliar el estudio a otros temas que no habían sido considerados originalmente por los organizadores, pero que podrían ayudar a encontrar otros patrones interesantes en otros ámbitos que a continuación se describen brevemente.

\section{Temas y palabras clave}

Anteriormente se mencionó que los documentos que se publican en los congresos TAEE están organizados en temas y subtemas, adicionalmente cada documento es descrito a través de un conjunto de palabras claves que son ingresadas por lo autores. Con esa información se propuso describir la relación entre palabras claves y los temas del congreso.

Una parte de la red se puede ver en la Figura 5.4, se trata de una red bipartita con dos tipos de nodos, por un lado los 9 temas generales (representados por rectángulos) y por otro las palabras claves (representadas como círculos) el tamaño de los nodos 


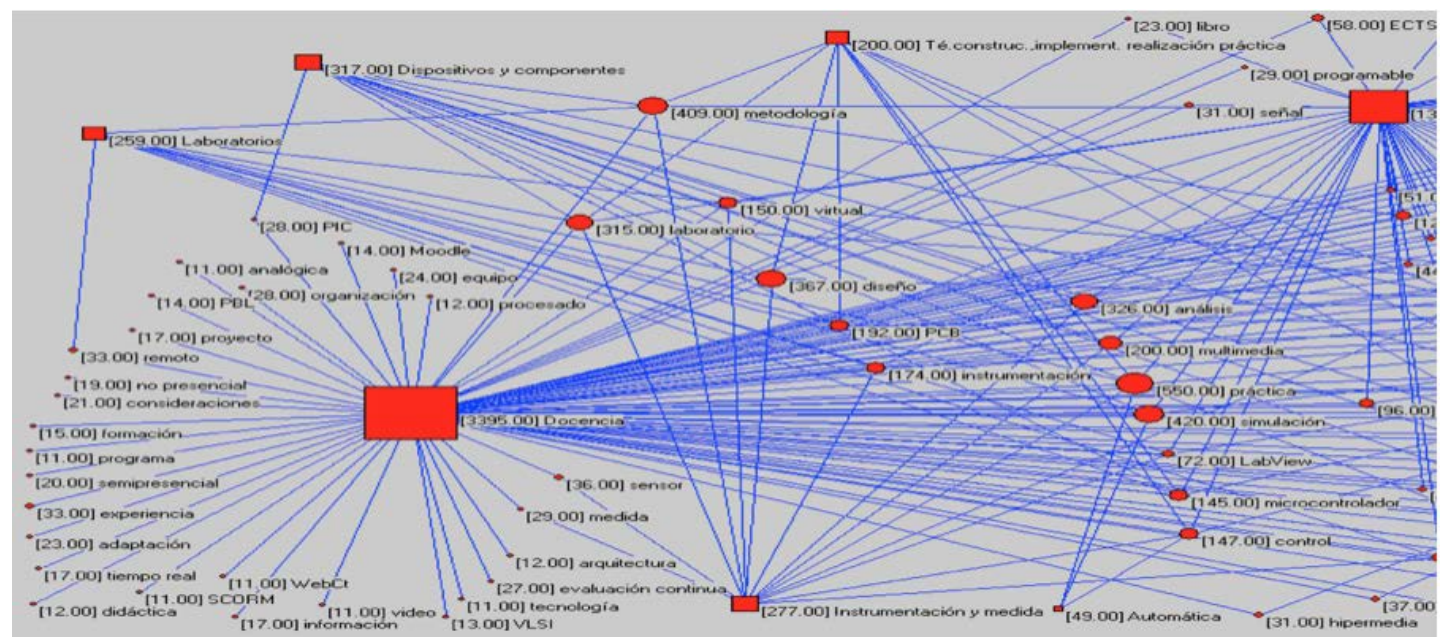

Figura 5.4: Temas y palabras claves - Una red con los temas representados por rectángulos y las palabras claves representados como círculos.

es proporcional al número de documentos que la utilizan, en cambio para los temas (rectángulos) el tamaño representa al número de palabras claves (grado del nodo).

La medida que se utilizó en este caso fue Hubs y Authorities o también conocida como HITS, cuyo resultado es una clasificación de nodos en grupos que se denominan hubs y authorities. El resultado de ejecutar la medida arrojó que los hubs son palabras clave y los authorities son los temas.

Finalmente la red ayudó a encontrar cuáles son la palabras que vinculan a los temas entre si y que posiblemente muestran temas comunes de trabajo entre autores, es decir muestran un potencial de colaboración que posiblemente antes pasó por desapercibido.

\section{Análisis de participantes}

Los autores de los documentos publicados en TAEE también fue otro de los análisis adicionales propuestos. El análisis se hizo con el fin de descubrir los patrones de colaboración de los autores. Con ese objetivo en mente se agrupó a los autores utilizando la medida K-core, que es capaz de encontrar grupos de autores que cuentan con al menos 4 enlaces entre si, como se puede ver en la Figura 5.5 .

\subsubsection{Validación}

Una vez expuesta la solución propuesta para el caso, en este apartado se presenta la validación de una de las hipótesis propuestas en esta tesis. La hipótesis a validar es: 


\section{VALIDACIÓN DE LAS HIPÓTESIS PROPUESTAS}

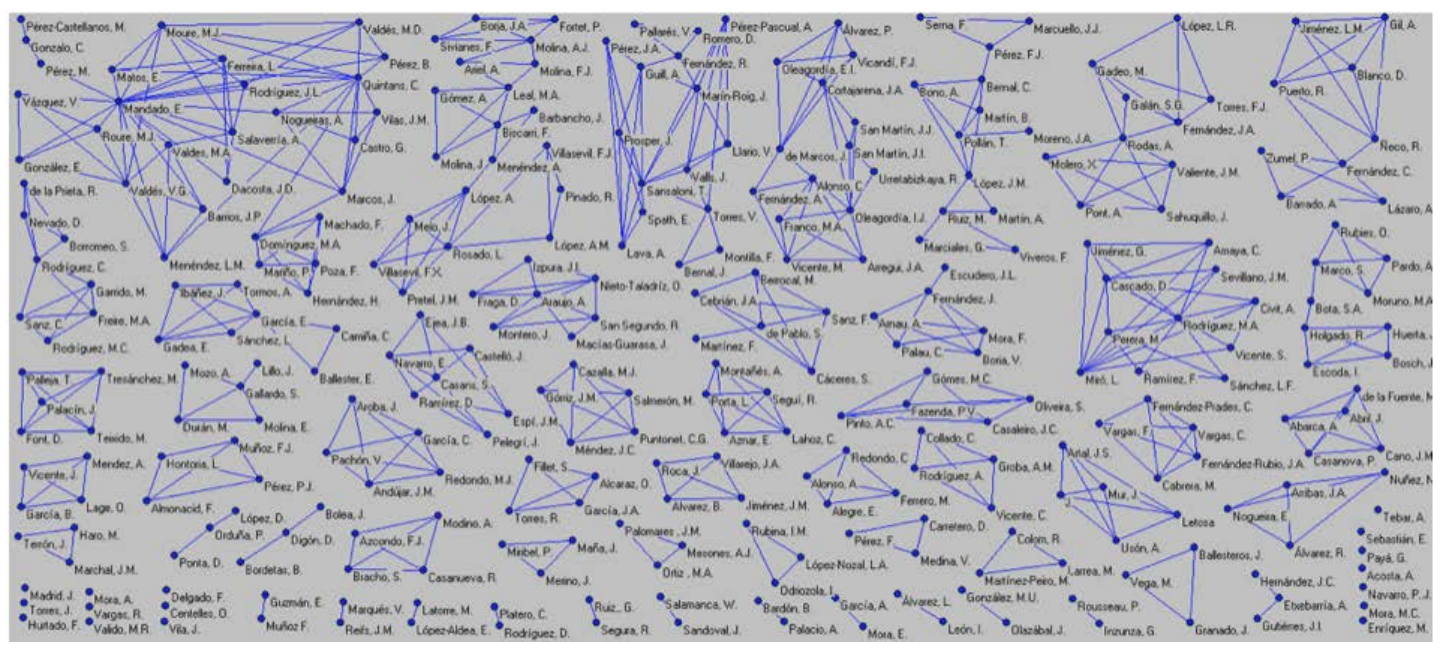

Figura 5.5: Participantes a los congresos - Una red que muestra los grupos (cores) creados a partir de la coautoría de trabajos.

H2: El Análisis de redes sociales o la ciencia de las redes es una herramienta de análisis que permite describir, desde el punto de vista de las relaciones, a diversas iniciativas educativas permitiendo obtener descripciones diagnósticas, realizar prospectiva y apoyar a la toma de decisiones.

El mecanismo que se utilizó para validar esta hipótesis fue dar respuesta a las preguntas propuestas por los organizadores de TAEE las mismas se pueden encontrar en la sección 5.2.2.1. Con este objetivo la solución propuesta utilizó los módulos Creación de redes y Análisis y visualización de redes, los mismos que permiten contar con una herramienta de análisis y visualización de datos basado en las relaciones (interacciones) de los diferentes actores participantes.

En el desarrollo de este caso se utilizaron los componentes: Creación de redes y Análisis y visualización de redes, el detalle de cada uno de ellos y su relación con las preguntas propuestas se muestra a continuación:

Creación de redes este componente se encuentra descrito en la sección 4.4 .2 . Específicamente, se utilizaron los módulos: Identificar redes (descrito en 4.4.2.1. e Instanciar redes (descrito en detalle en la sección 4.4.2.2).

Siguiendo la propuesta del primer módulo, creación de redes, se analizó las interacciones (explícitas e implícitas) y se llegaron a construir las siguientes 
redes:

- Explícitas: Co-autoría de trabajos, es una red no dirigida que tiene por nodos a autores de publicaciones y un enlace señala que dos autores (nodos) han participado en la creación de uno o más documentos. Esta red se utilizó para ampliar la respuesta a la Pregunta 1.

- Implícitas: Redes de organismos, es una red dirigida en donde los nodos son organismos participantes en TAEE y un enlace señala la cooperación entre organismos a través de sus miembros (autores de publicaciones). Esta red se utilizó para dar respuesta a la Pregunta 1. Red de temas y subtemas, es una red dirigida bipartita. En donde los nodos pueden pertenecer a dos tipos temas o subtemas, un enlace muestra que un subtema pertenece a un tema. Se empleó para responder a las Preguntas 2, 3 y 4. Finalmente la red de temas y palabras clave, es una red no dirigida bipartita en donde un nodo puede pertenecer a uno de dos tipos (temas o palabras clave), dentro de esta red un enlace indica que una palabra clave está asociada a un tema a través de los documentos que se describen a través de esa palabra clave y que fueron clasificados en un tema, la red se utilizó para responder a las preguntas 2 y 3 .

El segundo de los módulos, instanciar redes, ayudó a crear instancias con los datos para cada una de las redes identificadas, es decir permitió poblar las redes que posteriormente fueron utilizadas y como plantea el módulo se utilizó un modelo de almacenamiento relacional para almacenar y crear las redes. Las redes fueron creadas bajo demanda a través de consultas SQL, cuyos resultados fueron almacendos en archivos propios para la herramienta empleada (Pajek).

Finalmente el caso utilizó el módulo de análisis y visualización. El detalle se muestra a continuación:

Análisis y visualización de redes los detalles del componente se encuentran descritos en la sección 4.4.3. Dentro de este caso se utilizó el módulo denominado Analizar a través de métricas de SNA y visualizar que es escrito a detalle en 4.4.3.1. Como propone el modelo de enriquecimiento, se aplicaron diferentes medidas propias del SNA para encontrar patrones y comportamientos entre 


\section{VALIDACIÓN DE LAS HIPÓTESIS PROPUESTAS}

los nodos de la red. Esos patrones permitieron dar respuesta a las preguntas planteadas por lo organizadores del evento. Las medidas que se utilizaron fueron:

- Densidad: Para medir el nivel de cohesión de los organismos participantes.

- Centralidad: A través de las métricas de intermediación (betweenness) y cercanía (closeness) que permitieron encontrar nodos destacados por sus conexiones y cuya desvinculación de la organización del evento podría ponerlo en peligro ya que habrían otras organizaciones que se quedarían fuera. Mientras que la medida denominada grado nodal(degree) ayudó a ver el crecimiento o reducción de la ontología de temas del evento, lo que permite tomar acciones para mejorar aquellas que son de interés para el evento. Así como la clasificación de nodos según sus conexiones de entrada o salida a través de la aplicación de la medida denominada HITS.

- Medidas de topología: como K-Core que permitió encontrar los grupos de autores (co-autores) que se han formado durante las ediciones del evento. Y como estos grupos se han relacionado entre si o han permanecido aislados.

- Peso del enlace: El peso del enlace ayudó a analizar la evolución de la ontología, permitiendo conocer el número de publicaciones que han sido clasificados en cada uno de los temas. Esa visión permite a los interesados conocer la situación actual, así como tomar acciones futuras.

Otra de las propuestas del modelo, que se ejecuta a través del módulo análisis y visualización, es utilizar técnicas de visualización de datos para describir los hallazgos hechos. Los hallazgos son fruto de los análisis realizados a través de la construcción de redes y de la aplicación de la medidas. En este caso se utilizó un conjunto de imágenes para describir las respuestas a cada una de las preguntas propuestas. Si bien una imagen en cualquiera de sus formatos no es la mejor forma de describir una red, y menos aún cuando su tamaño es considerable. La aplicación de filtros y herramientas de visualización (tales como distribución de los nodos a través de diferentes algoritmos), colaboran en la construcción de imágenes que muestran información específica y detallada de los patrones que han sido encontrados. 


\subsection{Caso 1: Meta-análisis del proyecto TAEE aplicando análisis de redes}

sociales

Complementando lo escrito en los párrafos anteriores, la Tabla 5.3 muestra cómo un enfoque basado en las relaciones puede convertirse en una herramienta para analizar información que proviene de una iniciativa educativa como TAEE. En dicha tabla se describe cómo la construcción de las redes y el uso de las métricas propias de SNA ayudaron a responder cada una de las cuatro preguntas propuestas.

Al desarrollar el caso que se describe en este apartado y considerando los componentes y módulos que se utilizaron dentro del mismo, permiten afirmar que se pueden utilizar las redes, el análisis de redes, sus métricas y la visualización como una herramienta para realizar analítica de datos de eventos como un congreso, cuyos resultados pueden servir a los interesados para tener una imagen de la evolución de los congresos y su estado actual y les abre la posibilidad de tomar decisiones fundamentados en una análisis de datos que toma en cuenta las relaciones, como el SNA, y no las propiedades individuales, como lo hace la estadística. Por lo tanto se valida la hipótesis H2.

Dentro de los módulos que se utilizaron quedan algunos temas pendientes, así tenemos que dentro del componente de Creación de redes ejemplo:

- Identificar redes, no se utilizó las características de una red social, ya que los datos no provienen de una red social en línea.

- Instanciar redes, dentro de este módulo se plantea el uso de base de datos orientadas a grafos para almacenar la información, que en este caso tampoco se llegó a utilizar.

Mientras que para el componente de Análisis y visualización de redes, los temas pendientes fueron:

- Analizar vía métricas de SNA, no se utilizaron otro tipo de métricas que permitan analizar comunidades o clustering. Además considerando la diversidad de métricas existentes, este punto siempre tendrá pendientes.

- Dentro de la visualización, quedó pendiente el uso de otras técnicas de visualización de redes interactivas que permitan a los usuarios interactuar con la red y sus elementos (nodos y enlaces). 


\begin{tabular}{|c|c|c|c|c|c|c|c|c|}
\hline 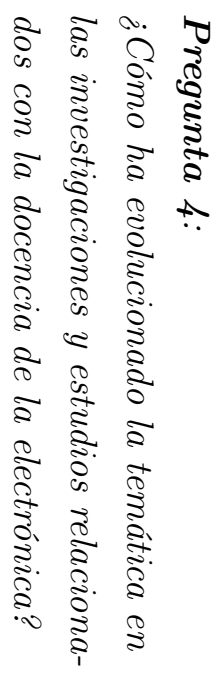 & 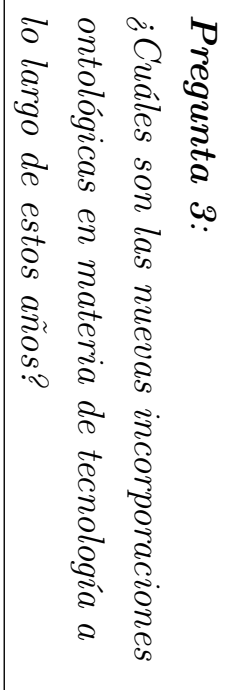 & & 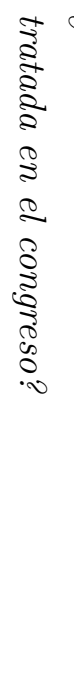 & 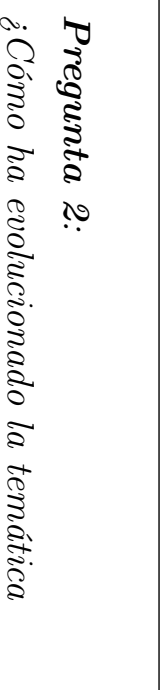 & 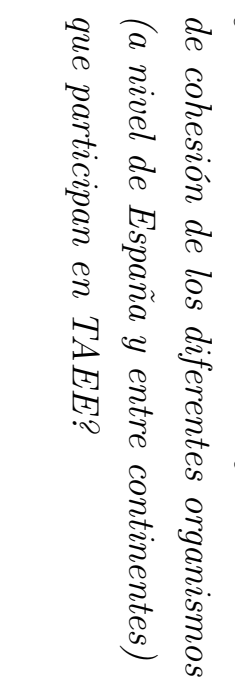 & 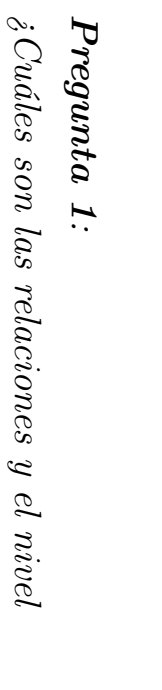 & 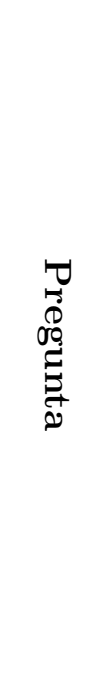 & \\
\hline 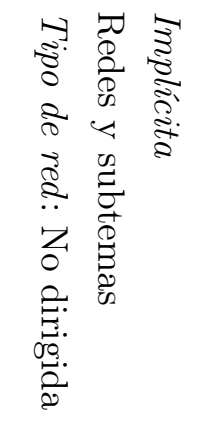 & 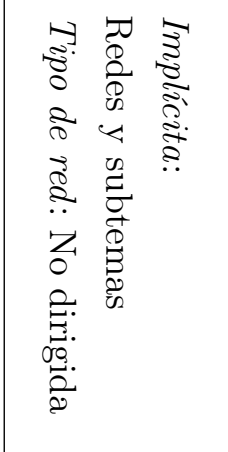 & 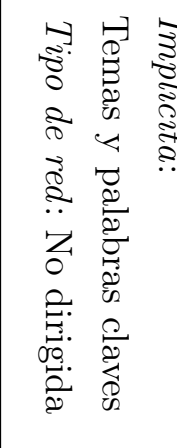 & & 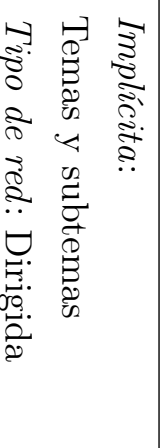 & 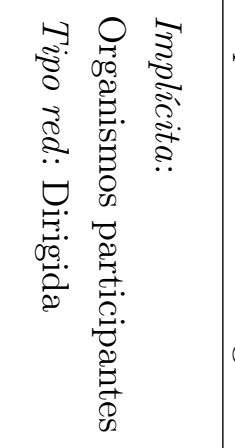 & 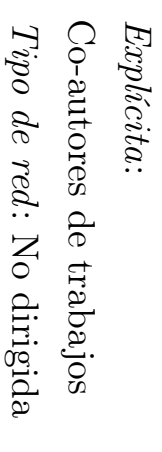 & 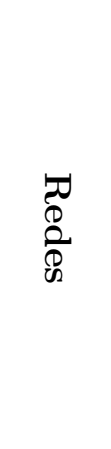 & \\
\hline 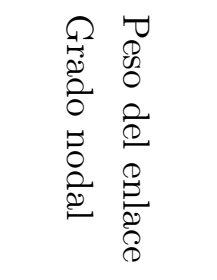 & 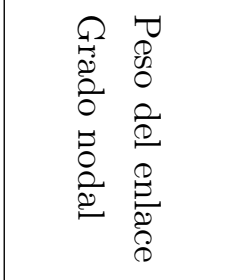 & $\underset{\sim}{\exists}$ & & $\begin{array}{ll}0 & 0 \\
0 & 0 \\
00 & 0 \\
0 & 0 \\
0 & 0 \\
0 & 0 \\
0 & 8 \\
0 & 0 \\
0 & 0 \\
0 & 0\end{array}$ & 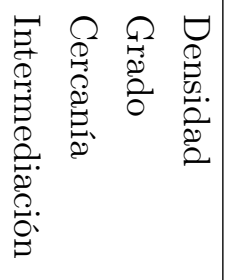 & 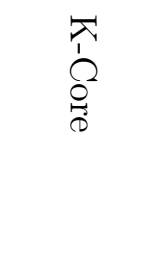 & 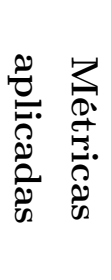 & \\
\hline 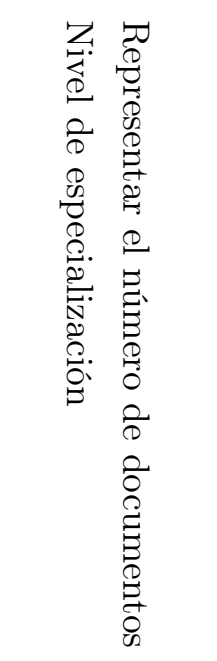 & 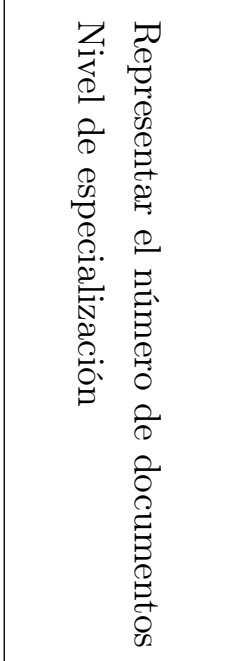 & 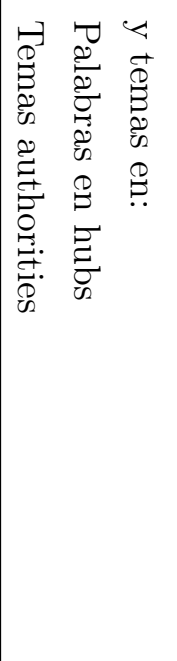 & 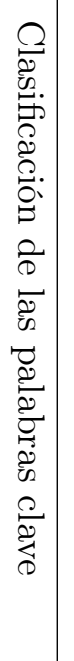 & 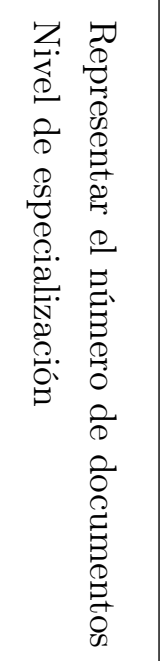 & 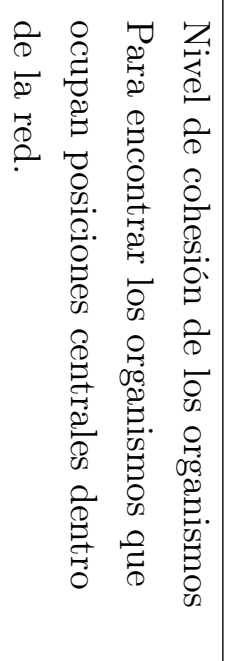 & 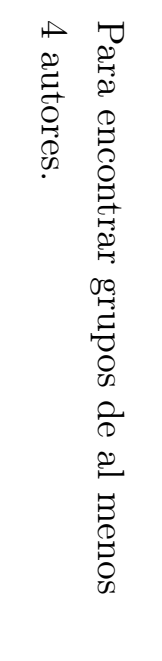 & 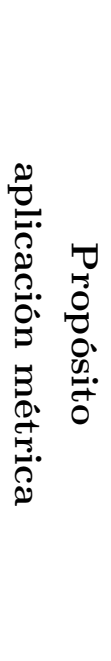 & \\
\hline
\end{tabular}




\subsection{Caso 2: El impacto de los Recursos Educativos Abier- tos en la Educación superior en España y Latinoamé- rica a través del Análisis de Redes Sociales}

En ese trabajo se evaluó a el análisis de redes sociales como una técnica para medir el impacto de los recursos educativos abiertos y mostrar los resultados de aplicar este tipo de análisis en las iniciativas OpenCourseWare de España y Latino América, con el objetivo de aportar concretamente en lo que se refiere a programas de medición y evaluación para instituciones que son parte de iniciativas OCW.

El detalle del trabajo lo pueden encontrar en Tovar et al. (2013b), mientras que una versión en español se publicó en el informe del proyecto "Aplicación de tecnologías web emergentes para el estudio del impacto de repositorio OpenCourse Ware españoles y latinoamericanos en la Educación Superior ${ }^{\text {1] }}$.

El trabajo realizado se integró, con otras propuestas, para desarrollar una aproximación que apoyen al descubrimiento y re-uso de OERs utilizando análisis de redes sociales, tecnologías de la web semántica y linked data para describir, analizar y visualizar el conocimiento compartido en iniciativas OER. El detalle de la integración está disponible en (Piedra et al. 2015a), mientras que la Figura 5.6 muestra un esquema general de la propuesta y la ubicación del análisis de redes sociales.

\subsubsection{Componentes y módulos utilizados}

El problema de medir el impacto del uso de OERs fue resuelto a través de la aplicación de dos componentes que son parte del modelo de enriquecimiento y que se relacionan estrechamente con la construcción de redes y el uso de métricas de SNA como una medida del impacto, es por ello que con este trabajo se utilizaron los componentes y módulos como se muestran ver en la Figura 5.7. En la Tabla 5.4 se puede un detalle del uso de los componentes y módulos. El uso de dichos componentes permitieron realizar la validación de la hipótesis $\mathbf{H 2}$, el detalle de la validación se encuentra en la Sección 5.3 .2 .

Los resultados que se presentaron en este ayudan a validar la hipótesis H2 (para detalles ver la sección 5.3.2 ya que permitieron construir un modelo de análisis de

${ }^{1}$ http://ocw.upm.es/informe-final-ocw Parte del programa e Estudios y Análisis. Proyecto EA 2011-0120 


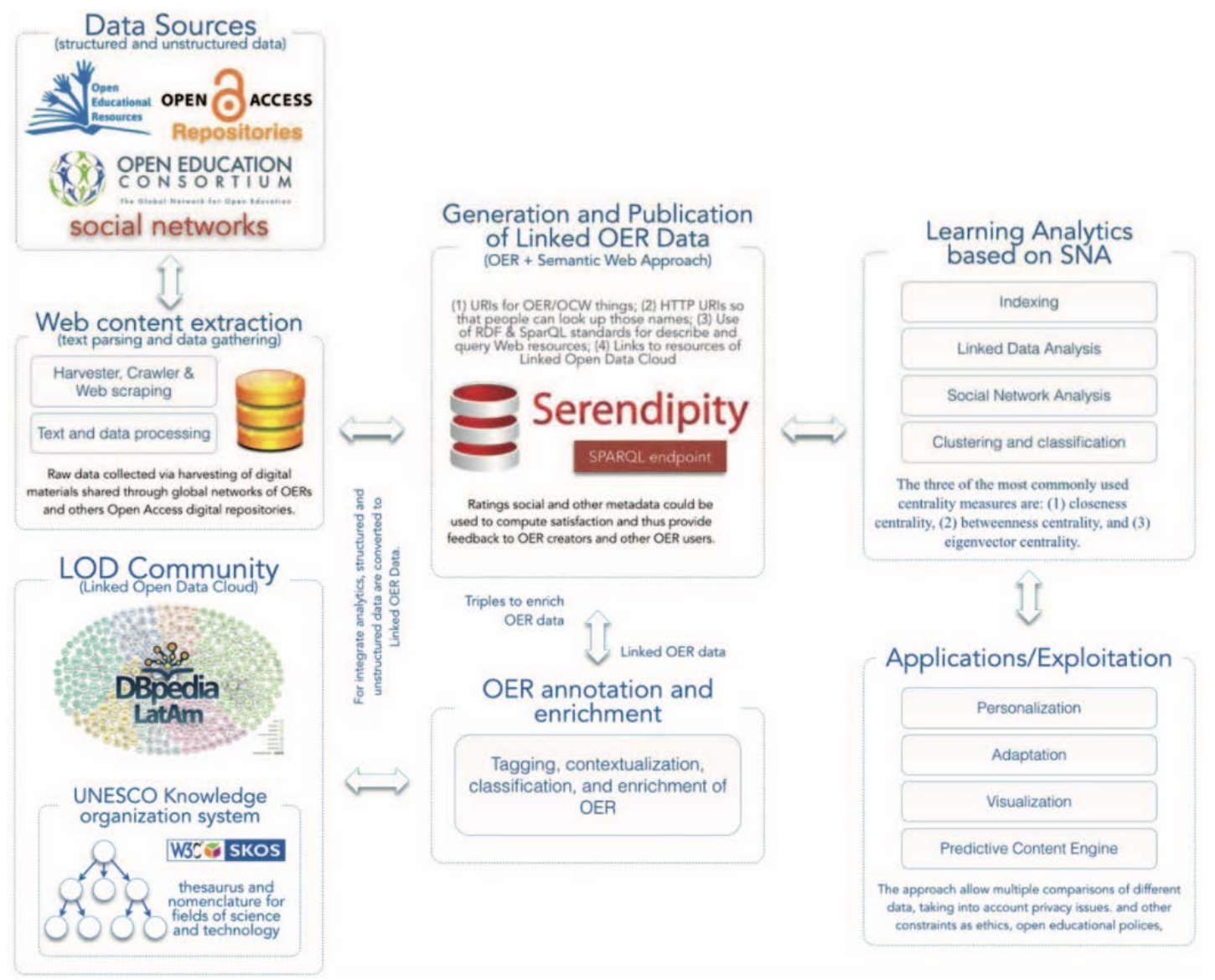

Figura 5.6: Visión integral del marco diseño en la propuesta - El análisis de redes sociales se parte fundamental del propuesta de la analítica del aprendizaje, a través de sus distintas métricas, especialmente las relacionadas con al centralidad. 
5.3 Caso 2: El impacto de los Recursos Educativos Abiertos en la Educación superior en España y Latinoamérica a través del Análisis de Redes Sociales

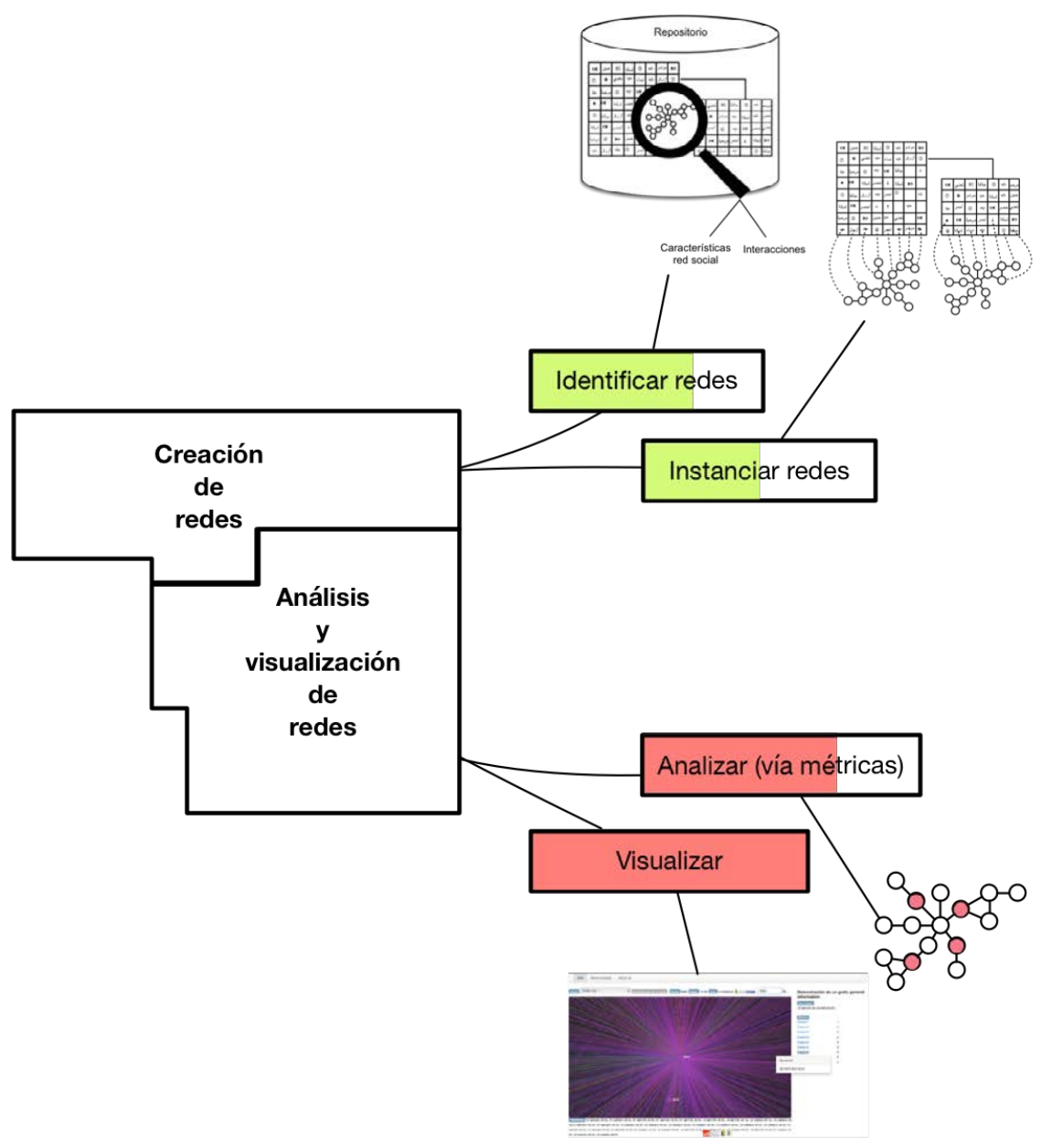

Figura 5.7: Componentes y módulos del modelo de enriquecimiento que se utilizaron en este caso - El caso empleó dos componentes del modelo y por cada componente dos módulos. El color en cada módulo señala el énfasis de cada módulo en el desarrollo del caso. 


\section{VALIDACIÓN DE LAS HIPÓTESIS PROPUESTAS}

Tabla 5.4: Componentes y módulos utilizados en el desarrollo de este caso. Este caso ayudó a validar la hipótesis H2.

\begin{tabular}{|c|c|}
\hline Usado & Componentes del modelo de enriquecimiento \\
\hline \multicolumn{2}{|r|}{ Creación de redes } \\
\hline \multicolumn{2}{|c|}{ Identificar redes } \\
\hline$\checkmark$ & $\begin{array}{l}\text { Redes explícitas. Se construyeron las siguientes redes: } \\
\text { - Co-autoría de cursos. }\end{array}$ \\
\hline$\checkmark$ & $\begin{array}{l}\text { Redes implícitas. Se construyeron las siguientes redes: } \\
\text { - Palabras clave de cursos. } \\
\text { - Autores a través del uso de palabras clave. }\end{array}$ \\
\hline$\checkmark$ & $\begin{array}{l}\text { Red de participantes: } \\
\text { - Autores de cursos }\end{array}$ \\
\hline$\checkmark$ & $\begin{array}{l}\text { Red del contexto: } \\
\text { - Palabras clave de los cursos }\end{array}$ \\
\hline \multicolumn{2}{|c|}{ Instanciar redes } \\
\hline$\checkmark$ & $\begin{array}{l}\text { Se utilizó: } \\
\text { - Base de datos relacional para almacenar los datos. } \\
\text { - Software SNA (Gephi) }\end{array}$ \\
\hline \multicolumn{2}{|r|}{ Análisis y visualización de redes } \\
\hline \multicolumn{2}{|c|}{ Analizar redes } \\
\hline$\checkmark$ & $\begin{array}{l}\text { Analizar a través de métricas de SNA. Métricas utilizadas: } \\
\text { - Grado (Degree). } \\
\text { - Intermediación (Betweenness). } \\
\text { - Grado medio (Average degree). } \\
\text { - Densidad (Density). } \\
\text { - Diámetro (Diameter) } \\
\text { - Longitud promedio (Average path length) }\end{array}$ \\
\hline \multicolumn{2}{|l|}{ Visualizar } \\
\hline$\checkmark$ & $\begin{array}{l}\text { - Imágenes dinámicas. } \\
\text { - Red sobre un mapa. } \\
\text { - Nube de palabras clave. }\end{array}$ \\
\hline \multicolumn{2}{|c|}{$\begin{array}{l}\text { Hipótesis a validar } \\
\text { (Con la ejecución de los componentes y módulos anteriores se busca } \\
\text { validar la siguiente hipótesis) }\end{array}$} \\
\hline H2 & $\begin{array}{l}\text { El Análisis de redes sociales o la ciencia de las redes es } \\
\text { una herramienta de análisis que permite describir, desde el } \\
\text { punto de vista de las relaciones, a diversas iniciativas } \\
\text { educativas permitiendo obtener descripciones diagnósticas, } \\
\text { realizar prospectiva y apoyar a la toma de decisiones. }\end{array}$ \\
\hline
\end{tabular}



superior en España y Latinoamérica a través del Análisis de Redes Sociales

datos basado en las relaciones para realizar diagnósticos de situaciones actuales, a su vez que permite ver a futuro a través del análisis de las potencialidades y ayuda a la toma de decisiones por parte de organizadores de diferentes iniciativas educativas como por OCW.

\subsubsection{Validación de hipótesis de investigación}

En esta sección se muestra los acciones ejecutadas buscando dar una solución al problema propuesto por el caso. Así como también se presenta una descripción de la validación de las hipótesis con las que se relaciona el caso.

\subsubsection{Construcción de la solución}

El trabajo tuvo como finalidad utilizar el SNA como un mecanismo para la medición del impacto de las iniciativas OCW, concretamente se trató de aportar a dos recomendaciones hechas por el OpenCourseWare Consortium en lo referente a la evaluación y medidas de programas OCW. Las dos recomendaciones fueron las siguientes:

- Permitir monitorear la utilidad y usabilidad de los Recursos Educativos Abiertos (OER por sus siglas en Inglés) y la eficiencia de los procesos de publicación, ayudando a identificar e implementar mejoras que puedan ser relevantes en el tiempo.

- Medir el uso e impacto de las partes involucradas en los sitios OCW ayuda a asegurar su propósito.

Para evaluar la utilidad del Análisis de Redes Sociales, dentro de los recursos educativos abiertos, diferentes redes sociales y no sociales fueron construidas, utilizando relaciones explícitas entre los diferentes participantes de iniciativas OCW, así por ejemplo: co-autoría para mostrar el estado actual de los recursos OCW. También se utilizaron relaciones implícitas como por ejemplo el etiquetado social (tagging) para medir el potencial de los OCW.

Mientras que para medir el impacto de los OCW, se obtuvieron varias relaciones de la información publicada por las universidades que luego fueron convertidas en redes y medidas a través de diferentes métricas del SNA. Los resultados obtenidos permitieron conocer el estado actual de OCW en Latino América, develar la organización informal 


\section{VALIDACIÓN DE LAS HIPÓTESIS PROPUESTAS}

detrás de las iniciativas OCW. También permitió conocer las folksonomías que surgen para describir los cursos y las potenciales redes de colaboración entre instituciones y profesores.

La fuente de datos se basa en información extraída de los recursos publicados por iniciativas OCW de instituciones de norte, centro y Sudamérica y Europa. Algunas estadísticas:

- 9 países (Costa Rica, México, Argentina, Brasil, Chile, Colombia, Ecuador, Perú, Venezuela y España).

- 2511 cursos escritos en Español.

- Las instituciones pertenecen a 2 iniciativas OpenCourseWare Consortium y OCW Universia.

- 3147 autores

- 6512 palabras claves o tags.

- Redes construidas Todas las redes que se construyeron buscaban aportar al propósito del trabajo realizado, medir el impacto de las iniciativas OCW.

\section{- Colaboración por etiquetas de cursos}

Para este análisis se construyeron folksonomías con las palabras claves que se utiliza para describir a los cursos. Se construyó una red por cada uno de los continentes participantes lo que permitió tener una visión general de las temáticas que se abordan en cada uno ya que generalmente son utilizadas como sistemas de clasificación.

Las redes que se construyeron tienen por nodos a las palabras claves y un enlace señala co-ocurrencia de las palabras claves en la descripción de uno o más cursos.

La figura 5.8 muestra las redes que se construyeron, cada una de las redes cambian en cuanto al número de elementos (nodos y enlaces) que intervienen, pero en todos destacan ciertos conceptos a través de la aplicación de la métrica intermediación (Betweenness). Así tenemos que para Europa: Ciencias sociales y jurídicas, enseñanzas técnicas y ciencias de la salud; mientras que para Sudamérica los conceptos que se destacan son: Educación y Aprendizaje por mencionar los dos primeros; para Norteamérica 
5.3 Caso 2: El impacto de los Recursos Educativos Abiertos en la Educación superior en España y Latinoamérica a través del Análisis de Redes Sociales

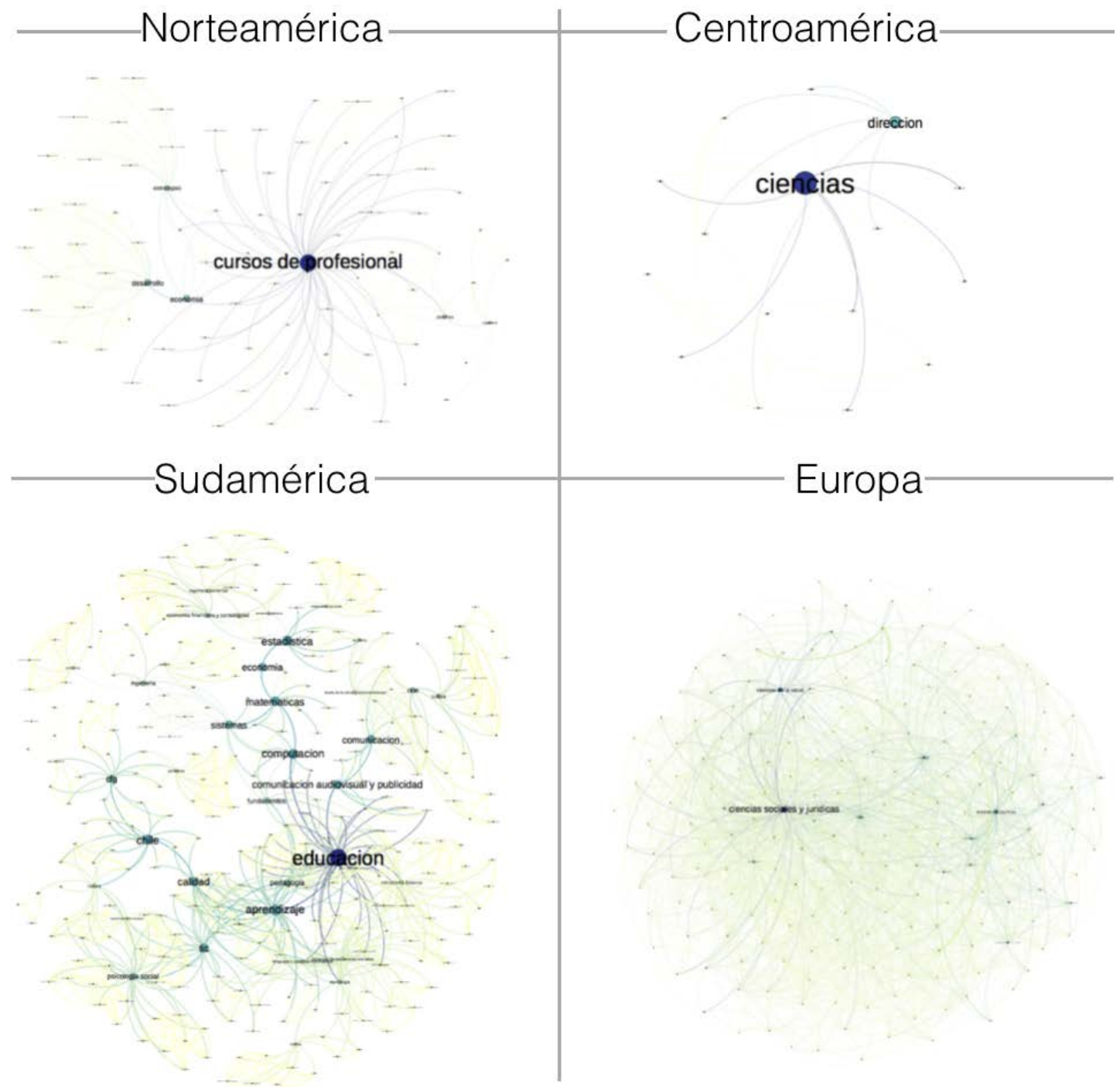

Figura 5.8: Redes de colaboración por etiquetas y continentes - Varias imágenes que muestran la colaboración en la construcción de conocimiento por parte de las instituciones dentro de cada uno de sus continente 


\section{VALIDACIÓN DE LAS HIPÓTESIS PROPUESTAS}

los conceptos que resaltan son: cursos de profesional, economía, desarrollo y estrategias; finalmente para Centroamérica son Ciencias y Dirección.

Lo anterior muestra diferencias entre las folksonomías permitiendo que en cada uno de los continentes existan temáticas predominantes que podrían marcar la orientación de los temas de los OCW en ese continente.

\section{- Redes de autores de cursos}

Para medir la colaboración entre los autores de los cursos se realizó el análisis de la co-autoría, es decir cuando dos o más profesores constan en la lista de creadores de un cursos.

Las redes que se formaron (una por continente) tienen por nodos a los creadores de los cursos, un enlace entre ellos señala que comparten la autoría de uno o más cursos.

En la figura 5.9 se puede ver ejemplos de las redes que se construyeron, aquí es necesario hacer notar que no existe una red para Centroamérica, debido a la falta de esa información.

\section{- Redes por etiquetas y autores}

Con el fin de medir el potencial de colaboración entre las redes, no el nivel actual, ya que existe poca colaboración como se vio en los párrafos anteriores, sino el potencial a futuro, se construyó una red entre autores cuyos cursos se encuentran descritos con al menos una misma palabras clave.

Una de las redes que se construyó tiene por nodos a autores de cursos y un enlace señala que utilizaron una misma palabra clave o etiqueta para describir sus cursos.

Otra de las redes que se empleó, es una red bipartita que tiene por nodos a autores y palabras claves y un enlace señala que un autor utilizó esa etiqueta.

La métrica que se utilizó fue el grado nodal de entrada que permite encontrar las palabras claves usadas con mayor frecuencia. En la figura 5.10 se puede ver un ejemplo del tipo de red que se construyó para mostrar el potencial de colaboración.

La colaboración se puede ver a nivel de temáticas y subclasificadas por universidad, ciudad, país y continente. Así como se puede ver en la Figura 5.11 en donde, se presenta una red construida sobre un mapa que muestra las universidades como nodos ubicados según su latitud y longitud y enlazadas con otras universidades que poseen cursos descritos con la misma palabra clave (science). También se muestra una nube 
5.3 Caso 2: El impacto de los Recursos Educativos Abiertos en la Educación superior en España y Latinoamérica a través del Análisis de Redes Sociales

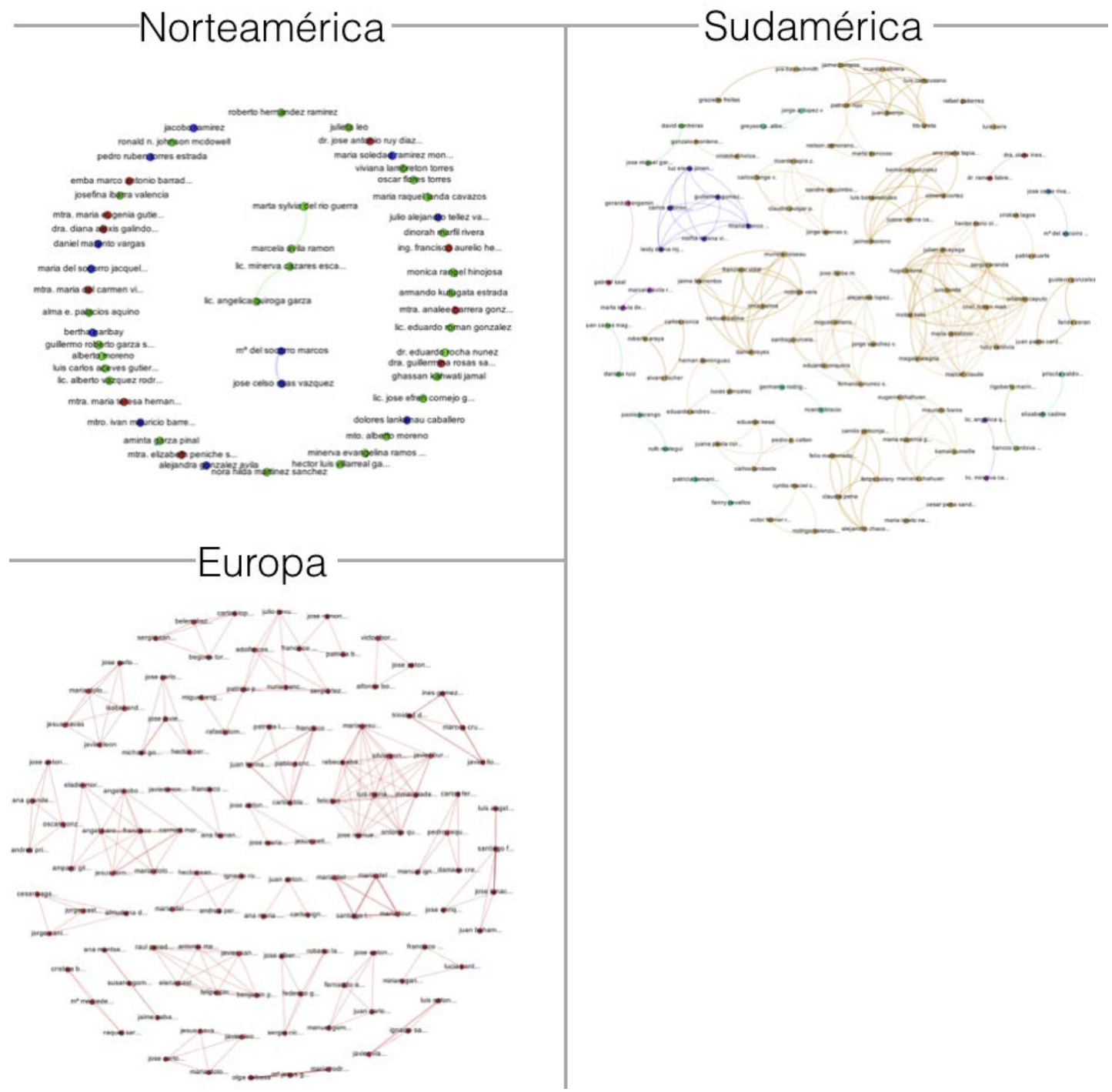

Figura 5.9: Redes de autores de cursos - Redes que muestran la co-autoría de los cursos, únicamente existen 3 debido a la carencia de datos 


\section{VALIDACIÓN DE LAS HIPÓTESIS PROPUESTAS}

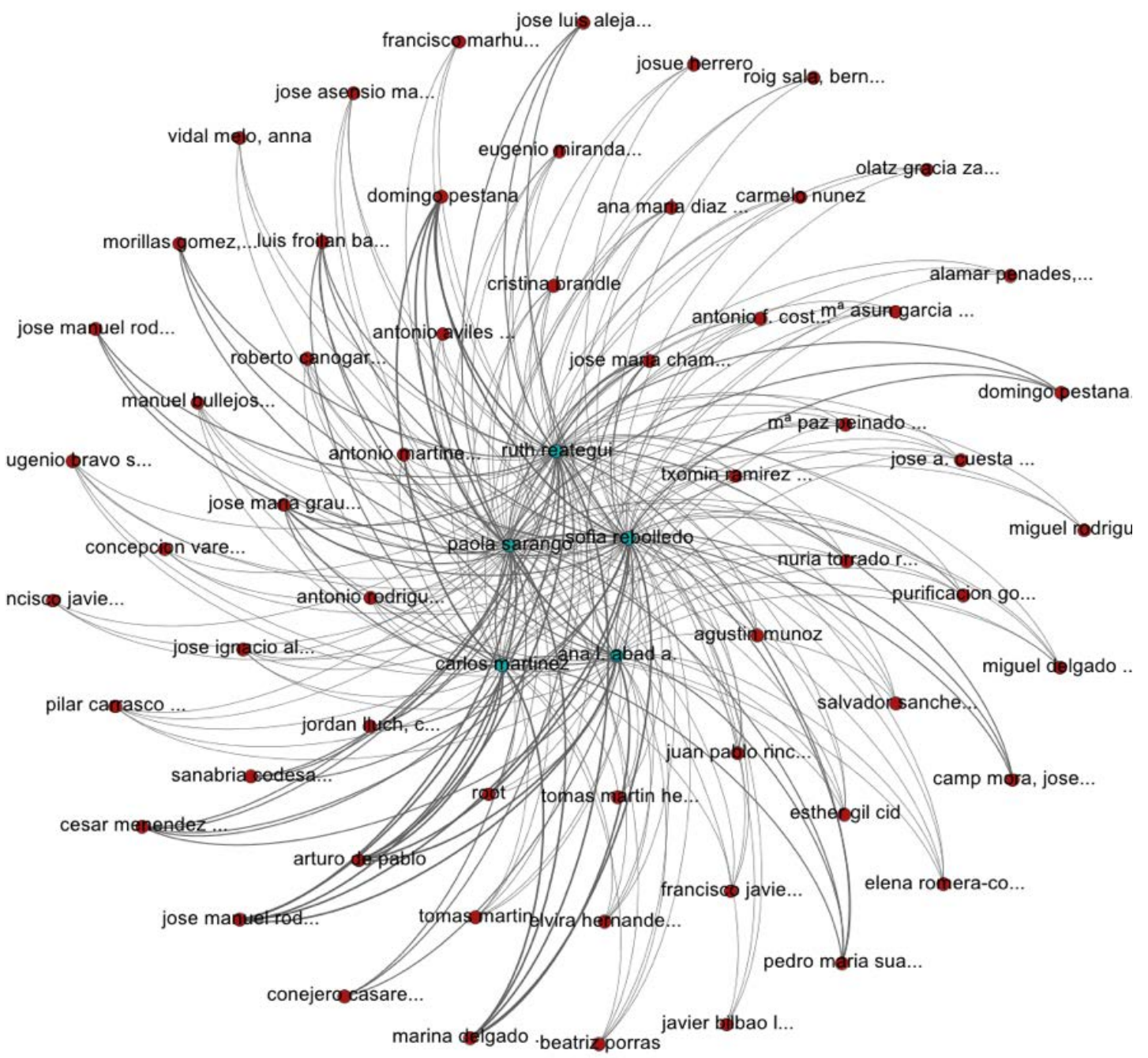

Figura 5.10: Colaboración entre América del Sur y España - Se muestra la colaboración para el tema matemática, es decir los cursos que han sido descritos con la palabra clave "matemática" 

superior en España y Latinoamérica a través del Análisis de Redes Sociales

de etiquetas que muestra las palabras clave relacionadas a science y que al seleccionar alguna se realiza una nueva búsqueda.

La colaboración entre universidades por continente se resume a continuación, partiendo de colaboración entre los 4 continentes, hasta llegar a 3 continentes. El potencial de colaboración entre instituciones de Europa y Latinoamérica se puede dar principalmente en las temáticas: administración, ciencias humanidades y educación.

Mientras que la colaboración entre Europa Norteamérica y Suramérica fluiría naturalmente en los temas: economía, finanzas, información, sistemas, tecnología, investigación, filosofía, desarrollo, cirugía, comercialización, chile, psicología e ingeniería.

Los temas de colaboración entre Europa, Centroamérica y Suramérica serían: sociales y materiales. Además existen 269 etiquetas que muestran un grado de entrada igual a dos, lo que muestra la capacidad de colaboración entre dos continentes.

\subsubsection{Validación}

En este apartado se presenta cómo el caso ayudó a validar la hipótesis $\mathbf{H 2}$ a través del uso de los componentes y módulos que el modelo de enriquecimiento propone. La hipótesis a validar es la siguiente:

H2: El Análisis de redes sociales o la ciencia de las redes es una herramienta de análisis que permite describir, desde el punto de vista de las relaciones, a diversas iniciativas educativas permitiendo obtener descripciones diagnósticas, realizar prospectiva y apoyar a la toma de decisiones.

Para validar esta hipótesis, el modelo de enriquecimiento debe ser capaz de:

- Describir la situación actual de las iniciativas OCW.

- Medir el impacto de las OCW

- Determinar el potencial de colaboración entre los participantes de los OCW.

Por lo tanto en del desarrollo del caso se utilizaron los módulos Creación de redes (ver sección 4.4.2) y Análisis de redes (ver sección 4.4.3), ya que el uso de estos componentes permiten contar con una herramienta de análisis y visualización de datos que se base en las relaciones de los diferentes actores presentes en el caso. 

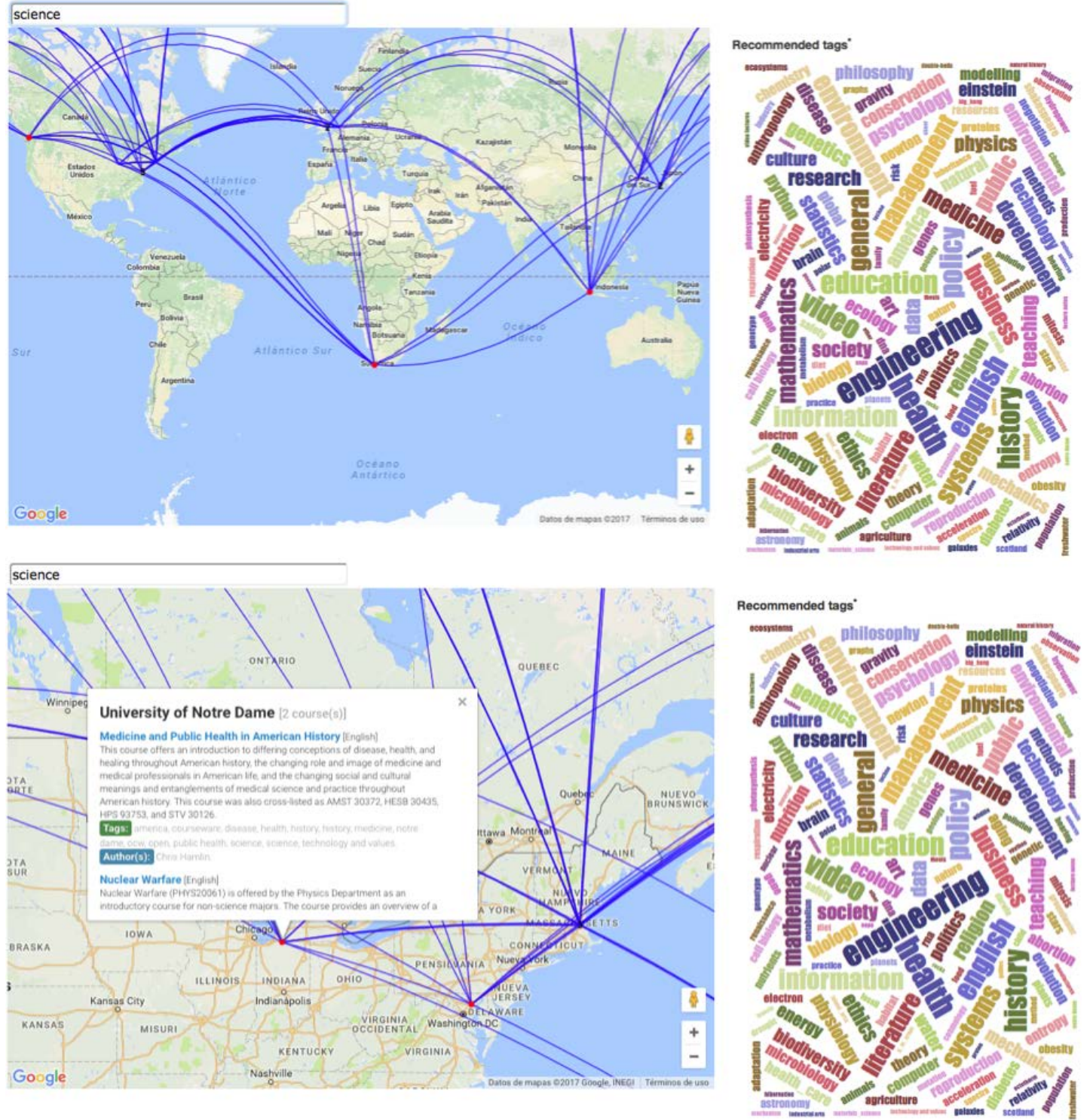

Figura 5.11: Red de colaboración geográfica - La red muestra las universidades con cursos descritos con la palabra clave science. 

superior en España y Latinoamérica a través del Análisis de Redes Sociales

En el desarrollo de este caso se utilizaron los componentes: Creación de redes y Análisis y visualización de redes. A continuación se presenta en detalle las propuestas del modelo y su uso dentro del caso.

Creación de redes este componente se encuentra descrito en la sección 4.4 .2 . Específicamente, se utilizaron los módulos: Identificar redes (descrito en 4.4.2.1) e Instanciar redes (descrito en detalle en la sección 4.4.2.2).

Identificar redes, utilizando este módulo fue posible identificar las siguientes redes:

- Co-autoría de cursos. La colaboración entre docentes para la creación de un curso. Los cursos son creados por varios docentes, lo que señala una relación de co-autoría el análisis de esos grupos de autores resulta interesante ya que describe el comportamiento de los docentes. La red ayuda a entender los procesos actuales de creación de cursos OCW.

- Co-ocurrencia de etiquetas (Folksonomía). Uso de etiquetas para describir los cursos. El uso de etiquetas como un mecanismo de clasificación y búsqueda ha sido ampliamente adoptado en diferentes iniciativas y los OCW no son la excepción. La co-ocurrencia de etiquetas puede ayudar a entender el contexto sobre el cual se desarrollan cada uno de los cursos. Esta red se utilizó para medir el impacto de los OCW dentro de cada uno de los continentes.

- Colaboración entre docentes. Los docentes utilizan etiquetas para describir los cursos. Los usuarios utilizan varias etiquetas dentro de sus cursos y uso compartido por parte de varios docentes muestra que existe un tipo de relación entre los docentes. La red ayuda a entender los procesos de publicación de un OCW, además de medir el potencial de colaboración.

Instanciar redes, es otro de los módulos que se utilizó dentro de este caso. Este módulo permitió construir las redes que posteriormente fueron utilizadas y como plantea el módulo se utilizó un modelo de almacenamiento relacional para crear las redes a través de consultas SQL, en este caso el resultado de las consultas fueron directamente introducidas en la herramienta siguiendo la notación señalada por los creadores, evitando así trabajar con archivos intermedios. 


\section{VALIDACIÓN DE LAS HIPÓTESIS PROPUESTAS}

Análisis y visualización de redes los detalles del componente se encuentran descritos en la sección 4.4.3. Dentro de este caso se utilizó el módulo denominado Analizar a través de métricas de SNA y visualizar que se escrito a detalle en 4.4.3.1.

Como propone el modelo de enriquecimiento, se aplicaron medidas de centralidad en busca de los nodos (palabras clave o usuarios, según el tipo red) más importantes y que ayuden a determinar la colaboración de las iniciativas OCW dentro de cada uno de sus continentes, así como también encontrar los patrones de colaboración en la creación de este tipo de recursos. Es por ello que se utilizaron las siguientes medidas:

- Grado. A través de esta medida fue posible encontrar las etiquetas que son mayormente utilizadas por los usuarios, ya sea por ciudad, país o continente, ayudando a determinar el potencial de colaboración que existe entre diferentes docentes e instituciones.

- Intermediación. Esta medida fue analizada desde la perspectiva de varios participantes tales como: docentes, estudiantes, autodidactas, universidades y creadores de políticas académicas. Desde la visión de los primeros tres grupos un valor de intermediación alto significa encontrar grupos de autores (docentes e instituciones) que están proveyendo recursos educativos dentro de un dominio de conocimiento específico. Mientras que para los dos últimos un valor de intermediación bajo significa una oportunidad para publicar material educativo en esa área de conocimiento. Adicionalmente esta medida ayudó a clasificar a los continentes según los temas que se desarrollan en los OCW. Finalmente esta medida permitió encontrar autores que crean cursos con otros grupos de autores.

- Otras medidas tales como: densidad, grado medio, diámetro, longitud promedio se utilizaron para describir las redes que se construyeron para analizar la situación actual y el impacto de los OCW en cada uno de los continentes.

Otra de las propuestas del modelo, que se ejecuta a través de éste componente y módulo es utilizar técnicas de visualización de datos para describir los hallaz- 


\subsection{Caso 2: El impacto de los Recursos Educativos Abiertos en la Educación superior en España y Latinoamérica a través del Análisis de Redes Sociales}

gos hechos fruto de los análisis realizados. Para este caso y como se vio en la construcción de la solución, se hicieron varios tipos de visualizaciones tanto de redes, como de nubes de etiquetas, mapas, etc. que permitieron construir un sitio interactivo y con la posibilidad de brindar una mejor experiencia a los usuarios e interesados en este tipo de análisis.

Al igual que el caso anterior, este caso demuestra que el SNA y la visualización de datos se puede utilizar como una herramienta para analizar de datos de iniciativas educativas, tales como OCW. Esta técnica de análisis que aquí se propone permite describir la información actual (descripción diagnóstica), así como también permite realizar descripciones de situaciones futuras (prospectiva), lo que sin lugar a dudas es un gran aporte, con lo cual la hipótesis H2 queda demostrada. Así el desarrollo del caso permitió medir el impacto de los OCW. En la Tabla 5.5 se presenta un resumen de cómo se llegó a validar la hipótesis $\mathbf{H 2}$.

Dentro de los módulos que se utilizaron quedan algunos temas pendientes, así tenemos que dentro del componente de Creación de redes ejemplo:

- Identificar redes, no se utilizó las características de una red social, ya que los datos no provienen de una red social en línea.

- Instanciar redes, dentro de este módulo se plantea el uso de base de datos orientadas a grafos para almacenar la información, que en este caso tampoco se llegó a utilizar.

Mientras que para el componente de Análisis y visualización de redes, los temas pendientes fueron:

- Analizar vía métricas de SNA, no se utilizaron otro tipo de métricas que permitan analizar comunidades o clustering. Además considerando la diversidad de métricas existentes, este punto siempre tendrá pendientes.

- Dentro de la visualización, quedó pendiente el uso de otras técnicas de visualización de redes interactivas que permitan a los usuarios interactuar con la red y sus elementos (nodos y enlaces). 


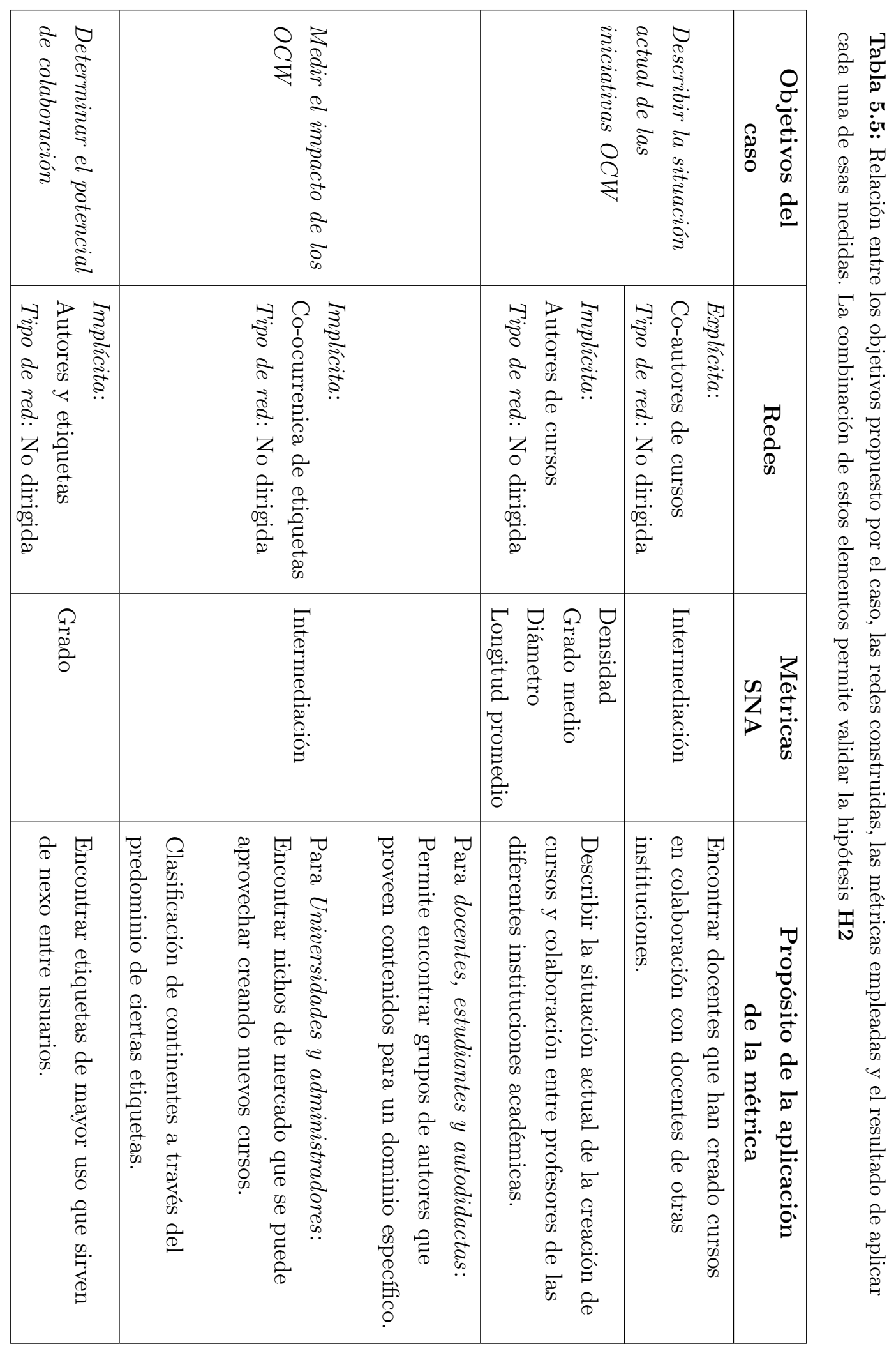




\subsection{Caso 3: MOOCKnowledge Study}

El trabajo utiliza el SNA como una herramienta para el análisis de las respuestas a encuestas realizadas a participantes de cursos OCW. El análisis que se hizo es de naturaleza exploratoria con el fin de mostrar los beneficios que se obtienen al aplicar SNA al conjunto de datos del proyecto antes mencionado.

Este trabajo se realizó bajo el proyecto denominado MOOCKnowledge Study: "Developing a knowledge base on Massive Open Online Courses focussing on Higher Education and Lifelong Learning", como parte de uno de los entregables propuestos dentro del proyecto.

\subsubsection{Componentes y módulos utilizados}

Las características del problema ayudan a determinar cuales componentes del modelo de enriquecimiento se deben usar, en este caso la característica más relevante del problema fue utilizar la información que provienen de las relaciones que surgen al contestar de forma similar una encuesta. La solución hace énfasis en el uso de las propiedades de los nodos como un elemento clasificador para la creación de perfiles. Además del análisis de grupos o clusters según las relaciones que se establecen entre los participantes, es una de las características de la solución. Es por ello que los componentes que se utilizaron se pueden ver en la Figura 5.12, mientras que en la Tabla 5.6 se muestra un resumen del uso de esos componentes y la hipótesis que se pretende validar con la solución del problema propuesto por este caso y que se describe en detalle en la sección 5.4 .2

La solución del problema que se describe en este caso, busca demostrar que el análisis de redes sociales se puede utilizar como una herramienta de análisis de iniciativas educativas ya que permite realizar descripciones diagnósticas, prospectiva y apoyar a la toma de decisiones. Por lo tanto la solución al problema propuesto en este caso pretende validar la hipótesis H2 (los detalles se encuentran en la sección 5.4.2.

\subsubsection{Validación de hipótesis de investigación}

En esta sección se muestra los acciones ejecutadas buscando dar una solución al problema propuesto por el caso. Así como también se presenta una descripción de la validación de las hipótesis con las que se relaciona el caso. 


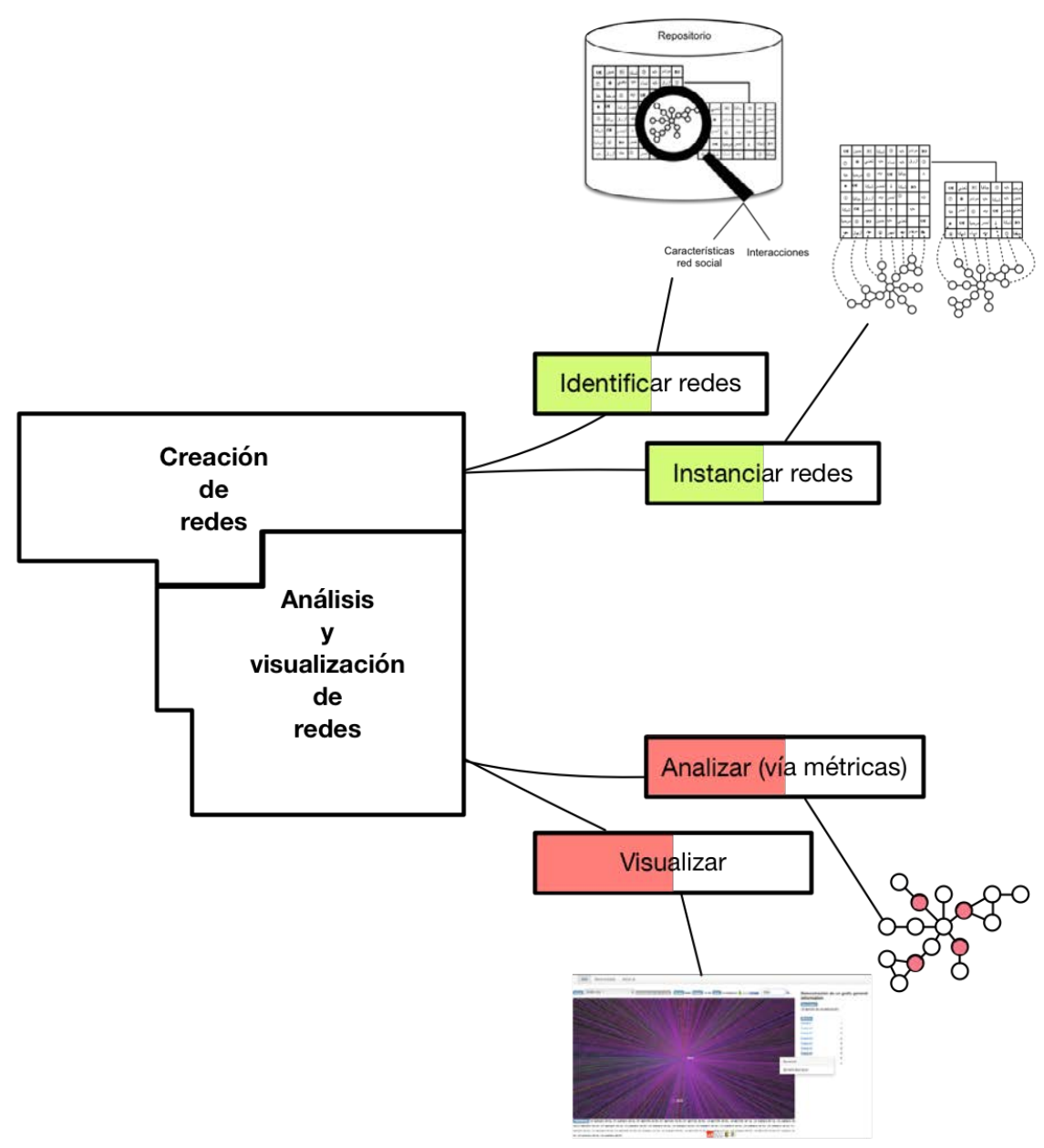

Figura 5.12: Componentes y módulos del modelo de enriquecimiento que se utilizaron en este caso - El caso empleó dos componentes del modelo y por cada componente dos módulos. El color en cada módulo señala el porcentaje que se empleó en el caso con respecto a lo que propone el modelo de enriquecimiento. 
Tabla 5.6: Componentes y módulos utilizados con la ejecución del caso que se describe en este apartado se busca validar la hipótesis $\mathbf{H 2}$

\begin{tabular}{|c|c|}
\hline Usado & Componentes del modelo de enriquecimiento \\
\hline & Creación de redes \\
\hline \multicolumn{2}{|c|}{ Identificar redes } \\
\hline$\checkmark$ & $\begin{array}{l}\text { Redes implícitas. Se construyeron las siguientes redes: } \\
\text { - Estudiantes que participaron en una encuesta. }\end{array}$ \\
\hline \multicolumn{2}{|c|}{ Instanciar redes } \\
\hline$\checkmark$ & $\begin{array}{l}\text { Se utilizó: } \\
\text { - Base de datos relacional para almacenar los datos. } \\
\text { - Software SNA (Gephi) }\end{array}$ \\
\hline \multicolumn{2}{|r|}{ Análisis y visualización de redes } \\
\hline \multicolumn{2}{|c|}{ Analizar redes } \\
\hline$\checkmark$ & $\begin{array}{l}\text { Analizar a través de métricas de SNA. Métricas utilizadas: } \\
\text { - Modularidad (Modularity). } \\
\text { - Intermediación (Betweenness). }\end{array}$ \\
\hline \multicolumn{2}{|c|}{ Visualizar } \\
\hline$\checkmark$ & - Imágenes dinámicas. \\
\hline \multicolumn{2}{|c|}{$\begin{array}{l}\text { Hipótesis a validar } \\
\text { (Con la ejecución de los componentes y módulos anteriores se pretende } \\
\text { validar la siguiente hipótesis) }\end{array}$} \\
\hline H2 & $\begin{array}{l}\text { El Análisis de redes sociales o la ciencia de las redes es } \\
\text { una herramienta de análisis que permite describir, desde el } \\
\text { punto de vista de las relaciones, a diversas iniciativas } \\
\text { educativas permitiendo obtener descripciones diagnósticas, } \\
\text { realizar prospectiva y apoyar a la toma de decisiones. }\end{array}$ \\
\hline
\end{tabular}




\section{VALIDACIÓN DE LAS HIPÓTESIS PROPUESTAS}

\subsubsection{Construcción de la solución}

El propósito de este trabajo fue utilizar el SNA como herramienta para realizar análisis de la información que proviene de ls respuestas a una encuesta.

Tomando en cuenta la naturaleza de los datos, se utilizó el SNA como herramienta para analizar los perfiles de los participantes y encontrar similitudes entre esos perfiles.Los perfiles se construyeron utilizando las respuestas a varias preguntas de la encuesta aplicada, si dos personas responden a todas las preguntas de la misma manera empiezan a ser parte de un mismo perfil.

El SNA ayudó a caracterizar esos perfiles y a encontrar participantes, que por sus características que pueden ser consideradas como idóneos y como su participación masiva podría cambiar el resultado en próximas ediciones del MOOC, permitiendo una transición desde el grupo actual hacia otro que posee las características deseas.

Para demostrar la validez de la propuesta se utilizó las repuestas de una encuesta que se aplicó a 715 participantes del MOOC de Test Anxiety Management. No se trabajó con todos los datos, sino únicamente con los participantes que respondieron a 7 preguntas del cuestionario, lo que redujo la fuente de datos 316 participantes.

La propuesta, consistió en buscar si existe alguna relación entre dos variables (Experiencias con MOOCs y el apoyo para actividades de desarrollo profesional).

- Redes construidas Se construyo una red con nodos que representan a los participantes del curso que respondieron a la encuesta. Un enlace entre dos nodos representa que ambos participantes respondieron de la misma manera a una de las 7 preguntas propuestas que son parte del análisis. Las respuestas a las preguntas fueron utilizadas como atributos de cada uno de los nodos. Lo que permitió trabajar con una red compuesta por 306 nodos y 23216 enlaces, en la Figura 5.13 se puede ver una ejemplo de la red. Ahí se puede ver como existen 3 grupos, cada uno identificado por un color.

Cada grupo representa un patrón de respuestas a las preguntas, así el primer grupo (color verde) tiene 153 nodos (50\%) y 11163 enlaces (48.08\%), el segundo 124 nodos y 2998 enlaces, mientras que el tercero 29 nodos y 354 enlaces. Dentro de cada grupo se puede encontrar diferentes patrones de respuestas a la preguntas propuestas.

La medida de SNA que se utilizó fue la intermediación (Betweenness) para encontrar nodos puente que unan a dos grupos y cuyas características pueden resultar las óptimas para futuras ediciones del curso. es decir ayuda a la toma de decisiones. 


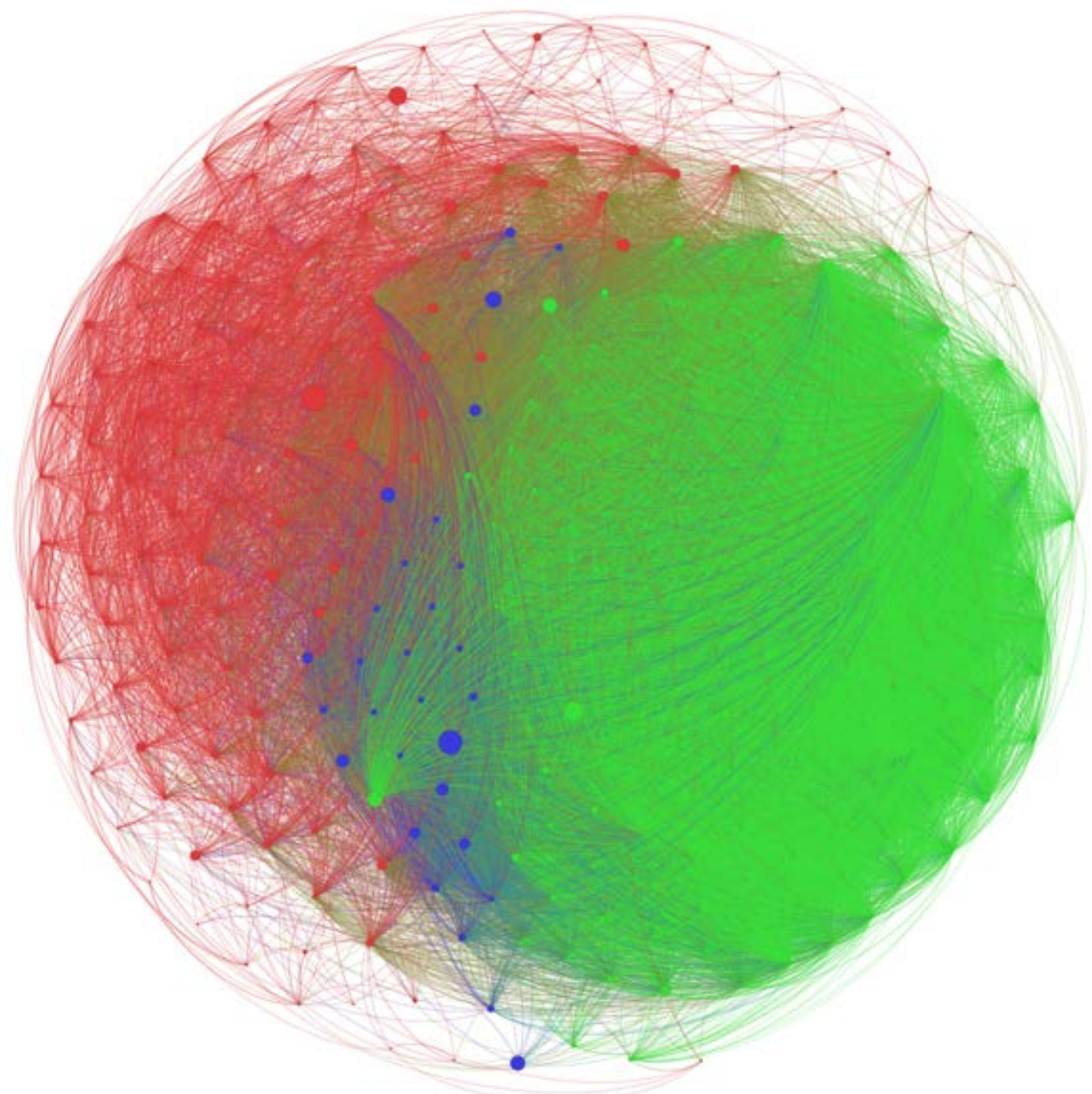

Figura 5.13: La red que se construyó en base a las respuesta de 7 preguntas La red muestra por sus colores los diferentes clusters o grupos. 


\section{VALIDACIÓN DE LAS HIPÓTESIS PROPUESTAS}

\subsubsection{Validación}

En este apartado se muestra como el caso permitió validar una hipótesis propuesta en esta tesis. La validación, al igual que en los casos anteriores, se base en el uso de algunos componentes y módulos del modelo de enriquecimiento propuesto.

En este apartado se presenta como el caso ayudó a validar la hipótesis $\mathbf{H 2}$ a través del uso de los componentes y módulos que el modelo de enriquecimiento propone. La hipótesis a validar es la siguiente:

H2: El Análisis de redes sociales o la ciencia de las redes es una herramienta de análisis que permite describir, desde el punto de vista de las relaciones, a diversas iniciativas educativas permitiendo obtener descripciones diagnósticas, realizar prospectiva y apoyar a la toma de decisiones.

La hipótesis se valida a través del modelo de enriquecimiento y su capacidad de identificar clusters de participantes y sus posibles conexiones en futuras ediciones de MOOCs que busquen realizar transiciones en sus perfiles de usuarios buscando por ejemplo mejorar el desempeño de los participantes del MOOC.

Para desarrollar este caso se utilizaron los componentes: Creación de redes y Análisis y visualización de redes. A continuación se presenta en detalle las propuestas del modelo y su uso dentro del caso.

Creación de redes este componente se encuentra descrito en la sección 4.4 .2 . Específicamente, se utilizaron los módulos: Identificar redes (descrito en 4.4.2.1) e Instanciar redes (descrito en detalle en el apartado 4.4.2.2.

Identificar redes, utilizando este módulo fue posible identificar la siguiente red:

- Usuarios similares. Se trata de una red no dirigida que tiene por nodos a participantes de la encuesta aplicada. Se establece un enlace entre dos nodos si dos participantes (nodos) dieron la misma repuesta a una de las preguntas que son parte del análisis.

El segundo de los módulos ayudó a crear instancias para cada una de las redes identificadas, es decir permitió construir las redes que posteriormente fueron utilizadas y como plantea el módulo se utilizó un modelo de almacenamiento 
relacional para crear las redes a través de consultas SQL, en este caso el resultado de las consultas fueron directamente introducidas en la herramienta siguiendo la notación señalada por los creadores.

Análisis y visualización de redes los detalles del componente se encuentran descritos en la sección 4.4.3. Dentro de este caso se utilizó el módulo denominado Analizar a través de métricas de SNA y visualizar que se escrito a detalle en 4.4.3.1.

Como propone el modelo de enriquecimiento, se aplicaron la siguientes medidas:

- Modularidad (Modularity) que es una medida de la estructura de una red que permite crear clusters (grupos) de nodos que están densamente conectados unos de otros respecto a otros nodos de la red.

- Intermediación dentro de la red que se construyó, esta medida ayudó a encontrar a ciertos nodos que sirven de puente de conexión entre diferentes clusters. Para este caso, estos nodos son importantes por que los nodos con una alto valor de intermediación posee características de los clusters que conecta y permitirían realizar una transición desde un cluster hacia otro.

Otra de las propuestas del modelo, que se ejecuta a través de éste componente y módulo, es utilizar técnicas de visualización de datos para describir los hallazgos hechos fruto de los análisis realizados. Para este caso este componente se utilizó una visualización basada en imágenes que a través de colores en cada uno de los nodos muestra los diferentes clusters.

Al igual que el caso anterior, este caso demuestra que el SNA y la visualización de datos se puede utilizar como una herramienta para analizar de datos de iniciativas educativas, tales como encuestas aplicadas a estudiantes de una iniciativa educativa como los MOOCs. Es decir que el modelo de enriquecimiento, basado en el estudio de la estructura de una red, propuesto puede ser utilizado como una técnica para estudiar diferentes aspectos relacionados con el desarrollo de actividades educativas, tales como: OCW, MOOCs, encuestas, etc. Por lo tanto se valida la hipótesis H2. La Tabla 5.7 muestra un resumen de la validación realizada. 


\section{VALIDACIÓN DE LAS HIPÓTESIS PROPUESTAS}

Tabla 5.7: Relación entre los objetivos propuesto por el caso, las redes construidas, las métricas empleadas y el resultado de aplicar cada una de esas medidas. La combinación de esos elementos permite validar la hipótesis $\mathbf{H 2}$

\begin{tabular}{|c|c|c|c|}
\hline $\begin{array}{l}\text { Objetivos del } \\
\text { caso }\end{array}$ & Redes & $\begin{array}{c}\text { Métricas } \\
\text { SNA }\end{array}$ & $\begin{array}{c}\text { Propósito de aplicar } \\
\text { la métrica }\end{array}$ \\
\hline \multirow{2}{*}{$\begin{array}{l}\text { Identificar clusters } \\
\text { y sus posibles } \\
\text { conexiones }\end{array}$} & \multirow{2}{*}{$\begin{array}{l}\text { Implícitas: } \\
\text { Usuarios similares } \\
\text { Tipo de red: } \\
\text { No dirigida }\end{array}$} & Modularidad & $\begin{array}{l}\text { Permite encontrar grups } \\
\text { según sus conexiones. }\end{array}$ \\
\hline & & Intermediación & $\begin{array}{l}\text { Encontrar nodos que } \\
\text { poseen características } \\
\text { de varios grupos. }\end{array}$ \\
\hline
\end{tabular}

Dentro de los módulos que se utilizaron quedan algunos temas pendientes, así tenemos que dentro del componente de Creación de redes ejemplo:

- Identificar redes, no se utilizó las características de una red social, ya que los datos no provienen de una red social en línea.

- Instanciar redes, dentro de este módulo se plantea el uso de base de datos orientadas a grafos para almacenar la información, que en este caso tampoco se llegó a utilizar.

Mientras que para el componente de Análisis y visualización de redes, los temas pendientes fueron:

- Analizar vía métricas de SNA, no se utilizaron otro tipo de métricas que permitan estudiar las comunidades o clusters identificados. Además considerando la diversidad de métricas existentes, este punto siempre tendrá pendientes.

- Dentro de la visualización, quedó pendiente el uso de otras técnicas de visualización de redes interactivas que permitan a los usuarios interactuar con la red y sus elementos (nodos y enlaces). 


\subsection{Caso 4: Recomendación de OERs compartidos en re- des sociales utilizando como base el análisis de redes sociales}

Este trabajo es la primera aproximación a la recomendación de recursos educativos abiertos que han sido publicados dentro de una red social en línea. Aquí se muestra como se puede utilizar los conceptos de SNA para realizar recomendaciones en dos temas concretos como lo son: Matlab y HTML5. El resultado es un conjunto de recursos que pueden ser incluidos dentro de alguna iniciativa educativa como un OCW o un MOOC o una aula en cualquier entorno virtual que traten sobre estos temas. El detalle del trabajo lo pueden encontrar en Lopez-Vargas et al. (2015b).

\subsubsection{Componentes y módulos utilizados}

El problema que se pretende resolver es recomendar recursos educativos publicados en una red social. Para resolver este problema se utilizó dos componentes del modelo de enriquecimiento. El primero es el componente que construye tópicos, mientras que el segundo es el componente de recomendación. El detalle del uso de los componentes y módulos se pueden ver en la Figura 5.14 y se describen en la Tabla 5.8, mientras que la validación de las hipótesis se detalla en la sección 5.5 .2 .

Tabla 5.8: El uso de los componentes y módulos utilizados en la solución de este caso, así como también las hipótesis (H1, H3 y H4) que se pretenden validar con el mismo.

\begin{tabular}{|l|l|}
\hline Usado & \multicolumn{1}{|c|}{ Componente/módulo del modelo de enriquecimiento } \\
\hline \multicolumn{1}{|c|}{ Captura de datos } \\
\hline Construcción de tópicos \\
\hline$\checkmark$ & $\begin{array}{l}\text { Los tópicos fueron de carácter general, elaborados manualmente. } \\
\text { Se trabajó con los siguientes tópicos: } \\
\bullet \text { matlab } \\
\bullet \text { html5 }\end{array}$ \\
\hline Recolectar datos \\
\hline$\checkmark$ & $\begin{array}{l}\text { • Se recolectó datos sin considerar políticas y límites. } \\
\text { • Se usó Twitter como fuente de datos. }\end{array}$ \\
\hline \multicolumn{2}{|c|}{ Creación de redes } \\
\hline Identificar redes Continúa en la siguiente página \\
\hline \multicolumn{2}{|c}{} \\
\hline
\end{tabular}




\section{VALIDACIÓN DE LAS HIPÓTESIS PROPUESTAS}

Tabla 5.8 - continuación de la página anterior

\begin{tabular}{|c|c|}
\hline Usado & Componente/módulo del modelo de enriquecimiento \\
\hline$\checkmark$ & $\begin{array}{l}\text { Redes explícitas. Se construyeron las siguientes redes: } \\
\text { - Menciones de usuarios (Mentions) } \\
\text { - Re-Tweets (RT) }\end{array}$ \\
\hline$\checkmark$ & $\begin{array}{l}\text { Redes implícitas. Se construyeron las siguientes redes: } \\
\text { - Etiquetas (hashtags) publicadas en cada tweet }\end{array}$ \\
\hline$\checkmark$ & $\begin{array}{l}\text { Red de participantes: } \\
\text { - Redes de cuentas de Twitter. }\end{array}$ \\
\hline$\checkmark$ & $\begin{array}{l}\text { Red del contexto: } \\
\text { - Hashtags }\end{array}$ \\
\hline \multicolumn{2}{|c|}{ Instanciar redes } \\
\hline$\checkmark$ & $\begin{array}{l}\text { Se utilizó: } \\
\text { - Base de datos relacional para almacenar los datos. } \\
\text { - Software SNA (Gephi) }\end{array}$ \\
\hline \multicolumn{2}{|r|}{ Análisis y visualización de redes } \\
\hline \multicolumn{2}{|c|}{ Analizar redes } \\
\hline$\checkmark$ & $\begin{array}{l}\text { Analizar a través de métricas de SNA. Métricas utilizadas: } \\
\text { - Intermediación (Betweenness). }\end{array}$ \\
\hline \multicolumn{2}{|c|}{ Visualizar } \\
\hline$\checkmark$ & • Imágenes dinámicas. \\
\hline \multicolumn{2}{|r|}{ Recomendar } \\
\hline \multicolumn{2}{|l|}{ Social } \\
\hline$\checkmark$ & - Se usó una red de usuarios. \\
\hline \multicolumn{2}{|c|}{ Contenidos } \\
\hline$\checkmark$ & $\begin{array}{l}\text { Se trabajó con información que proviene de: } \\
\text { - La red social (hashtags) } \\
\text { - De los recursos compartidos (Title, Description, Keywords) }\end{array}$ \\
\hline \multicolumn{2}{|r|}{ (2) } \\
\hline$\checkmark$ & $\begin{array}{l}\text { Se garantiza } \\
\text { - Acceso }\end{array}$ \\
\hline \multicolumn{2}{|r|}{$\begin{array}{l}\text { Hipótesis a validar } \\
\text { (Con la ejecución de los componentes y módulos anteriores se buscó } \\
\text { validar las siguientes hipótesis) }\end{array}$} \\
\hline H1 & $\begin{array}{l}\text { Un modelo de enriquecimiento que utilice la información } \\
\text { publicada en una red social, además de su estructura, con el } \\
\text { propósito de encontrar recursos, personas temas relacionados } \\
\text { y roles, apoya a la consecución de los } \\
\text { objetivos de las iniciativas educativas que lo implementen. }\end{array}$ \\
\hline
\end{tabular}



utilizando como base el análisis de redes sociales

Tabla 5.8 - continuación de la página anterior

\begin{tabular}{|l|l|}
\hline Usado & Componente/módulo del modelo de enriquecimiento \\
\hline $\mathbf{H 3}$ & $\begin{array}{l}\text { Las relaciones entre usuarios, su comportamiento a } \\
\text { través del tiempo complementados con el contenido que } \\
\text { se difunde en una red social, analizados a través de un } \\
\text { enfoque de análisis de redes sociales permite desarrollar } \\
\text { un modelo de recomendación confiable. }\end{array}$ \\
\hline $\mathbf{H 4}$ & $\begin{array}{l}\text { Priorizar la información que ha sido expuesta dentro } \\
\text { de una red social sobre aquella que no lo fue, permite } \\
\text { construir un sistema de ranking para recursos difundidos } \\
\text { en una red social. }\end{array}$ \\
\hline \hline
\end{tabular}

La solución que se propuso al problema fue utilizar la información publicada en una red social, su estructura subyacente para encontrar recursos, personas y temas relacionados que ayuden a estudiantes en su formación. Por las características del problema, a través de la solución del mismo se busca validar la hipótesis $\mathbf{H 1}$.

Otra de las características de la solución es utilizar el SNA para realizar análisis de las relaciones entre usuarios y las relaciones del contenido que se encuentran publicado dentro de la red social para desarrollar un modelo de recomendación. El desarrollo de ese modelo de recomendación permitirá validar la hipótesis H3. Es necesario contar con un algoritmo de validación que use la información publicada en la red social en línea y los contenidos de los recursos, para buscar validar la hipótesis $\mathbf{H 4}$. El detalle de la validación de ambas hipótesis se encuentra en la sección 5.5.2.

\subsubsection{Validación de hipótesis de investigación}

En esta sección se muestra los acciones ejecutadas buscando dar una solución al problema propuesto por el caso. Así como también se presenta una descripción de la validación de las hipótesis con las que se relaciona el caso.

\subsubsection{Construcción de la solución}

El trabajo propuesto buscó encontrar una solución al siguiente problema: Encontrar un grupo de URLs publicadas en Twitter que puedan ser utilizadas como OERs y que complementen las necesidades de aprendizaje de una persona en un dominio particular. 


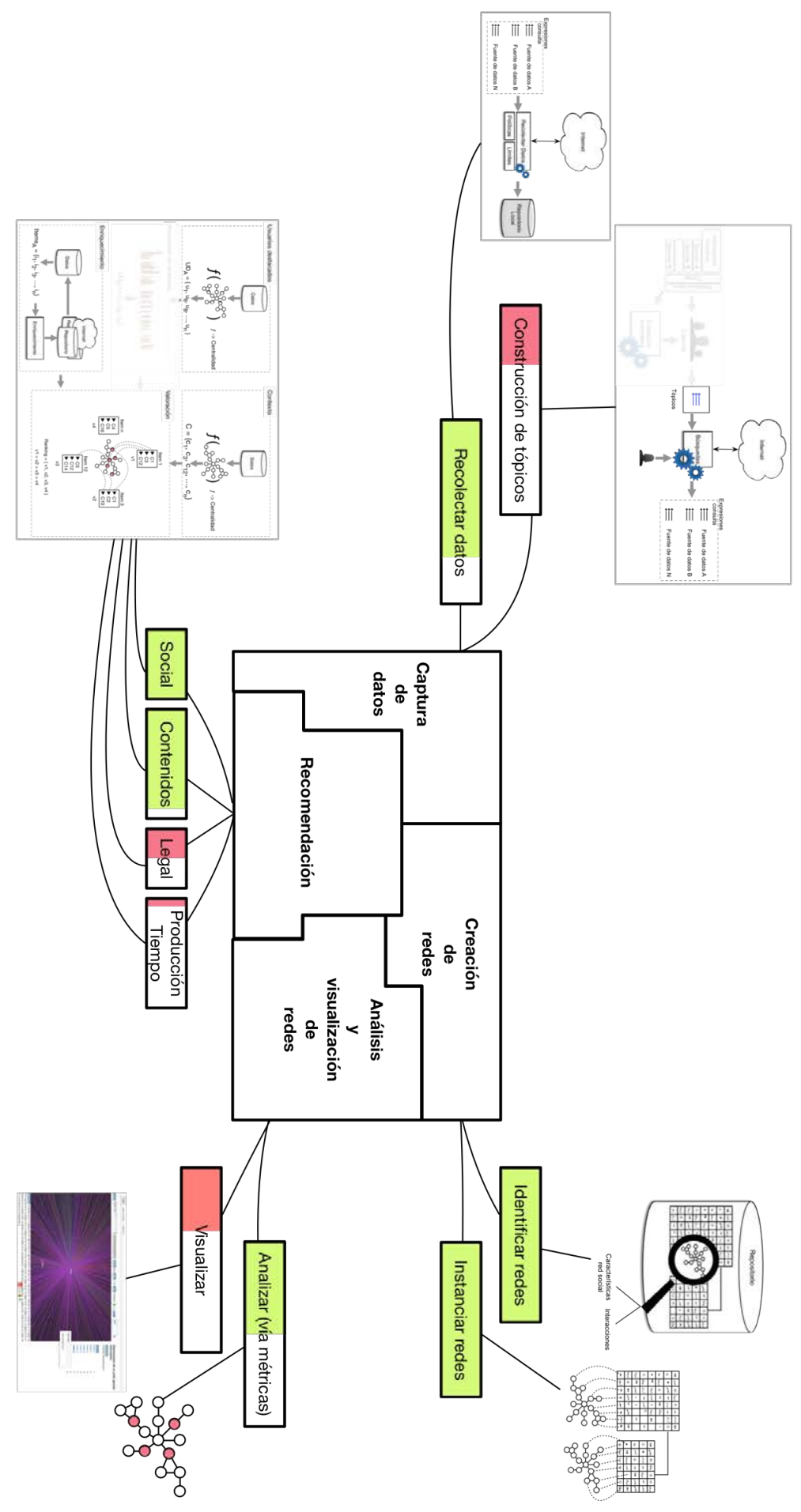

Figura 5.14: Componentes y módulos del modelo de enriquecimiento que se utilizaron en este caso - El casó empleó todos los componentes y módulos, aunque no todos en igual proporción como indican los colores en cada uno de los ellos. 


\subsection{Caso 4: Recomendación de OERs compartidos en redes sociales}

utilizando como base el análisis de redes sociales

Analizando el problema se llegó a determinar las características clave que permitieron encontrar la mejor solución al problema, esas características son:

- La materia prima serán las URLs

- Las URLs serán consideradas como OERs complementarios.

- Se necesita de un mecanismo para capturar la mayor cantidad de información posible, debido a que las necesidades y características de los usuarios son desconocidas.

- Los sistemas de recomendación tradicionales no son una opción ya que el perfil del usuario es desconocido y necesitan que entre usuario y URL exista alguna interacción previa.

Un problema con las características descritas anteriormente demanda de una solución que use técnicas alternativas que solvente cada una de ellas, las tecnologías seleccionadas fueron:

- Expansión de consultas, a través de Link data como un mecanismo que permite agregar información.

- El análisis de redes sociales, como el modelo base para la generación de recomendaciones.

- La influencia de los usuarios como un mecanismo que garantice la calidad de los OERs recomendados.

La fuente de datos estuvo compuesta por Tweets que fueron recolectados, en un lapso de 30 días, a través de búsquedas sucesivas de las hashtags \#matlab y "\#html5" utilizando el API de búsqueda de Twitter. La tabla 5.9 muestra las estadísticas de la fuente de datos que se empleó para el proyecto.

- Redes construidas Se construyeron dos tipos de redes, por un lado una red que representa a la folksonomía con las hashtags como nodos y los enlaces señala coocurrencia de hashtags. Por otro lado se construyó una red de cuentas de usuarios de Twitter, en donde los nodos son cuentas de usuario y los enlaces pueden representar un 


\section{VALIDACIÓN DE LAS HIPÓTESIS PROPUESTAS}

Tabla 5.9: Estadísticas de la información recolectada desde Twitter

$\begin{array}{lrr}\text { Unidad } & \text { \#matlab } & \text { “\#html5” } \\ \text { Tweets } & 2957 & 3666 \\ \text { Re-tweets } & 598 & 655 \\ \text { Mentions } & 1752 & 789 \\ \text { Users } & 3128 & 2412 \\ \text { Hashtags } & 477 & 851 \\ \text { URLs } & 679 & 851\end{array}$

re-tweet a una mención. La primera red es una red no dirigida, mientras que la segunda es una red dirigida.

La Figura 5.15 muestra un ejemplo de las redes que se construyó para \#matlab, tanto a nivel de usuarios como hashtags. Para encontrar a los usuarios influyentes y los conceptos destacados se utilizó la medida de centralidad denominada Intermediación (Betweenness) que permite encontrar nodos que sirven de enlace, esto ubicado en el contexto que de los datos serían usuarios que a través de sus publicaciones unen o participan en diferentes grupos, tienen acceso a una mayo diversidad de datos.

\subsubsection{Validación}

En este apartado se muestra como el caso permitió validar algunas de las hipótesis propuestas en esta tesis y cuyo detalle se encuentra en la sección 3.6. Concretamente la ejecución de este caso permitió validar las hipótesis:

H1: Un modelo de enriquecimiento que utilice la información publicada en una red social, además de su estructura, con el propósito de encontrar recursos, personas, temas relacionados y roles, apoya a la consecución de los objetivos de las iniciativas educativas que lo implementen.

H3: Las relaciones entre usuarios, su comportamiento a través del tiempo complementadas con el contenido que se difunde en una red social analizados a través de un enfoque de análisis de redes sociales permite desarrollar un modelo de recomendación confiable. 

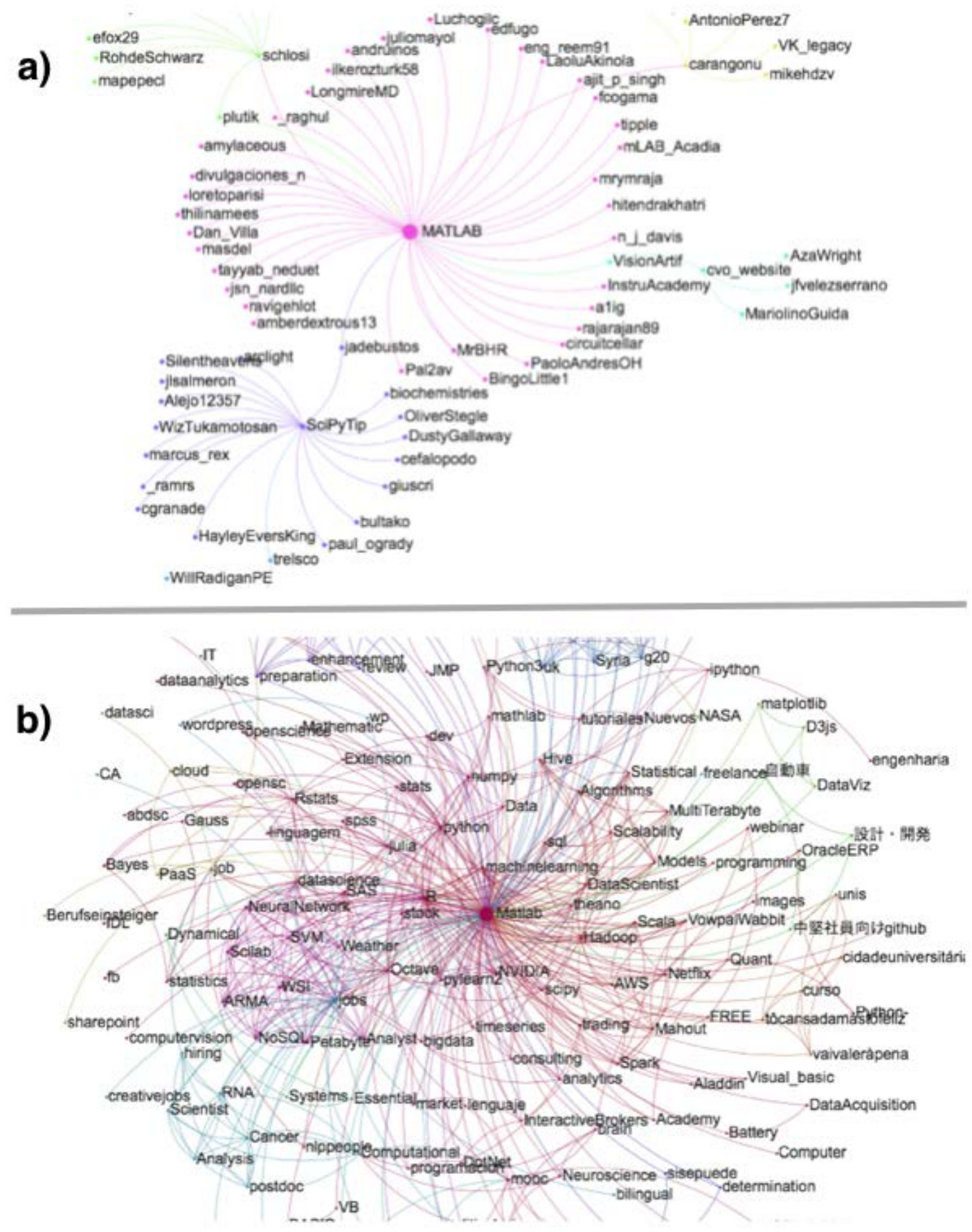

Figura 5.15: Una ejemplo de las redes que se construyeron para \#matlab - La red a) muestra a los usuarios, aquellos de mayor tamaño son los influyentes; b) muestra los conceptos hashtags aosiaciados destacados por la medida su intermediación. 


\section{VALIDACIÓN DE LAS HIPÓTESIS PROPUESTAS}

H4: Priorizar la información que ha sido expuesta dentro de una red social sobre aquella que no lo fue, permite construir un sistema de ranking para recursos difundidos en una red social.

Para la validación de las hipótesis el modelo de enriquecimiento debería ser capaz de captar datos que son publicados en una red social en línea y encontrar recursos educativos que apoyen en el proceso de enseñanza aprendizaje de una iniciativa educativa. Haciendo énfasis en la recuperación de los recursos educativos para validar las hipótesis, el modelo de enriquecimiento debería ser capaz de construir un modelo de recomendación y algoritmo de valoración basado en redes y las medidas que el SNA propone.

Para desarrollar este caso se utilizaron los componentes: Captura de datos, Creación de redes y Análisis y visualización de redes y Recomendación. A continuación se presenta en detalle las propuestas del modelo y su uso dentro del caso.

Captura de datos este componente se encuentra descrito en el apartado 4.4.1. Específicamente se utilizaron los módulos: Construcción de tópicos (detalles en el apartado 4.4.1.1 y Recolección de datos (descrito en la sección 4.4).

Construcción de tópicos, los tópicos son los temas que necesitan ser enriquecidos con recursos extraídos desde las redes sociales. En este caso, se trabajó directamente con dos tópicos sobre dos temas concretos(matlab y html5), dejando sin usar la primera parte de este módulo. Una vez definidos los tópicos, estos fueron transformados en expresiones de búsqueda para la red social Twitter, así los tópicos se transformaron en \#matlab y \#html5. Tal como se plantea en el modelo de enriquecimiento dentro de éste módulo, la recolección de datos debe respetar las políticas y límites impuestos por la fuente de datos. Para este caso se optó por realizar búsquedas cada sesenta minutos, lo que permitió respetar las normas del API de Twitter. Esta decisión podría dejar de fuera algunas publicaciones (tweets) que podrían tener recursos relevantes para los temas que se busca enriquecer. Para este primer experimento se buscó captar datos, sin que los mismos sean completos. 

utilizando como base el análisis de redes sociales

Creación de redes este componente se encuentra descrito en la sección 4.4 .2 . Específicamente, se utilizaron los módulos: Identificar redes (descrito en 4.4.2.1) e Instanciar redes (descrito en detalle en el apartado 4.4.2.2).

Identificar redes, el modelo de enriquecimiento plantea que para realizar recomendaciones es necesario crear las siguientes redes:

- Una red fruto de interacciones entre usuarios, la cual se denomina social. Para este caso la red se formó cuando un usuario menciona a otro o un usuario vuelve a publicar información publicada anteriormente por otro usuario. Dentro de Twitter la primera acción se denomina mención y se expresa dentro de un tweet anteponiendo el símbolo @ al nombre del usuario. Mientras que la segunda acción se denomina re-tweet y se consigue iniciando el contenido de un tweet con el texto $R T$ seguido de @ y el nombre del usuario.

- La segunda red que propone el modelo es denominada contexto y se obtiene del contenido que es publicado dentro de la red social en línea. Para este caso se utilizaron hashtags que es parte del contenido que es compartido dentro de los tweets. Un hashtag es cualquier texto que inicia con el símbolo $\#$.

Instanciar redes, con los datos recolectados en el componente anterior y las redes identificadas es posible crear instancias de cada una de las redes. En este caso se utilizó un modelo de almacenamiento relacional para el almacenamiento de los datos y para crear las redes se utilizó consultas SQL que fueron directamente introducidas en la herramienta que se utilizó con ese objetivo.

Análisis y visualización de redes los detalles del componente se encuentran descritos en la sección 4.4.3. Dentro de este caso se utilizó el módulo denominado Analizar a través de métricas de SNA y visualizar que se escrito a detalle en 4.4.3.1.

Como propone el modelo de enriquecimiento, se aplicó la medida de centralidad denominada Intermediación (Betweenness) en ambas redes (social y contexto), 


\section{VALIDACIÓN DE LAS HIPÓTESIS PROPUESTAS}

a continuación el detalle:

- Para la red denominada social, esta medida permite encontrar nodos (usuarios) que se destacan por ser nodos que conectan diferentes secciones de la red (otros grupos de usuarios), es decir sus publicaciones son lo suficientemente amplias para causar interés entre varios usuarios, provocando así un efecto en varios grupos de usuarios, lo que convierte a ese usuario en un vínculo entre diferentes usuarios.

- Dentro de la red de contexto, los nodos (hashtags) con un mayor nivel de intermediación son nodos con un significado amplio que siempre o casi siempre están presentes junto a otros conceptos. Esta amplia relación denota que son conceptos generales que siempre están presentes cuando se habla de un tema permitiendo tener así una visión del contexto del tema.

La visualización de datos, es un módulo que no fue ampliamente utilizado dentro de este problema, sin embargo se utilizó parcialmente a través de la generación de visualización a través del plugin LoxaWebSite Exporter 1 que es una herramienta que se construyó en el desarrollo de esta tesis.

Recomendar este componente se encuentra descrito en la sección 4.4.4, mientras que a nivel de módulos se utilizaron los siguientes: Usuarios destacados (que se describe en la sección 4.4.4.1), Contenidos compartidos en la red social Contexto (descrito en la sección 4.4.4.5), Enriquecimiento de ítems (la descripción la pueden encontrar en 4.4.4.3), Legal (ver detalles en la sección 4.4.4.4) y Valoración cuyos detalles están en la sección 4.4.4.6.

Usuarios destacados, dentro del modelo de enriquecimiento se considera como usuarios destacados a aquellos usuarios que provienen de la red de usuarios denominada social que se analizó en párrafos anteriores. En este caso esos usuarios destacados se encontraron a través de la intermediación (Betweenness) que es una medida de entre muchas, aunque el modelo podría usar cualquier otra medida de centralidad, según el problema que se resuelve. La recomendación general del modelo es utilizar una medida de centralidad.

${ }^{1}$ http://www.j4loxa.com/sna/gephi/plugins/index.html 


\subsection{Caso 4: Recomendación de OERs compartidos en redes sociales utilizando como base el análisis de redes sociales}

Contenidos compartidos en la red social - Contexto. Dentro del componente de recomendación también se utiliza la red con se construye con los contenidos que se difunden a través de la red social (a lo que el modelo denomina contexto), es por ello que en el caso se construyó una red utilizando las etiquetas o hashtags de los tweets publicados cuya construcción y análisis se describió en párrafos anteriores. Al igual que con los usuarios se recomienda usar una medida de centralidad para determinar los elementos clave del contexto.

Una vez identificados los usuarios destacados, el siguiente paso a ejecutar según el modelo es enriquecer la información de los recursos publicados por dichos usuarios. El propósito de este módulo es obtener mayor información de cada recurso. Es por ello que por cada recurso se recuperó el título, descripción y keywords. Esta información será utilizada para calcular el rating (valoración) de cada uno de los recursos.

Una vez que se ha reunido toda la información, el modelo propone un algoritmo de valoración que asigna un rating a cada recurso. Para ello utiliza el contenido expuesto socialmente y el contenido del recurso enriquecido.

La aplicación del módulo de recomendación, como muestran las Tablas 5.10 y 5.11 es capaz de generar otros resultados diferentes si se compara con los recursos más difundidos dentro de la red. La Tabla 5.10 muestra las 10 primeras URLs compartidas en Twitter descritas con el hashtag \#html5, la posición se calculó por el número de veces que fueron compartidas. Mientras que la Tabla 5.11 muestra las 10 primeras URLs obtenidas utilizando el modelo de enriquecimiento que se propone en esta tesis. El análisis completo lo pueden encontrar en el Anexo 7.2 .3

Finalmente el módulo de validación Legal se limitó a garantizar el acceso a los recursos, sin analizar si los recursos poseen algún tipo de licencia abierta tales como Creative Commons que permitan su re-uso. Para garantizar el acceso a los recursos, se verificó que cada uno de ellos estén disponibles a través del código HTTP que devuelve el servidor, seleccionando únicamente aquellos recursos cuyo código es igual 200.

La ejecución de este caso ayudó a validar varias hipótesis que se plantearon en la construcción del modelo de enriquecimiento, lo que nos permite afirmar que se puede 


\section{VALIDACIÓN DE LAS HIPÓTESIS PROPUESTAS}

Tabla 5.10: Diez URLs populares compartidas en Twitter descritas con el hashtag \#html5

\begin{tabular}{|l|l|l|}
\hline \multicolumn{1}{|c|}{ URL } & \multicolumn{1}{|c|}{ Descripción del sitio } & Posición \\
\hline https://goo.gl/PNS193 & $\begin{array}{l}\text { Herramienta para descargar vídeos } \\
\text { desde YouTube }\end{array}$ & 1 \\
\hline https://goo.gl/8vcT34 & Servicio de hosting & 2 \\
\hline https://goo.gl/aahV1N & Tema para Wordpress & 3 \\
\hline https://goo.gl/FaMW6L & Cuenta de Twitter & 4 \\
\hline \hline https://goo.gl/GNrnSf & $\begin{array}{l}\text { Animaciones interactivas basadas en } \\
\text { HTML5 y Javascript }\end{array}$ & 5 \\
\hline https://goo.gl/NHpq10 & Noticia sobre HTML5 & 6 \\
\hline https://goo.gl/8mVcp0 & Tutorial para crear una aplicación Web & 7 \\
\hline https://goo.gl/3seYLW & Noticia sobre HTML5 & 8 \\
\hline https://goo.gl/bu60Je & Plugins para desarrolladores Web & 9 \\
\hline \hline https://goo.gl/w0z7ou & Plantilla basada en HTML5 & 10 \\
\hline
\end{tabular}

utilizar como una herramienta para extraer información publicada en una red social. La extracción se realiza a través del análisis de la estructura subyacente a la red social, para así encontrar recursos, personas y temas relacionados que ayuden a estudiantes en su formación. El uso combinado de las relaciones entre usuarios y el uso de las relaciones que se encuentran en el contenido publicado en una red social han permitido desarrollar un modelo de recomendación.

Para mostrar cómo se validaron las hipótesis, es necesario analizar cada un de ellas desde el análisis de dos elementos de una sistema de recomendación. El primero elemento, es el modelo de recomendación, es decir cómo se generan las recomendaciones. El segundo elemento el algoritmo de valoración (ranking). Ambos elementos se analizan desde el punto de vista del análisis de las redes sociales (redes y medidas).

Para el primer elemento la Tabla 5.12 muestra cómo se puede puede construir un modelo de recomendación utilizando una red social y las relaciones entre los usuarios de la misma, con el fin de encontrar a aquellos usuarios con publicaciones relevantes en diferentes grupos de usuarios, por lo tanto se valida la hipótesis $\mathbf{H 3}$.

Para el segundo elemento, algoritmo de valoración (ranking), la Tabla 5.13 muestra cómo se puede construir un algoritmo de valoración (ranking) utilizando redes y medidas del SNA. Este algoritmo es complementado con la discriminación del origen de los datos 
Tabla 5.11: Diez URLs recomendadas por el modelo de enriquecimiento propuesto.

\begin{tabular}{|l|l|l|}
\hline \multicolumn{1}{|c|}{ URL } & \multicolumn{1}{|c|}{ Descripción del sitio } & Posición \\
\hline https://goo.gl/7ySev & $\begin{array}{l}\text { Tutoriales en formato vídeo para } \\
\text { enseñar HTML5, CSS3, Javascript. }\end{array}$ & 1 \\
\hline https://goo.gl/RXFTa1 & $\begin{array}{l}\text { Libro de programación en HTML5 con } \\
\text { Javascript y CSS3. }\end{array}$ & 2 \\
\hline https://goo.gl/tyt4Nq & $\begin{array}{l}\text { Tutoriales, código fuente para } \\
\text { aprender a desarrollar un proyecto Web. }\end{array}$ & 3 \\
\hline https://goo.gl/bWbh65 & $\begin{array}{l}\text { Fotografía de un libro para } \\
\text { aprender HTML5, Javascript y jQuery. }\end{array}$ & 4 \\
\hline https://goo.gl/ugWxLD & $\begin{array}{l}\text { Cupón de descuento para un curso } \\
\text { sobre HTML5 en Udemy. }\end{array}$ & 5 \\
\hline https://goo.gl/d00vC0 & $\begin{array}{l}\text { Entrada de un blog de una herramienta } \\
\text { popular en el desarrollo de sitios Web. }\end{array}$ & 6 \\
\hline https://goo.gl/HrZAZQ & $\begin{array}{l}\text { Sitio Web oficial de la W3C de } \\
\text { entrenamiento online para } \\
\text { desarrolladores Web. }\end{array}$ & 7 \\
\hline https://goo.gl/8EfD & $\begin{array}{l}\text { Tutoriales para aprender HTML a través } \\
\text { de ejemplos conocido como w3schools }\end{array}$ & 8 \\
\hline https://goo.gl/78mH & W3Schools tutoriales Web Online & 9 \\
\hline \hline https://goo.gl/GbOv88 & $\begin{array}{l}\text { Lecturas sobre el desarrollo de compo- } \\
\text { nentes Web. }\end{array}$ & 10 \\
\hline
\end{tabular}




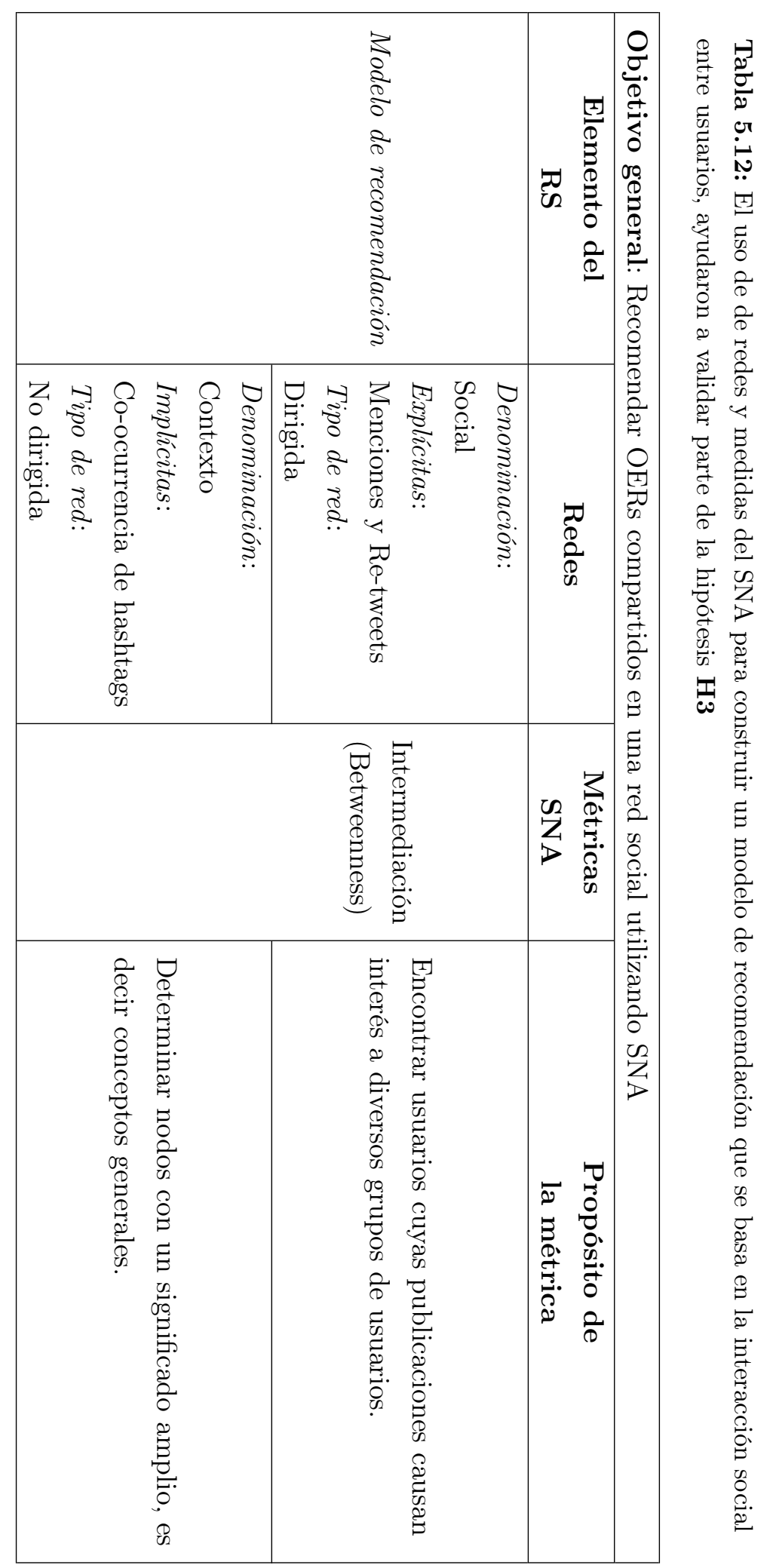



utilizando como base el análisis de redes sociales

como se muestra en la sección 4.4.4.6, por lo tanto es así como se valida la hipótesis H4.

La validación de las hipótesis H3 y $\mathbf{H} 4$ permiten validar la hipótesis $\mathbf{H} 1$ ya que como se mencionó anteriormente, el uso de un modelo de recomendación y un algoritmo de valoración que utilice la información que se publica en una red social y la estructura de esa red, permite construir un modelo de enriquecimiento para iniciativas educativas que se basen en el uso de recursos educativos abiertos.

Dentro de los módulos que se utilizaron quedan algunos temas pendientes, así tenemos que dentro del componente de Captura de datos los temas pendientes fueron:

- Construcción de tópicos, no se utilizó: a)la estructura de la iniciativa educativa, b) a un grupo de expertos y c) la extracción automática, ya que como se mostró anteriormente se definieron dos tópicos generales

En el módulo de Creación de redes, los temas pendientes fueron:

- Instanciar redes, dentro de este módulo se plantea el uso de base de datos orientadas a grafos para almacenar la información, que en este caso tampoco se llegó a utilizar.

Mientras que para el componente de Análisis y visualización de redes, los temas pendientes fueron:

- Analizar vía métricas de SNA, no se utilizaron otro tipo de métricas que permitan analizar comunidades o clustering. Además considerando la diversidad de métricas existentes, este punto siempre tendrá pendientes.

Finalmente dentro del componente de Recomendación, el tema pendiente fue:

- Utilizar el la producción vista bajo el lente del tiempo para cada uno de los usuarios con el fin de mejorar la selección de los mismos. 


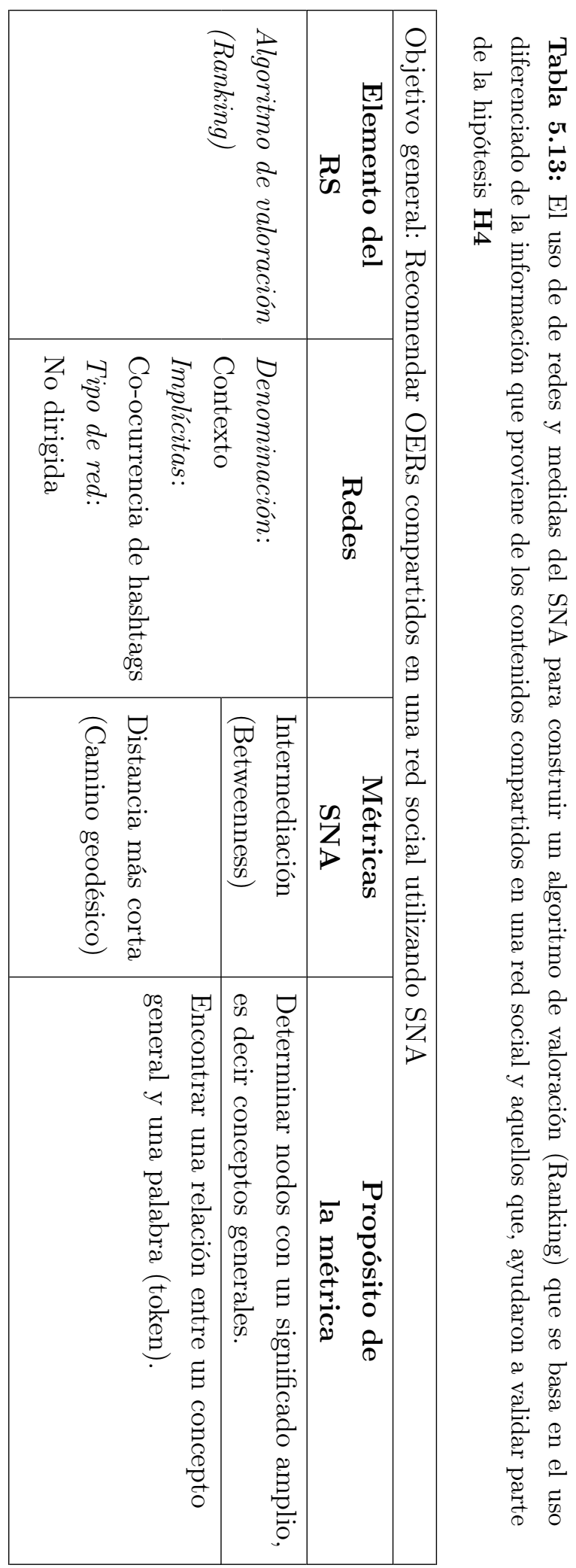




\subsection{Caso 5: Recomendación de OERs para Emprendimien- to utilizando un marco de trabajo basado en Análisis de Redes Sociales}

Con el primer camino trazado, descrito en la sección 5.5. en donde se construyó la primera versión del modelo de recomendación, era necesario integrarlo para construir un modelo de enriquecimiento completo que se puede aplicar a varias iniciativas que utilicen recursos educativos abiertos.

En este trabajo se realizó esa implementación, tomando como base el proyecto StartUP ${ }^{1}$ que busca utilizar OERs para ayudar a desarrollar y potenciar las habilidades emprendimiento que los alumnos inscriptos necesitan.

Los resultados del modelo de enriquecimiento se integraron con los caminos de aprendizaje (learning paths) de la plataforma desarrollada por StartUP. Estos caminos de aprendizaje son generados para cada uno de los inscritos y que se construye según las necesidades de formación individuales. El detalle del trabajo lo pueden encontrar en Lopez-Vargas et al. (2015a).

\subsubsection{Componentes y módulos utilizados}

Durante este caso se pudo utilizar la mayoría de los componentes y los módulos que forman el modelo de enriquecimiento, así como muestra la Figura 5.16, en la Tabla 5.14 se puede ver a detalle el uso de los componentes y módulos así como también el uso de esos elementos colaboraron con la validación de las hipótesis H1, H3 y H4, el detalle se puede encontrar en la sección 5.6 .2

Tabla 5.14: Componentes y módulos utilizados, el uso de los mismos buscó validar las hipótesis H1, H3, H4 y H5

\begin{tabular}{|l|l|}
\hline Usado & Componente/módulo del modelo de enrequecimiento \\
\hline \multicolumn{2}{|c|}{ Captura de datos } \\
\hline Construcción de tópicos \\
\hline$\checkmark$ & $\begin{array}{l}\text { Los tópicos se construyeron para cada una de las competencias } \\
\text { definidas por el modelo de StartUP. } \\
\text { Un listado completo lo pueden encontrar en la Tabla } 5.15\end{array}$ \\
\hline \multicolumn{2}{|c|}{ Continúa en la siguiente página } \\
\hline
\end{tabular}

$\sqrt[1]{\text { http://www.startupproject.eu }}$ 


\section{VALIDACIÓN DE LAS HIPÓTESIS PROPUESTAS}

Tabla 5.14 - continuación de la página anterior

\begin{tabular}{|c|c|}
\hline Usado & Componente/módulo del modelo de enrequecimiento \\
\hline \multicolumn{2}{|c|}{ Recolectar datos } \\
\hline$\checkmark$ & $\begin{array}{l}\text { - Se recolectó datos considerando políticas y límites. } \\
\text { - Se usó Twitter como fuente de datos. }\end{array}$ \\
\hline \multicolumn{2}{|r|}{ Creación de redes } \\
\hline \multicolumn{2}{|c|}{ Identificar redes } \\
\hline$\checkmark$ & $\begin{array}{l}\text { Redes explícitas. Se construyeron las siguientes redes: } \\
\text { - Menciones de usuarios (Mentions) } \\
\text { - Re-Tweets (RT) }\end{array}$ \\
\hline$\checkmark$ & $\begin{array}{l}\text { Redes implícitas. Se construyeron las siguientes redes: } \\
\text { - Etiquetas (hashtags) publicadas en cada tweet }\end{array}$ \\
\hline$\checkmark$ & $\begin{array}{l}\text { Red de participantes: } \\
\text { - Redes de cuentas de Twitter. }\end{array}$ \\
\hline$\checkmark$ & $\begin{array}{l}\text { Red del contexto: } \\
\text { - Hashtags }\end{array}$ \\
\hline \multicolumn{2}{|c|}{ Instanciar redes } \\
\hline$\checkmark$ & $\begin{array}{l}\text { Se utilizó: } \\
\text { - Base de datos relacional para almacenar los datos. } \\
\text { - Software SNA (Gephi) }\end{array}$ \\
\hline \multicolumn{2}{|r|}{ Análisis y visualización de redes } \\
\hline \multicolumn{2}{|c|}{ Analizar redes } \\
\hline$\checkmark$ & $\begin{array}{l}\text { Analizar a través de métricas de SNA. Métricas utilizadas: } \\
\text { - Intermediación (Betweenness). }\end{array}$ \\
\hline \multicolumn{2}{|c|}{ Visualizar } \\
\hline$\checkmark$ & $\begin{array}{l}\text { - Imágenes dinámicas. } \\
\text { - Sitio Web que muestra los resultado. } \\
\text { - Nube de palabras clave. }\end{array}$ \\
\hline \multicolumn{2}{|r|}{ Recomendar } \\
\hline \multicolumn{2}{|l|}{ Social } \\
\hline$\checkmark$ & - Se usó una red de usuarios. \\
\hline \multicolumn{2}{|c|}{ Contenidos } \\
\hline$\checkmark$ & $\begin{array}{l}\text { Se trabajó con información que proviene de: } \\
\text { - La red social (hashtags) } \\
\text { - De los recursos compartidos (Title, Description, Keywords) }\end{array}$ \\
\hline \multicolumn{2}{|l|}{ Legal } \\
\hline$\checkmark$ & $\begin{array}{l}\text { Se garantiza } \\
\text { - Acceso }\end{array}$ \\
\hline
\end{tabular}

Hipótesis a validar

(Con la ejecución de los componentes y módulos anteriores se buscó validar las siguientes hipótesis) 

marco de trabajo basado en Análisis de Redes Sociales

Tabla 5.14 - continuación de la página anterior

\begin{tabular}{|l|l|}
\hline Usado & Componente/módulo del modelo de enrequecimiento \\
\hline $\mathbf{H 1}$ & $\begin{array}{l}\text { Un modelo de enriquecimiento que utilice la información } \\
\text { publicada en una red social, además de su estructura, con el } \\
\text { propósito de encontrar recursos, personas temas relacionados } \\
\text { y roles, apoya a la consecución de los } \\
\text { objetivos de las iniciativas educativas que lo implementen. }\end{array}$ \\
\hline $\mathbf{H 3}$ & $\begin{array}{l}\text { Las relaciones entre usuarios, su comportamiento a } \\
\text { través del tiempo complementados con el contenido que } \\
\text { se difunde en una red social, analizados a través de un } \\
\text { enfoque de análisis de redes sociales permite desarrollar } \\
\text { un modelo de recomendación confiable. }\end{array}$ \\
\hline $\mathbf{H 4}$ & $\begin{array}{l}\text { Priorizar la información que ha sido expuesta dentro } \\
\text { de una red social sobre aquella que no lo fue, permite } \\
\text { construir un sistema de ranking para recursos difundidos } \\
\text { en una red social. }\end{array}$ \\
\hline \hline
\end{tabular}

La solución que se propuso al problema fue utilizar la información publicada en una red social y su estructura subyacente para encontrar recursos, personas y temas relacionados que ayuden a estudiantes en su formación, y así validar la hipótesis H1.

Una de las características de la solución es el uso combinado de las relaciones entre usuarios y de las relaciones que se encuentran en el contenido publicado dentro de la red social en linea utilizando el SNA con el fin de desarrollar un modelo de recomendación. De esta forma se busca validar la hipótesis H3

Otra de las características fue hacer énfasis en el uso de la información que había sido publicada en la red social, que se considera primordial por haber sido expuesta a un conglomerado de personas, dejando en segundo plano a la información que proviene de actividades aisladas y desarrolladas de forma personal. Esta aproximación busca validar la hipótesis $\mathbf{H 4}$.

\subsubsection{Validación de hipótesis de investigación}

En esta sección se muestra los acciones ejecutadas buscando dar una solución al problema propuesto por el caso. Así como también se presenta una descripción de la 


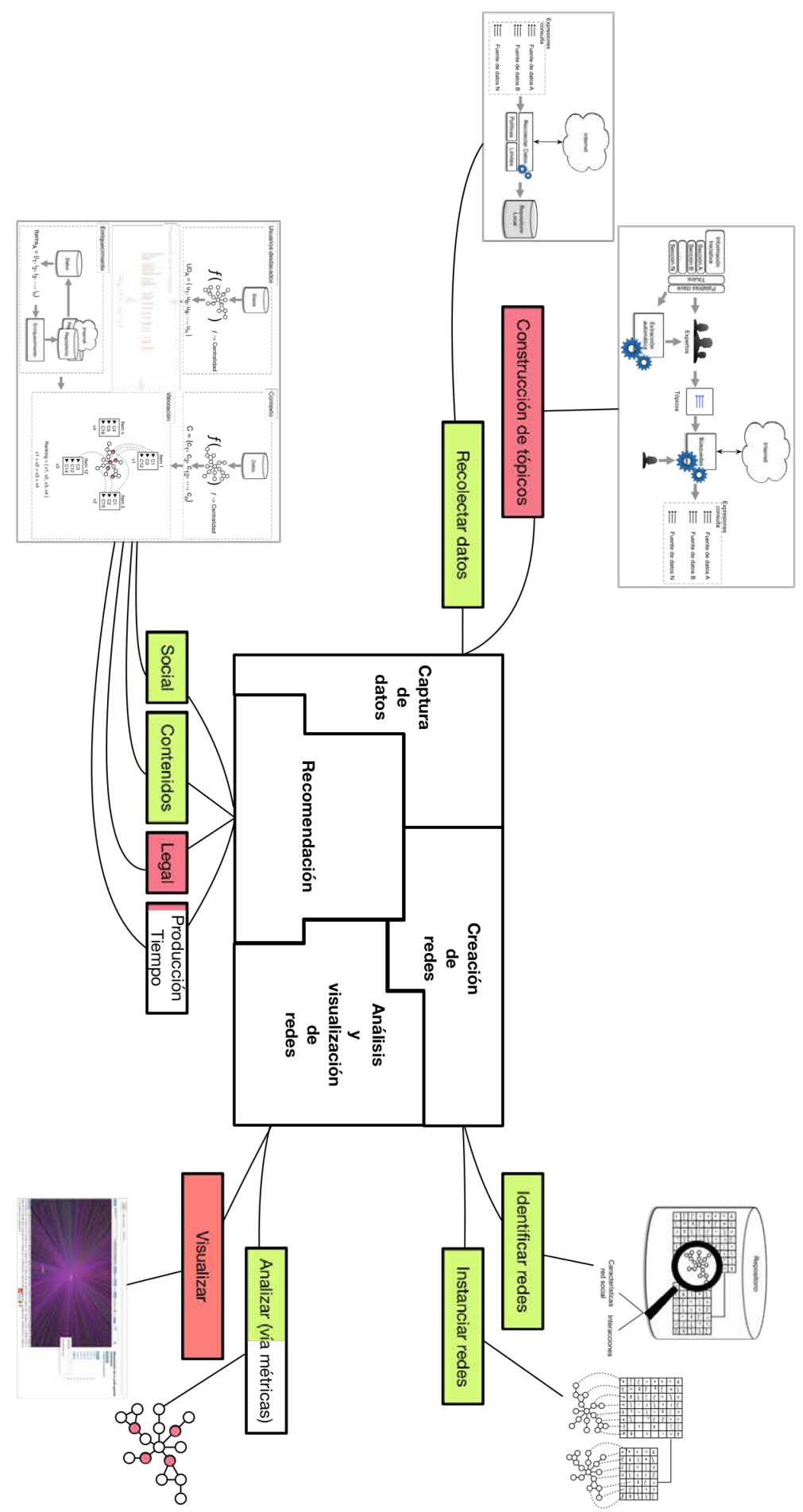

Figura 5.16: Componentes y módulos del modelo de enriquecimiento que se utilizaron en este caso - El casó empleó todos los componentes y módulos, aunque no todos los módulos fueron utilizados en igual proporción como indican los colores en cada uno de los ellos. 


\subsection{Caso 5: Recomendación de OERs para Emprendimiento utilizando un marco de trabajo basado en Análisis de Redes Sociales}

validación de las hipótesis con las que se relaciona el caso.

\subsubsection{Construcción de la solución}

El propósito en este trabajo fue implementar y validar un modelo de enriquecimiento, que incluye el sistema de recomendación descrito anteriormente, para la iniciativa StartUP que busca proporcionar recursos educativos abiertos efectivos que ayuden a cubrir las necesidades individuales de aprendizaje de los emprendedores.

Para ello, el proyecto StartUP definió la Matriz de competencias del emprendedor en donde se identifican 4 áreas (Negocios, Administración, Comunicación y Autodesarrollo) y dentro de cada área existen un grupo de competencias que se deben desarrollar, por ejemplo el área de Negocios tiene las siguientes competencias: planificación empresarial, la financiación y la planificación financiera, aspectos legales y marco legal(habilidades de contratación), ventas y marketing, tecnología y conocimiento de redes.

Las competencias de cada una de las áreas se convirtieron en las entradas del modelo de enriquecimiento, mientras que las salidas por cada una de las áreas y competencias fueron las siguientes:

- Un conjunto de usuarios (cuentas de Twitter) que puede ser considerados relevantes en un dominio.

- Temas relacionados (hashtags) que permiten ampliar la visión que el aprendiz puede tener del tema.

- Recursos educativos abiertos, que son las URLs que se han extraído desde la red social.

Cada uno de estos resultados se integraron con los caminos de aprendizaje (learning paths) que la plataforma desarrollada para StartUP genera por cada uno de los inscritos y que se construye según las necesidades individuales de formación.

La fuente de datos se construyó así: las competencias, para cada una de las 4 áreas, fueron transformadas manualmente en expresiones de búsqueda (palabras y/o hashtags) que permitan obtener resultados en la red social Twitter que fue la fuente de datos, para luego ser seleccionadas según los resultados obtenidos dentro del campo del emprendimiento. Una vez identificados las expresiones de búsqueda, se recolectó la información. 


\section{VALIDACIÓN DE LAS HIPÓTESIS PROPUESTAS}

Tabla 5.15: Expresiones de búsqueda por área y por competencias con el número de Tweets con URL

\begin{tabular}{cllr}
\multirow{2}{*}{ Área } & \multicolumn{1}{c}{ Competencias } & \multicolumn{1}{c}{$\begin{array}{r}\text { Expresión } \\
\text { de búsqueda }\end{array}$} & $\begin{array}{r}\text { Nro. Tweets } \\
\text { con URL }\end{array}$ \\
& Business planning & \#businessplanning & 1683 \\
Business & Financial planning & \#financialplanning & 7783 \\
& Networking skills & \#networking \#skills & 850 \\
& Interpersonal skills & interpersonal skills & 429 \\
Communication & Non verbal & nonverbal & 1496 \\
& Presentation skills & \#presentation \#skills & 968 \\
& Public speaking & public speaking & 1568 \\
& Goal setting & goal setting & 4103 \\
& Leadership initiative & \#leadership \#initiative & 1132 \\
& Project management & \#project \#management & 3290 \\
& Risk management & \#riskmanagement & 1811 \\
& Team working & teamworking & 282 \\
& Time management & \#timemanagement & 1578 \\
Self-development & Assertiveness & \#assertiveness & 1780
\end{tabular}

En la Tabla 5.15 se muestran las expresiones de búsqueda utilizadas, así como también el número de Tweets que tienen una URL, ya que las redes que se construyeron se limitan a trabajar con Tweets que poseen al menos una URL, esta es una de las diferencias con el trabajo mostrado en la sección anterior.

\section{- Redes construidas}

Se construyeron redes, una por cada competencia, con el objetivo de aportar a cada una de ellas con los tres tipos de resultados descritos.

$\mathrm{Al}$ igual que el trabajo anterior, las relaciones explícitas entre usuarios que se identificaron en este trabajo fueron re-tweets y menciones entre los usuarios, mientras que para la identificación de relaciones implícitas se usó la co-ocurrencia de hahstags. Esto permitió construir dos clases de redes: i)una con usuarios en donde los nodos son cuentas de Twitter y las relaciones entre ellos señalan un re-tweet o mención; ii) la segunda red con hashtags, en esta red los nodos son hashtags y los enlaces (relaciones) muestran que las hashtags estuvieron presentes en un mismo tweet. Para ambas redes el peso 


\subsection{Caso 5: Recomendación de OERs para Emprendimiento utilizando un marco de trabajo basado en Análisis de Redes Sociales}

de la relación muestra la cantidad de re-tweets/menciones y la cantidad coincidencias respectivamente.

Para cada uno de las redes se identificaron a los nodos (usuarios y hashtags) relevantes utilizando la medida de centralidad denominada Intermediación (Betweenness), permitiendo así encontrar aquellos nodos que son puente y además acceso a otros grupos de personas y a otros grupos de temas relacionados.

Una vez identificados los nodos destacados en las redes, inicia el proceso de recomendación. En este proceso se seleccionan las URLs que son publicadas por los usuarios destacados y se evalúa su importancia usando los hashtags relevantes detectados con anterioridad, cumpliendo así la valoración social (usuarios) y la valoración de contenidos (hashtags). Mientras que la valoración legal, uso de licencias abiertas, está sujeto a la existencia o no de una licencia tanto a nivel de metadata, anotaciones o etiquetas html.

El resultado del modelo de enriquecimiento puede verse en un sitio Web de demostración que se construyo y que se denomina StartUP demo social OER discovery 1 Ese sitio Web muestra tres aproximaciones que se utilizaron, dos de ellos basado en Web Semántica. La Figura 5.17 muestra capturas de pantalla de la aplicación de demostración que se desarrolló.

\subsubsection{Validación}

En este apartado se muestra como el caso permitió validar algunas de las hipótesis propuestas como parte del modelo de enriquecimiento que propuesto. Concretamente las hipótesis a validadar son:

H1: Un modelo de enriquecimiento que utilice la información publicada en una red social, además de su estructura, con el propósito de encontrar recursos, personas, temas relacionados y roles, apoya a la consecución de los objetivos de las iniciativas educativas que lo implementen.

H3: Las relaciones entre usuarios, su comportamiento a través del tiempo complementadas con el contenido que se difunde en una red social analizados a través de un enfoque de análisis de redes sociales permite desarrollar un modelo de recomendación confiable.

\footnotetext{
${ }^{1}$ http://j4loxa.com/sna/ser/recommender/
} 
Startup demo social OER discovery

a)
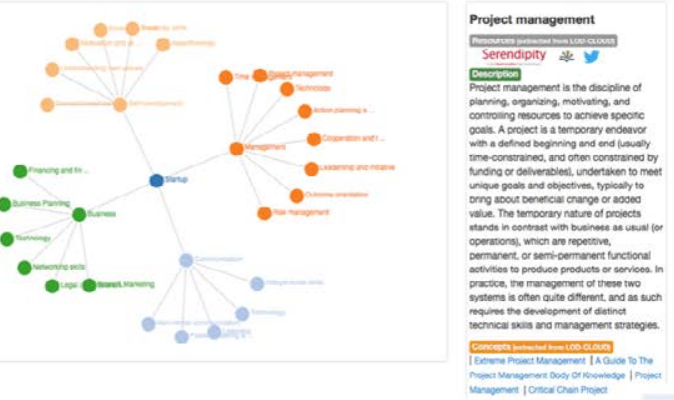

c)

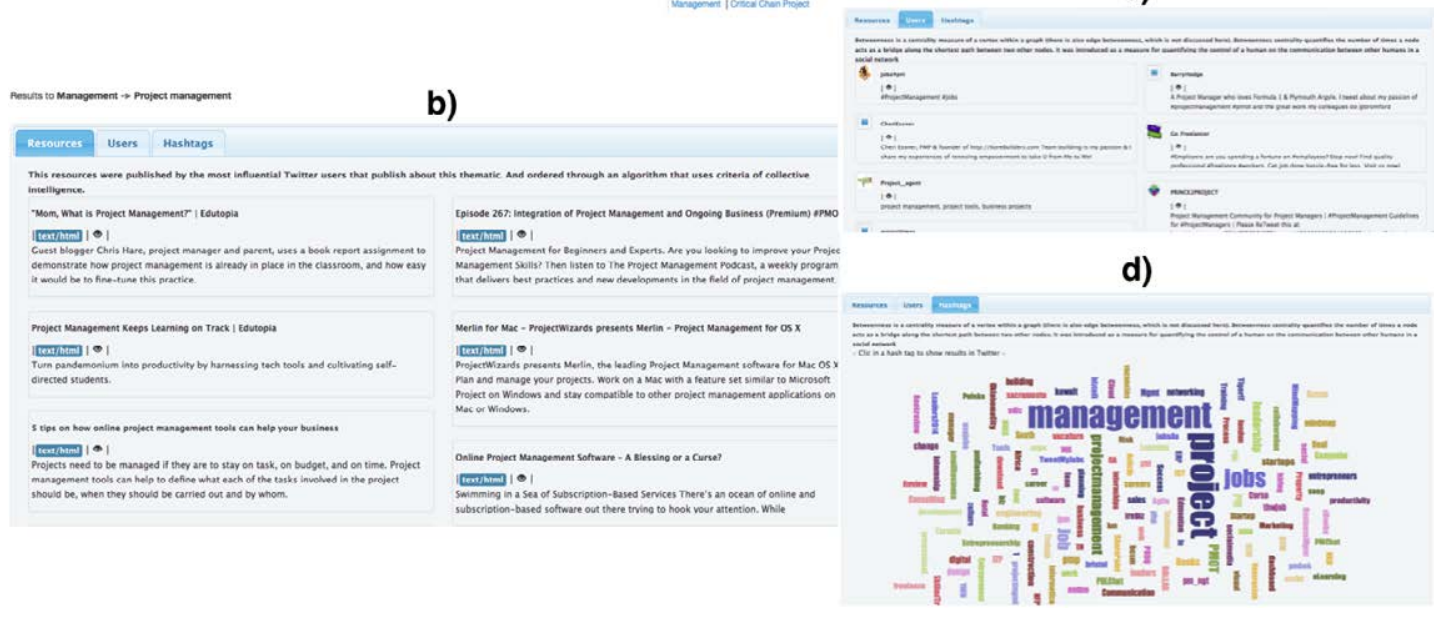

b)

Figura 5.17: Imágenes que muestra las diferentes pantallas del Demo que se construyó para StartUP project - En la sección a) muestra la aplicación completa, mientras que las secciones b) recursos digitales, c) Usuarios y d) Temas relacionados, muestran las secciones específicas que aportó el modelo de enriquecimiento que se presenta en esta tesis. Todas ellas muestran información relacionadas al área Management y con la competencia Project management 


\subsection{Caso 5: Recomendación de OERs para Emprendimiento utilizando un marco de trabajo basado en Análisis de Redes Sociales}

H4: Priorizar la información que ha sido expuesta dentro de una red social sobre aquella que no lo fue, permite construir un sistema de ranking para recursos difundidos en una red social.

Para la validación de las hipótesis el modelo de enriquecimiento debería ser capaz de captar datos que son publicados en una red social en línea y encontrar recursos educativos que apoyen en el proceso de enseñanza aprendizaje de una iniciativa educativa. Haciendo énfasis en la recuperación de los recursos educativos para validar las hipótesis, el modelo de enriquecimiento debería ser capaz de construir un modelo de recomendación y algoritmo de valoración basado en redes y las medidas que el SNA propone.

Este caso es similar al caso que se muestra en la sección 5.5.2, es por ello que aquí se hará énfasis únicamente en los elementos que no fueron utilizados en el caso 4.

Captura de datos este componente se encuentra descrito en el apartado 4.4.1. Dentro de este caso y a diferencia del caso 4, se utilizó la información de la iniciativa para encontrar para encontrar un conjunto de tópicos, que como se muestra en la Tabla 5.15, se basaron en una matriz de competencias definidas para emprendedores.

Recomendar este componente se encuentra descrito en la sección 4.4.4. En este caso el módulo Legal (descrito en la sección 4.4.4.4) se agregó el análisis del uso de las licencias abiertas que permitan re-uso, es por ello que se utilizó expresiones regulares para buscar licencias creative commons dentro del contenido HTML de cada uno de los recursos.

Para este caso la mayoría de las actividades se realizaron de forma automática, con la publicación de resultados (recursos) de forma periódica que permite tener nuevos datos cada cierto tiempo que está atado directamente con la cantidad de datos que pueden ser recogidos desde la redes sociales en línea.

Para la validación de las hipótesis, anteriormente propuestas se utilizó la misma técnica que para el caso 4, es decir la creación de un modelo de recomendación y un algoritmo de valoración que se base en redes y en las medidas que el análisis de redes sociales posee. Para los detalles ver las Tablas 5.12 y 5.13 


\section{VALIDACIÓN DE LAS HIPÓTESIS PROPUESTAS}

La validación de las hipótesis $\mathbf{H 3}$ y $\mathbf{H} 4$ permiten validar la hipótesis $\mathbf{H} 1$ ya que como se mencionó anteriormente, el uso de un modelo de recomendación y un algoritmo de valoración que utilice la información que se publica en una red social y la estructura de esa red, permite construir un modelo de enriquecimiento para iniciativas educativas que se basen en el uso de recursos educativos abiertos.

La ejecución de este caso ayudó a validar casi todas las hipótesis que se plantearon dentro del modelo de enriquecimiento, lo que nos permite afirmar que se puede utilizar como una herramienta para extraer información publicada en una red social utilizando su estructura subyacente para encontrar recursos, personas y temas relacionados que ayuden a estudiantes en su formación. El uso combinado de las relaciones entre usuarios y el uso de las relaciones que se encuentran en el contenido publicado en una red social han permitido desarrollar un modelo de recomendación.

Dentro de los módulos que se utilizaron quedan algunos temas pendientes, así tenemos que dentro del componente de Captura de datos los temas pendientes fueron:

- Construcción de tópicos, no se utilizó: a)la estructura de la iniciativa educativa, b) a un grupo de expertos y tampoco c) la extracción automática. Ya que como se mostró anteriormente se definieron dos tópicos generales

En el módulo de Creación de redes, los temas pendientes fueron:

- Instanciar redes, dentro de este módulo se plantea el uso de base de datos orientadas a grafos para almacenar la información, que en este caso tampoco se llegó a utilizar.

Mientras que para el componente de Análisis y visualización de redes, los temas pendientes fueron:

- Analizar vía métricas de SNA, no se utilizaron otro tipo de métricas que permitan analizar comunidades o clustering. Además considerando la diversidad de métricas existentes, este punto siempre tendrá pendientes.

Finalmente dentro del componente de Recomendación, el tema pendiente fue:

- Utilizar el la producción vista bajo el lente del tiempo de cada uno de los usuarios con el fin de mejorar la selección de los mismos. 


\subsection{Resumen de la validación de las hipótesis propuestas}

Esta sección muestra un resumen de la validación de las hipótesis que fue posible a través del desarrollo de cada uno de los casos que se describieron anteriormente. Las Tablas 5.16 y 5.17 muestra un resumen de la validación de las hipótesis y los métodos de validación que se utilizaron en cada uno de ellos.

Utilizando el orden con el cual se expusieron los casos, es posible identificar dos etapas bien marcadas en el desarrollo de este proyecto de investigación. La primera una etapa donde se utilizó el SNA como una herramienta de análisis. Mientras que la segunda muestra la construcción del modelo de enriquecimiento con fundamentos en el SNA. A continuación se muestra como esos trabajos permiten validar cada una de las hipótesis que se proponen en esta tesis.

La hipótesis H2 pretende dar al SNA la categoría de una herramienta de análisis para iniciativas educativas desde el punto de vista de diversas relaciones, esto se comprueba en los casos 1, 2 y 3 en donde se representó la información, que proviene de iniciativas educativas tales como OpenCourseWare y MOOCs, como una red para aplicar los conceptos y métricas del SNA. Los resultados de esos análisis han sido una descripción de la situación actual de las iniciativas individuales del grupo; prospectiva, mostrando el potencial de colaboración que podría existir si se dan ciertas condiciones y finalmente los resultados del análisis se pueden usar para la toma de desiciones, buscando mejorar la situación actual de la iniciativa explotando las potencialidades que posee.

La hipótesis $\mathbf{H 1}$ propone que el modelo de enriquecimiento, a través de la explotación de la información de las redes sociales y su estructura, ayuda a que las iniciativas educativas puedan cumplir sus objetivos. Esto se comprueba con los casos 4 y 5 en donde se pudo aplicar el modelo de enriquecimiento, en una primera instancia en un ensayo teórico (caso 4), para luego pasar a su implementación práctica (caso 5) en donde el modelo fue utilizado por una iniciativa basada en cursos para la formación de emprendedores y que recibió comentarios favorables de los recursos que el modelo propuso, así como también críticas que permitieron que el mismo evolucione.

La hipótesis H3 que establece que sólo el análisis de las relaciones existentes entre usuarios de una red es insuficiente para desarrollar un modelo de recomendación y que necesita ser complementado con los análisis del comportamiento de los usuarios en el 


\begin{tabular}{|c|c|c|c|c|c|c|c|c|}
\hline 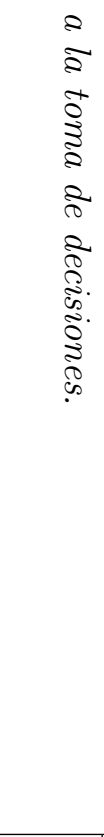 & 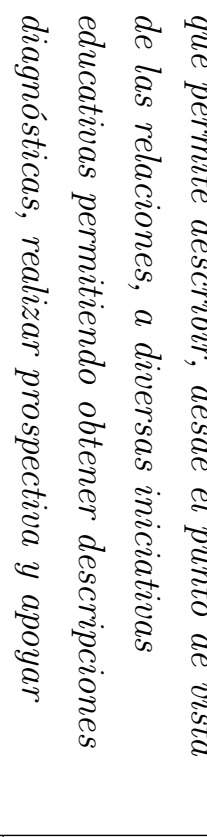 & 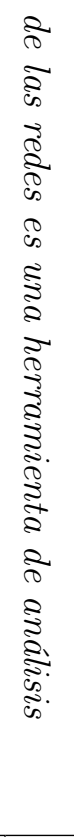 & 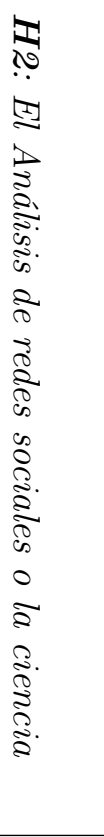 & 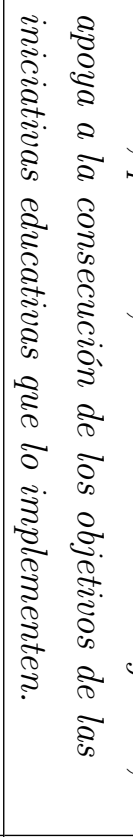 & 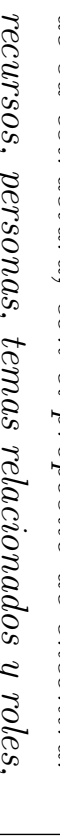 & 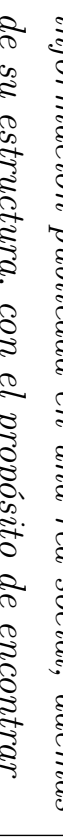 & & \\
\hline $\begin{array}{l}\text { @ी } \\
\text { ळू } \\
\text { co }\end{array}$ & $\begin{array}{l}0 \\
0 \\
0 \\
N\end{array}$ & & 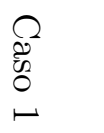 & & 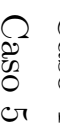 & & & \\
\hline 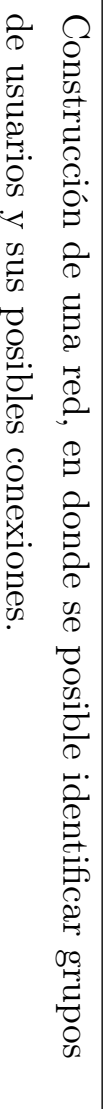 & 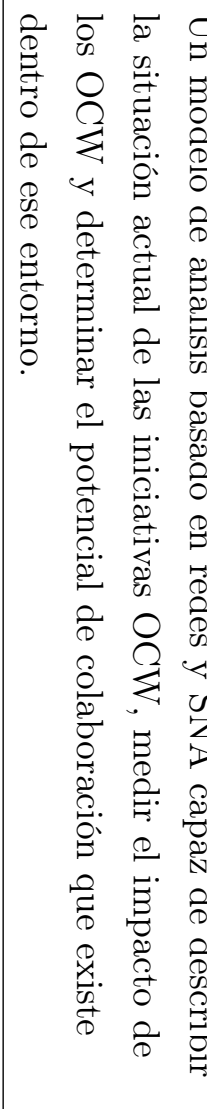 & 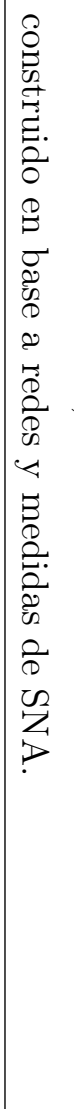 & 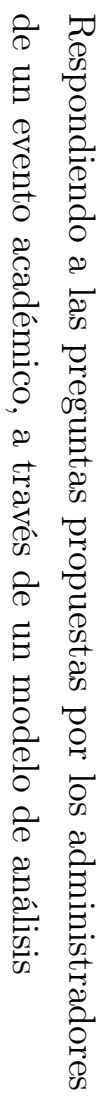 & 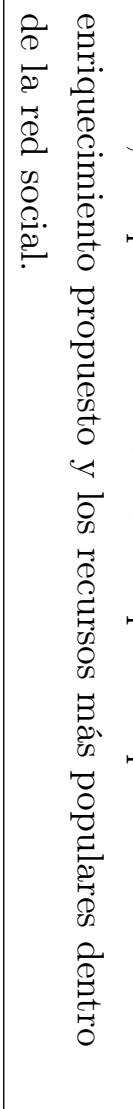 & 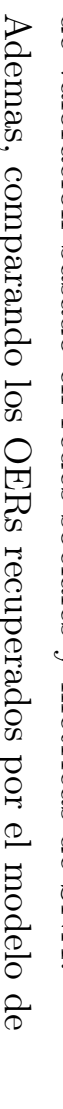 & 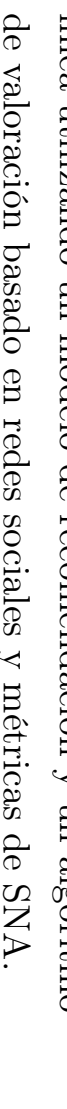 & & \\
\hline
\end{tabular}




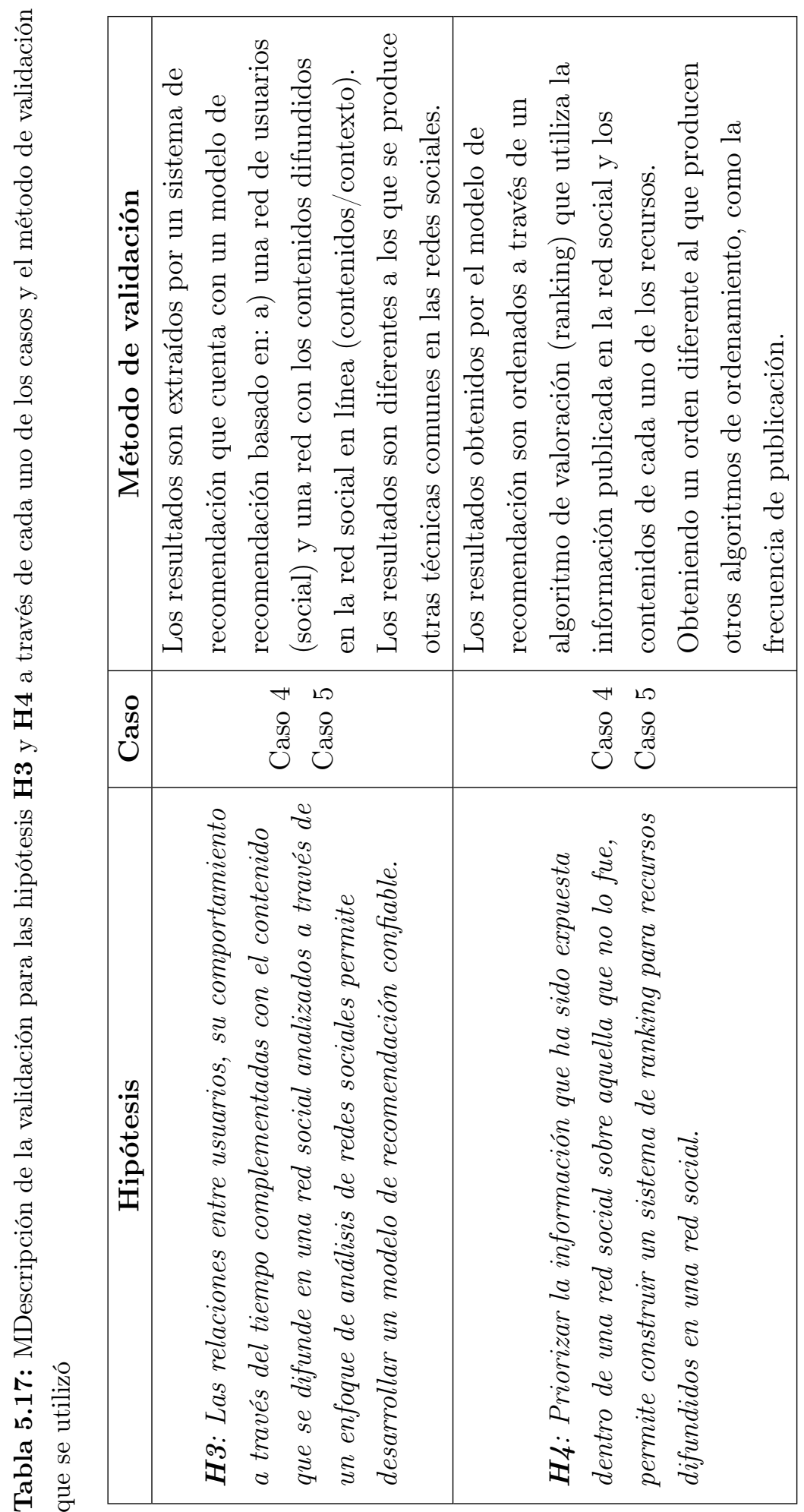




\section{VALIDACIÓN DE LAS HIPÓTESIS PROPUESTAS}

tiempo y la información del contexto se comprueba en los casos 4 y 5 ya que en ellos se utiliza estos elementos para diseñar e implementar un modelo de recomendación que utilice una red social y otro de contexto, aún no se llega a implementar el análisis de la producción de los usuarios en el tiempo. Luego de la evaluación real que se hizo en el caso 5, se observó la necesidad de mejorar la recomendación de usuarios y es por ello que se definió el estudio del comportamiento de los usuarios en el tiempo.

La hipótesis H4 que promueve la priorización de la información expuesta socialmente sobre aquella que no lo es, se comprueba con los casos 4 y 5 , ya que es ahí cuando se desarrolló un algoritmo de ranking que valora de forma diferenciada a la información según de donde proviene, dando una valoración mayor a aquella que proviene de la red social y una valoración menor a aquella que es fruto de un esfuerzo individual, aislado (información extraída de una página Web). Hay que recordar que el caso 5 es la implementación real del modelo de enriquecimiento. 


\section{6 \\ Conclusiones y trabajos futuros}

\subsection{Conclusiones}

En esta tesis se presenta un modelo de enriquecimiento basado en el meta-análisis de datos a través de la aplicación del análisis de redes sociales SNA con el objetivo de aportar a diferentes iniciativas educativas que utilicen a los recursos educativos abiertos (OER) como una estrategia dentro del proceso de enseñanza/aprendizaje. La abundancia de las redes y de la información que puede expresarse como una red y sobre todo las consecuencias que esto trae, hace necesario que se preste atención a las redes y sobre todo se analice la estructura de la red para buscar aplicaciones prácticas de la misma, que apoyen a las actividades cotidianas que como seres humanos desarrollamos.

La noción de una red, sea social o no-social, hace énfasis en las relaciones que se dan entre entidades/actores que en conjunto participan en alguna actividad ya sea explícitamente o implícitamente. Es por ello que este trabajo hace énfasis en el estudio y análisis de las relaciones para aportar al movimiento educativo abierto permitiendo por un lado analizar iniciativas educativas y por otro lado encontrar OERs que se publican en redes sociales en línea y que gracias a la interacción social son valorados y destacados, y que podrían convertirse en recursos a valiosos a utilizar dentro de las iniciativas educativas.

Aprovechar las manifestaciones, de diferente índole, que se dan entre seres humanos ha sido uno de los ejes conductores de este trabajo, ya que estamos convencidos que cualquier participación que provenga de un conglomerado humano trae con sigo un valor agregado, una ganancia, un enriquecimiento. Una vez finalizada la investigación 


\section{CONCLUSIONES Y TRABAJOS FUTUROS}

se describen los principales hallazgos y resultados conseguidos:

- El análisis de las relaciones implícitas existentes entre los diferentes participantes que intervienen en una iniciativa educativa o en los datos publicados en una red social, permite encontrar otro tipo de patrones de interacción que complementan a los encontrados cuando se analiza la información que proviene de las relaciones explícitas.

- La recuperación de recursos compartidos en una red social en línea necesita del análisis de dos tipos de redes. El primer tipo, es una red que se forma por las interacciones entre usuarios, mientras que el segundo tipo es una red que se forma por ciertos elementos que están presentes en el contenido de las publicaciones. Este análisis complementario permite encontrar recursos valiosos que pueden incorporarse a iniciativas educativas, dejando de lado recursos menos importantes, muchos de los cuales pueden ser considerados spam.

- El texto que acompaña a una publicación que se hace dentro de una red social, es más relevante que otro que no fue expuesto, ya que el primero ha sido valorado, consensuado y utilizado por un conglomerado de personas mientras que el segundo es el resultado de un trabajo individual que carece de consenso.

- La información que acompaña a un recurso publicado dentro de una red social, como microblogging, es insuficiente para describir un recurso, es por ello que se debe hacer uso de información que se publica en formatos como open graph o twitter card para encontrar otra información que ayude a la descripción del recurso. Si bien este tipo de información no tendrá la misma valoración, es necesaria.

- Las medidas de centralidad aplicadas a redes sociales y de contexto permiten tener un acceso más rápido a los recursos valiosos que fueron publicados en la red social en línea y que son lo suficientemente amplios para adaptarse a las necesidades concretas de un usuario de la iniciativa eduativa.

A través de los diferentes casos se ha podido comprobar que la propuesta de un modelo de enriquecimiento es capaz de aprovechar las diferentes relaciones que existen dentro de las iniciativas educativas para encontrar información valiosa que puede ser analizada a través del análisis de redes sociales y sus métricas. Gracias a esos casos 
se pudo demostrar que el análisis de redes sociales se puede usar como un modelo de recomendación que ayuda a encontrar recursos educativos que han sido compartidos dentro de una red social.

\subsection{Contribuciones}

En esta sección se revisan las principales contribuciones de la tesis y cómo hemos resuelto los problemas de investigación abiertos. Definimos los siguientes objetivos:

O1.- Elaborar un modelo de enriquecimiento para iniciativas educativas basadas en OER, que tenga como fuente de datos a la información difundida en una red social y que a través de un meta-análisis de los datos aplicando análisis de redes sociales maximice el uso de la información.

O2.- Utilizar las manifestaciones de la inteligencia colectiva presentes en actividades colaborativas masivas desarrolladas por seres humanos.

O3.- Desarrollar un modelo de recomendación de recursos educativos que explote la información que una estructura de red y su comportamiento dinámico poseen.

O4.- Implementar el modelo de enriquecimiento propuesto con el fin de validarlo y agregar características al mismo en un ciclo de desarrollo y mejora continuo.

El desarrollo de la tesis ha generado las siguientes contribuciones:

- C1. Un modelo de enriquecimiento para iniciativas educativas que utiliza la información que se publica en una red social en línea y la representación de las interacciones entre diversos elementos para encontrar y recomendar recursos educativos que pueden ser utilizados para colaborar a cumplir el objetivo de la iniciativa educativa.

- C2. Una herramienta de análisis para iniciativas educativas que a través del análisis de las diferentes relaciones que se dan entre los actores que intervienen en las iniciativas sea capaz de realizar una descripción diagnóstica de la situación actual de la iniciativa y del potencial que existe dentro de ella. 


\section{CONCLUSIONES Y TRABAJOS FUTUROS}

- C3. Un modelo de recomendación que utiliza las interacciones sociales de los usuarios de una red social en línea, así como el contenido que en ella se difunde para encontrar recursos que pueden ser utilizados dentro de iniciativas educativas que se basen en el uso de OERs.

- C4. Un algoritmo de valoración, que utiliza la información expuesta dentro de una red social en línea y la información que proviene de los recursos para asignar un valor a cada uno de los recursos, dando mayor peso a la información que fue expuesta en la red social.

\subsection{Líneas futuras de investigación}

Una vez concluida la investigación y la validación del modelo propuesto, se identifican algunos temas y oportunidades de investigación que pueden desarrollarse a futuro.

- La extracción de tópicos, dentro del componente de captura de datos, es un proceso que se realiza manualmente, sin embargo existe la posibilidad de convertirse en un modelo automático utilizando técnicas de los sistemas de recuperación de información.

- Utilizar técnicas de minería de datos como análisis de sentimientos en los contenidos publicados en la red social en línea, permitiría clasificar los contenidos y seleccionar aquellas publicaciones clasificadas como positivas para construir y analizar redes según lo propuesto en este modelo.

- Ampliar el estudio de la evolución de las redes en el tiempo, como un sistema dinámico, con el fin de encontrar otros indicadores que permitan mejorar la aproximación que el modelo de enriquecimiento propone para la clasificación de nodos según su producción en el tiempo.

- Considerando la diversidad de las medidas de centralidad, que permiten destacar nodos por su ubicación, resulta de interés utilizar otras medidas de centralidad para determinar los cambios en los resultados que fueron obtenidos en esta tesis y llegar a determinar, si fuera el caso, la utilidad de esas medidas en procesos similares al propuesto aquí. 
- Implementar algoritmos de similitud que complementen al algoritmo basado en distancias que se propone en el componente de recomendación para que se incluya no sólo la similitud sintáctica o de la distancia de una red, sino la similitud semántica.

- La gran cantidad de datos con los que se podría contar hace que el modelo necesite ser implementado bajo mecanismos de BigData, es por ello que resultaría importante analizar la implementación actual y llegar a determinar los cambios que se deben realizar para poder ejecutarse en herramientas desarrolladas para el manejo de grandes volúmenes de datos.

- Investigar e implementar mecanismos que permitan encontrar la licencia de un recurso si esta se encuentra implementada a través de microformatos u otras alternativas como vocabularios propuestos por schema.org.

- Enriquecer la información del contexto (contenido compartido en la red social, tales como hashtags) con información semántica disponible por ejemplo en la dbpedia.

- Utilizar el modelo de enriquecimiento propuesto con otras redes sociales en línea o fuente de datos cuyos datos puedan representarse como redes. 
6. CONCLUSIONES Y TRABAJOS FUTUROS 


\section{Anexos}

\subsection{Anexo A: SERRecomender Documentación de servi- cios Web}

Este anexo muestra la documentación de los servicios Web que se desarrollaron como parte de la plataforma tecnológica. Son servicios Web RESTful que pueden ser invocados desde tipo cualquier cliente. Los resultados que devuelven están clasificados en 3 grupos: Recursos, Usuarios (cuentas de usuarios) y Contexto (Hashtags).

\subsubsection{Recursos}

URI base: /serrecomender/v1/webresources/ser/text

Método: GET

Descripción: Devuelve un grupo de Recursos extraídos desde las redes sociales.

Parámetros:

- $\boldsymbol{t}$ (Mandatorio): Es el texto de consulta del cual se necesita obtener recursos.

Salida: JSON (JSON-P)

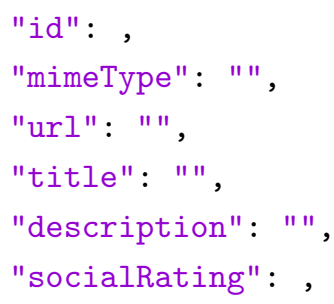




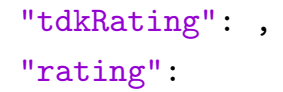

De donde:

- $\boldsymbol{i d}$ - Identificador del recurso - Entero largo (Long).

- mimeType - Tipo MIME del recurso - Cadena de Texto (String).

- url - Localizador que permite acceder al recurso donde fue publicado - Cadena de Texto (String).

- title - Título del recurso - Cadena de Texto (String).

- description - Descripción del recurso - Cadena de Texto (String).

- socialRating - Valor calculado por el modelo de enriquecimiento en base a la información expuesta dentro de la red social - Real (Double).

- tdkRating - Valor calculado por el modelo de enriquecimiento en base a la información que no ha sido expuesta dentro de la red social (título, descripción y palabras clave o keywords) - Real (Double).

- rating - La suma de los dos valores anteriores - Real (Double)

\section{Ejemplo:}

URL invocada: /serrecommender/v1/webresources/ser/text? $\boldsymbol{t}=$ technology

\section{Salida:}

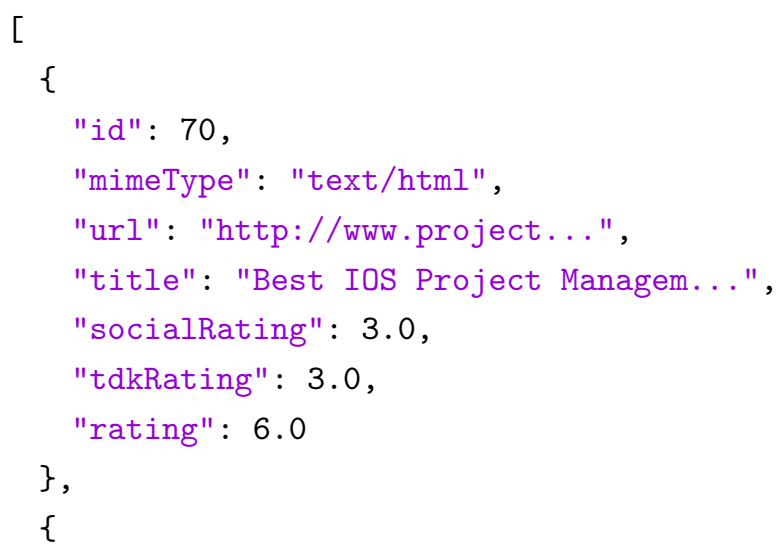




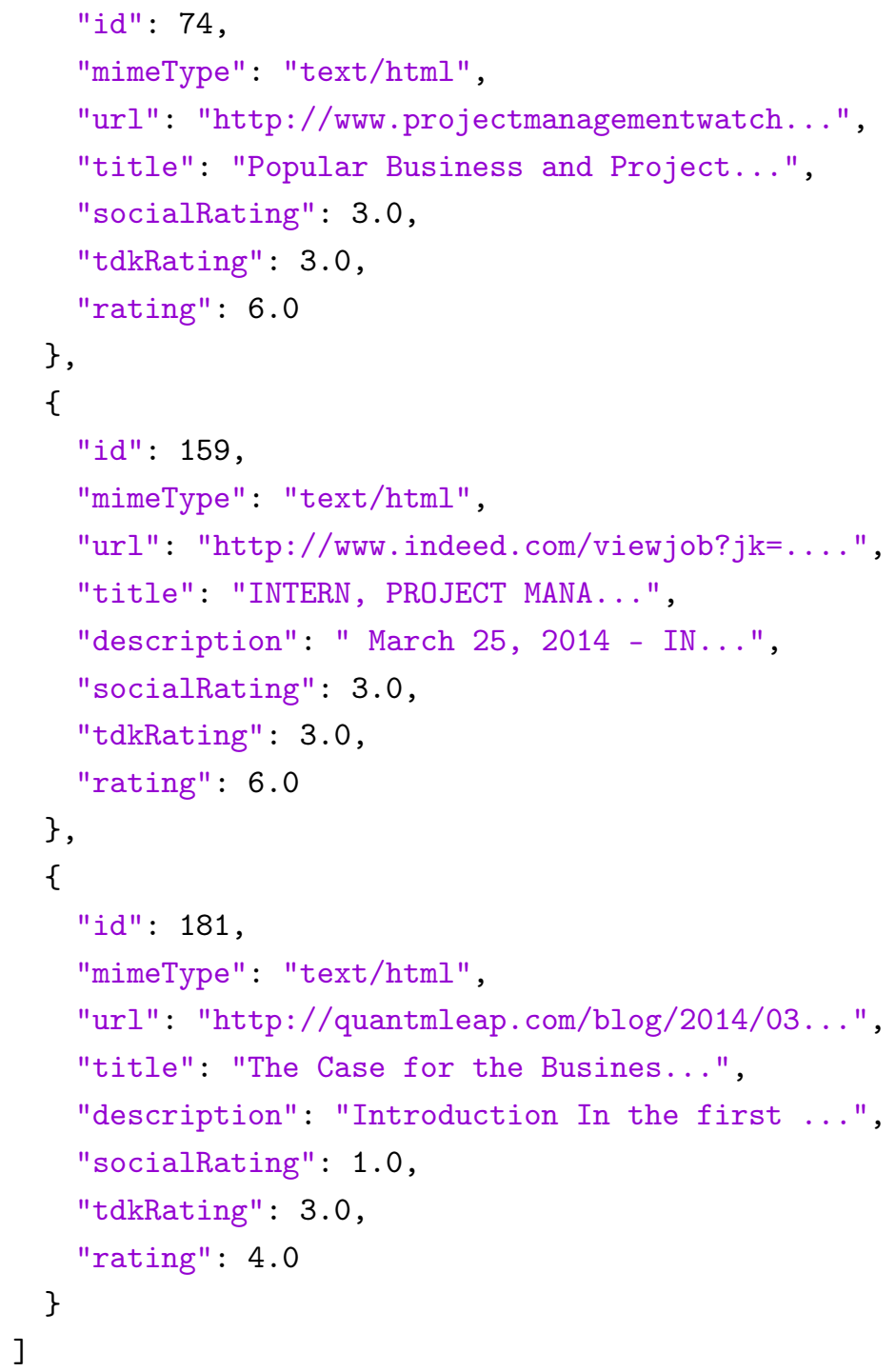

\subsubsection{Usuarios (cuentas de usuarios)}

URI base: /serrecommender/v1/webresources/users

Método: GET

Descripción: Devuelve un grupo de cuentas de usuarios extraídas desde la red social Twitter.

\section{Parámetros:}

- skill (Mandatorio): Es el texto de consulta del cual se necesita obtener los 
usuarios.

Salida: JSON (JSON-P)

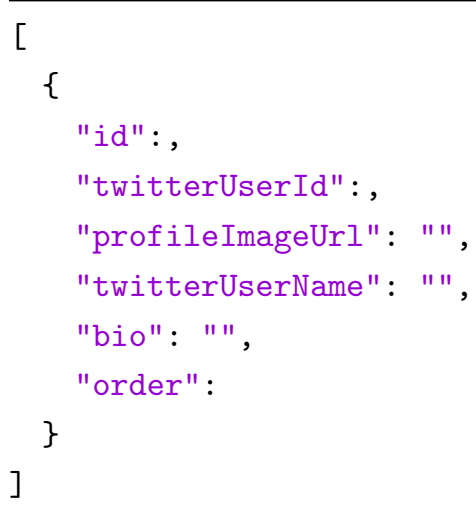

De donde:

- $\boldsymbol{i d}$ : Identificador interno del usuario - Entero largo (Long).

- twitterUserId: Identificador del usuario en Twitter - Entero largo (Long).

- profileImageUrl: Imagen del perfiel del usuario en Twitter - Cadena de Texto (String)

- twitterUserName: Nombre del usuario en Twitter - Cadena de Texto (String).

- bio: Biografía del usuario publicada en Twitter - Cadena de Texto (String).

- order: Posición del usuario asignado por el algoritmo de valoración - Entero (Integer).

\section{Ejemplo:}

URL invocada: /serrecommender/v1/webresources/users?skill=Networking \%20skills

\section{Salida:}

[

\{

"id": 568 ,

"twitterUserId": 7144422,

"profileImageUrl":

"http://pbs.twimg.com/profile_images/1861146796/Twitter_-_Avatar_normal.png", 


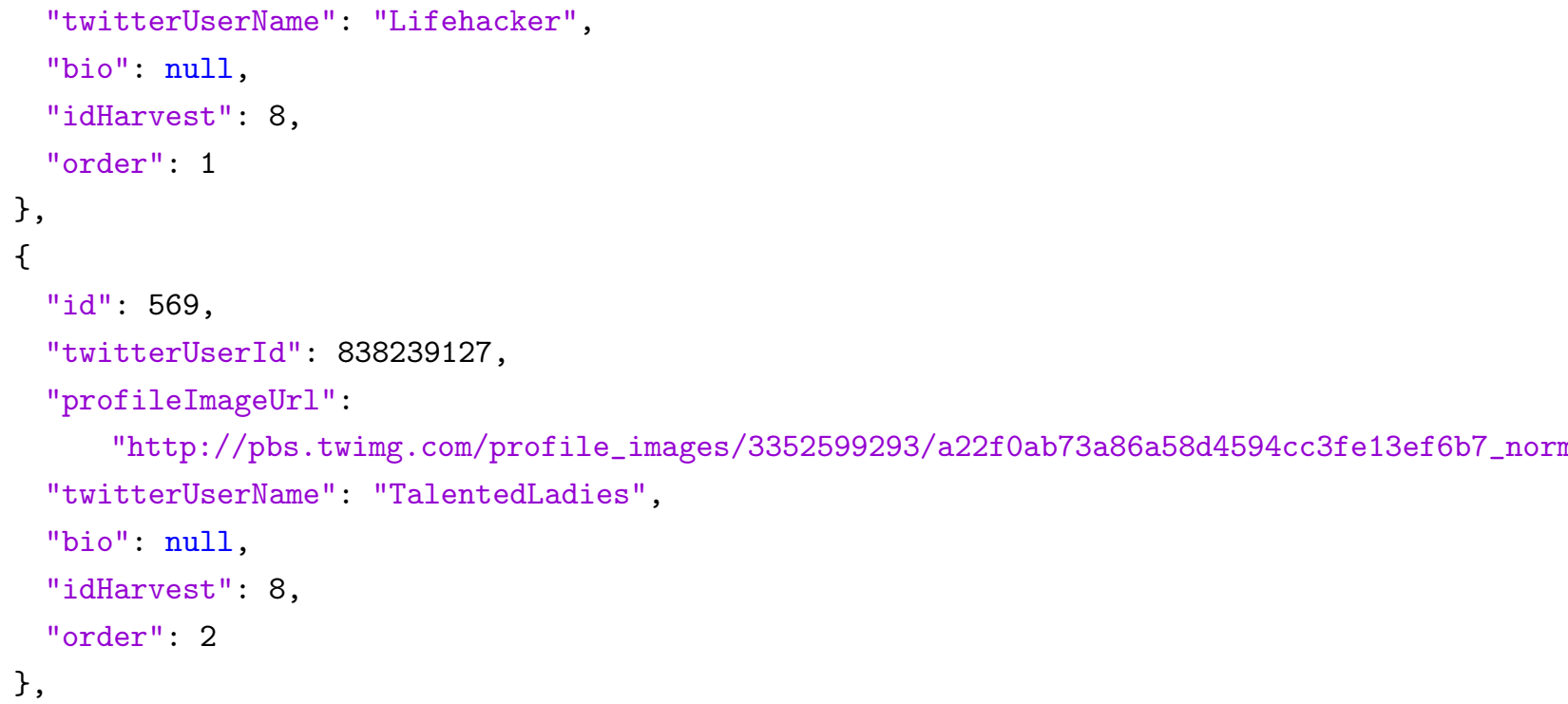

\subsubsection{Hashtag relacionadas}

URI base: /serrecommender/v1/webresources/hashtag

Método:GET

Descripción: Devuelve un grupo de Hashtags extraídas desde Twitter y que se recomiendan para un tema determinado.

\section{Parámetros:}

- skill (Mandatorio): Texto de consulta del cual se necesita obtener las etiquetas.

Salida: JSON (JSON-P)

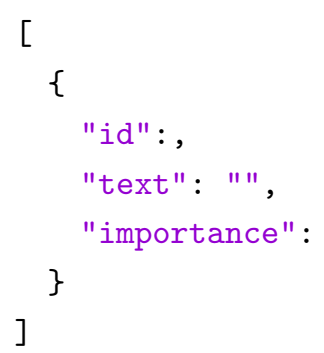

De donde: 
- id: Indentificador interno del hashtag - Entero (Long).

- text: Etiqueta (sin \#) - Cadena de Texto (String).

- importance: Valor que señala la relación el término de consulta.

\section{Ejemplo:}

URL invocada: /serrecommender/v1/webresources/hashtag?skill=Networking \%20skills

\section{Salida:}

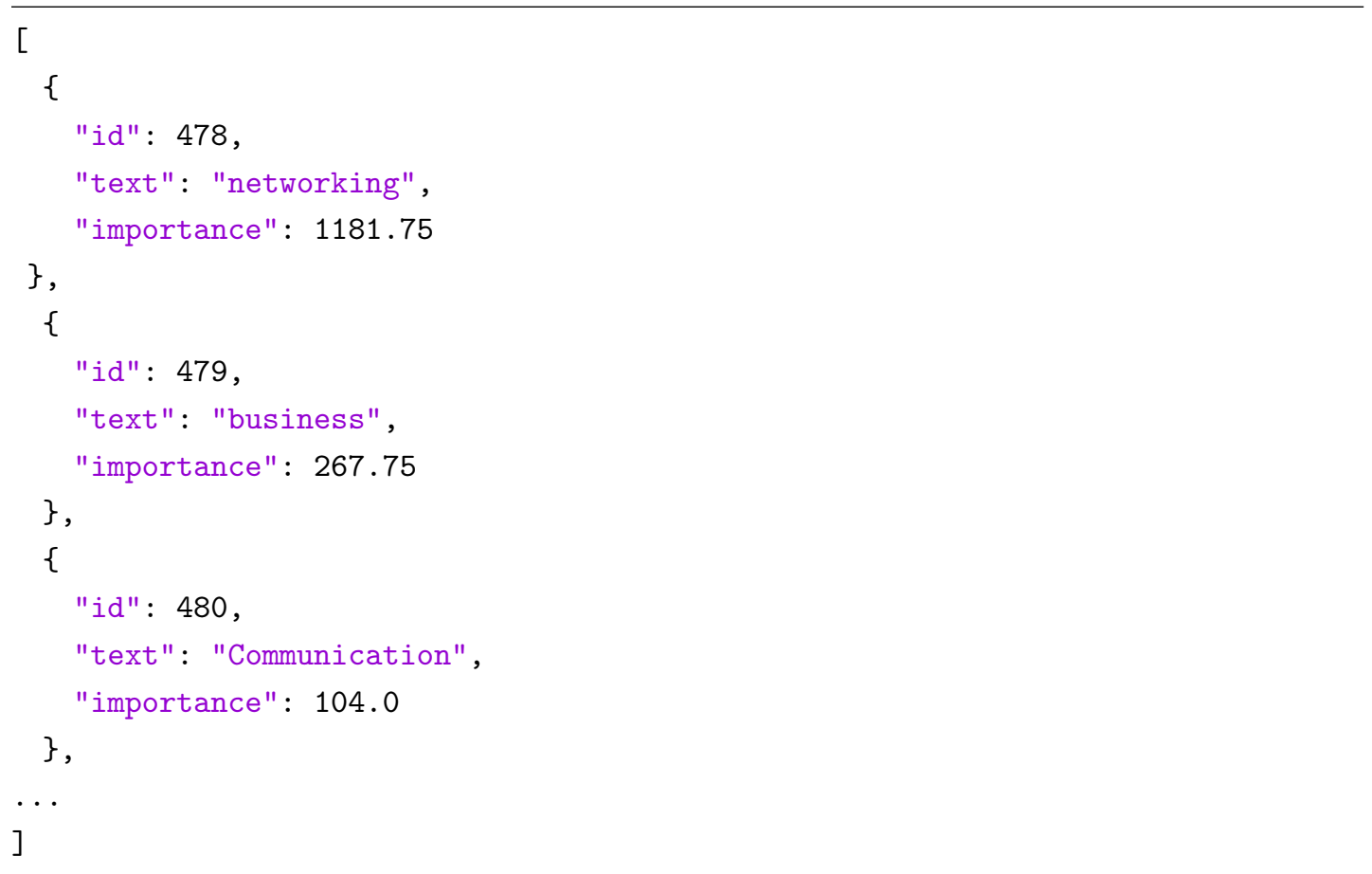


7.2 Anexo B - Análisis de los resultados de la aplicación del modelo

Tabla 7.1: Resumen de los Tweets recolectados clasificados bajo el criterio de poseer una URL (un recurso)

\begin{tabular}{|l|l|r|r|}
\hline \multicolumn{1}{|c|}{ Característica } & \multicolumn{2}{|c|}{ Valor } & $\%$ \\
\hline Nro. Tweets sin URL & \multicolumn{2}{|c|}{14313} & $15(\mathrm{a})$ \\
\hline \multirow{2}{*}{$\begin{array}{l}\text { Nro. Tweets } \\
\text { con URL }\end{array}$} & Válidas & 65774 & $71(\mathrm{c})$ \\
\cline { 2 - 4 } & No válidas & 13153 & $14(\mathrm{~d})$ \\
\cline { 2 - 4 } & Total & 78927 & $\begin{array}{r}85(\mathrm{~b}) \\
(\mathrm{c}+\mathrm{d})\end{array}$ \\
\hline Nro. total Tweets & \multicolumn{2}{|c|}{93240} & $\begin{array}{r}100 \\
(\mathrm{a}+\mathrm{b})\end{array}$ \\
\hline
\end{tabular}

\subsection{Anexo B - Análisis de los resultados de la aplicación del modelo}

En este Anexo se muestran los análisis que se realizaron y que ayudan a describir a una red, principalmente cuando el tamaño de la misma complica su representación visual.

Los imágenes que a continuación se muestran corresponden a los datos obtenidos al analizar los datos recolectados para \#HTML5.

\subsubsection{Descripción de la fuente de datos}

El proceso de recolección se hizo en un periodo de aproximadamente 80 días. La recolección se realizó utilizando el API REST de Twitter con ejecuciones cada 60 minutos. La Tabla 7.1 muestra un resumen de los Tweets recolectados en ese periodo de tiempo.

La Tabla 7.2 muestra un resumen de los usuarios y de su comportamiento en cuanto al número de menciones o re-tweets que reciben tanto si están en Tweets que tienen URLs (h) (válidas (f) y no válidas (g)) o si están en Tweets sin URLs (c). La tabla muestra que en Tweets sin URLs se menciona (a) más usuarios que en Tweets que tienen URL (d). Sin embargo el comportamiento cambia cuando se visualiza los retweets, existe una mayor cantidad de usuarios (e) que reciben un re-tweet si el Tweet contiene una URL válida comparados con los usuarios que están en Tweets sin URLs (b). En la parte final de la tabla, se muestra que dentro de los usuarios existe también 
Tabla 7.2: Información de los usuarios, clasificados por su aparición en Tweets con o sin URLs

\begin{tabular}{|c|c|c|c|c|c|}
\hline \multirow{12}{*}{ Usuarios } & \multicolumn{3}{|c|}{ Criterio } & Valor & $\%$ \\
\hline & \multirow{4}{*}{\multicolumn{2}{|c|}{$\begin{array}{l}\text { Aparecen en Tweets } \\
\text { sin } U R L\end{array}$}} & Menciones & $\begin{array}{r}7046 \\
(\mathrm{a})\end{array}$ & $\begin{array}{r}43 \\
(\text { respecto de } c)\end{array}$ \\
\hline & & & Re-Tweets & 3021 & \\
\hline & & & & 16201 & \\
\hline & & & Total & (c) & (respecto de $i)$ \\
\hline & \multirow{5}{*}{$\begin{array}{l}\text { Aparecen en Tweets } \\
\text { con } U R L\end{array}$} & \multirow{3}{*}{ Válidas } & Menciones & $\begin{array}{r}5543 \\
(\mathrm{~d})\end{array}$ & $\begin{array}{r}27 \\
\text { (respecto de } f \text { ) }\end{array}$ \\
\hline & & & Re-Tweets & $\begin{array}{r}4641 \\
(\mathrm{e})\end{array}$ & $\begin{array}{r}23 \\
(\text { respecto de } f \text { ) }\end{array}$ \\
\hline & & & Total & $\begin{array}{r}19845 \\
\text { (f) }\end{array}$ & $\begin{array}{r}99 \\
(\text { respecto de } h) \\
\end{array}$ \\
\hline & & \multicolumn{2}{|c|}{ No válidas } & $\begin{array}{r}228 \\
(\mathrm{~g})\end{array}$ & $\begin{array}{r}1 \\
(\text { respecto de } h)\end{array}$ \\
\hline & & \multicolumn{2}{|l|}{ Total } & $\begin{array}{r}20073 \\
(\mathrm{~h}) \\
(\mathrm{f}+\mathrm{g})\end{array}$ & $\begin{array}{r}55 \\
\text { (respecto de } i \text { ) }\end{array}$ \\
\hline & \multicolumn{3}{|l|}{ Total } & $\begin{array}{r}36294 \\
(i) \\
(\mathrm{c}+\mathrm{h}) \\
\end{array}$ & 100 \\
\hline & \multicolumn{3}{|c|}{$\begin{array}{l}\text { Usuarios que no son autores de al menos } \\
\text { un Tweet (sólo son mencionados o rt) }\end{array}$} & $\begin{array}{r}8515 \\
(j)\end{array}$ & \\
\hline
\end{tabular}

un grupo de usuarios que no son autores de Tweets, únicamente aparecen en menciones o re-tweets (j). Este comportamiento es confirmado por el trabajo de Suh et al. (2010) en donde se afirma un Tweet con una URL tiene mayores posibilidades de recibir un re-tweet.

El número de veces que se menciona a un usuario o se hace un re-tweet es clasificado también por el uso o no de URLs. La Tabla 7.3. La tabla muestra que un usuario tiene una mayor probabilidad de ser mencionado o recibir un re-tweet si el los Tweets tienen una URL. Esto a pesar que en la Tabla 7.2 se pudo ver que existen más usuarios que reciben una mención si los Tweets no poseen una URL (a), frente a los usuarios en 
Tabla 7.3: Cantidad de veces que los usuarios reciben un re-tweets o menciones, si han sido o no publicados en Tweets que contienen URLs

\begin{tabular}{|l|r|r|}
\hline & Con URL & Sin URL \\
\hline \multirow{2}{*}{ Re-Tweets } & 32490 & 7955 \\
& $(\mathrm{a})$ & $(\mathrm{b})$ \\
\hline \multirow{2}{*}{ Menciones } & 16597 & 16087 \\
& (c) & (d) \\
\hline
\end{tabular}

Tabla 7.4: El uso de los hashtags dentro del grupo de datos que se utilizó.

\begin{tabular}{|l|r|}
\hline \multicolumn{1}{|c|}{ Medida } & Valor \\
\hline Nro. total de Hashtags únicas & 7842 \\
(a) \\
\hline Nro. total de hashtags únicas en Tweets con URL & 6419 \\
(b) \\
\hline Nro. total de hashtags únicas en Tweets con URLs válidas & 5883 \\
(c) \\
\hline Nro. total de hashtags en Tweets con URLs válidas & 218539 \\
& (d) \\
\hline Nro. total de hashtags únicas en Tweets sin URL & 2851 \\
& (e) \\
\hline
\end{tabular}

Tweets con URL (d), es decir un usuario es mencionado hasta 3 o 4 veces (Tabla 7.3 valor (c) / Tabla 7.2 valor (c)) si está en un Tweet con una URL, mientras que si el Tweet no posee URL será mencionado hasta 2 veces (Tabla 7.3 valor (d) / Tabla 7.2 valor (a))

Finalmente la Tabla 7.4 se muestra el resumen del uso de las Hashtags dentro del grupo de datos que se está analizando.

En la Tabla 7.1 se dijo que el número total de Tweets con URLs válidas es de 65774, si se relaciona con el valor d de la Tabla 7.4 obtenemos que un Tweet con una URL válida en promedio tiene entre 3 o 4 hashtags.

\subsubsection{Distribución de los grados}

Una de las formas para estudiar una red es analizar la distribución de los grados nodales. Gracias a los trabajos realizados por Onnela et al. (2007) y Kwak et al. (2010) 


\section{ANEXOS}

es conocido que el grado de los nodos dentro de una red de seguidores en Twitter siguen una distribución conocida como Ley de Poder. La Figura 7.1 muestra la distribución del grado nodal. En ella se puede ver dentro de la red existen muchos nodos con poco grado, y pocos nodos con un grado alto, es decir existen pocos nodos denominados hubs.

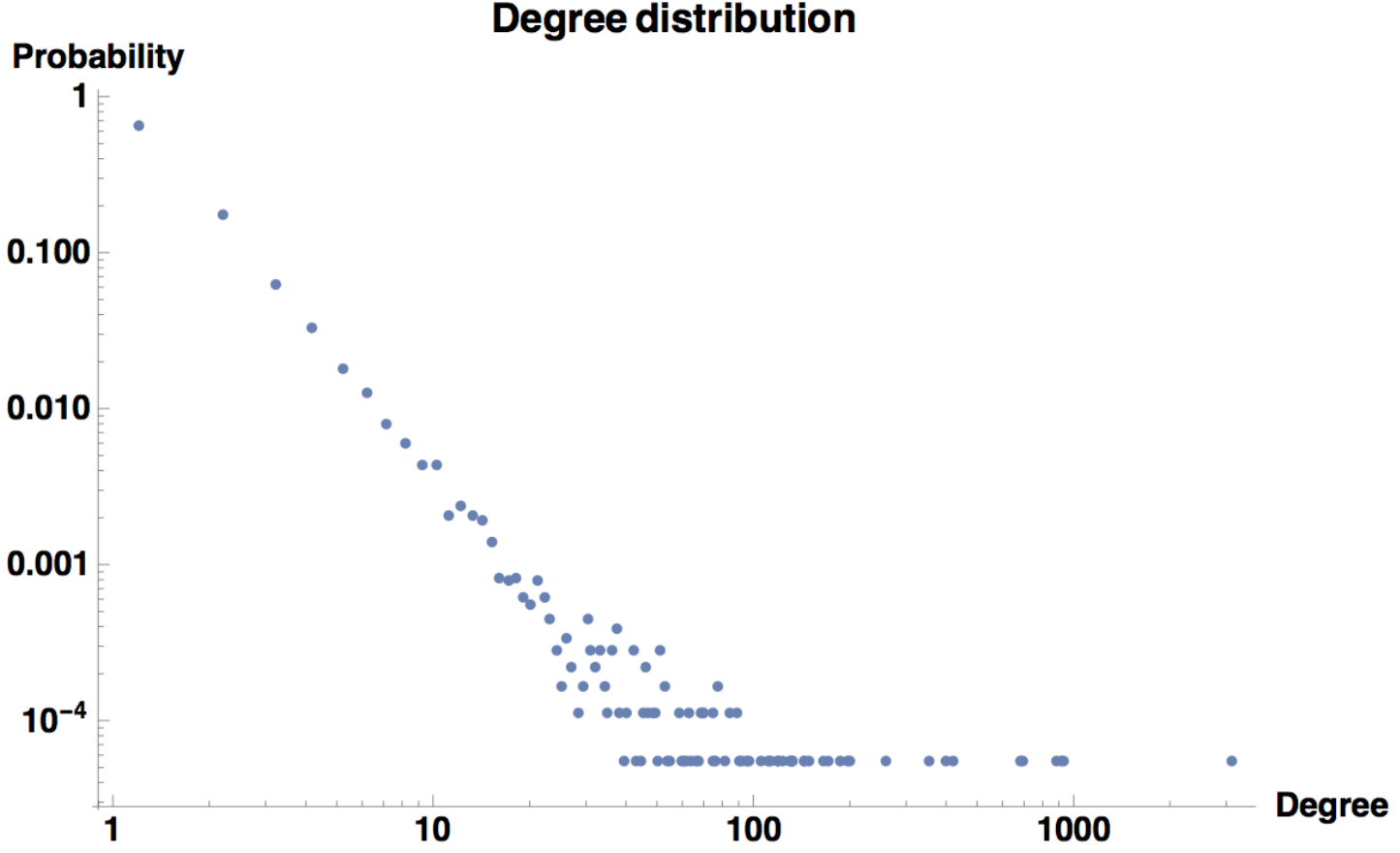

Figura 7.1: Distribución del grado nodal para la red de menciones y re-tweets entre usuarios - El grado nodal sigue una distribución de Ley de Poder que es común en redes reales.

Las figuras 7.2 y 7.3 muestran la distribución para el grado de entrada y salida respectivamente. De la misma forma como se mencionó en el párrafo anterior, los gráficos muestran que existen muchos nodos con poco grado de entrada o de salida, mientras que existen pocos nodos con mucho grado de entrada o de salida.

Contextualizando los análisis que gracias a las imágenes fue posible realizar, se puede afirmar que existen muchos usuarios (nodos) que han sido pocas veces mencionados o que recibieron pocos re-tweets (ver la Figura 7.2 ya que en la red construida el grado de entrada muestra una mención o re-tweet a un usuario). Así también es posible afirmar que pocos son los usuarios que reciben muchas menciones o re-tweets.

Dentro de la misma contextualización, con la Figura 7.3 podemos ver que existen pocos usuarios que hacen muchas menciones o re-tweets, la gran mayoría de usuarios 
hacen varias menciones o re-tweets.

\section{Probatility}

\section{Indegree distribution}

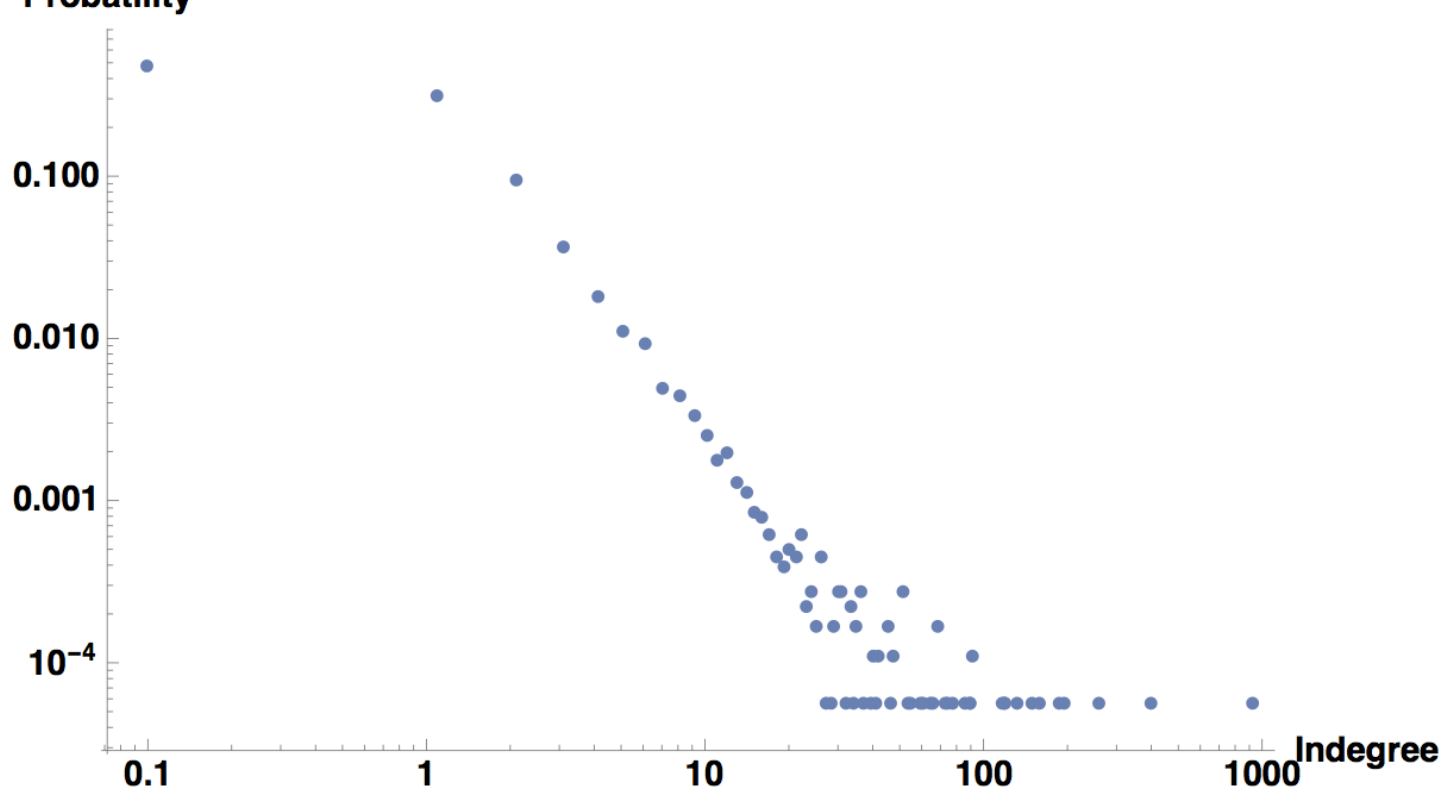

Figura 7.2: Distribución del grado de entrada para la red de menciones y retweets entre usuarios - El grado de entrada sigue una distribución de Ley de Poder que es común en redes reales.

Está afirmación puede ser confirmada con el promedio de de menciones y re-tweets que puede recibir un usuario cuando publica información sobre \#HTML5. En promedio un usuario puede recibir entre cero y una menciones (0.71 para se exactos), mientras que podría recibir entre uno y dos re-tweets (1.18 exactamente).

Cuando se analiza únicamente los usuarios que recibieron menciones y que compartieron una URL válida el valor sube 0.85 . Lo mismo sucede con los re-tweets cuando se el tweet incluye una URL, la probabilidad aumenta a 1.64. Es decir que existe mayor probabilidad de recibir una mención o un re-tweet si el se adjunta una URL al tweet que se publicará.

La distribución del grado de la red de hashtags se puede ver en la Figura 7.4 Al igual que con las distribuciones anteriores se puede apreciar que sigue una distribución de Ley de Poder. Es decir que existen muchas hashtags con poco grado, mientras que existen pocas hashtags con un grado extremadamente alto.

Finalmente se analizó el comportamiento de los nodos con el objetivo de determinar 
Probability

\section{Outdegree distribution}

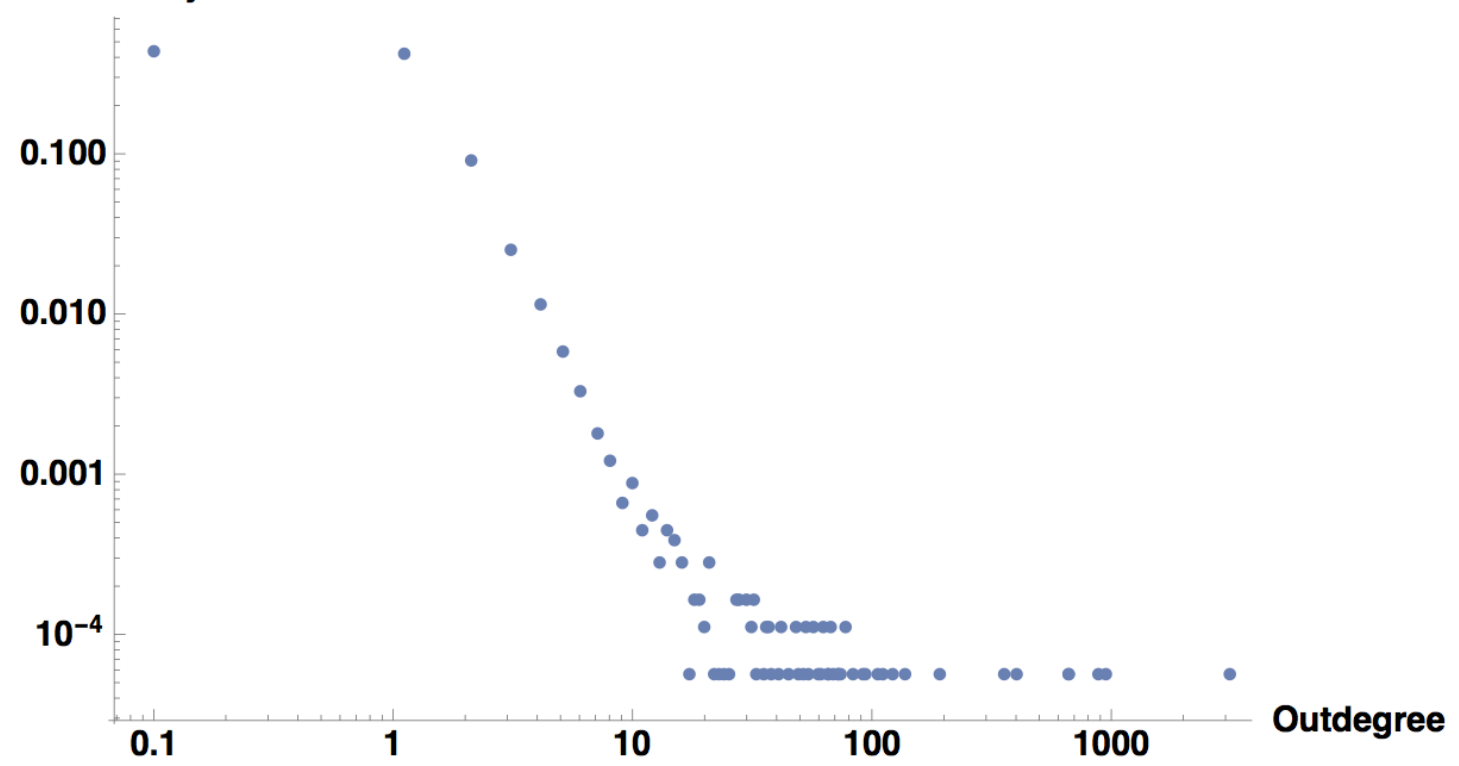

Figura 7.3: Distribución del grado de salida para la red de menciones y retweets entre usuarios - El grado de entrada sigue una distribución de Ley de Poder que es común en redes reales.

si existe una tendencia entre los usuarios con mucho grado de entrada a relacionarse con usuarios con mucho grado de salida, dentro del contexto, si los usuarios que reciben muchas menciones o re-tweets a su vez hacen muchas menciones o re-tweets. Dentro del redes sociales a este comportamiento se lo denomina homofilia (Lazarsfeld et al. 1954). Analizando la Figura 7.5 se puede ver existe homofilia en aquellos nodos con grados pequeños, no así en aquellos nodos con grados altos. Es decir los usuarios que han recibido muchas menciones o re-tweets no hacen muchas menciones. También es posible decir que los usuarios que hacen muchas menciones o re-tweets no reciben el mismo número.

\subsubsection{Usuarios - Social}

A continuación se presenta algunos análisis que muestran y comparan los datos obtenidos, por el modelo de enriquecimiento propuesto en esta tesis, frente a los datos obtenidos a través de conteos. Esta información es un complemento a la información que se muestra en la sección 5.5 . 


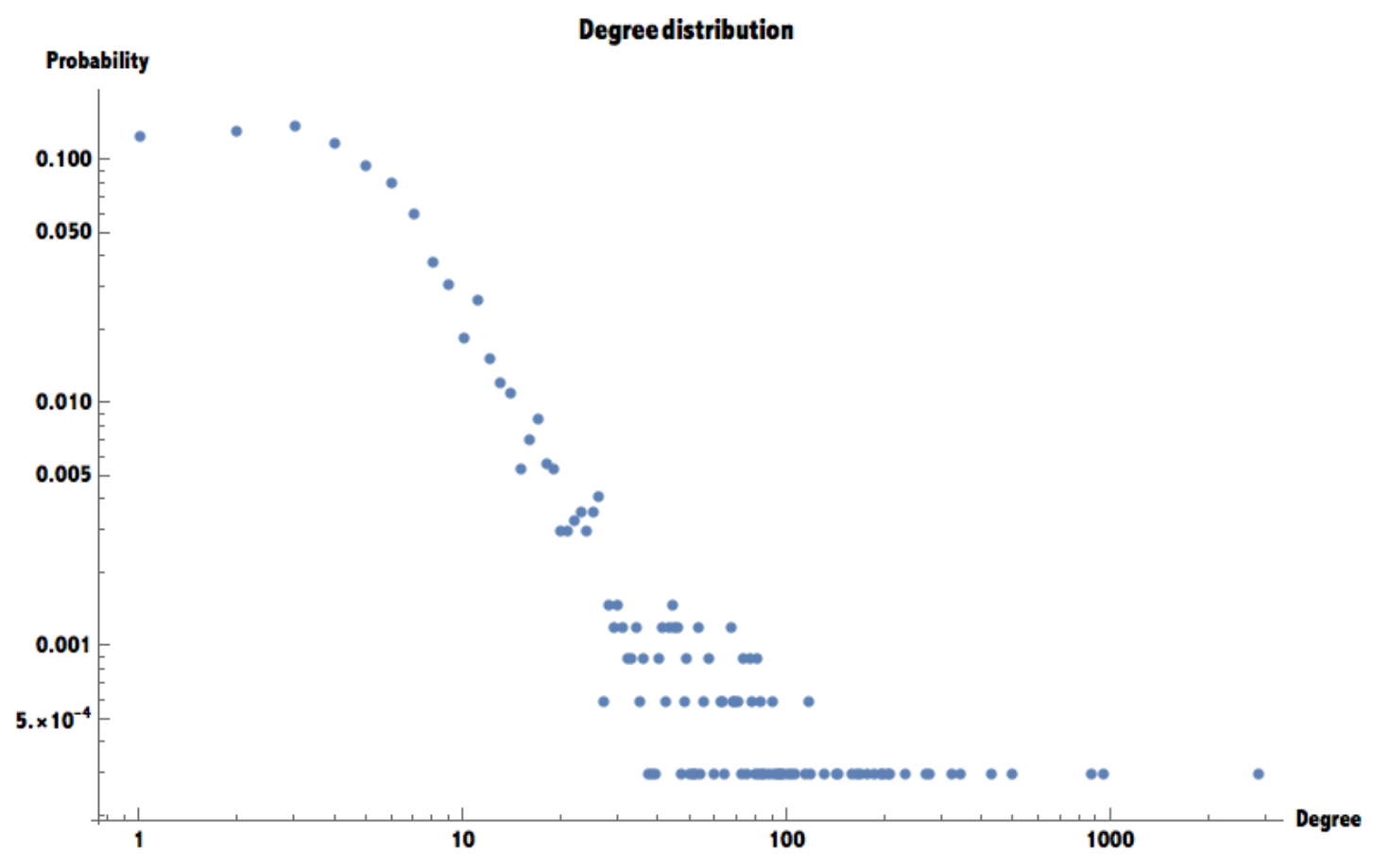

Figura 7.4: Distribución del grado de la red hashtags - El grado de entrada sigue una distribución de Ley de Poder que es común en redes reales. 


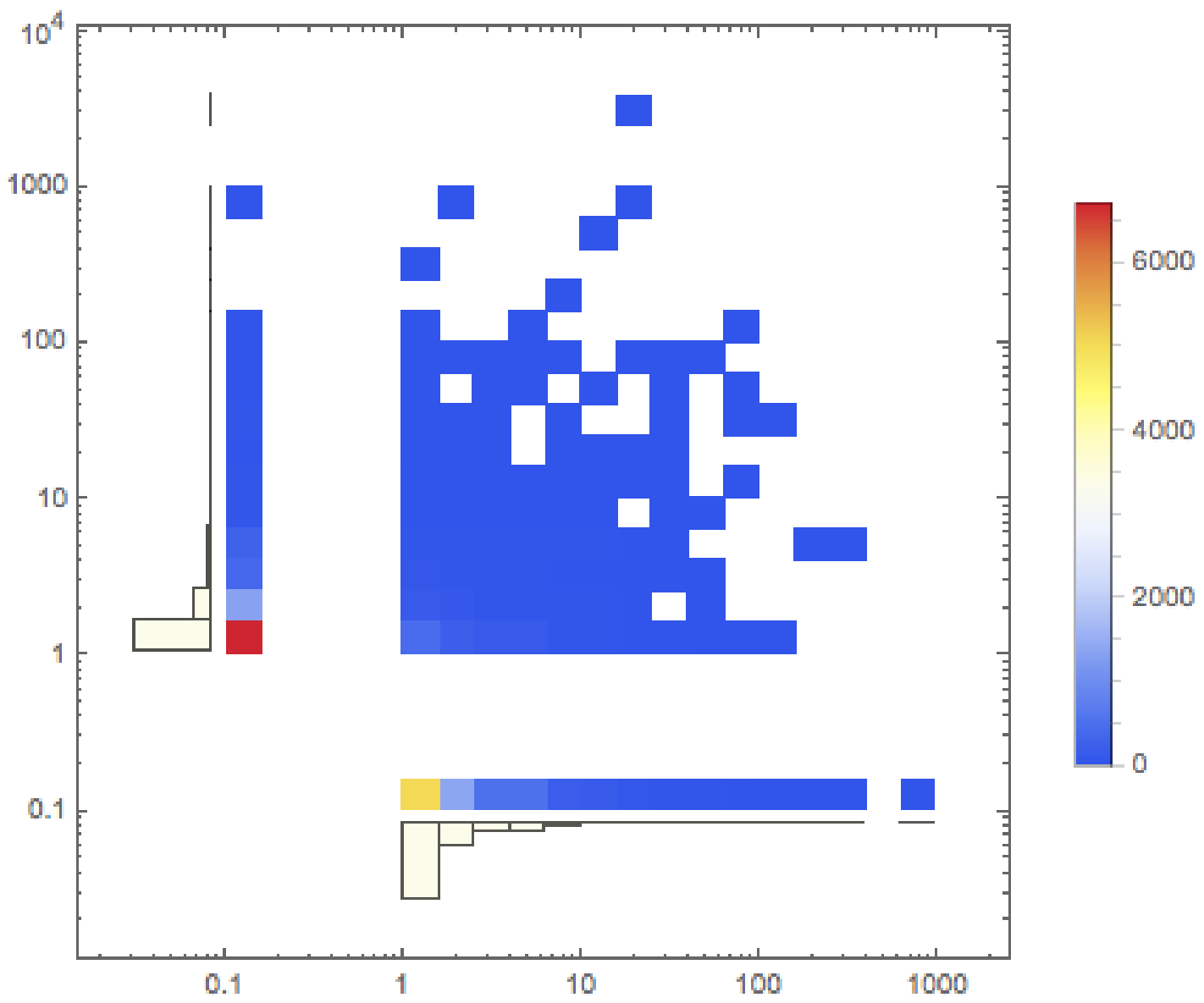

Figura 7.5: Relación entre los usuarios según su grado de entrada (eje Y) y el grado de salida (eje X) - Este mapa de calor ayuda a determinar si en la red de usuarios existe o no homofilia. Para elaborar esta imagen se agregó 0.1 a todos los valores, para evitar que los valores 0 no sean representados ya que se utiliza escala logarítmica. 
Tabla 7.5: Lista de los usuarios destacados que ocupan los 10 primeros lugares según la medida de Intermediación (Betweenness)

\begin{tabular}{|l|l|r|r|r|r|}
\hline Orden & \multicolumn{1}{|c|}{$\begin{array}{c}\text { Nombre } \\
\text { Usuario }\end{array}$} & $\begin{array}{c}\text { Nro. } \\
\text { Tweets }\end{array}$ & $\begin{array}{c}\text { Nro. } \\
\text { Menciones }\end{array}$ & $\begin{array}{c}\text { Nro. } \\
\text { Re-Tweets }\end{array}$ & $\begin{array}{c}\text { Orden } \\
\text { Conteo }\end{array}$ \\
\hline 1 & HTML5Digest1 & 8575 & 71 & 4 & 1 \\
\hline 2 & CssFact & 11 & 1 & 32 & 558 \\
\hline 3 & stevefaulkner & 43 & 66 & 117 & 123 \\
\hline 4 & HTMLdaily & 157 & 14 & 218 & 29 \\
\hline 5 & CsharpCorner & 34 & 141 & 42 & 160 \\
\hline 6 & jcoz1968 & 282 & 22 & 668 & 16 \\
\hline 7 & HTMLxprs & 38 & 15 & 135 & 134 \\
\hline 8 & themifycloud & 740 & 0 & 108 & 7 \\
\hline 9 & Bleutrade & 2 & 300 & 12 & 5210 \\
\hline 10 & themify_cloud & 931 & 1 & 190 & 6 \\
\hline
\end{tabular}

El número total de usuarios únicos que se obtuvo es de 39489, muchos de esos usuarios son usuarios (33149) que poseen un perfil en Twitter, mientras que 6340 son usuarios que no se ha podido determinar si se trata de cuentas válidas en Twitter. Esto se debe a que para hacer una mención o RT no es mandatorio utilizar cuentas válidas. Luego de ejecutar la medida de centralidad el número de usuarios destacados es de 5511, es decir que el modelo trabajaría con aproximadamente el $14 \%$ de los usuarios.

En las Tablas 7.5 y 7.6 se pueden ver los 10 primeros usuarios según el modelo y según el número de Tweets. Comparando ambas tablas se puede ver que existe diferencias en los resultados y que también existen coincidencias. Entre las similitudes encontramos que el primer usuario es el mismo. También se encontró que los usuarios _themify_cloud y themify_cloud aparecen en ambos listados aunque en diferente orden. Mientras difieren en 7 cuentas que no se repiten en ambas tablas.

Para la Table 7.5 la columna denominada Orden Conteo señala la posición que el usuario ocupa según el orden que determina el número de Tweets publicados. Mientras que en la Tabla 7.6 la columna Orden Modelo señala la posición que ocupa el usuario por la medida utilizada por el modelo. 
Tabla 7.6: Lista de los 10 primeros usuarios según el número de Tweets que han publicado.

\begin{tabular}{|l|l|r|r|r|r|}
\hline Orden & \multicolumn{1}{|c|}{$\begin{array}{c}\text { Nombre } \\
\text { Usuario }\end{array}$} & $\begin{array}{c}\text { Nro. } \\
\text { Tweets }\end{array}$ & $\begin{array}{c}\text { Nro. } \\
\text { Menciones }\end{array}$ & $\begin{array}{c}\text { Nro. } \\
\text { Re-Tweets }\end{array}$ & $\begin{array}{c}\text { Orden } \\
\text { Modelo }\end{array}$ \\
\hline 1 & HTML5Digest1 & 8575 & 71 & 4 & 1 \\
\hline 2 & js_digest & 3689 & 4 & 0 & 31 \\
\hline 3 & javascriptd & 1807 & 1 & 0 & 910 \\
\hline 4 & Epricity & 1363 & 3 & 984 & 920 \\
\hline 5 & semtexui & 941 & 12 & 1656 & 24 \\
\hline 6 & themify_cloud & 931 & 1 & 190 & 10 \\
\hline 7 & themifycloud & 740 & 0 & 108 & 8 \\
\hline 8 & DesignLearnBot & 670 & 4 & 1508 & 936 \\
\hline 9 & itknowingness & 615 & 0 & 2 & 170 \\
\hline 10 & themifycloud1 & 448 & 3 & 116 & 23 \\
\hline
\end{tabular}

\subsubsection{Hashtags - Contexto}

$\mathrm{Al}$ igual que la sección anterior, aquí se presenta y compara las etiquetas que son obtenidas por popularidad y aquellas obtenidas por el modelo de enriquecimiento. En la Tabla 7.7 se muestran las diez primeras etiquetas que se obtuvieron.

En este caso se puede ver que existen algunas coincidencias entre las etiquetas obtenidas por conteo, así com aquellas obtenidas aplicando una medida de centralidad.

\subsubsection{Análisis de resultados}

En esta sección se analizaran los recursos que se han obtenido y su relación con las redes (usuarios y hashtags) que han contribuido para obtener esos valores.

El primer análisis que se hará proviene del rating que el recurso ha obtenido. Como se explicó en la Sección 4.4.4.6 se utiliza dos tipos de datos para calcular el rating de un recurso. El primer tipo de dato proviene de la información expuesta socialmente (dentro de la red social) en forma de hashtags y que fueron analizados a través de una red no dirigida de co-ocurrencia de hashtags. El segundo tipo de dato proviene de la información que no fue expuesta socialmente (obtenido del título, descripción y keywords del recurso). La Tabla 7.8 muestra el origen del rating y el aporte de cada uno de los tipos de datos. 
Tabla 7.7: Las diez primeras etiquetas que se obtuvieron tanto por conteo como a través de una medida de centralidad denominada Betweenness (Intermediación).

\begin{tabular}{|l|l|l|}
\hline Posición & Conteo & $\begin{array}{c}\text { Modelo } \\
\text { (Intermediación) }\end{array}$ \\
\hline 1 & html5 & html5 \\
\hline 2 & css3 & javascript \\
\hline 3 & html & css3 \\
\hline 4 & javascript & job \\
\hline 5 & css & jobs \\
\hline 6 & Rt & css \\
\hline 7 & web & Empleo \\
\hline 8 & jQuery & web \\
\hline 9 & webdesign & jQuery \\
\hline 10 & WordPress & html \\
\hline
\end{tabular}

Tabla 7.8: Aporte al rating de los diez primeros recursos por parte de la información expuesta socialmente (red de contexto - contenidos) y la información que proviene del título, descripción y keywords del recurso y que se considera no expuesta a un conglomerado.

\begin{tabular}{|r|r|r|r|}
\hline URL & $\begin{array}{c}\text { Rating social } \\
\text { (contenido expuesto ) }\end{array}$ & $\begin{array}{c}\text { Rating privado } \\
\text { (no expuesto) }\end{array}$ & Rating \\
\hline $\mathbf{1}$ & 6 & 32 & 38 \\
\hline $\mathbf{2}$ & 1.2 & 36 & 37.2 \\
\hline $\mathbf{3}$ & 9.6 & 28 & 35.6 \\
\hline $\mathbf{4}$ & 1 & 33 & 34 \\
\hline $\mathbf{5}$ & 1 & 32 & 33 \\
\hline $\mathbf{6}$ & 5 & 27 & 32 \\
\hline $\mathbf{7}$ & 3 & 28 & 31 \\
\hline $\mathbf{8}$ & 2 & 29 & 31 \\
\hline $\mathbf{9}$ & 4 & 27 & 31 \\
\hline $\mathbf{1 0}$ & 3 & 27 & 31 \\
\hline
\end{tabular}




\section{ANEXOS}

En la Tabla 7.8 se puede ver como el de forma mayoritaria el rating recibe un aporte mucho mayor por la información no expuesta socialmente. La explicación para este tipo de comportamiento es que un recurso posee mucho más información que proviene de su contenido (título, descripción y keywords) en promedio un recurso posee entre 22 o 23 palabras, mientras que a nivel de hashtags un recurso tiene entre 3 o 4 hashtags.

Si ordenamos los recursos, no por su rating, sino únicamente por el rating del contexto (contenido expuesto socialmente) se puede observar que existe un cambio en los resultados (Tabla 7.9). Esos resultados no coinciden con los que se muestra en la Tabla 5.11 que como se mostró en la Tabla 7.8 el rating viene dado por el aporte mayoritario de la información que no fue expuesta socialmente.

Analizando los resultados de ambas tablas 7.9 y 7.8 se puede ver que existe una relación inversa entre ambos valores, es decir cuando el rating de la información no expuesta en la red social es máxima, el rating calculado por la información social no pertenece a sus valores más altos.

En la Tabla 7.10 se puede ver como los usuarios han contribuido en encontrar esos valores. En esa tabla se muestran los diez primeros usuarios sugeridos por el modelo de enriquecimiento y como esos usuarios contribuyen con resultados en cada uno de los cuartiles según el rating de cada recurso. La Figura 7.6 muestra gráficamente los resultados de la tabla. 
Tabla 7.9: Los diez primeros recursos ordenados por el rating que se obtiene de la información expuesta dentro de la red social que dentro del modelo se denomina contexto. El rating TDK proviene de información que no ha sido expuesta dentro de la red social (título, descripción y keywords del recurso)

\begin{tabular}{|r|l|l|r|r|}
\hline Orden & \multicolumn{1}{|c|}{ URL } & \multicolumn{1}{|c|}{ Descripción } & $\begin{array}{c}\text { Rating } \\
\text { contexto }\end{array}$ & $\begin{array}{c}\text { Rating } \\
\text { TDK }\end{array}$ \\
\hline $\mathbf{1}$ & https://goo.gl/28AB9z & $\begin{array}{l}\text { Vídeo en YouTube seleccionados } \\
\text { para CSS }\end{array}$ & 18.0 & 10.0 \\
\hline $\mathbf{2}$ & https://goo.gl/NLxDWf & $\begin{array}{l}\text { Aprender a usar Javascript } \\
\text { y HTML5 }\end{array}$ & 18.0 & 7.0 \\
\hline $\mathbf{3}$ & https://goo.gl/nWwZh4 & $\begin{array}{l}\text { Vídeo en YouTube seleccionados } \\
\text { para jQuery }\end{array}$ & 14.4 \\
\hline $\mathbf{4}$ & https://goo.gl/A4JGV2 & $\begin{array}{l}\text { HTML5 y CSS3 Tutorial y } \\
\text { demostración (hover slide) }\end{array}$ & 12.0 & 12 \\
\hline $\mathbf{5}$ & https://goo.gl/5ngLEi & $\begin{array}{l}\text { Blog acerca de diseño y } \\
\text { desarrollo Web. }\end{array}$ & 6.0 \\
\hline $\mathbf{6}$ & https://goo.gl/4qEmZ4 & $\begin{array}{l}\text { Programación básica de HTML } \\
\text { y CSS }\end{array}$ & 9.6 & 9.0 \\
\hline $\mathbf{7}$ & https://goo.gl/NdlWnW & $\begin{array}{l}\text { Desarrollo en HTML5, CSS y } \\
\text { Javascript de WebApps }\end{array}$ & 9.6 & 3.0 \\
\hline $\mathbf{8}$ & https://goo.gl/snB5Nh & Juegos en línea & 9.6 & 3.0 \\
\hline $\mathbf{9}$ & https://goo.gl/tyt4Nq & $\begin{array}{l}\text { Tutoriales, código fuente, } \\
\text { programación. }\end{array}$ & $\begin{array}{l}\text { Herramientas HTML5 y plugins } \\
\text { para jQuery }\end{array}$ & 9.6 \\
\hline $\mathbf{1 0}$ & https://goo.gl/bu6OJe & 26.0 \\
\hline
\end{tabular}


Tabla 7.10: El número de recursos (URLs) producidas por cada uno de los usuarios y clasificados según el cuartil de los rating de cada recurso

\begin{tabular}{|r|r|r|r|r|}
\hline User Id. & Q1 & Q2 & Q3 & Q4 \\
\hline $\mathbf{1}$ & 1194 & 1054 & 1060 & 971 \\
\hline $\mathbf{2}$ & - & 1 & 1 & 9 \\
\hline $\mathbf{3}$ & 13 & 20 & 6 & 4 \\
\hline $\mathbf{4}$ & 2 & 48 & 45 & 56 \\
\hline $\mathbf{5}$ & 1 & 18 & 6 & 3 \\
\hline $\mathbf{6}$ & - & 61 & 95 & 123 \\
\hline $\mathbf{7}$ & - & 3 & - & 26 \\
\hline $\mathbf{8}$ & 1 & 3 & - & 9 \\
\hline $\mathbf{9}$ & - & 2 & - & - \\
\hline $\mathbf{1 0}$ & 3 & 3 & - & 14 \\
\hline
\end{tabular}

- $\begin{array}{llll}\text { Q1 } & \text { Q2 } & \text { Q3 } & \text { Q4 }\end{array}$

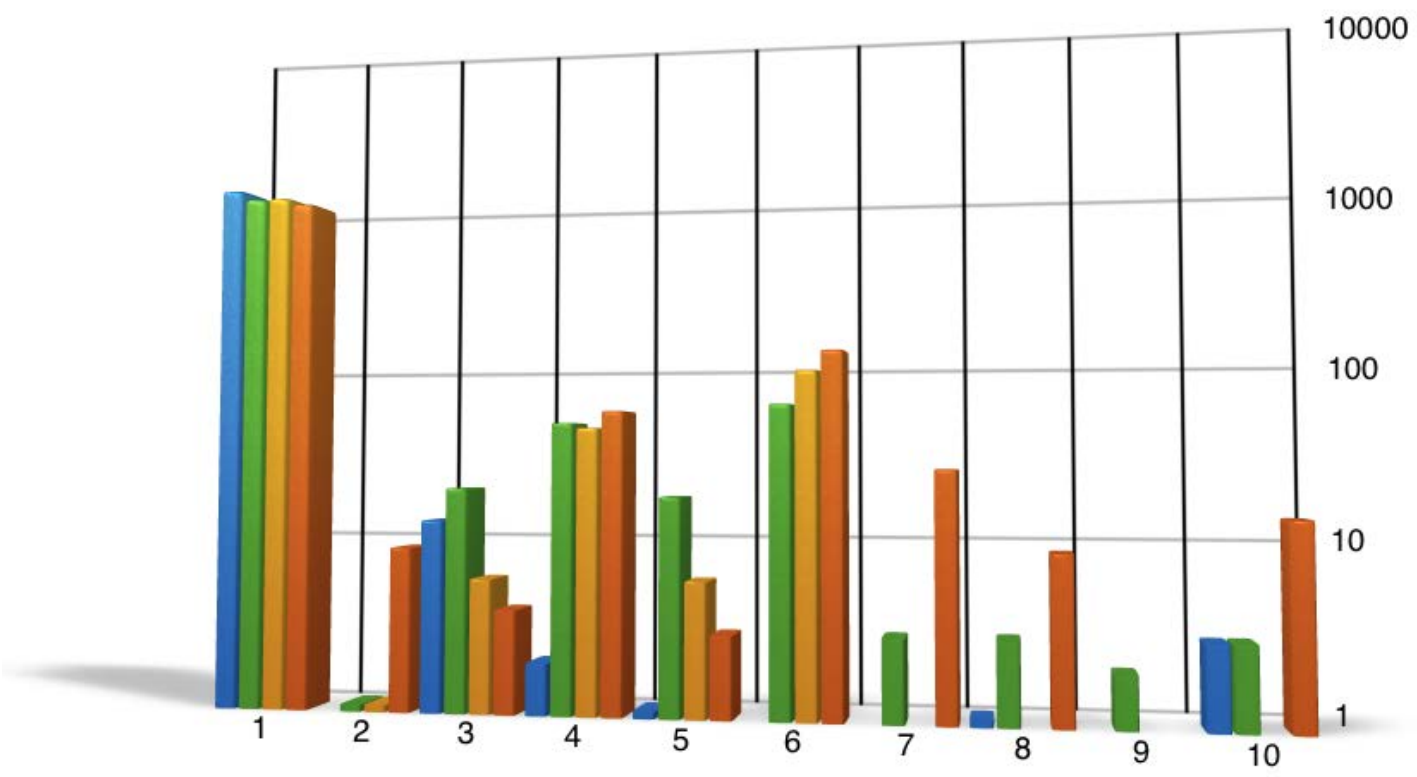

Figura 7.6: La imagen muestra la relación entre los diez primeros usuarios y el rating de los recursos que han publicado) - En la imagen se puede ver la relación entre los diez primeros usuarios, según su nivel de centralidad medido por Betweenness y el rating (divididos en cuartiels) de los recursos (URLs) que han publicado. 
Tabla 7.11: Recursos obtenidos según el ranking social del contexto

\begin{tabular}{|r|l|l|}
\hline Posición & \multicolumn{1}{|c|}{ Descripción del sitio } & Id. usuario \\
\hline $\mathbf{1}$ & $\begin{array}{l}\text { Tutoriales en formato vídeo para } \\
\text { enseñar HTML5, CSS3, Javascript. }\end{array}$ & 1 \\
\hline $\mathbf{2}$ & $\begin{array}{l}\text { Libro de programación en HTML5 con } \\
\text { Javascript y CSS3. }\end{array}$ & $\begin{array}{l}\text { Tutoriales, código fuente para } \\
\text { aprender a desarrollar un proyecto Web. }\end{array}$ \\
\hline $\mathbf{4}$ & $\begin{array}{l}\text { Fotografía de un libro para } \\
\text { aprender HTML5, Javascript y jQuery. }\end{array}$ & 1 \\
\hline $\mathbf{5}$ & $\begin{array}{l}\text { Cupón de descuento para un curso } \\
\text { sobre HTML5 en Udemy. }\end{array}$ & 1 \\
\hline $\mathbf{6}$ & $\begin{array}{l}\text { Entrada de un blog de una herramienta } \\
\text { popular en el desarrollo de sitios Web. }\end{array}$ & 1 \\
\hline $\mathbf{7}$ & $\begin{array}{l}\text { Sitio Web oficial de la W3C de } \\
\text { entrenamiento online para desarrolladores Web. }\end{array}$ & 1 \\
\hline 8 & $\begin{array}{l}\text { Tutoriales para aprender HTML a través } \\
\text { de ejemplos conocido como w3schools }\end{array}$ & 1 \\
\hline 9 & W3Schools tutoriales Web Online & 1 \\
\hline 10 & $\begin{array}{l}\text { Lecturas sobre el desarrollo de compo- } \\
\text { nentes Web. }\end{array}$ & 1 \\
\hline
\end{tabular}


7. ANEXOS 


\section{Referencias Bibliográficas}

Abdulwahed, M., Nagy, Z., and Crawford, A. (2012). Development and evaluation of open educational resources for enhancing engineering students' learning experience. pages $\mathrm{H} 4 \mathrm{C} 14-\mathrm{H} 4 \mathrm{C} 18$. 41,56

Abelson, H., Adida, B., Linksvayer, M., and Yergler, N. (2008). ccrel: The creative commons rights expression language. Technical report, Technical report, Creative Commons, 2008. http://wiki. creativecommons. org/Image: Ccrel-1.0. pdf. 96

Adomavicius, G., Sankaranarayanan, R., Sen, S., and Tuzhilin, A. (2005). Incorporating contextual information in recommender systems using a multidimensional approach. ACM Transactions on Information Systems, 23(1):103-145. cited By 545. 38

Aggarwal, C. C., editor (2011). Social Network Data Analytics. Springer. 42

Aggarwal, C. C. (2016). Recommender Systems - The Textbook. Springer. 28, 34, 36, 39,40

Aggarwal, C. C., Wolf, J. L., Wu, K.-L., and Yu, P. S. (1999). Horting hatches an egg: A new graph-theoretic approach to collaborative filtering. In Knowledge Discovery and Data Mining, pages 201-212. 32

Alahmadi, D. H. and Zeng, X.-J. (2015). Ists: Implicit social trust and sentiment based approach to recommender systems. Expert Systems with Applications, 42(22):8840 - 8849. 34

Andrade, A., Ehlers, U.-D., Caine, E., Carneiro, R., Conole, G., Kairamo, A.-K., and Holmberg, C. (2011). Beyond oer: Shifting focus from resources to practices. Duisburg-Essen, pp. 1Á191,[online] Available at: http://www. oerasia. org/OERResources/8. pdf. 18

Arendt, A. and Shelton, B. (2009). Incentives and disincentives for the use of opencourseware. International Review of Research in Open and Distance Learning, 10(5 SPL.ISS.). 22

Armentano, M., Godoy, D., and Amandi, A. (2012). Topology-based recommendation of users in micro-blogging communities. Journal of Computer Science and Technology, 27(3):624-634. 40

Atenas, J. and Havemann, L. (2014). Questions of quality in repositories of open educational resources: a literature review. Research in Learning Technology, 22(0). 47

Bakshy, E., Hofman, J. M., Mason, W. A., and Watts, D. J. (2011). Everyone's an influencer: quantifying influence on twitter. In Proceedings of the fourth ACM international conference on Web search and data mining, pages 65-74. ACM. 44

Barabási, A.-L. (2016). Network Science. Cambridge University Press. $27,78,81$

Barabasi, A.-L. and Albert, R. (1999). Emergence of scaling in random networks. 286:509-512. 25 


\section{REFERENCIAS BIBLIOGRÁFICAS}

Barros, H., Costa, E., Magalhães, J., and Paiva, R. (2015). Integrating educational repositories to improve the reuse of learning objects. In Proceedings of the 30th Annual ACM Symposium on Applied Computing, pages 270-272. ACM. 51

Batool, K. and Niazi, M. A. (2014). Towards a methodology for validation of centrality measures in complex networks. PloS one, 9(4):e90283. 44

Bedi, P., Kaur, H., and Marwaha, S. (2007). Trust based recommender system for the semantic web. In Proceedings of the 20th International Joint Conference on Artifical Intelligence, IJCAI'07, pages 2677-2682, San Francisco, CA, USA. Morgan Kaufmann Publishers Inc. 43

Bohrer, E., Nakayma, M. K., Silveira, R. A., and Teodoroski, R. d. C. C. (2016). Initiatives and experiences in open educational resources (oer) in higher education: A reflective roadmap. In Computers in Education (SIIE), 2016 International Symposium on, pages 1-6. IEEE. 50

Borgatti, S. and Everett, M. (1997). Network analysis of 2-mode data. 78

Boyd Farmer, L. and Sackett, C. (2009). The connexions project: Using computer technology to connect ideas and people. Public Knowledge Journal, 1(1). 10

Breese, J. S., Heckerman, D., and Kadie, C. (1998). Empirical analysis of predictive algorithms for collaborative filtering. In Proceedings of the Fourteenth conference on Uncertainty in artificial intelligence, pages 43-52. Morgan Kaufmann Publishers Inc. 30

Bressan, M., Leucci, S., Panconesi, A., Raghavan, P., and Terolli, E. (2016). The limits of popularity-based recommendations, and the role of social ties. In Proceedings of the 22Nd ACM SIGKDD International Conference on Knowledge Discovery and Data Mining, KDD '16, pages 745-754, New York, NY, USA. ACM. 42

Brody, T. (2017). Registry of open access repositories (roar). 18

Brown, S. (2010). From vles to learning webs: The implications of web 2.0 for learning and teaching. Interactive Learning Environments, 18(1):1-10. cited By 39. 47

Burke, R. (2007). Hybrid Web Recommender Systems, pages 377-408. Springer Berlin Heidelberg, Berlin, Heidelberg. 3637

Butcher, N. (2015). A basic guide to open educational resources (OER). Commonwealth of Learning, Vancouver and UNESCO. 47

Butcher, N. and Hoosen, S. (2014). How openness impacts on higher education, iite policy brief. 13

Carbonell, M. and Pons, J. (2015). Open educational resources for enhancing the learning of calculus in engineering education: Last improvements: Televoting system and specific thematic math videos. volume 2015February. 56

Carroll, F., Kop, R., and Woodward, C. (2008). Sowing the seeds of learner autonomy: Transforming the vle into a third place through the use of web 2.0 tools. volume 1, pages 152-159. cited By 4.47

Cataldi, M. and Aufaure, M.-A. (2015). The 10 million follower fallacy: audience size does not prove domaininfluence on twitter. Knowledge and Information Systems, 44(3):559-580. 44

Cha, M., Haddadi, H., Benevenuto, F., and Gummadi, P. K. (2010). Measuring user influence in twitter: The million follower fallacy. Icwsm, 10(10-17):30. 44 


\section{REFERENCIAS BIBLIOGRÁFICAS}

Chicaiza, J., López, J., Piedra, N., Martínez, O., and Tovar, E. (2010). Usage of social and semantic web technologies to design a searching architecture for software requirement artefacts. IET software, 4(6):407417. 48

Chicaiza, J., Piedra, N., López, J., and Caro, E. T. (2015). Promotion of self-learning by means of open educational resources and semantic technologies. In Information Technology Based Higher Education and Training (ITHET), 2015 International Conference on, pages 1-6. IEEE. 20

Chua, F.-F. and Tay, E.-S. (2012). Developing virtual learning environment 2.0 using web services approach. pages 230-234. cited By 5. 47

Creelman, A. and Ossiannilsson, E. (2011). Quality indicators within the use of open educational resources in higher education. 19

D'Antoni, S. (2006). The virtual university: Models and messages, lessons from case studies. UNESCO-IIEP. 18

de la Fuente, J. R. (2009). New dynamics of higher education and research for societal change and development. Universidades, 59(42):3-5. 18

Dichev, C. and Dicheva, D. (2012). Is it time to change the oer repositories role? In Proceedings of the 12th ACM/IEEE-CS joint conference on Digital Libraries, pages 31-34. ACM. 50

Downes, S. (2007a). Models for sustainable open educational resources. Interdisciplinary journal of knowledge and learning objects, 3:29-44. 11

Downes, S. (2007b). Models for sustainable open educational resources. Interdisciplinary journal of knowledge and learning objects, 3(1):29-44. 12

Ehlers, U.-D. (2011). Extending the territory: From open educational resources to open educational practices. Journal of Open Flexible and Distance Learning, 15(2):1-10. 16

Erdős, P. and Rényi, A. (1959). On random graphs i. Publ. Math. (Debrecen), 6:290. 25

Etgar, M. (2008). A descriptive model of the consumer co-production process. Journal of the academy of marketing science, 36(1):97-108. 51

Evans, C. (2014). Twitter for teaching: Can social media be used to enhance the process of learning? British Journal of Educational Technology, 45(5):902-915. cited By 19. 48

Farrow, R., Pitt, R., de los Arcos, B., Perryman, L.-A., Weller, M., and McAndrew, P. (2015). Impact of oer use on teaching and learning: Data from oer research hub (2013-2014). British Journal of Educational Technology, 46(5):972-976. $12,13,15$

García-Saiz, D., Palazuelos, C., and Zorrilla, M. (2014). Data mining and social network analysis in the educational field: An application for non-expert users. Studies in Computational Intelligence, 524:411-439. cited By 1. 49

Geser, G. (2007). Open Educational Practices and Resources. OLCOS Roadmap, 2012. ERIC. 1945

Granovetter, M. (1973). The strength of weak ties. The American Journal of Sociology, 78(6):1360-1380. 81

Gupta, P., Goel, A., Lin, J., Sharma, A., Wang, D., and Zadeh, R. (2013). Wtf: The who to follow service at twitter. pages 505-514. cited By 45. 40 


\section{REFERENCIAS BIBLIOGRÁFICAS}

Gürsel, A. and Sen, S. (2009). Producing timely recommendations from social networks through targeted search. In Proceedings of The 8th International Conference on Autonomous Agents and Multiagent Systems - Volume 2, AAMAS '09, pages 805-812, Richland, SC. International Foundation for Autonomous Agents and Multiagent Systems. 43

Guy, I. (2015). Social recommender systems. In Recommender Systems Handbook, pages 511-543. Springer. 39

He, J. and Chu, W. W. (2010). Data Mining for Social Network Data, chapter A Social Network-Based Recommender System (SNRS), pages 47-74. Springer US, Boston, MA. 35

Hernández-García, Á., González-González, I., Jiménez-Zarco, A. I., and Chaparro-Peláez, J. (2015). Applying social learning analytics to message boards in online distance learning: A case study. Computers in Human Behavior, 47:68-80. 49

Holden, C. (2003). From local challenges to a global community: learning repositories and the global learning repositories summit. The Academic ADL Co-Lab. 18

Huang, Z., Chung, W., Ong, T.-H., and Chen, H. (2002). A graph-based recommender system for digital library. $J C D L$ '02, pages 65-73. 37

Hylén, J. (2007). Giving knowledge for free. The emergence of open educational resources. OECD, Paris. 10. 11

Jalili, M., Salehzadeh-Yazdi, A., Asgari, Y., Arab, S. S., Yaghmaie, M., Ghavamzadeh, A., and Alimoghaddam, K. (2015a). Centiserver: a comprehensive resource, web-based application and $\mathrm{r}$ package for centrality analysis. PloS one, 10(11):e0143111. 44

Jalili, M., Salehzadeh-Yazdi, A., Asgari, Y., Arab, S. S., Yaghmaie, M., Ghavamzadeh, A., and Alimoghaddam, K. (2015b). Centiserver: A comprehensive resource, web-based application and $\mathrm{r}$ package for centrality analysis. PLOS ONE, 10(11):1-8. 92

Jeh, G. and Widom, J. (2002). SimRank: A Measure of Structural-Context Similarity. In Proc. of International Conference on Knowledge Discovery and Data Mining (SIGKDD), Edmonton, Alberta, Canada. ACM. 32

Jøsang, A. (2001). A logic for uncertain probabilities. International Journal of Uncertainty, Fuzziness and Knowledge-Based Systems, 9(3):279-212. 42

Kandylas, V. and Dasdan, A. (2010). The utility of tweeted urls for web search. In Proceedings of the 19th international conference on World wide web, pages 1127-1128. ACM. 2

Kang, D., Kwon, K., Sohn, J., Joo, B.-G., and Chung, I.-J. (2014). Content Recommendation Method Using FOAF and SNA, pages 93-104. Springer Netherlands, Dordrecht. 35

Kang, Z., Peng, C., Yang, M., and Cheng, Q. (2016). Top-n recommendation on graphs. volume 24-28-October2016, pages 2101-2106. cited By 0. 33

Katz, L. (1953). A new status index derived from sociometric analysis. Psychometrika, VOL. 18, NO. 1:39- 43. 32

Kurka, D. B., Godoy, A., and Zuben, F. J. V. (2015). Online social network analysis: A survey of research applications in computer science. CoRR, abs/1504.05655. 39

Kwak, H., Lee, C., Park, H., and Moon, S. (2010). What is twitter, a social network or a news media? In Proceedings of the 19th international conference on World wide web, pages 591-600. ACM. 44191 


\section{REFERENCIAS BIBLIOGRÁFICAS}

Lam, J. (2015). Collaborative Learning Using Social Media Tools in a Blended Learning Course, pages 187-198. Springer International Publishing, Cham. 48

Latapy, M., Magnien, C., and Vecchio, N. D. (2008). Basic notions for the analysis of large two-mode networks. Social Networks, 30(1):31-48. 79

Lazarsfeld, P. F., Merton, R. K., et al. (1954). Friendship as a social process: A substantive and methodological analysis. Freedom and control in modern society, 18(1):18-66. 194

Lazer, D., Pentland, A., Adamic, L., Aral, S., Barabási, A.-L., Brewer, D., Christakis, N., Contractor, N., Fowler, J., Gutmann, M., Jebara, T., King, G., Macy, M., Roy, D., and Van Alstyne, M. (2009). Social science: Computational social science. Science, 323(5915):721-723. cited By 861. 24

Leavitt, A., Burchard, E., Fisher, D., and Gilbert, S. (2009). The influentials: New approaches for analyzing influence on twitter. Web Ecology Project, 4(2):1-18. 44

Lewis, T. G. (2011). Network Science: Theory and Applications. Wiley. 67

Lopez-Vargas, J., Piedra, N., Chicaiza, J., and Tovar, E. (2015a). Oer recommendation for entrepreneurship using a framework based on social network analysis. Revista Iberoamericana de Tecnologias del Aprendizaje, 10(4):262-268. cited By 2. 163

Lopez-Vargas, J., Piedra, N., Chicaiza, J., and Tovar, E. (2015b). Recommendation of oers shared in social media based-on social networks analysis approach. volume 2015-February. cited By 0. 147

López Vargas, J., Piedra, N., Chicaiza, J., Tovar, E., Blázques, M., Castro, M., Arriaga, J., Pescador, F., Romo, J., Casquero, O., Benito, M., and Landaluce, A. (2010). Meta-analysis of the taee project applying social network analysis. pages 129-136. cited By 2. 110

Lu, L., Zhou, T., Zhang, Q.-M., and Stanley, H. E. (2016). The h-index of a network node and its relation to degree and coreness. Nat Commun, 7. 40

Ma, X., Li, C., Bailey, J., and Wijewickrema, S. (2017). Finding influentials in twitter: A temporal influence ranking model. arXiv preprint arXiv:1703.01468. 43

Massa, P. and Avesani, P. (2009). Trust Metrics in Recommender Systems, pages 259-285. Springer London, London. 43

Masterman, L. (2015). Does an open world need new pedagogies or can existing pedagogies suffice. In 14 th European Conference on e-Learning-ECEL, pages 339-346. 16, 19

McGuire, M. (2014). Finding and sharing educational resources using twitter, hashtags and storify. pages 678-682. cited By 0. 12,48

Mika, P. (2007). Social Networks and the Semantic Web: 5 (Semantic Web and Beyond). Springer US. 67

Milgram, S. (1967). The small world problem. Psychology Today, 67(1):61-67. 25

Minguillón, J. (2010). Analyzing hidden semantics in social bookmarking of open educational resources. In Research Conference on Metadata and Semantic Research, pages 8-17. Springer. 48, 50,51

Morgado, L., Fonseca, B., Martins, P., Paredes, H., Cruz, G., Maia, A., Nunes, R., and Santos, A. (2012). Social networks, microblogging, virtual worlds, and web 2.0 in the teaching of programming techniques for software engineering: A trial combining collaboration and social interaction beyond college. 56 


\section{REFERENCIAS BIBLIOGRÁFICAS}

Murphy, A. (2012). Benchmarking open educational practices in higher education. In Proceedings of the 29th Annual Conference of the Australasian Society for Computers in Learning in Tertiary Education (ASCILITE 2012). Australasian Society for Computers in Learning in Tertiary Education (ASCILITE). 19

Murray-Rust, P. and Rzepa, H. S. (2004). Budapest open access initiative. J Digital Inf, 5:248. 10

Newman, M. E. J., Barabási, A. L., and Watts, D. J. (2006). The structure and dynamics of networks. Princeton University Press, Princeton NJ. 25, 26

Nottingham, U. (2017). Opendoar directory of open access repositories. 18

Okada, A. and Leslie, S. (2012). Open educators and colearners as djs: reuse, remix, and recreate oer collaboratively! In Collaborative Learning 2.0: Open Educational Resources, pages 78-102. IGI Global. 50. 51

Oliveira, L. and Moreira, F. (2010). Integration of web 2.0 applications and content management systems on personal learning environments. cited By 1. 47

Onnela, J.-P., Saramäki, J., Hyvönen, J., Szabó, G., Lazer, D., Kaski, K., Kertész, J., and Barabási, A.-L. (2007). Structure and tie strengths in mobile communication networks. Proceedings of the National Academy of Sciences, 104(18):7332-7336. 191

OpenCourseWare, M. (2006). 2005 program evaluation findings report. Recuperado de http://ocw.mit.edu/ ans7870/global/05_Prog_Eval_Report_Final.pdf 10,21

O'Reilly (2005). What is web 2.0? design patterns and business models for the next generation of software. Technical report, O'Reilly Network. 11

Ozsoy, M. G. and Polat, F. (2013). Trust based recommendation systems. In Proceedings of the 2013 IEEE/ACM International Conference on Advances in Social Networks Analysis and Mining, ASONAM '13, pages 12671274, New York, NY, USA. ACM. 43

Page, L., Brin, S., Motwani, R., and Winograd, T. (1999). The pagerank citation ranking: Bringing order to the web. Technical report, Stanford University. 3244

Park, D., Kim, H., Choi, I., and Kim, J. (2012). A literature review and classification of recommender systems research. Expert Systems with Applications, 39(11):10059-10072. 41

Piedra, N., Chicaiza, J., Lopez, J., and Caro, E. T. (2014a). Supporting openness of moocs contents through of an oer and ocw framework based on linked data technologies. In Global Engineering Education Conference (EDUCON), 2014 IEEE, pages 1112-1117. IEEE. 19

Piedra, N., Chicaiza, J., López, J., and Caro, E. T. (2016). Integrating oer in the design of educational material: Blended learning and linked-open-educational-resources-data approach. In Global Engineering Education Conference (EDUCON), 2016 IEEE, pages 1179-1187. IEEE. 20

Piedra, N., Chicaiza, J., López, J., Martínez, O., and Caro, E. (2010a). An approach for description of open educational resources based on semantic technologies. pages 1111-1119. cited By 6. $10,12,18$

Piedra, N., Chicaiza, J., López, J., Romero, A., and Tovar, E. (2010b). Measuring collaboration and creativity skills through rubrics: Experience from utpl collaborative social networks course. In Education Engineering (EDUCON), 2010 IEEE, pages 1511-1516. IEEE. 48

Piedra, N., Chicaiza, J., López, J., Tovar, E., and Martínez, O. (2010c). Design study of oer-cc ontology: A semantic web approach to describe open educational resources. pages 207-209. cited By 3. 18 


\section{REFERENCIAS BIBLIOGRÁFICAS}

Piedra, N., Chicaiza, J., López, J., Tovar, E., and Martinez, O. (2011). Finding oers with social-semantic search. In Global Engineering Education Conference (EDUCON), 2011 IEEE, pages 1195-1200. IEEE. 48

Piedra, N., Chicaiza, J., López, J., and Tovar Caro, E. (2015a). Towards a learning analytics approach for supporting discovery and reuse of oer an approach based on social networks analysis and linked open data. volume 2015-April, pages 978-988. cited By 1. 123

Piedra, N., Chicaiza, J., López-Vargas, J., and Caro, E. T. (2015b). Seeking open educational resources to compose massive open online courses in engineering education an approach based on linked open data. $J$. UCS, 21(5):679-711. 19

Piedra, N., Tovar, E., Colomo-Palacios, R., Lopez-Vargas, J., and Chicaiza, J. (2014b). Consuming and producing linked open data: The case of opencourseware. Program, 48(1):16-40. 18,35

Pušnik, M., Šumak, B., and Hericko, M. (2010). Investigation of virtual learning environment in the context of web 2.0. In Mobile, Hybrid, and On-Line Learning, 2010. ELML'10. Second International Conference on, pages 1-6. IEEE. 47

Qian, F., Zhao, S., Tang, J., and Zhang, Y. (2016). Sors: Social recommendation using global rating reputation and local rating similarity. Physica A: Statistical Mechanics and its Applications, 461:61 - 72. 43

Resnick, P. and Varian, H. R. (1997). Recommender systems. Communications of the ACM, 40(3):56-58. 29

Ricci, F., Rokach, L., and Shapira, B. (2011). Introduction to Recommender Systems Handbook, pages 1-35. Springer US, Boston, MA. $28,29,36$

Richardson, W. (2006a). Blogs, Wikis, Podcasts, And Other Powerful Web Tools For Classrooms. 11

Richardson, W. (2006b). The new face of learning: the internet breaks schools walls down. 51

Rodriguez, S., Perez, R., Iglesias, M., Rifon, L., Nistal, M., Pesqueira, A., and Gestalz, M. (2015). The impact of open educational resources in teacher activities. a perception survey. volume 2015-February. 56

Sanchez, J., Gonzalez, C., Alayon, S., and Gonzalez, P. (2013). Using social networks at university: The case of school of computer science. pages 492-496. 56

Santos, A., Cobo, C., and Costa, C. (2015). Recursos educativos abiertos: Casos de américa latina y europa en la educación superior. 20

Santos-Hermosa, G., Ferran-Ferrer, N., and Abadal, E. (2012). Recursos educativos abiertos: repositorios y uso. Profesional de la Informacion, 21(2):136-145. cited By 10. 18

Sarwar, B., Karypis, G., Konstan, J., and Riedl, J. (2000). Analysis of recommendation algorithms for ecommerce. In Proceedings of the 2nd ACM conference on Electronic commerce, pages 158-167. ACM. 31

Sarwar, B., Karypis, G., Konstan, J., and Riedl, J. (2001). Item-based collaborative filtering recommendation algorithms. In Proceedings of the 10th international conference on World Wide Web, pages 285-295. ACM. 29

Schaffert, S. (2006). Semantic social software: Semantically enabled social software or socially enabled semantic web? In Proceedings of the SEMANTICS 2006 conference, pages 99-112, Vienna, Austria. OCG. 11

Schein, A. I., Popescul, A., Ungar, L. H., and Pennock, D. M. (2002). Methods and metrics for cold-start recommendations. In Proceedings of the 25th annual international ACM SIGIR conference on Research and development in information retrieval, pages 253-260. ACM. 36 


\section{REFERENCIAS BIBLIOGRÁFICAS}

Schoch, D., Valente, T. W., and Brandes, U. (2017). Correlations among centrality indices and a class of uniquely ranked graphs. Social Networks, 50:46-54. 44

Scott, J. P. and Carrington, P. J. (2011). The SAGE Handbook of Social Network Analysis. SAGE Publications Ltd. 80

Sellami, K., Ahmed-Nacer, M., and Tiako, P. (2014). From social network to semantic social network in recommender system. CoRR, abs/1407.3392. 40

Seroussi, Y., Bohnert, F., and Zukerman, I. (2011). Personalised rating prediction for new users using latent factor models. In Proceedings of the 22nd ACM conference on Hypertext and hypermedia, pages 47-56. ACM. 28

Shum, S. and Ferguson, R. (2012). Social learning analytics. Educational Technology and Society, 15(3):3-26. cited By 68. 49

Siemens, G. (2005). Connectivism: A learning theory for the digital age. International Journal of Instructional Technology and Distance Learning, 2(1):3-10. 49

Simhal, A., Kanumuru, V.-G., Holmes, A., and Berger, E. (2015). Exploring the use of student taught classes to introduce new technical topics to engineering undergraduates. volume 2015-February. 56

Smith, G. (2004). Folksonomy: social classification. Blog article, August. 65

Song, Y., Zhuang, Z., Li, H., Zhao, Q., Li, J., Lee, W.-C., and Giles, C. (2008). Real-time automatic tag recommendation. pages 515-522. cited By 0. 41,42

Stan, J., Muhlenbach, F., and Largeron, C. (2014). Recommender Systems Using Social Network Analysis: Challenges and Future Trends, pages 1522-1532. Springer New York, New York, NY. 28

Suh, B., Hong, L., Pirolli, P., and Chi, E. H. (2010). Want to be retweeted? large scale analytics on factors impacting retweet in twitter network. In Social computing (socialcom), 2010 ieee second international conference on, pages 177-184. IEEE. 190

Sun, Z., Han, L., Huang, W., Wang, X., Zeng, X., Wang, M., and Yan, H. (2015). Recommender systems based on social networks. Journal of Systems and Software, 99:109 - 119. 43

Take, S. W. (2009). Learning, teaching, and scholarship in a digital age. Educational Researcher, 38(4):246-259. 45

Tang, J., Hu, X., and Liu, H. (2013). Social recommendation: a review. Social Network Analysis and Mining, 3(4):1113-1133. 40

Tavakolifard, M. and Almeroth, K. (2012). Social computing: An intersection of recommender systems, trust/reputation systems, and social networks. IEEE Network, 26(4):53-58. cited By 20. 24

Taylor, J. C. (2007). Open courseware futures: creating a parallel universe. e-Journal of Instructional Science and Technology (e-JIST), 10(1):4-9. 19

Tim, O. et al. (2005). What is web 2.0? design patterns and business models for the next generation of software. 45

Torres, A. and Guerrero, C. (2013). Learning content development with social tools: Learning generated content in engineering. Revista Iberoamericana de Tecnologias del Aprendizaje, 8(3):111-118. 56 


\section{REFERENCIAS BIBLIOGRÁFICAS}

Tovar, E., De La Cmara, M., Saenz, J., and Castro, M. (2012). Innovative learning experiences in a technical university using open educational resources. In American Society for Engineering Education. American Society for Engineering Education. 19

Tovar, E., Dimovska, A., Piedra, N., and Chicaiza, J. (2013a). Ocw-s: Enablers for building sustainable open education evolving ocw and mooc. In Global Engineering Education Conference (EDUCON), 2013 IEEE, pages 1262-1271. IEEE. 19

Tovar, E., Lopez-Vargas, J., Piedra, N., and Chicaiza, J. (2013b). Impact of open educational resources in higher education institutions in spain and latin americas through social network analysis. 35,123

Tovar, E. and Piedra, N. (2014). Guest editorial: Open educational resources in engineering education: Various perspectives opening the education of engineers. IEEE Transactions on Education, 57(4):213-219. 56

Tovar, E., Piedra, N., López, J., and Chizaiza, J. (2016). Open Education Practices as Answer to New Demands of Training in Entrepreneurship Competences: The Role of Recommender Systems, pages 3-18. Springer International Publishing, Cham. 20

Tunkelang, D. (2009). A twitter analog to pagerank. The Noisy Channel. 44

Türker, İ., Şehirli, E., and Demiral, E. (2016). Uncovering the differences in linguistic network dynamics of book and social media texts. SpringerPlus, 5(1). cited By 0.80

UNESCO (2002). Forum on the impact of open courseware for higher education in developing countries: final report. 13

UNESCO (2011). Guidelines for open educational resources (oer) in higher education. 47

UNESCO (2012). 2012 paris oer declaration, 2012 world open educational resources (oer) congress. 47

UNESCO (2016). Study on international collaboration on open educational resources (oer). 13

UNESCO-IIEP (2005-2008). International institute for educational planning community of interest on open educational resources. 10

Valente, T. W., Coronges, K., Lakon, C., and Costenbader, E. (2008). How correlated are network centrality measures? Connections (Toronto, Ont.), 28(1):16. 44

Vaquero, L. M. and Cebrian, M. (2013). The rich club phenomenon in the classroom. Scientific Reports, 3:1174 $\mathrm{EP}-.49$

Vargas-Arcila, A., Baldassarri, S., and Arciniegas, J. (2016). Analysis of metadata schemas for marking up educational content [análisis de esquemas de metadatos para la marcación de contenidos educativos]. Formacion Universitaria, 9(5):85-96. cited By 0. 18

Vladoiu, M. (2011). State-of-the-art in open courseware initiatives worldwide. Informatics in Education, 10(2):271-294. 21

Walczowski, L. and Ellis, M. (2008). Using web 2.0 technology to support learning and teaching. volume 1, pages 178-182. cited By 0. 47

Walter, F. E., Battiston, S., and Schweitzer, F. (2008). A model of a trust-based recommendation system on a social network. Autonomous Agents and Multi-Agent Systems, 16(1):57-74. 43

Wang, Z., Tan, Y., and Zhang, M. (2010). Graph-based recommendation on social networks. In Han, W.-S., Srivastava, D., Yu, G., Yu, H., and Huang, Z. H., editors, APWeb, pages 116-122. IEEE Computer Society. 40 


\section{REFERENCIAS BIBLIOGRÁFICAS}

Wang, Z., Zhu, W., Cui, P., Sun, L., and Yang, S. (2013). Social Media Retrieval, chapter Social Media Recommendation, pages 23-42. Springer London, London. 38,41

Watts, D. J. and Strogatz, S. H. (1998). Collective dynamics of 'small-world' networks. Nature, (393):440-442. 25

Weller, M. (2010). Big and little oer. In Open Ed 2010 Proceedings. 5051

Weng, J., Lim, E.-P., Jiang, J., and He, Q. (2010). Twitterrank: Finding topic-sensitive influential twitterers. pages 261-270. cited By 444. 40

Wiley, D. A. (2003). Connecting learning objects to instructional design theory: A definition, a metaphor, and a taxonomy. 18

Wimpenny, K., Merry, S., Tombs, G., and Villar-Onrubia, D. (2016). Opening up education in south mediterranean countries: A compendium of case studies and interviews with experts about open educational practices and resources. 20

Yan, R., Lapata, M., and Li, X. (2012). Tweet recommendation with graph co-ranking. volume 1, pages 516-525. cited By 24. 40

Yang, C., Sun, J., and Zhao, Z. (2010). Personalized recommendation based on collaborative filtering in social network. volume 1, pages 670-673. 41

Yazdanfar, N. and Thomo, A. (2013). Link recommender: Collaborative-filtering for recommending urls to twitter users. volume 19, pages 412-419. 41

Zhao, H., Yang, L., and Wang, Y. (2010). The personal learning environment (ple) based on web 2.0. pages 22-25. cited By 3. 47 